\title{
Willingness to pay for and property rights beliefs on river water quality improvements in Central Chile - an application of the Choice Experiment method
}

\author{
Dissertation \\ to obtain the $\mathrm{Ph}$. D. degree \\ in the International Ph. D. Program for Agricultural Sciences in Goettingen (IPAG) \\ at the Faculty of Agricultural Sciences, \\ Georg-August-University Göttingen, Germany
}

presented by

Carlos Alberto Huenchuleo Pedreros

born in Cañete, Chile

Göttingen, November 2011 
1. Name of supervisor: Prof. Dr. Rainer Marggraf

2. Name of co-supervisor: Prof. Dr. Pablo Villalobos Mateluna

Date of dissertation: July 21th, 2011

Author:

Carlos Alberto Huenchuleo Pedreros

Contact information:

Environmental and Resource Economics Research Group

Department of Agricultural Economics and Rural Development

Georg-August-Universität Göttingen

Platz der Göttinger Sieben 5

D-37073 Göttingen, Germany

Email: chuench@uni-goettingen.de; c.huenchuleo@gmail.com 


\section{Abstract}

Although significant improvements have been achieved in past years, river water quality in Chile is still poor in some places. In particular, the negative effect of pulp mill wastewater on river water quality has received significant attention. Studies indicate that the river environment downstream from pulp mills is considered as severely compromised in Chile. In this regard, I present results of a Choice Experiment (CE) study designed to analyze respondent preferences for river water quality attributes affected by pulp mill wastewater in Central Chile. The CE included policy-relevant attributes on river pollution risk and on river water quality effects that have an impact on threatened species as well as on the yield of local fisheries. Moreover, we tested the extent to which a different framing of a stated preference valuation exercise in terms of the environmental property rights distribution ('Industry Pays' vs 'Citizens pay') impacts stated demand for environmental quality improvements.

All three environmental attributes and the payment attribute were highly significant predictors of choice $(\mathrm{P}<0.001)$. Calculated mean WTP values for a scenario of substantial improvement the river water qulity was $\sim 13 \mathrm{USD} /$ household/yr. The introduction of attitudinal, socialpsychology, and fairness-related cognitions improved model performance substantially. Most respondents were willing to pay under the 'Industry Pays' frame for more restrictive water quality policies implemented by the government to enforce reductions in pulp mill wastewater pollution. In contrast, only a minority stated a willingness to pay for directly to the industry via the 'Citizens pay' frame.

The resulting valuation findings close a gap in the valuation of Chilean river water resources, and contribute to the academically interesting but meagre international database on valuation 
studies from emerging economies. From the perspective of relevance for Chilean water politics, it has to be considered that there is a continuing prevalence of free-market policies in Chile. Still, respondents support the 'Industry pays' frame as the principle on which to base environmental legislation more strongly. 


\section{Acknowledgement}

I want to express my gratitude with different persons and institutions that supported my studies in different memorable ways. I thank Dr. Jan Barkmann for his advice and suggestions to improve my study, sharing his experiences and knowledgments with me, and for his patience during hard times. My gratitude to Prof. Dr. Rainer Marggraf for accepting me as his PhD student, supporting me during all phases of my studies and supervising my work. I thank Prof. Dr. Pablo Villalobos for encouraging me to carried out my doctoral studies in Göttingen, his support during my field research and his comments to my work. My gratitude to Prof. Marcela Ibañez, Ph.D. for her interesting comments and suggestions in order to improve my dissertation. I am grateful to institutions that funded my studies in Germany: the Comisión Nacional de Investigación Científica y Tecnológica (CONICYT) Chile and the Deutscher Akademischer Austausch Dienst (DAAD) Germany.

Furthermore, I thank to

- Christine Schwenkner for her help during my studies.

- My collegues Frank von Walter, Johanna Schott, Sandra Rajmis, Vladimir González, and Byron Maza for their support and friendship.

- My collegues of the working group for their support.

- Survey assistants during my field research and 378 anonymous participants during the pilot study and main study.

I am deeply grateful with my family for their unconditional love. This dissertation is to my wife Johanna and my son Sebastián. 


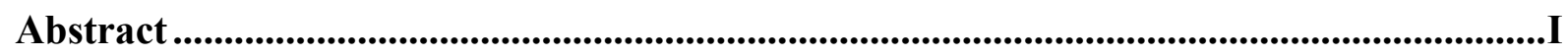

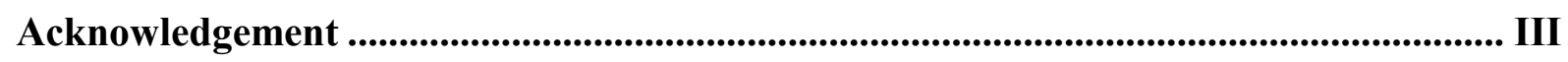

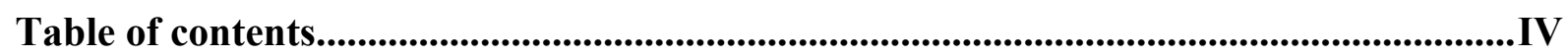

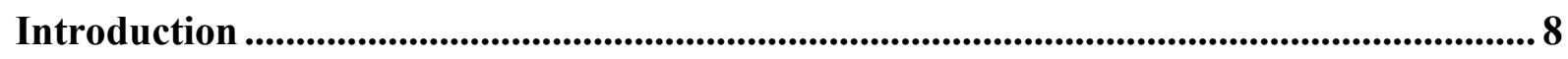

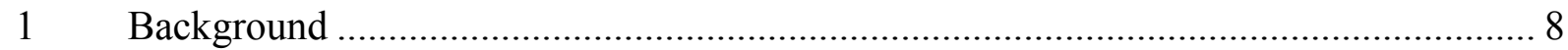

2 Research framework and objectives of the study .................................................. 10

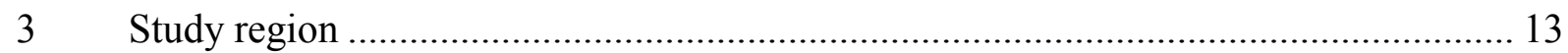

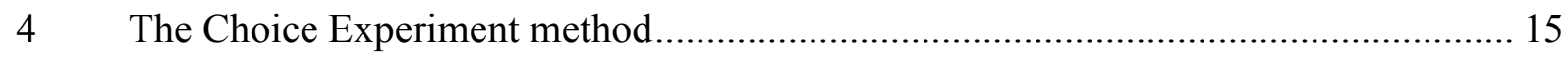

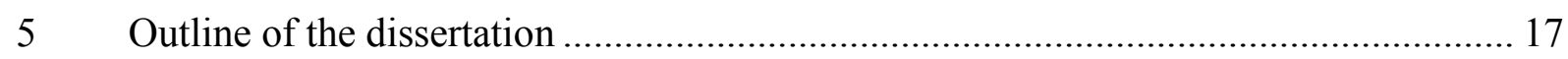

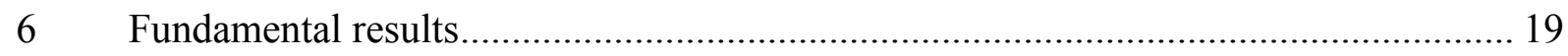

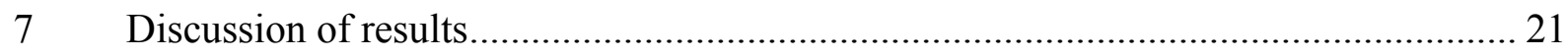

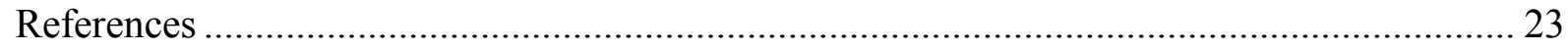

\section{Chapter 1}

Benefits of protecting the ecosystem services of the endemic Ruil forests of Central

Chile with the choice experiment method ................................................................... 27

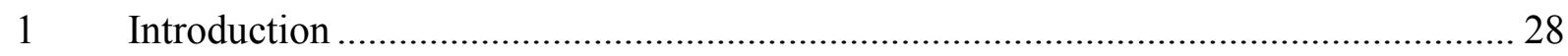

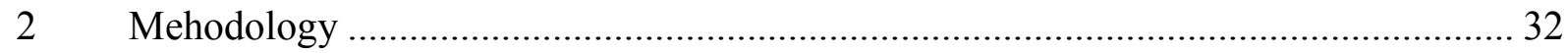

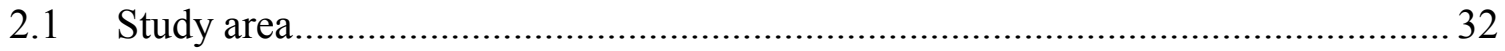

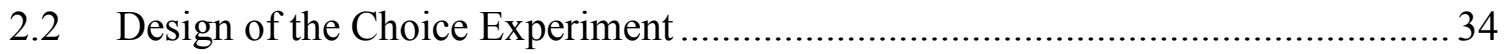

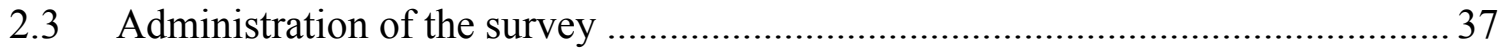

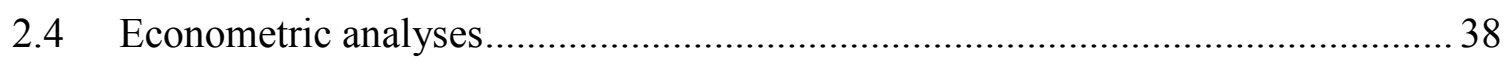

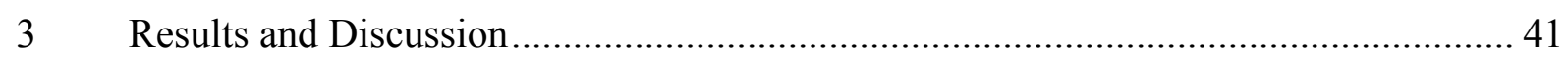

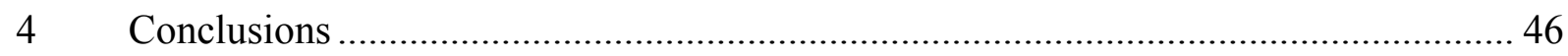

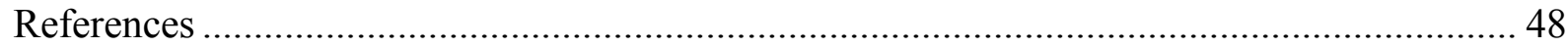

\section{Chapter 2}

Economic valuation of river-based ecosystem services subject to fairness considerations in Central Chile using a Choice Experiment ..................................................................5 52

1 Introduction 


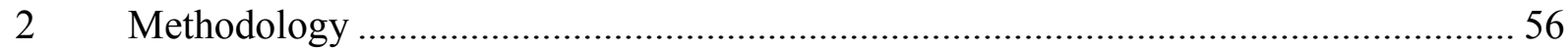

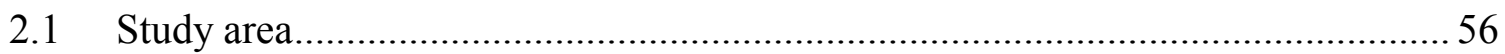

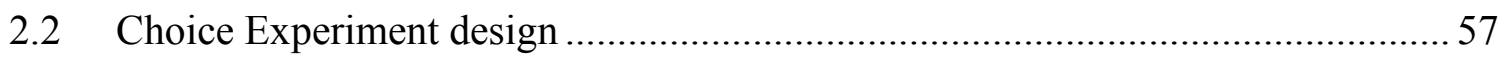

2.3 Fairness of paying for river water quality improvements ..................................... 61

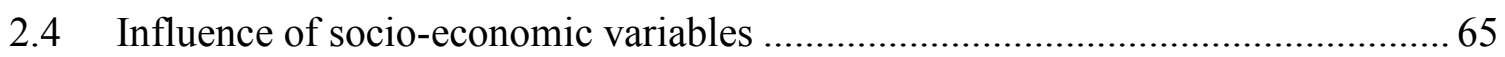

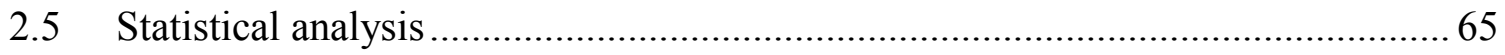

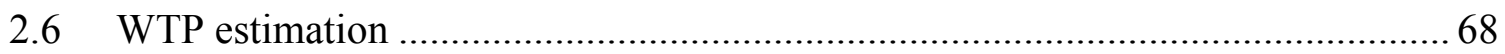

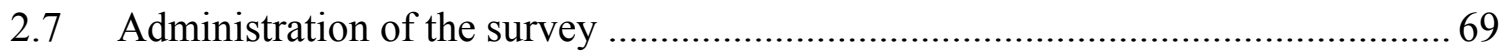

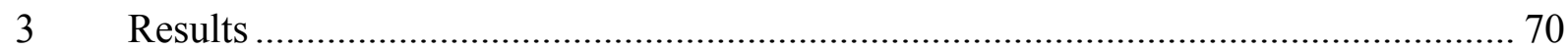

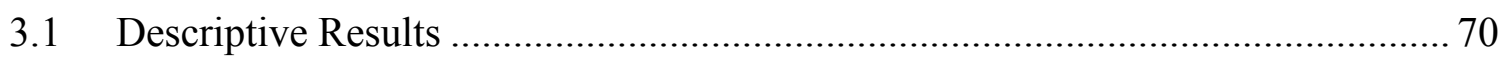

3.2 Fairness impacts on paying for river water quality improvements ........................ 71

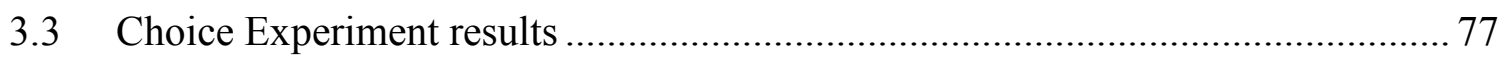

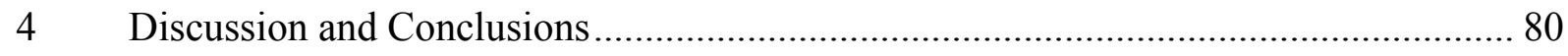

4.1 Interpretation of fairness dimensions ........................................................... 81

4.2 Influence of fairness dimensions on respondents choice ……………………….... 83

4.3 Interpretation of welfare measures................................................................... 85

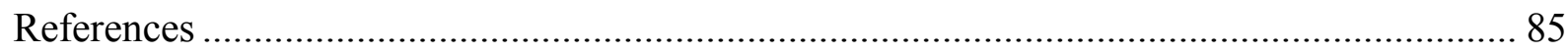

\section{Chapter 3}

Attitudinal determinants of willingness-to-pay for river water quality improvements in

Central Chile: A choice experiment approach .......................................................................91

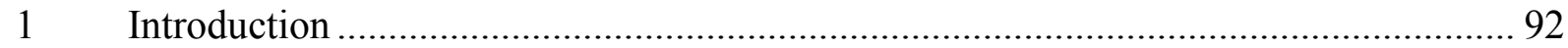

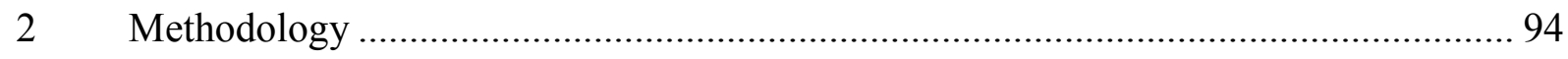

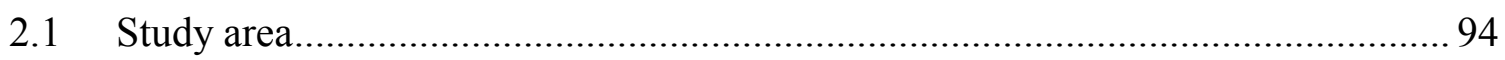

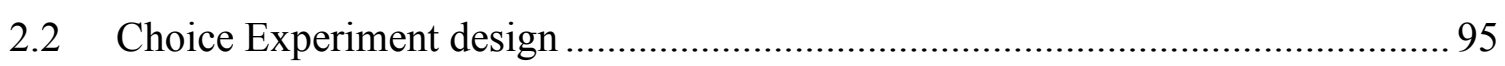

2.3 Potential influence of attitudinal and socio-demographic characteristics on

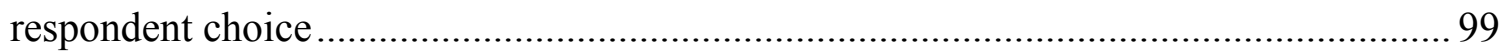

2.4 Administration of the survey ........................................................................... 103

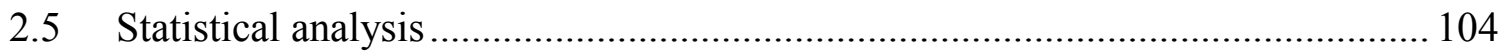

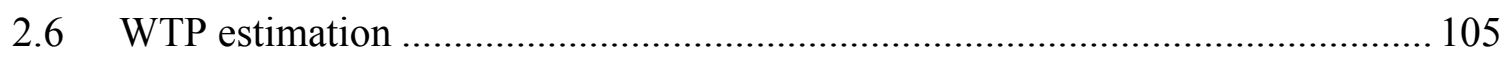

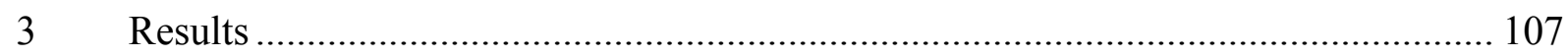

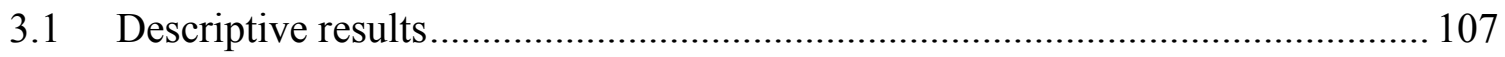

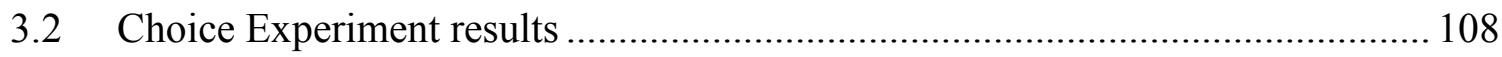


4 Discussion 111

References 116

\section{Chapter 4}

Social-psychology determinants of river water quality improvement in Central Chile: a

Choice Experiment application .................................................................................... 120

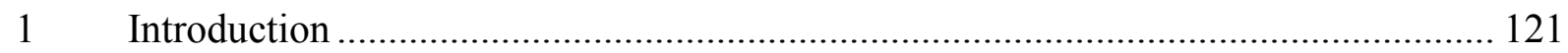

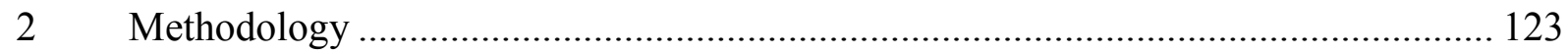

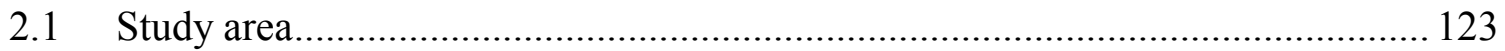

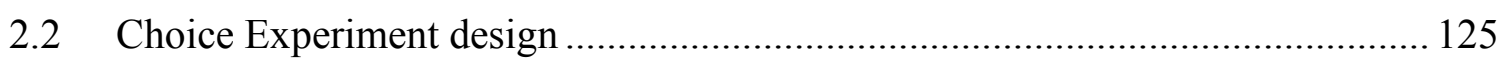

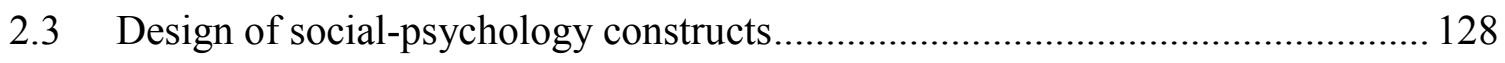

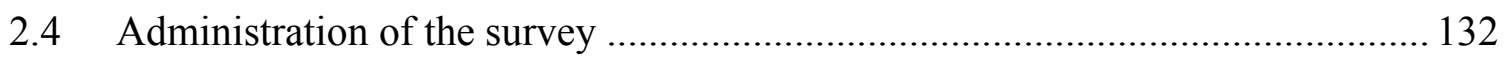

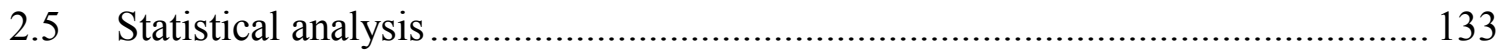

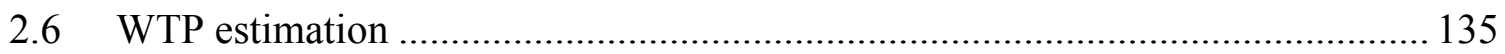

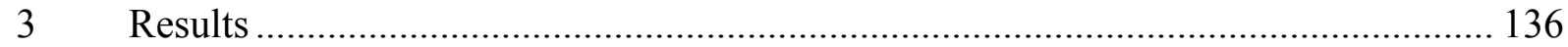

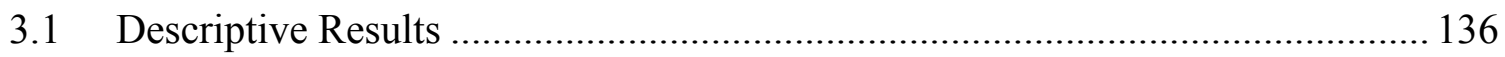

3.2 Respondents perceptions on severity and response efficacy items...................... 137

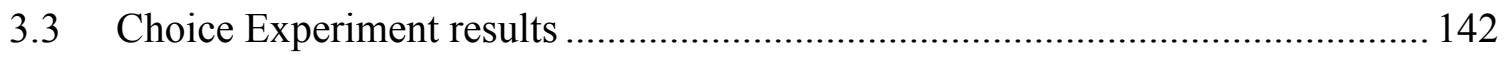

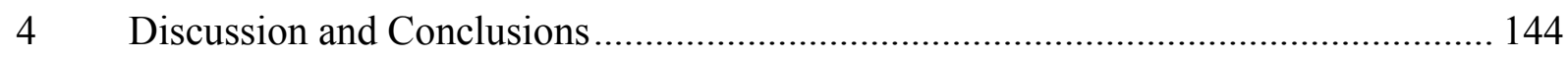

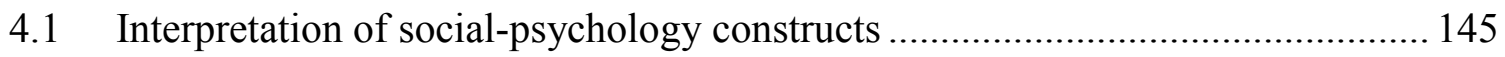

4.2 Interpretation of Choice Experiment results ..................................................... 146

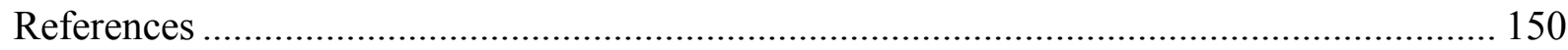

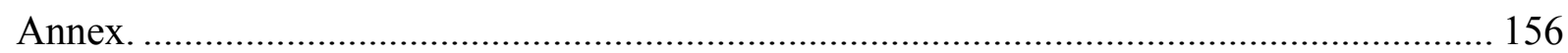

\section{Chapter 5}

A matter of Coase: Influence of property right beliefs on Willingness-to-Pay for river water quality in absence of transaction costs.............................................................................. 157

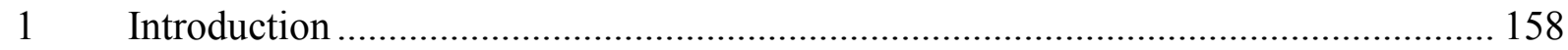

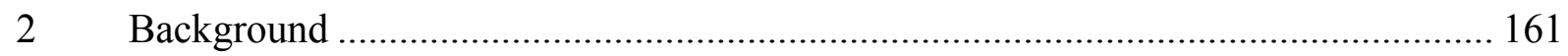

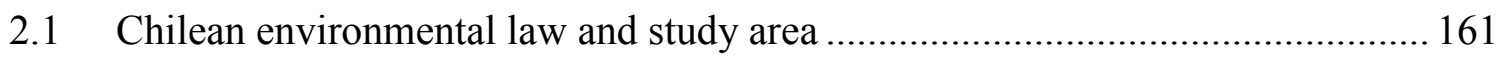

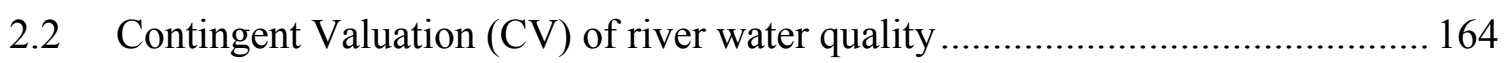

2.3 A formal hypothesis for testing the implications of the Coase Theorem ............ 166

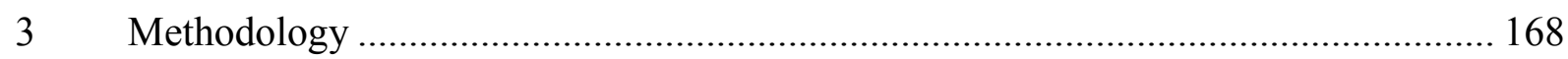




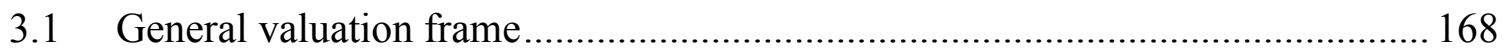

3.2 Potential predictors of willingness to pay ........................................................ 172

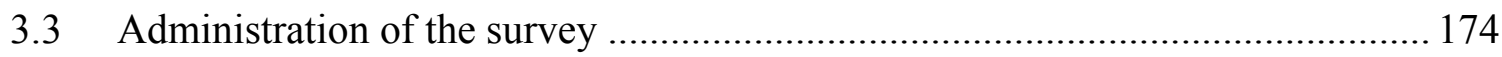

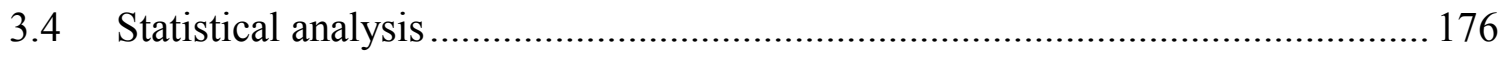

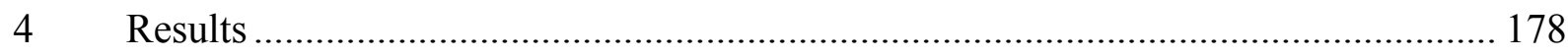

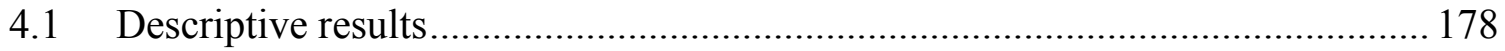

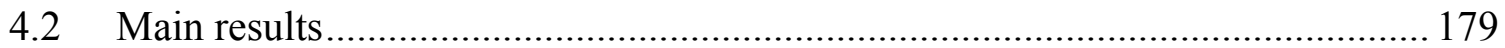

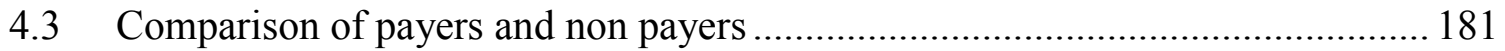

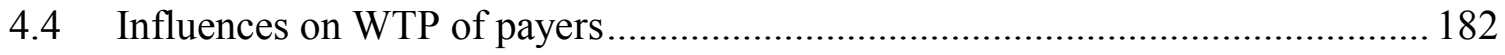

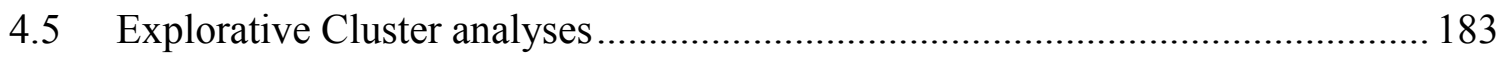

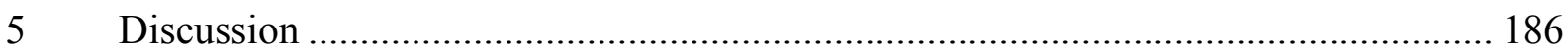

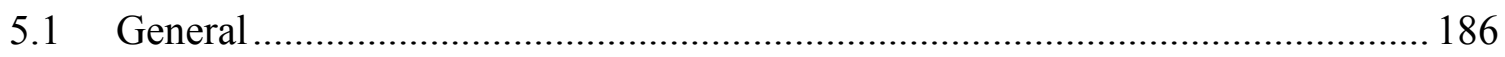

5.2 Further observations on the WTP differences ................................................... 188

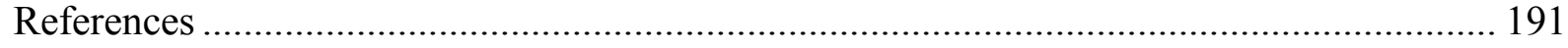

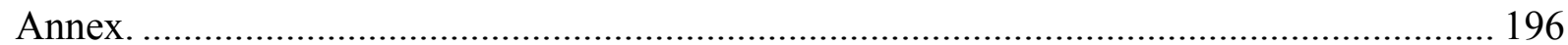

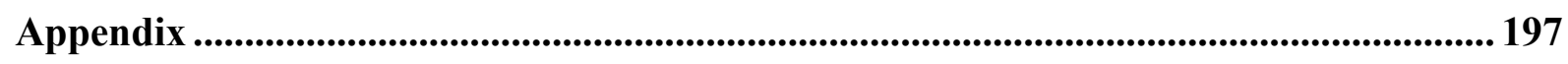

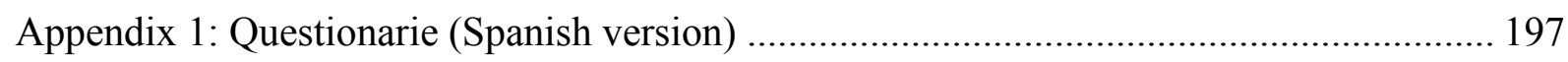

Appendix 2: Example a of choice set with visual aids (Spanish version)............................. 209

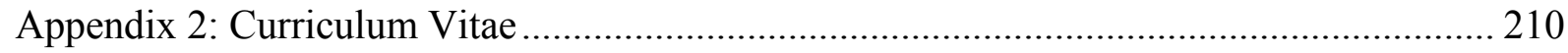




\section{Introduction}

\section{Background}

Despite substantial improvements in river water quality during the last decade, river pollution is still common in Central Chile (OCDE-CEPAL, 2005). Main sources of pollution are household and industry wastewater. In particular, river pollution from the pulp mill industry has received significant attention in the last years. Celulose wastewater violating national water quality standards have produced severe damages to river ecology and to the livelihoods in communities downstream the paper mills (SISS 2008, Vergara and Encina 2008). Namely, this is the case of the Mataquito and Itata rivers of Central Chile. While recent reports indicate positive chemical water quality parameters in these rivers (Cade-Idepe 2004ab), an important share of riparian species is regarded as threatened (Habit et al. 2006).

Against this background, this study presents an environmental economics study to analyze economic preferences ("willingness-to-pay"; WTP) of households located downstream the pulp mill industry for river water quality improvements at the Mataquito and Itata rivers. We use this setting, inter alia, for the investigation of several methodological issues regarding stated preference studies that attempt to elicit consumer/citizen WTP. For example, one of the reasons for survey respondent to reject stating her/his WTP ("protest response") is the perception that it would be unfair to ask them to pay for the environmental good at stake (Jorgensen et al. 2001). Respondents may solely regard the pulp mill industry as responsible for the pollution, so industry should pay not citizens. Such issues of fairness are of substantial importance for emerging economy countries such as Chile in which environmental regulation is being increasingly introduced while strong income and wealth disparities prevail. Like most 
of Chilean politics, Chilean environmental policy is characterized by a pronounced freemarket stance. The Chilean electorate did not challenge the free market stance of the leading political forces in Chile in any of the past general elections. In this situation, it is unclear if citizens exclusively favor industry contributions to improve environmental quality or if the affected population is willing to contribute itself by directly to paying for the improvements. This line of thought prompted an investigation of the influence of fairness condiderations on WTP for water quality improvements in Chile as an integral part of this dissertation project.

Respondent preferences for non-market goods such as river water quality do not only depend on the characteristics of the goods but also on respondent beliefs, perceptions and attitudes towards the goods being valued (e.g., Barkmann et al. 2008). Accounting for these factors may substantially improve the ability of stated preference models to represent preference heterogeneity among the investigated population. To take advantage of and contribute to the accumulating knowledge on such influences, respondent attitudes towards water quality are included in the survey, and analyzed with regard to their influence on WTP for river water quality improvements. As an extension of several attitudinal items in the questionnaire, also items on the perceived severity of river pollution and on perceived response efficacy of water quality policies to cope with river pollution on the WTP for river quality are examined.

In the last chapter of this dissertation, some wider implications of the "fairness" topic introduced above are explored. Specifically, a formal model that allows for testing hypotheses on some implications of the Coase Theorem is developed. According to Coase (1960), the initial distribution of environmental property rights among different groups of actors does not affect the optimal level of environmental quality achieved by a bargaining solution among the groups of actors. It is not obvious how this insight of Coase should be applied to the frequent 
case in which property rights in the environmental goods at stake are not defined. In fact however, environmental regulation does introduce de facto property rights in the utilisation of environmental goods. For example, a regulation that sets a binding water quality standard does, de facto, grant the right to industry to utilize the waste discharge services of the river up to the limit set. Thus, the regulation of the utilisaiton of public environmental goods can be investigated from a property rights perspective.

With respect to the case of river water pollution brought about by a certain industry, this means that the Coase Theorem can be applied: The location of the optimum level of water quality should not depend on whether industry has a "right to pollute" or whether citizens have a right to an uncompromised level of environmental quality. Interestingly, there is no direct empirical evidence showing that the initial property rights distribution is in fact irrelevant with respect to the identification of the optimal level of environmental quality in cases of applied environmental policy. Quite to the contrary, a number of observations suggest that actual human behavior in potential Coase-type bargaining situations is affected by such property rights considerations. In this regard, it appears as a rewarding scientific problem to investigate if a different framing of a stated preference valuation question in terms of contrasting environmental property rights distribution influences WTP for river quality improvements.

\section{Research framework and objectives of the study}

The dissertation project was integrated in the junior research group Valuation of Ecosystem Functions and Services headed by Dr. J. Barkmann at the Environmental Economics and Natural Resource Economics Group, Department of Agricultural Economics and Rural 
Development, Georg-August-Universität Göttingen. It was funded by the Chilean Comisión Nacional de Investigación Cientifica y Tecnológica (CONICYT) and Deutscher Akademischer Austausch Dienst (DAAD). In addition, the field research was sponsored by the Environmental Economics and Natural Resource Economics Group and by Göttinger Graduiertenschule Gesellschaftswissenschaften at Georg-August-Universität Göttingen.

The analysis of respondent WTP for attributes of river water quality improvements is the main focus of the study (general objective, Figure 1). The dissertation is divided into two components that mirror the basic structure of the valuation interview instrument that I designed and used. First, the impact of potential determinants of respondent WTP for river quality is studied with the Choice Experiment (CE) method. This part includes the analysis of the influences of fairness considerations, attitudinal, and social-psychology factors on WTP (specific objectives 1, 2, and 3). Second, the influence of alternative institutional frames in terms of property rights distribution is analyzed with the Contingent Valuation (CV) method (specific objective 4). Both, $\mathrm{CE}$ and $\mathrm{CV}$, were integrated into the same empirical valuation interview instrument. The valuation frame of the CV study builds upon the frame used in the CE part of the interview that directly precedes the CV part of the valuation interview.

The described setup of the study allows for the investigation of the following general and specific objectives:

General objective (GO):

- To estimate the willingness-to-pay of local residents living downstream the Itata and Mataquito river pulp mills for attributes of river water quality improvement. 
The resulting valuation findings close a gap in the valuation of Chilean river water resources, and contribute to the international database on valuation studies from emerging economies.

Specific objective 1 (SO1):

- To analyze the impact of fairness concerns on the rate of protest responses as well as on the willingness-to-pay for river water quality improvements.

These findings should allow for an assessment of whether or not 'ultra'-market approaches to improving water quality in Chile based in Coase-type bargaining are a potential policy option for applied environmental issues. The results contribute to the international debate on the influence of fairness concerns on the results and interpretations of stated preference studies.

Specific objective 2 (SO2):

- To determine the influence of attitudinal factors on respondent willingness-to-pay for river water quality improvements.

The results contribute to knowing whether and to what extent attitudinal factors influence preferences for river water quality improvements in Chile.

Specific objective 3 (SO3):

- To determine the influence of social-psychology constructs on respondent willingnessto-pay for river water quality improvements.

In particular, I analyze the influence of perceived severity of river pollution and perceived response efficacy of coping measures on respondents choices. The findings contribute to the international debate on the influence of social-psychology variables on the results and interpretations of stated preference studies. 
Specific objective 4 (SO4):

- To analyze the influence of alternative institutional frames on respondent willingnessto-pay for river water quality improvements.

I challenge a Coase-type hypothesis that alternative frameworks ('Industry pays' versus 'Citizens Pay') do not show different WTP values. Moreover, I analyze the influence of property right beliefs on valuation results. If the hypothesis is found to be false, this would contribute to the fundamental economic discussion on the real-world applicability of the Coase Theorem. In applied terms, it gives essential guidance on how to frame and design economic mechanisms for dealing with water pollution.

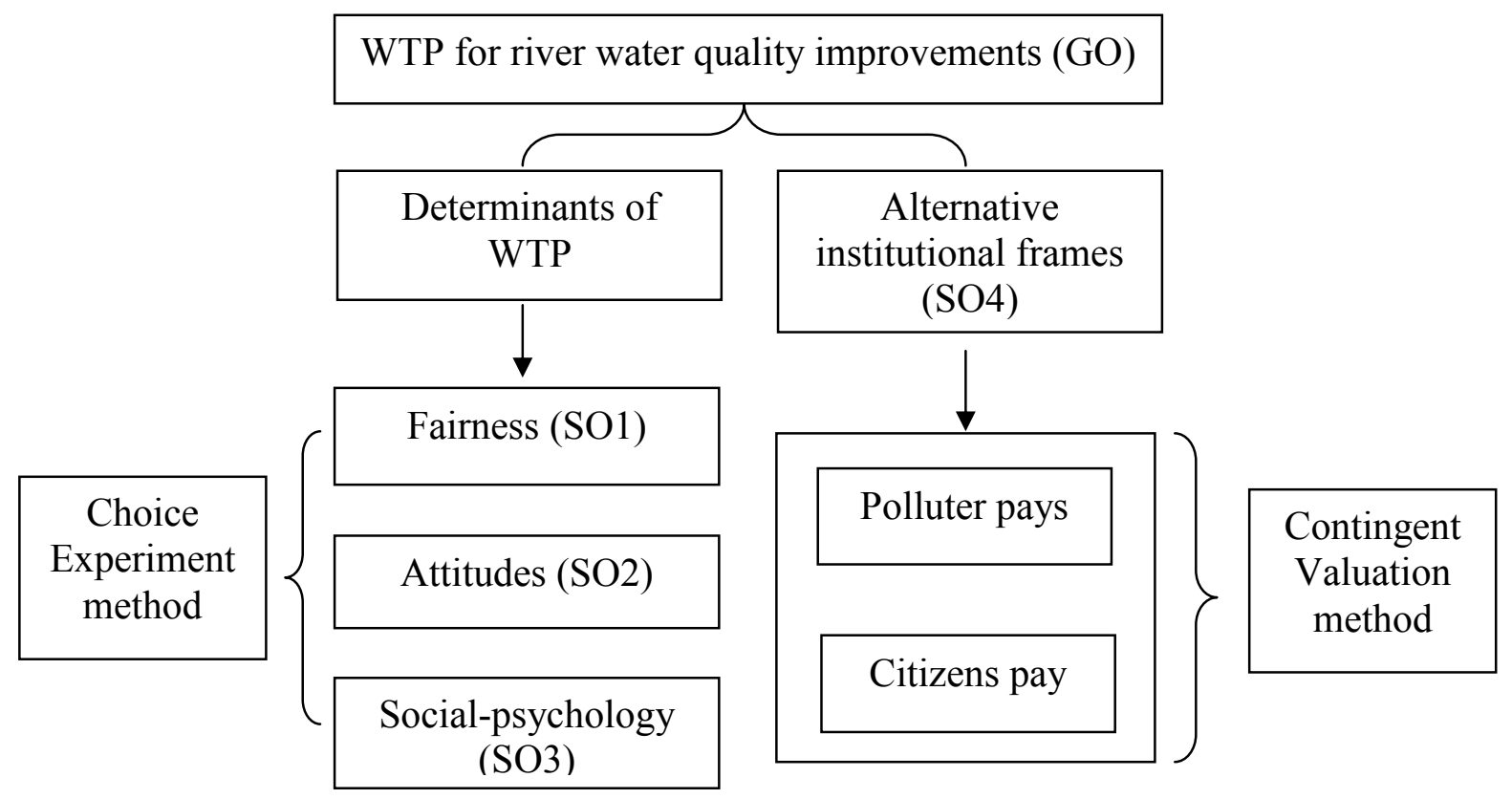

Figure 1. Research framework

\section{$3 \quad$ Study region and sampling}

The study area is located at downstream sections of the Mataquito and Itata river watersheds in the VII Maule region and the VIII Bío-Bío region of Central Chile (Figure 2). Both rivers 
receive wastewater from the pulp mill industry. The study area includes four communities (Mataquito River: Licantén and Curepto; Itata River: Coelemu and Trehuaco). The sampling framework included 2,141 inhabitants at the Mataquito River site and 13,521 inhabitants at the Itata River site (population data extracted from INE 2005). In addition to the pulp mills, the main economic activities in the study area are agriculture, local fisheries at the estuary, and forestry with plantations of exotic Pinus radiata (Monterrey Pine) that supply wood for the pulp mills (INE 2009).

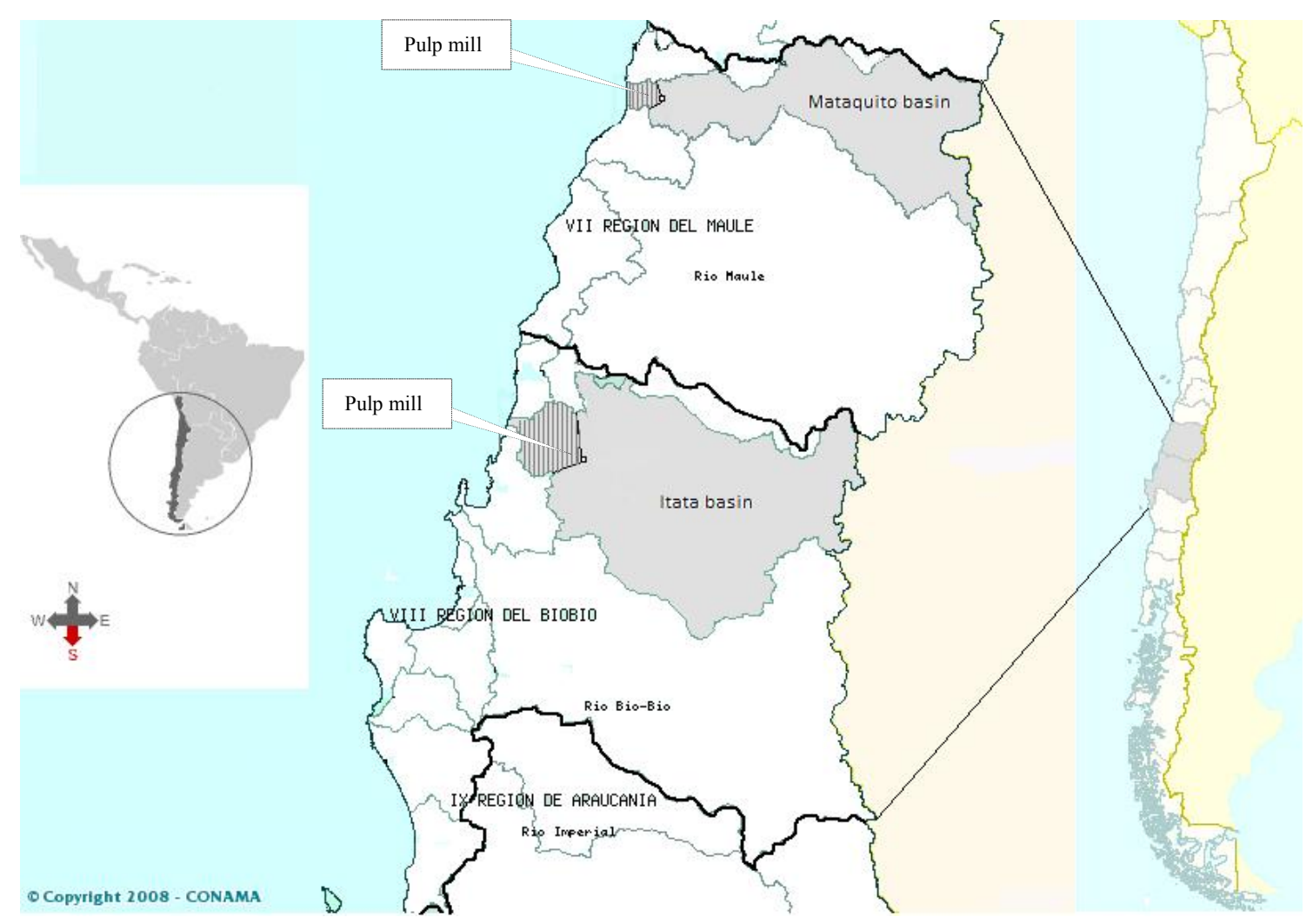

Figure 2. Location of the study area (adapted from CONAMA-SINIA 2008); actual study area hatched.

The face-to-face interview survey was conducted by four trained university students and me from February to April 2009. For the survey, we considered households located in communities downstream from the pulp mills that live adjacent to the river along the main 
roads. According to the National Census of 2002 (INE 2005), the total household number at the Mataquito river site is 883 and 4,001 at the Itata site. We sampled a minimum of 150 households from each site by a systematic sampling procedure (Babbie 2008:224).

\section{$4 \quad$ The Choice Experiment method}

The CE method is a combination of Lancaster's characteristics theory of value (Lancaster, 1966) and random utility theory (Luce, 1959; McFadden, 1973). Methodologically, direct environmental valuation methods are based on 'constructed' hypothetical markets assessing respondent demand for an improvement in an environmental good. The CE method is based on reconstructing economic preferences from respondent choices in alternative valuation scenarios made during a valuation interview. The scenarios offered to respondents differ by the levels (characteristics) that a number of different attributes display (Bateman et al. 2002:278).

The CE was applied to the valuation of different attributes of river water and river ecosystem quality (short: river quality). Attributes of the status of river ecology such as presence of certain water plants, fish, bird and other animal species were with the CE method studied by Hanley et al. (2006ab), Álvarez-Farizo et al. (2007), Morrison and Bennett (2004), and Bateman et al. (2006). Recreation attributes (boating, fishing, and swimming) were analyzed by Morrison and Bennett (2004) and Bateman et al. (2006). Moreover, the importance of river flow rate and local jobs (Hanley et al. 2006a), aesthetics (Hanley et al. 2006b), and of water supply (Álvarez-Farizo et al. 2007) have been investigated. In all cases, the CE attributes were found to be significant determinants of choice. 
In the introductory framing section of the $\mathrm{CE}$ interview used in this study, respondents were asked to contribute to the identification of better water quality policy options for the two rivers. To this effect, the scenarios presented to respondents were clad as policy option outcomes The outcomes were, in turn, described through selected attributes of river water quality, and a mandated payment.

Based on pre-study results and Chilean national environmental data (SISS 2008-2009; SERNAPESCA 2007ab; Bioma 2008; Araya et al. 2006; CONAF 1993), three policy-relevant attributes of river quality improvement were constructed: river pollution risk, number of threatened species, and local fishery yields (Table 1). Each attribute and its respective levels were explained to respondents using examples with visual aids. For each attribute, one level corresponds to the current situation (status quo). For the payment attribute, an additional mandatory annual payment per household on the electricity bill was utilized.

Table 1. Attributes and levels in the CE

\begin{tabular}{|c|c|c|}
\hline Attribute & Definition & Levels \\
\hline Pollution risk & $\begin{array}{l}\text { River pollution risk (\% non } \\
\text { compliance with regulations) }\end{array}$ & $25_{\mathrm{SQ}}, 20,15,10$ \\
\hline Threatened species & Number of threatened species $\left(\mathrm{N}^{\mathrm{o}}\right)$ & $25_{\mathrm{SQ}}, 20,15,10$ \\
\hline Fisheries yield & Increase in fisheries yield (\%) & $0_{\mathrm{SQ}}, 10,25,50$ \\
\hline Payment $^{\S}$ & Charge to the electricity bill (CLP) & $\begin{array}{l}0_{\mathrm{SQ}}, 500,1000,2000, \\
3000\end{array}$ \\
\hline
\end{tabular}




\section{$5 \quad$ Outline of the dissertation}

Following this introduction, the dissertation is organised in five chapters that are formatted for submission to scientific journals. Chapter 1 is a precursor study about an application of the CE method for the valuation of a forest resource in Chile. Chapters 2, 3, 4, and 5 present the results of the main study on the valuation of river quality improvements.

The first manuscript (Chapter 1) Benefits of protecting the ecosystem services of the endemic Ruil forests of Central Chile with the choice experiment method will be submitted to the journal Forest Policy and Economics. A preliminary version of this manuscript 'Ecosystem Service Valuation of Ruil (Nothofagus alessandrii) Forests in Central Chile: An application of the choice experiment method' (Villalobos, Huenchuleo 2010) was published in Bennett J. and Birol E. (eds) Choice Experiments in Developing Countries: Implementation, Challenges and Policy Implications, Edward Elgar Publishing Ltd., UK. The first manuscript presents an empirical application of the Choice Experiment method to ecosystem services valuation of the endemic Ruil forests (Nothofagus alessandrii) in Central Chile. We analyze respondent WTP for the surface area of Ruil forest actually protected, scenic beauty generated by the forest, and for conservation programs for the flora and fauna of Ruil forests at large. Moreover, we investigate the influence of socio-demographic characteristics of respondents on their preferences for Ruil forest protection.

The second manuscript (Chapter 2) Economic valuation of river-based ecosystem services subject to fairness considerations in Central Chile using a Choice Experiment (Huenchuleo, Barkmann, Marggraf) was submitted to the journal Regional Environmental Change. We investigate the influence of fairness concerns on protest responses as well as on WTP. This 
should allow for an assessment of whether ultra-market approaches to improving river water quality in Chile are a potential policy option. This manuscript focuses on specific objective 1 of this dissertation.

The third manuscript (Chapter 3) Attitudinal determinants of willingness-to-pay for river water quality improvements in Central Chile: A choice experiment approach will be submitted to the Latin-American journal Ciencia e Investigación Agraria. We analyze the influence of respondent attitudes on WTP for river water quality improvements. In particular, we investigate attitudes toward: water resources, water pollution sources, and the valuation scenario. This manuscript covers specific objective 2 of this dissertation.

The fourth manuscript (Chapter 4) Social-psychology determinants of river water quality improvement in Central Chile: a Choice Experiment application will be submitted to the journal Population and Environment. Social-psychology constructs have been shown to influence behavioral intentions to cope with environmental risks. However, few applications have analyzed the impact of predictors from formal psychology theory on the outcome of stated preferences studies. River pollution by pulp mills may pose a severe, but uncertain threat to respondent livelihoods. Thus, our contribution analyzes the influence of perceived severity of river pollution and of response efficacy of water quality policies on WTP for water quality improvements. In the $\mathrm{CE}$, the behavioral intention is observed through the respondent behavior (choice). This manuscript covers specific objective 3 of this dissertation.

The fifth manuscript (Chapter 5) A matter of Coase: Influence of property right beliefs on Willingness-to-Pay for river water quality in absence of transaction costs will be submitted to the journal Environment and Development Economics. Pulp mill wastewater is regarded as 
negatively affecting the welfare of respondents located downstream the pulp mills in our study area. In such cases, Coase (1960) suggests that - in absence of transaction costs - the allocation of property rights (right to damage downstream hydrology versus right to enjoy undamaged hydrologic ecosystem services) does not affect the realisation of a Pareto-efficient solution to the externality problem. As transaction costs are often prohibitive, real world implementations of Coase-type solutions regarding public environmental goods are rare. In this regard, we test the extent to which a different framing of a stated preference valuation exercise in terms of the environmental property rights distribution impacts stated demand for environmental quality improvements. We asked respondents for their maximum WTP for a river quality improvement (i) via payments to enforce the compliance of the pulp mill with more restrictive water quality policies ('Industry pays') or (ii) via direct payments to the pulp mill industry to reduce wastewater discharges into the river ('Citizens pay'). Moreover, we investigate the influence of property right beliefs on the valuation process. This manuscript covers specific objective 4 of this dissertation.

\section{$6 \quad$ Fundamental results}

The majority of respondents believe that the current river water quality is poor in the two rivers of the researech area, and that it will be worse in the future. Consequently, most respondents agree that river water quality is not well protected by law. They are aware of the negative effects of wastewater (and excessive fertilizer use) on river ecology. Most respondents perceive a high severity of river pollution and a high response efficacy of water quality policies. Respondents believe that it is unfair to ask them to pay for water quality improvements necessitated by industry; rather, the government or industry should pay. Still, most respondents were willing to pay for more restrictive water quality policies implemented 
by the government to enforce a reduction of wastewater discharged into the river. Regarding the valuation scenario, about half of the respondents consider the electricity bill a suitable payment vehicle and most of them stated that they were certain about their choices in the CE exercise.

Eighty-four per cent of the respondents choose alternatives other than the status quo scenario at least once during the $\mathrm{CE}$ interview ('payers'). All estimated models were highly significant overall $\left(\mathrm{P}\left(\chi^{2}\right)<0.0001\right)$. All attributes were significant predictors of choice with high pseudo$\mathrm{R}^{2}$ (constant only) values of $0.20-0.30$. Such Pseudo- $\mathrm{R}^{2}$ values correspond to $\mathrm{R}^{2}$ values between 0.45 and 0.6 in the ordinary least squares model equivalents (Hensher et al. 2005: 338-9). The attribute coefficients displayed the expected signs. The results indicate a disutility for higher river pollution risk, for higher numbers of threatened species, and for higher payments for water quality improvements. Positive utility was derived from higher fishery yields. The alternative specific constant (ASC) was not significant in all models. Calculated mean WTP for a scenario of substantial improvement in all river water attributes was $\sim 13$ USD/household/yr.

One out of three fairness dimensions from a factor analysis was a significant predictor of choice. A Personal Payment Rejection dimension represents those respondents who cannot afford to pay or believe that they already pay enough taxes. Respondents holding the respective attitudes and beliefs, display lower preferences for reductions in the number of Threatened species on average. Respondents who regard the wastewater dumped into the river more strongly as negative showed higher preferences for reductions in river pollution risk. Those who disagreed more strongly that rivers are well protected by law displayed higher preferences for reductions in the number of threatened species. Respondents displaying 
higher scores for the Response Efficacy and Severity constructs had higher preferences for reductions in river pollution risk and the number of threatened species. Moreover, rural respondents with higher education were more likely to be willing to pay for river quality improvements.

A much higher proportion of respondents were willing to pay under the 'Industry pays' frame (79\%) compared to the 'Citizens pay' frame (19\%). Mean maximum WTP under the 'Industry pays' scenario was significantly higher than WTP in the 'Citizens pay' frame. This finding rejects the Coase-type hypothesis that predicts the absense of such an influence. Respondents who felt more strongly that it was unfair to pay were likely to be willing to pay less for river water quality improvements under both frames. Respondents who felt entitled to river water quality improvements had a higher WTP under the 'Industry pays' scenario. Respondents who stated not to have a problem with paying industry also had a higher WTP under the contrasting 'Citizens pay' frame.

\section{$7 \quad$ Discussion of results}

The findings of this study close a gap in the valuation of Chilean river water resources and contribute to the academically interesting but meagre international database on valuation studies from emerging economies. The CE study was conducted successfully with a very high response rate $(98 \%)$. The introduction of fairness-related cognitions improved model performance substantially. Nevertheless, the direct influence of fairness considerations on WTP for improving river water quality is low as the Personal Payment Rejection dimension does, in fact, represent a more general payment rejection with only little meaning from a specific fairness perspective. Interaction terms of the attributes with respondent attitudes were 
significant predictors of choice. The influence of these predictors differed between the Mataquito and Itata river sites to some extent. Our findings suggest that attitudinal variables deserve more attention in the analysis of preferences for water resource improvement in emerging economies. Social-psychology constructs showed a significant influence on respondent WTP for river water quality improvements. Most respondents showed a problem focussed behaviour towards the reduction of river pollution risk. These results suggest that social-psychology constructs provide an attractive methodological tool for the assessment of preferences for water quality improvement.

Alternative institutional frames for the valuation of river quality improvements that represent a differing initial distribution of property rights in an environmental resource have a significant influence on respondent willingness-to-pay. Respondents were more willing to pay for government enforcement of pulp mill compliance to stricter wastewater regulations ('Industry pays') than for the contrasting option of paying directly to industry for river quality improvements ('Citizens pay'). Consequently, a stated prefernece study that elicits demand for river quality improvement using an Industry pays frame documents a different (higher) demand curve than a study using the contrasting Citizens pay frame. Assuming an identical supply curve, two differing optimum points of environmental quality result. Our results indicate that the initial allocation of property rights may affect the realization of bargaining solutions to the externality problem fundamentally inconsistent with the Coase Theorem. Our findings have substantial importance also from an applied water quality policy making point of view. Even though a free-market stance prevails in Chile, respondents support the 'Industry pays' frame much more strongly as the principle on which to base environmental legislation that the alternative 'Citizens pay' frame. 


\section{References}

Álvarez-Farizo B, Hanley N, Barberán R, Lázaro A (2007) Choice modelling at the "market stall": Individual versus collective interest in environmental valuation. Ecological Economics 60: 743-751.

Araya I, Quiñones R, Dresdner J, Barriga O, Carrasco P, Campos N, Leiva M, Hernandez A, Ponce R, Rivas R (2006) Diagnóstico social, económico y productivo de las comunidades de pescadores artesanales de la desembocadura del Itata y zonas adyacentes, entre Cobquecura y Dichato. Programa de Estudios Económicos y Sociales del Sector Pesquero, Universidad de Concepción, Chile.

Babbie EA (2008) The basics of social research, Fourth Edition. Thomson Learning, Inc. USA.

Bateman I, Carson T, Day B, Hanemann M, Hanley N, Hett T, Jones-Lee M, Loomes G, Mourato S, Özdemiroglu E, Pearce D, Sugden R, Swanson J (2002) Economic valuation with stated preferences techniques: a manual, Edward Elgar, Cheltenham, UK and Northampton, MA, USA.

Bateman IJ, Cole MA, Georgiou S, Hadley DJ (2006) Comparing contingent valuation and contingent ranking: A case study considering the benefits of urban river water quality improvements. Journal of Environmental Management 79: 221-231.

Bioma (2008) Consultoría para la recopilación de información sobre la biodiversidad en apoyo a la elaboración del anteproyecto de norma secundaria de calidad ambiental para la protección de las aguas de la cuenca del Mataquito. Bioma BGA Consultores.

Birol E, Karousakis K, Koundouri P (2006) Using economic valuation techniques to inform water resources management: A survey and critical appraisal of available techniques and an application. Science of the Total Environment 365: 105-122.

Birol E, Karousakis K, Koundouri P (2008a) Using a Choice Experiment to Inform Implementation of the European Union Water Framework Directive: The Case of Cheimaditida Wetland in Greece. In Choice Experiments Informing Environmental Policy. A European Perspective. Edited by Birol, E. and Koundouri, P. Edward Elgar Publishing Ltd. UK.

Birol B, Koundouri P, Kountouris Y (2008b) Using the Choice Experiment Method to Inform River Management in Poland: Flood Risk Reduction versus Habitat Conservation in the 
Upper Silesia Region. In Choice Experiments Informing Environmental Policy. A European Perspective. Edited by Birol, E. and Koundouri, P. Edward Elgar Publishing Ltd. UK.

Cade-Idepe Consultores en Ingeniería (2004a) Diagnóstico y clasificación de los cursos y cuerpos de agua según objetivos de calidad - cuenca río Mataquito. Dirección General de Aguas, Ministerio de Obras Públicas, Chile. http://www.sinia.cl/1292/articles31018_Mataquito.pdf. Accessed 26 June 2008

Cade-Idepe Consultores en Ingeniería (2004b) Diagnóstico y clasificación de los cursos y cuerpos de agua según objetivos de calidad - cuenca río Itata. Dirección General de Aguas, Ministerio de Obras Públicas, Chile. http://www.sinia.cl/1292/articles31018_Itata.pdf. Accessed 26 June 2008

Coase R (1960) The problem of social cost. Journal of Law and Economics 3, 1-44. CONAF (1993) Libro rojo de los vertebrados terrestres de Chile. Corporación Nacional Forestal - CONAF, Ministerio de Agricultura de Chile. Santiago, Segunda Edición. CONAMA (2006) Análisis económico y social de la norma de calidad secundaria para la protección de las aguas continentales superficiales en la cuenca del río Maipo. Región Metropolitana de Santiago.

CONAMA-SINIA (2008) Información geográfica territorial regional. Sistema Nacional de Información Ambiental Territorial (SINIA), Ministerio del Medio Ambiente, Chile. http://territorial.sinia.cl/portal/descargas.php. Accessed 30 September 2010.

EULA (2006) Análisis general del impacto económico de la norma secundaria de calidad de aguas en la cuenca del río Bio-Bio, en el sector silvoagropecuario. Universidad de Concepción.

Habit E, Dyer B, Vila I (2006) Estado de conocimiento de los peces dulceacuícolas de Chile. Gayana 70, 1: 100-113.

Hanley N, Colombo S, Tinch D, Black A, Aftab A (2006a) Estimating the benefits of water quality improvements under the Water Framework Directive: are benefits transferable? European Review of Agricultural Economics 33, 3: 391-413.

Hanley N, Wright RE, Alvarez-Farizo B (2006b) Estimating the economic value of improvements in river ecology using choice experiments: an application to the water framework directive. Journal of Environmental Management 78: 183-193.

Hensher DA, Rose JM, Greene WH (2005) Applied choice analysis: a primer. Cambridge University Press, Cambridge (UK). 
INE (2005) Chile: Ciudades, Pueblos, Aldeas y Caseríos. Censo 2002, Instituto Nacional de Estadísticas - INE, Chile. http://www.ine.cl/canales/chile estadistico/ demografia_y_vitales/demografia/demografia.php. Accessed 20 April 2008

INE (2009) Censo Agropecuario 2007. http://www.censoagropecuario.cl/. Accessed 5 May 2008

Lancaster KA (1966) A new approach to consumer theory. Journal of Political Economics, $74,132-157$.

Luce D (1959) Individual Choice Behaviour, John Wiley, New York, NY.

McFadden D (1974) Conditional Logit Analysis of Qualitative Choice Behavior, in P. Zarembka, (ed.), Frontiers in Econometrics, Academic Press, New York.

Morrison M, Bennett J (2004) Valuing New South Wales rivers for use in benefit transfer.

The Australian Journal of Agricultural and Resource Economics 48, 4: 591-611.

OCDE-CEPAL (2005) Evaluaciones del desempeño ambiental - Chile. Organización de

Cooperación y Desarrollo Económicos - Comisión Económica para América Latina y el Caribe. Ed. Naciones Unidas, CEPAL.

Orrego R, Burgos A, Moraga-Cid G, Inzunza B, Gonzalez M, Valenzuela A, Barra R, Gavilán J (2006) Effects of pulp and paper mill discharges on caged Rainbow Trout

(Oncorhynchus mykiss): Biomarker responses along a pollution gradient in the Bio-Bio river, Chile. Environmental Toxicology and Chemistry 25, 9: 2280-2287.

Postel SL, Thompson Jr BH (2005) Watershed protection: Capturing the benefits of nature's water supply services. Natural Resources Forum 29: 98-108.

SERNAPESCA (2007a) Valorización Desembarque Regional Años 2005 - 2006, Región del Maule. Servicio Nacional de Pesca, Chile. http://www.sernapesca.cl/ index.php?option $=$ com_remository\&Itemid $=246 \&$ func $=$ fileinfo $\& i d=1957$. Accessed 1 May 2008

SERNAPESCA (2007b) Concesiones de Acuicultura. Estuarios propuestos como Areas Apropiadas en la Región del Maule. Servicio Nacional de Pesca, Chile. http://www.sernapesca.cl/index.php?option=com_content\&task=view\&id=498\&Itemid= 686. Accessed 1 May 2008

Silva E (1996) Market Economics, and Environmental Policy in Chile. Journal of Interamerican Studies and World Affairs 38, 4: 1-33.

SISS (2009) Cumplimiento de normas de descargas de Residuos Líquidos, DS 90/00

Descarga a cuerpos de agua superficiales, años 2006-2007-2008. Superintendencia de 
Servicios Sanitarios - SISS, Chile. http://www.siss.cl/propertyvalue-2309.html. Accessed 25 January 2009

SISS (2008) Informe de Gestión Sector Sanitario 2007. Superintendencia de Servicios

Sanitarios, Chile. http://www.siss.cl/articles-6245_informegestion.pdf. Accessed 30

March 2008

Vergara A, Encina F et al (2008) Informe Final - Evaluación Ambiental en el río Mataquito.

Facultad de Ingeniería - Facultad de Recursos Naturales, Universidad Católica de

Temuco. http://www.cutchile.cl/paloma/04\%20articles-

44336_InformeFinalRioMataquito.pdf. Accessed 15 January 2009

Zenteno P, López A, Mardones C, Montoya F (2009) Análisis de impacto económico y social de anteproyecto de normas secundarias de calidad - cuenca río Mataquito. DSS Ambiente. Ministerio de Obras Públicas, Chile.

http://www.dga.cl/otros/SAD/CQA5072.pdf. Accessed 01 June 2010 
Chapter 1

\title{
Benefits of protecting the ecosystem services of the endemic Ruil forests of Central Chile with the choice experiment method
}

Carlos Huenchuleo Pedreros, Jan Barkmann, Pablo Villalobos Mateluna

\begin{abstract}
This study presents an empirical application of the Choice Experiment method to ecosystem services valuation of the endemic Ruil forests (Nothofagus alessandrii) in Central Chile. We analyzed preferences for the surface area of Ruil forest actually protected, scenic beauty generated by the forest, and for conservation programs for the flora and fauna of the Ruil forests at large. CE results indicated that $58.4 \%$ of the respondents have chosen improvement alternatives for Ruil forests which is relative high considering the low average income of respondents. Nested logit model results showed that the cost attribute, as well as the environmental attributes, turned out to be highly significant predictors of respondent choices. We calculated a mean WTP of 2 USD/month for improvements of the surface area of Ruil forests (0.73 USD/month), of their scenic beauty (0.58 USD/month) and of the preservation of species living in Ruil forests (0.66 USD/month). Aggregated WTP values in the study area indicate an interesting potential even for local Ruil conservation initiatives. Moreover, incentives provided by the national law for native forests do not cover the benefits that Ruils forests provide to local non-agricultural households.
\end{abstract}

Key words: forest conservation, choice experiment method, willingness-to-pay. 


\section{$1 \quad$ Introduction}

Nothofagus alessandrii (Ruil) is a forest species endemic to the VII Maule Region of Chile. It is a very rare deciduous species of mesomorphic areas restricted to tiny fragments ( 349 ha) of the coastal hills (Secano Costero) of the Maule Region. According to the Conservation International, it is considered a top conservation priority (Conservation International, 2007). Ruil is listed as endangered in the Red Data Book for the Terrestrial Flora of Chile (Moreno, 2004). In 1985, the Chilean National Forest Corporation (CONAF) declared the Ruil an endangered species in need of protection (Benoit, 1989). In 1995, Ruil forest was declared a National Monument by Ley $\mathrm{N}^{\circ} 13$ of the Chilean government.

Factors threatening fragments of Ruil forests include ilegal logging of mature trees, forest conversion for subsistence agriculture, grazing of domestic animals, and the establishment of forest plantations (Olivares et al 2005). Especially, the extensively planted exotic Monterey pine (Pinus radiata) presents a threat because of its greater ability to obtain water and its aggressive colonization of suitable sites (Grez et al., 1998; Donoso, 1996). The remaining fragments of $N$. alessandrii are often surrounded by plantations of $P$. radiata, which further aggravates the situation compared to cases of more mixed vegetation around the fragments (Olivares et al., 2005). Even in localities where relatively well-conserved fragments are found, negative influences of the surrounding $P$. radiata matrix (genetic isolation, changed meso-climatic conditions) limit recuperation or expansion of existing stands (Olivares, 2005). Buffer zones protecting $N$. alessandrii fragments from surrounding pine plantations are absent (Olivares et al. 2005). The expected climate change in the VII region may exacerbate threats to Ruil as (i) average annual precipitation is expected to decrease, and (ii) in past years Ruil has shown very low natural renewal (CONAMA, 2002). 
In 1974 the Chilean Forest Development Law (Ley 701) introduced subsidies for afforestation, particularly for the establishment of commercially viable plantations (Neira et al. 2002). It generated a significant development of the forest sector but also have negative environmental and social impacts on rural populations. Due to the fact that there are no economic and social instruments that promot the protection of native forests in Chile and its biological diversity, basically only the forestry plantations industry benefits from Ley 701 (CODEFF, 1996).

The SNASPE reserves (Sistema de Areas Silvestres Protegidas del Estado - Wildlife Protected Areas System of the State) were established beginning 1984. The inclusion of an area requires proper compensation payments to private landowners. Most of the native forest land is in private hands in Chile, and the government has only very limited resources to buy land for conservation purposes. In $1999,29 \%$ of the total area of native forests was included in SNASPE, but some forest types are poorly represented and reserve size is often inadequate (Neira et al., 2002). This is the case for Ruil, for which only 24.7 ha $(7.1 \%)$ are included in protected areas owned by the government.

In 2008, the Law for Native Forests and Forest Development was enacted (Law 20.283). This law strengthens natural resource conservation and protection projects. For example, it promotes the recognition of non-timber goods and ecosystem services that forests provide. It includes a competitive fund to implement activities for conserving and recovering native forests. In practice, the law provides once a maximum of $5 \mathrm{UTM} / \mathrm{ha}$ (366 USD/ha) for implementing a long term conservation plan. The first competitive fund was being opened for bids in 2010. Therefore, the fundamental legal procedures for Ruil conservation are principally in place, while the actual implementation of Ruil conservation measures depends 
mainly on economic considerations.

Alternatives to the implementation of incentive-based conservation schemes have often failed in the past (Pagiola and Platais, 2001). They indicate that traditional solutions to forest conservation are of two types: (i) to legally regulate the type of forest use, and (ii) to carry out protective measures. Protective measures are imperfect and costlier than preventive measures. Regarding legal regulations, it is often difficult to fulfil them given the large distances between users, and, their fulfilment can result in high costs for economically disadvantaged users by prohibiting profitable activities. Pagiola and Platais (2001) conclude that the recognition of this problem and failures of previous approaches have led to the development of systems where land users are compensated for the environmental services that their lands generate, thus making compatible the users' incentives with those of the society as a whole.

The calculation of the (total) economic value of a forest ecosystem is difficult because of the inherent multi-functionality of forest ecosystems (Riera and Mogas 2006). The remaining Ruil forests may be attributed a substantial non-use value because of the potentially high ethical importance of their conservation. For instance, Ruil forest is considered a National Monument. The diversity of values suggest a valuation strategy that not only generates a comprehensive measure of the economic preferences for Ruil protection, but also a differentiated estimate that reflects at least some of the multifunctional benefits of Ruil forests.

There exist an important number of studies about the valuation of forest ecosystem services by using Choice Experiments (CEs). Most studies have focused on citizen preferences for forest conservation through specific conservation programs and forest management practices 
(Lehtonen et al. 2006, Xu et al. 2003, Horne et al 2005, Nielsen et al 2007, Rolfe et al. 2000, Watson et al. 2004, Riera 2006, Barkmann et al. 2007, Biénabe and Hearne 2006, Christie et al. 2007, Hanley et al. 1998). All of them have studied attributes that arise from aspects such as biodiversity, aesthetic, or recreation.

Some authors assessed social attributes of forest conservation such as job losses (Xu et al. 2003) and conservation effects on local people (Rolfe et al. 2000). Attributes valued also include physical and geographical aspects such as tree characteristics (Nielsen et al 2007, Hanley et al. 1998), location and area (Rolfe et al. 2000, Watson et al. 2004). Barkmann et al. (2007) focused on indirect use benefits such as protection against soil erosion, flooding, and on protection against uncertain future environmental threats. Erosion control has also been valued as an important benefit of forest conservation (Riera and Mogas 2006, Barkmann et al. 2007).

Biénabe and Hearne (2006) analysed preferences for nature conservation and scenic beauty of private forests through a system of Payments for Environmental Services (PESs). Christie et al. (2007) focused on the valuation of improvements to recreational facilities such as type of trail, general facilities, information, surroundings, and distance. More specialist forest user groups or rural dwellers are willing to pay more for improvements than general users such as urban dwellers and forest non-users (Hanley et al. 1998, Christie et al. 2007).

All attributes studied were statistically significant predictors of WTP for forest conservation. The CE demonstrated that choice tradeoffs may involve a variety of environmental and socioeconomic factors, rather than exclusive monetary tradeoffs (Rolfe et al. 2000). Moreover, it is highlighted that CE success depends to a large extent on the selection of attributes and their 
levels. (Watson et al. 2004). Relatively few studies were carried out in South-America using CEs. Furthermore, according to our knowledge, no studies about forest resources benefits have been carry out in Chile using CEs.

The following section describes the methodology including a description of the study area, survey design, and the empirical methods used (section 2). Then, our results are presented in section 3, followed by a discussion of main findings. Finally, we present main conclusions.

\section{Mehodology}

\subsection{Study area}

The study area is located in the costal dry lands (Secano Costero) of VII Maule Region in Central Chile (Figure 1). The natural distribution of Nothofagus alessandrii is restricted to the coastal mountains that extend from $35^{\circ}$ to $36^{\circ} \mathrm{S}$ in fragments situated to the western side of mountains at altitudes of 150 to $500 \mathrm{~m}$. Ruil forests are placed in four communities: Curepto, Constitución, Empedrado and Chanco. The majority of owners are smallholders who live in substantial poverty generating income from raising domestic animals, charcoal production and small gardens. A second group of small landowners lives closer to urban centres and receives substantial off-farm income (Olivares et al., 2005).

There are only 24.7 ha $(7.1 \%)$ of Ruil forests included in protected areas owned by the government (SNASPE), namely the Reserva Nacional Los Ruiles - National Reserve "Los Ruiles". The reserve includes Ruil forests from Chanco and Empedrado communities. The remaining Ruil forests belong to small landowners (165.3 ha) and forest companies (162.9 
ha).

Forest companies protect part of Ruil forests (128.1 ha) based on economic considerations through environmental and commercial certifications. It includes a privately owned protected area (Parque Los Ruiles de Empedrado - "Los Ruiles” Park of Empedrado community) which covers 66 ha of Ruil forest that has been established by the forest company Bosques de Chile. Moreover, recently CONAF has acquired 79 ha of Ruil fragments near the National Reserve "Los Ruiles" that will be part of the Reserve in the future. Considering this scenario, to date $34 \%$ (120 ha) of the remaining Ruil forest is not included in any form of protection scheme (Olivares et al., 2005).

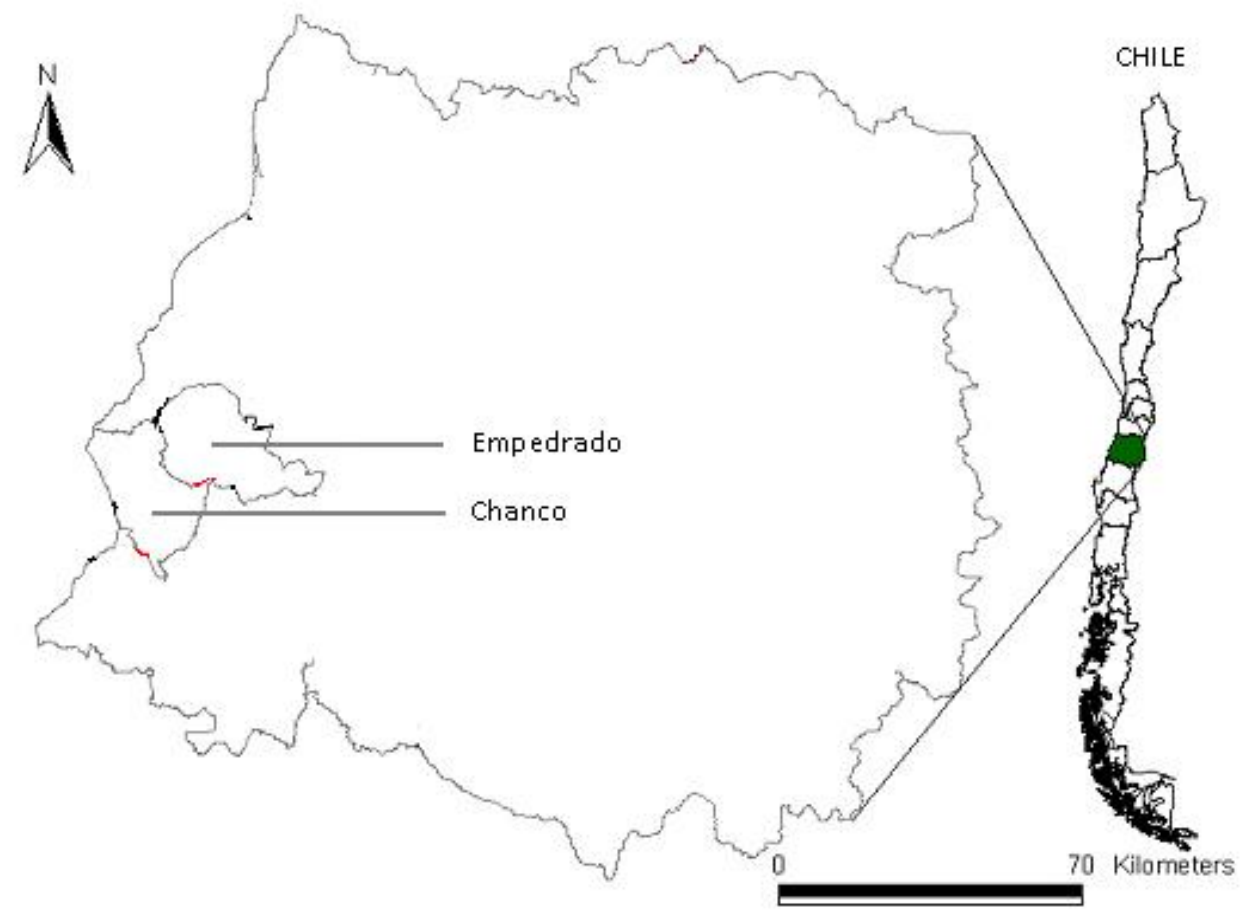

Figure 1. Location of the study area.

Source: National Commission of Environment - CONAMA (2005). 


\subsection{Design of the Choice Experiment}

During the pre-study phase of this investigation, interviews were conducted with specialists from $\mathrm{CONAF}^{1}, \mathrm{CONAMA}^{2}$, academics and specialists related to forest management in the VII Region. In addition, an exhaustive review of the existing literature was undertaken. Based on this, four attributes were identified: Ruil forest surface area effectively protected (Ruil Area), scenic beauty ${ }^{3}$, protection and conservation of plant and animal species that inhabit Ruil forests (Biodiversity), and a monthly fee to protect the Ruil forests (Payment).

The attribute Ruil Area was designed by using three different levels of surface area. Currently, the Ruil surface effectively protected is 24.7 ha, a proposed intermediate level of surface effectively protected is 170 ha, and the highest proposed level is 349 ha. The last level is the actual total Ruil surface available. Surface area is a highly relevant characteristic for the status of the Ruil forests because of the small area remaining and the endangered status of the species.

The Scenic Beauty attribute is a concept that involves subjective aspects linked to the aesthetic enjoyment of a natural area. The Ruil forests substantially increase the scenic beauty of the local landscapes often dominated by pine plantations. In order to increase the benefits that the local population can reap from the remaining Ruil forests, access to these forests can be improved. Three levels were defined for the Scenic Beauty attribute: one path in the whole area (current situation - lower level), implementation of two paths and two viewpoints

\footnotetext{
${ }^{1}$ CONAF: Corporación Nacional Forestal (National Forestry Corporation) -Chile

${ }^{2}$ CONAMA: Comisión Nacional del Medio Ambiente (National Environment Commission) -Chile

${ }^{3}$ Attribute names are capitalized in italics
} 
(intermediate level), and the implementation of two paths, two viewpoints, guided visits with delivery of information leaflets (highest level).

The third attribute is Biodiversity. Ruil forests harbour a rich flora and fauna. Pudu (Pudu puda), Copihue (Lapageria rosea), Carpinterito (Picoides lignarius) and Pitao (Pitavia punctata) are representative species that are protected by law in Ruil forests. These species are important from an ecological and ethno-cultural point of view. However, at present there are no plans for the recovery and preservation of these species, although their populations are also in a state of decline (Benoit 1989, Olivares et al. 2005, IUCN 2011). This description represents the actual situation (lower level). A second improved scenario considers a recovery plan for Pudu and Copihue (intermediate level), and the third alternative consists of a recovery plan for Pudu, Copihue, Carpinterito and Pitao (highest level).

The attribute Payment represents the means (payment vehicle) by which the funds for the Ruil forest protection program would be collected from the local population. In this case, a mandatory monthly charge for protecting Ruil was chosen. Technically, the charge would be collected along with the utility fees (water services). If a respondent chooses an option with a certain monthly charge printed on it, this means that respondent's income is effectively diminished by this amount. Respondents were informed that the money raised would permit financing an Environmental Protection Fund directed exclusively to the protection of the Ruil through the implementation and maintenance of the alternative preferred by the majority of the surveyed people. Currently, there is no charge for Ruil protection (lower level). After the pre-test, two significant amounts of Payment were selected: 3,000 Chilean pesos - CLP $(\sim 5.70$ USD, intermediate level) and 6,000 CLP ( 11.40 USD, highest level). 
Table 1 shows the selected attributes, their basic definitions and their respective levels. The current situation of each attribute is named Status Quo (SQ). In addition, for a better understanding of the attributes, a description in words and maps was provided to respondents.

Table 1. Attributes and levels

\begin{tabular}{lll}
\hline Attribute & Definition & Levels \\
\hline Ruil Area & Ruil forest surface area & Low: 24.7 (SQ); Medium; 170; High: \\
& effectively protected (ha). & 349 \\
Scenic Beauty & Aesthetic enjoyment of a & Low: 1 path (SQ); Medium: 2 paths \\
& natural area provided by Ruil & and 2 viewpoints; High: 2 paths, 2 \\
& forests. & viewpoints, guided visits with delivery \\
& & of information leaflets \\
Biodiversity & Diversity of different species & Low: No recovery plan (SQ); Medium: \\
& of plants and animals. & Recovery plan to Pudu and Copihue; \\
& & High: Recovery plan to Pudu, Copihue, \\
& & Carpinterito and Pitao \\
Payment & Monthly fee to protect Ruil & 0 (SQ); 3,000; 6,000 \\
& Forest (CLP). & \\
\hline
\end{tabular}

Note: Monthly fee in CLP (1 USD $\approx 525$ CLP, January 2006)

From a full-factorial design of four attributes times three levels for each one, $81\left(3^{4}\right)$ possible attribute level combinations, an orthogonal main effects design of nine combinations (choice sets) were obtained. These nine choice sets were used to print nine cardboard choice cards A (variants of card C - SQ). Using a shifting technique, permutations among the attribute levels of the nine card A scenarios are carried out generating nine more scenarios (card B). No restrictions were imposed on this design so in some choice sets there is no strict utility balance. Together with an always identical choice card representing the Status Quo level of the attributes, nine choice sets were formed. Each choice set consisted of one card A, one card 
B, and a Status Quo - card C. An example of a choice set is shown in Table 2.

Table 2. Example choice set

\begin{tabular}{llll}
\hline Attribute & Card A & Card B & Card C - SQ \\
\hline Ruil Area & 349 ha & 24.7 ha & 24.7 ha \\
Scenic Beauty & 1 path & $\begin{array}{l}\text { 2 paths and 2 } \\
\text { viewpoints }\end{array}$ & 1 path \\
& & No recovery plan & No recovery plan \\
Biodiversity & Pudu, Copihue, & & \\
& Carpinterito and Pitao & & 0 CLP \\
Payment & 6,000 CLP & 3,000 CLP & \\
\hline
\end{tabular}

\subsection{Administration of the survey}

The survey was conducted in the communities of Empedrado and Chanco in January 2006. Because of logistical reasons we excluded Curepto and Constitución communities from the survey. Of the 1,743 non-agricultural households of the research region (INE, 2005), 160 households were proportionally sampled (Chanco: 98 households; Empedrado 62 households). The head of the household or the person who determined the use of family income, was interviewed. When someone was not found the next door household was surveyed.

The study considered only non-agricultural 'urban' households because it is likely that their household cash income is not affected by any Ruil protection measures. Nevertheless, these households consume basic services such as electricity and potable water, through which local payments for a Ruil conservation fund could be collected. In addition to basic socio-economic variables, respondents were asked several forest- and species-related knowledge questions, 
how they would like to pay for such a program (type of payment vehicle: water bill or power bill), and which attribute is the most important to them. Socio-demographic variables included in the survey are presented in Table 3.

Table 3. Variables on socio-demographic characteristics of respondents.

\begin{tabular}{|c|c|c|}
\hline Variable & Definition & Format \\
\hline Age & Respondent age & Continuous variable \\
\hline Income $^{a}$ & Monthly household income & Ordered eight-point items scale \\
\hline Education $^{b}$ & Respondent education level & Ordered six-point items scale \\
\hline $\operatorname{Sex}$ & Sex of respondent & Dummy variable (1: Male, 0 : Female) \\
\hline
\end{tabular}

\subsection{Econometric analyses}

We estimated two-level NL models with partial degeneracy (Hunt, 2000). Given that we have three elemental alternatives, one branch with two alternatives and one branch with a single alternative (degenerated branch) were obtained.

Suitable NL model tree-structures were identified, and the corresponding models estimated with NLOGIT 4.0. The inclusive value was set to 1.0 for the degenerated branch (Status Quo), and the model initiated with starting values obtained from a non-nested NL model (Hensher et al., 2005:530). All scale parameters were normalized at the lowest level (RU1). The vector of utility coefficients is estimated with maximum likelihood estimation procedures. As model statistics, we report adjusted pseudo- $R^{2}$ values in relation to a 
'constants only' model. Values between 0.45 and 0.55 correspond to $R^{2}$ values of 0.85 and 0.95 in their ordinary least squares equivalences (Hensher et al., 2005:338).

The estimated choice model also includes an alternative specific constant (ASC). It picks up systematic choice variation between the status quo alternative and the proposed alternatives that cannot be explained by the attributes. The $A S C$ was coded as a dummy variable with values 1 for the generic alternatives $(\mathrm{A}$ and $\mathrm{B})$ and 0 for the status quo alternative $\mathrm{C}$.

Respondent choices do not only depend on alternative attributes but also on their sociodemographic characteristics. To test for such influences, interaction terms of the $A S C$ and of the attributes were generated. Barkmann et al. (2007) indicate that interaction terms can improve the predictive capacity of the model, and are used to test hypotheses on socioeconomic and attitudinal influences on preferences. If a deterministic utility component $U_{i}$ is hypothesized to be a linear function of attribute $X_{i}$ itself plus an interaction term of the attribute $X_{i}$ with an individually varying variable $Y, U_{i}$ can be expressed as

$$
U_{i}\left(X_{i}, Y\right)=\beta_{Y X} * X_{i} * Y+\beta_{X} * X_{i}
$$

with

$\beta_{Y X}$ : utility coefficient of the interaction term.

The improved model was generated stepwise by initially including all statistically significant interactions terms from single interactions models and then deleting non-significant interaction terms one-by-one. Significant interactions terms of socio-demographic characteristics were reported in the improved model sequentially. 
$\mathrm{CE}$ is consistent with utility maximization and demand theory, at least when a status quo scenario is included in the choice set (Bateman et al, 2002). Hence, they allow a suitable estimation of monetary welfare measures such as Willingness-to-Pay (WTP). Based on the quantification of the utility coefficients of the NL model, a maximum marginal WTP (mWTP) for a marginal (1 unit) attribute level changes can be estimated as

$$
m W T P=-\frac{\beta_{X}}{\beta_{c}}
$$

where

$\beta_{x}$ : utility coefficient of any of the environmental attributes and,

$\beta_{c}$ : marginal utility of income given by the coefficient of the payment attribute coefficient.

These ratios are known as implicit prices. They are also useful for identifying the relative importance of different attributes. Furthermore, the welfare change generated by an improvement in Ruil forest conservation was calculated. The change from level of quality $Q^{0}$ (status quo) to $Q^{1}$ is calculated as a Compensating Variation $C V$ (Louviere et al., 2000:340). $C V$ is the amount of money that equates the status quo utility level $\left(U^{0}\right)$ with the next utility level $\left(U^{l}\right)$. In other words, $C V$ is the maximum willingness to pay to achieve a higher quality level.

$$
C V\left(Q^{0} \rightarrow Q^{1}\right)=-\frac{1}{\beta_{C}} *\left[U^{1}-U^{0}\right]
$$




\section{$3 \quad$ Results and Discussion}

Results from socio-demographic and attitudinal variables studied are presented in Table 4. A total of 98 female $(61 \%)$ and 62 male (39\%) were interviewed. This imbalance on respondent gender is because most respondents founded at the household during the survey were women. The average age of respondents was 42 years. The most representative education category of respondents was the range 9 to 12 years of education (41\%), equivalent to an incomplete secondary education. Average household income was 248,438 CLP/month ( 473 USD/month). Pudu and Copihue are well known species compared to Pitao and the Carpinterito. At least for two of the four explicitly mentioned species, respondents had some knowledge. Among the two unknown species was Pitao; this is worrying, as this species is the most endangered of the four species included.

Judged by an attitudinal question, the most important attributes were Ruil Area (49\%) and Biodiversity (35\%). Payment attribute was the most important attribute for $13 \%$ of the respondents and Scenic Beauty just for 3\% of them. 31\% of respondents felt that the most convenient payment vehicle would be a contribution to the forest conservation fund to be collected along with the water bill. $17 \%$ of respondents selected always the current situation status quo $(\mathrm{n}=27)$. This value is lower than other similar studies such as $33 \%$ (Horne, 2006), 18\% (Watson et al, 2004), and 21\% (Horne et al, 2005). This situation can be explained by the low average income at nearby communities where $35 \%$ of households get incomes lower than the current monthly Chilean minimum wage (equivalent to US\$280). 
Table 4. Descriptive results

\begin{tabular}{lll}
\hline Variables & Response & Value \\
\hline Ruil knowledge & $\%$ Yes & 71 \\
Pudu knowledge & $\%$ Yes & 93 \\
Copihue knowledge & $\%$ Yes & 100 \\
Carpinterito knowledge & $\%$ Yes & 57 \\
Pitao knowledge & $\%$ Yes & 11 \\
Attribute importance & Ruil Area; Biodiversity; Payment; Scenic & $49 ; 35 ; 13 ; 3$ \\
& Beauty (respondents \%) & \\
Status quo choice & Always zero payment (respondents \%) & 17 \\
Payment vehicle preferred & Water bill; Power bill (respondents \%) & $31 ; 19$ \\
Sex & \% Female & 61 \\
Age & Average age & 42 \\
Education & At least 9 to 12 years (\%) & 41 \\
Income & Average household income (CLP/month) & 248,438 (473 \\
& & USD)
\end{tabular}

$\S_{\text {: }}$ Average income was estimated using middle points for each income category.

The results of the nested logit analysis are presented in Table 5. All estimated models are overall highly significant (Table $5 ; P\left(\chi^{2}\right)<0.0001$ ). Furthermore, models present a pseudo- $R^{2}$ equal to 0.47 and 0.54 for models (a) and (b) respectively, indicating a suitable model fit. The model (a) shows signs of attributes coefficients according to expectations. Coefficients sign indicates a positive utility for higher Ruil Area, higher level of Scenic Beauty, higher level of Biodiversity, and disutility of higher Payment for Ruil forests ecosystem services. These estimates indicated that the attributes presented are significant predictors of the respondent choice. The exception was the disutility obtained for high Scenic Beauty. The alternative specific constant - ASC (non-status quo) is positive in all models indicating that, all else equal, respondents have a preference for non status-quo alternatives. 
The Ruil Area attribute yield a positive utility on respondents choice which confirms the importance of this attribute to the respondents as was given on the attitudinal question. This finding corroborates results supporting the significance of forest surface area effectively protected (Watson et al., 2004). High and Medium levels of Biodiversity attribute also derive a positive utility on individuals choice. This finding confirms results indicating that attributes representing enrichment of forest biodiversity have a significant and positive effect on respondent WTP (Xu et al., 2003, Garber-Yonts et al., 2004, Watson et al., 2004, Horne at al., 2005).

The effect of the Scenic Beauty attribute on respondent choice is not clear (see Table 5). While Medium level of Scenic Beauty yields a positive utility in respondent choice, High level of Scenic Beauty produces a disutility. The positive effect of this attribute is supported by most of the literature (Xu et al., 2003, Horne at al., 2005, Biénabe and Hearne, 2006). The disutility obtained from High level of Scenic Beauty may be explained by the low importance (3\%) given by respondents to this attribute. Moreover, the additional elements incorporated in the High level of Scenic Beauty (guided visits and delivery of information leaflets) may not be relevant to respondent decisions. In this regard, a more carefully selection of attribute levels should be taken in consideration in further research.

Socio-demographic characteristics of respondents had a significant impact on respondent choice (model b). Younger respondents are more likely to choose a non-status quo alternative $\left(A S C^{*} A g e\right)$. Respondents of higher income are more prompted to choose alternatives that show higher Ruil Area (Ruil Area*Income) and Medium levels of Scenic Beauty (Medium Scenic Beauty*Income) and Biodiversity (Medium Biodiversity*Income). Respondents of higher education level are more likely to experience a positive utility from High and Medium 
levels of Biodiversity (High Biodiversity*Education, Medium Biodiversity*Education). Moreover, respondents of higher education level are more prompted to experience a lower disutility of higher Payment for Ruils forests ecosystem services (Payment* Education). We obtained results similar to Biénabe and Hearne (2006) who find that higher education level of respondents yield a positive utility on respondents choice. So, respondents of higer education level are more likely to choose an alternative that is different to the status quo. Our results are in line with Rolfe et al. (2000) who found that younger respondents are more prompted to choose non-status quo alternatives. Compared to the model (a), socio-demographic characteristics improve the predictive power of the model (pseudo- $\mathrm{R}^{2}$ ) from 0.468 (by about $0.077)$ to 0.545 .

We conducted a non-market valuation of Ruil forests ecosystem services based on a simple, conservative policy scenario, and on model (a) parameter estimates (Table 6). We found significant marginal WTP values for each attribute. The calculated marginal WTP for Ruil Area, High Biodiversity, Medium Biodiversity, and Medium Scenic Beauty point at appreciable benefits that the local population derives from the Ruil forests.

The marginal WTP values per household corresponds to $0.005 \mathrm{USD} / \mathrm{month}$ for one additional hectare of Ruil Area, 0.578 USD/month for Medium improvement on Scenic Beauty, and 0.656 USD/month for Medium improvement on Biodiversity (see Table 6). The scenario considers that Ruil Area increase to 145 ha, Scenic Beauty improves from Low to Medium level, and Biodiversity improves from Low to Medium level. Estimated total aggregated WTP (compensating surplus) for the scenario change is about 1,994 USD/month ( Mio CLP 1.05/ month). 
Table 5. Valuation of Ruil forests ecosystem services in Central Chile.

\begin{tabular}{|c|c|c|}
\hline Variable & $\begin{array}{l}\text { (a) Attributes } \\
\text { only }\end{array}$ & $\begin{array}{l}\text { (b) Attributes + } \\
\text { interaction terms }\end{array}$ \\
\hline Ruil Area $\$$ & $0.275^{* * *}$ & $0.424 * * *$ \\
\hline High Scenic Beauty & $-0.509 * *$ & $-0.498 * *$ \\
\hline Medium Scenic Beauty & $0.318^{*}$ & $0.295^{*}$ \\
\hline High Biodiversity & $0.351 *$ & 0.298 \\
\hline Medium Biodiversity & $0.361 *$ & 0.234 \\
\hline Payment $^{\%}$ & $-0.550 * * *$ & $-0.685 * * *$ \\
\hline$A S C($ non-SQ) & $0.747 * *$ & $0.845 * * *$ \\
\hline$A S C($ non-SQ)*Age & & $-0.191 *$ \\
\hline Ruil Area*Income & & $0.106^{*}$ \\
\hline Medium Scenic Beauty*Income & & $0.416 * *$ \\
\hline High Biodiversity $^{*}$ Education & & $0.617 * * *$ \\
\hline Medium Biodiversity*Income & & $0.453^{*}$ \\
\hline Medium Biodiversity*Education & & $0.595 * * *$ \\
\hline Payment*Education & & $0.065 * *$ \\
\hline Log-likelihood & -828.613 & -708.095 \\
\hline $\mathrm{P}\left(\mathrm{Chi}^{2}\right) ; \mathrm{DF}$ & $<0.0001 ; 8$ & $<0.0001 ; 15$ \\
\hline IV of non degenerated branch (nonCardB) & 0.331 & 0.319 \\
\hline Pseudo-R ${ }^{2}$ (const only) ${ }^{\S}$ & 0.468 & 0.545 \\
\hline Observations & 160 & 160 \\
\hline \multicolumn{3}{|c|}{$* * *$ : significant at $\mathrm{p} \leq 0.001 ; * *$ : significant at $\mathrm{p} \leq 0.01 ; *$ : significant at $\mathrm{p} \leq 0.05$} \\
\hline \multicolumn{3}{|c|}{ \$: Ruil Area in hundred hectares; \%: Payment in USD } \\
\hline \multicolumn{3}{|c|}{$\begin{array}{l}\S \text { : Pseudo- } \mathrm{R}^{2} \text { (constant only) values between } 0.45 \text { and } 0.55 \text { correspond to } \mathrm{R}^{2} \text { values } \\
\text { between } 0.85 \text { and } 0.95 \text { value in the linear model equivalent (Hensher et al. } 2005: 338-9 \text { ). }\end{array}$} \\
\hline
\end{tabular}

The estimated benefits from protecting Ruil forests ecosystem services represent a measure of the minimum compensation that smallholders should receive for the Ruil forest ecosystem services that their land yield to local non-agricultural households. As an example, we may compare estimated WTP values with current incentive for protecting native forests in Chile. We calculated a total aggregated WTP of $61 \mathrm{USD} / \mathrm{ha} / \mathrm{yr}$ for Ruil forests effectively protected. The Chilean Law of Native Forest offers an incentive of $355 \mathrm{USD} / \mathrm{ha} /$ once for protecting native forests of high ecological value (Minagri 2008). This incentive may cover a 
compensation payment of $61 \mathrm{USD} /$ ha to Ruil forests householders by only six years approximately. This result suggests that the long-run protection of Ruil forests by local smallholders under current forest law is not fully safeguarded. So, additional forest conservation schemes should be studied.

Table 6. Marginal non-market WTP and exemplary policy scenario calculations based on model (a) statistics

\begin{tabular}{|c|c|c|c|}
\hline & Ruil area & Scenic beauty & Biodiversity \\
\hline Marginal Unit & $\begin{array}{l}1 \text { hectare } \\
\text { increase }\end{array}$ & $\begin{array}{c}\text { Low to Medium } \\
\text { level }\end{array}$ & $\begin{array}{c}\text { Low to Medium } \\
\text { level }\end{array}$ \\
\hline $\begin{array}{l}\text { Marginal mean WTP per } \\
\text { household (USD/month) }\end{array}$ & 0.005 & 0.578 & 0.656 \\
\hline Scenario change & 145 ha increase & $\begin{array}{l}\text { none to medium } \\
\text { improvement }\end{array}$ & $\begin{array}{l}\text { none to medium } \\
\text { improvement }\end{array}$ \\
\hline $\begin{array}{l}\text { Mean scenario WTP per } \\
\text { household (USD/month) }\end{array}$ & 0.725 & 0.578 & 0.656 \\
\hline $\begin{array}{l}\text { Total scenario WTP per } \\
\text { household (USD/month) }\end{array}$ & & 1.959 & \\
\hline $\begin{array}{l}\text { Aggregated scenario WTP } \\
\text { (USD/month) } \\
\text { Total aggregated scenario } \\
\text { WTP (USD/month) }\end{array}$ & 738 & $(\sim$ Mio CLP 1.05 & nonth) \\
\hline
\end{tabular}

Aggregation based on $1,743 *(160-67) / 160=1,018$ households in the study area that are willing to pay. 1 USD 525 CLP (January 2006)

\section{Conclusions}

This study presents results from an application of the choice experiment method to an ecosystem services valuation of Ruil forests (Nothofagus alessandrii) in Chile. Although, Ruil conservation is a national Chilean task, insufficient public funds for conservation suggested an investigation of the local economic appreciation of the non-market value of the ecosystem services generated by Ruil forests. In particular, we analyzed preferences for Ruil Area 
effectively protected, for the Scenic Beauty generated by the forest, and Biodiversity of the Ruil forests at large.

CE results indicate that $83 \%$ of respondents have chosen improvement alternatives for Ruil forests at least once which is substantiall considering the low average income of respondents. Nested logit models results showed that the cost attribute, as well as all environmental attributes, were significant predictors of respondent choices. Nevertheless, the effect of the Scenic Beauty attribute was not clear. The maximum likelihood test and pseudo- $R^{2}$ statistics indicate that the overall model is statistically significant and hold a good model fit. We found significant WTP values for each attribute. Local population derives appreciable benefits from the Ruil forests. If aggregated across the local population, these economic preferences indicate an interesting potential even for local Ruil conservation initiatives.

Chile has a unique opportunity to continue growing and developing, protecting the environment and conserving its natural heritage. All of this implies doubling creative efforts in order to effectively and efficiently administer the natural resources. The implementation of a new generation of devices for environmental management is becoming an imperative for the country's forestry and environmental policy. In this sense, green businesses, and in particular environmental services, open up the possibility for forestry and environmental policies to find common ground.

The recent proclamation of the Law for native forest recovery and forest promotion is very significant to the Chilean environmental and forestry sector. In this new legal context, the valuation methods, and particularly the Choice Experiment method, constitute a valuable tool for quantifying monetary incentives that the owners of the native forests favored by this law 
should receive. Our results indicate that estimated monetary incentives exceed the funds aimed to protect Ruil forest. So, additional economic mechanism should be studied in order to complement current governmental subsidies.

\section{References}

Azqueta D (2002) Introducción a la Economía Ambiental. Mc Graw-Hill, Madrid, España.

Balmford A, Bruner A, Cooper P, Costanza R, Farber S, Green R.E., Jenkins M, Jefferiss P, Jessamy V, Madden J, Munro K, Myers N, Naeem S, Paavola J, Rayment M, Rosendo S, Roughgarden J, Trumper K, Turner RK (2002) Economic reasons for conserving wild nature. Science Magazine 9: 950:953.

Barkmann J, Glenk K, Keil A, Leemhuis C, Dietrich N, Gerold G, Marggraf R (2008) Confronting unfamiliarity with ecosystem functions: The case for an ecosystem service approach to environmental valuation with stated preference methods. Ecological Economics 65, 48-62.

Barkmann J, Glenk K, Handi H, Sundawati L, Witte JP, Marggraf R (2007) Assessing economic preferences for biological diversity and ecosystem services at the Central Sulawesi rainforest margin - a choice experiment approach. In: Tscharntke T, Leuschner C, Zeller M, Guhardja E, Bidin A (Hg) Stability of Tropical Rainforest Margins: Linking Ecological, Economic and Social Constraints of Land Use and Conservation. Environmental Science Series, Springer Verlag, Berlin, 181-208.

Bateman I, Carson T, Day B, Hanemann M, Hanley N, Hett T, Jones-Lee M, Loomes G, Mourato S, Özdemiroglu E, Pearce D, Sugden R, Swanson J (2002) Economic valuation with stated preferences techniques: a manual, Edward Elgar, Cheltenham, UK and Northampton, MA, USA.

Benoit I (1989) Libro Rojo de la Flora Terrestre Chilena. Corporación Nacional Forestal, Santiago. Chile. 157 p.

Biénabe E, Hearne R (2006) Public preferences for biodiversity conservation and scenic beauty within a framework of environmental services payments. Forest Policy and Economics 9: 335-348.

Christie M, Hanley N, Hynes S (2007) Valuing enhancements to forest recreation using 
choice experiment and contingent behaviour methods. Journal of Forest Economics 13: $75-102$.

Conservation International (2007) Biodiversity Hotspots - Chilean Winter Rainfall Valdivian Forests. http://www.biodiversityhotspots.org/xp/Hotspots/chileanforests/ pages/default.aspx. Accessed 01 May 2006

Costanza R, d'Arge A, de Groot R, Farberk S, Grasso M, Hannon B, Limburg K, Naeem S, O’Neill R, Paruelo J, Raskin R, Suttonkk P, van den Belt M (1997) The value of the world's ecosystem services and natural capital. Nature 387: 253-260.

Donoso C (1996) Ecology of Nothofagus Forests in Chile Central pp 271-292. In: The Ecology and Biogeography of Nothofagus Forests, Veblen TT, Hill RS, Read T (eds) Yale University Press, Michigan, USA.

Garber-Yonts B, Kerkvliet J, Johnson R (2004) Public Values for Biodiversity Conservation Policies in the Oregon Coast Range. Forest Science 50: 589-602.

Grez AA, Bustamante RO, Simonetti JA, Fahrig L (1998) Landscape Ecology, Deforestation, and Forest Fragmentation: The Case of the Ruil Forest in Chile, in: Chávez, E., Middleton, J. (eds.) (1998). La ecología del paisaje como base para el desarrollo sustentable en América Latina. htpp://www.brocku.ca/epi/lebk/lebk.html. Accessed 20 August 2006

Hanley N, Wright R, Adamowicz V (1998) Using Choice Experiments to Value the Environment. Design Issues, Current Experience and Future Prospects. Environmental and Resource Economics 11: 413-428.

Hanley N, Wright R, Alvarez-Farizo B (2006) Estimating the economic value of improvements in river ecology using choice experiments: an application to the water framework directive. Journal of Environmental Management 78: 183-193.

Horne P (2006) Forest Owners' Acceptance of Incentive Based Policy Instruments in Forest Biodiversity Conservation - A Choice Experiment Based Approach. Silva Fennica 40: 169-178.

Horne P, Boxall P, Adamowicz W (2005) Multiple-use management of forest recreation sites: a spatially explicit choice experiment. Forest Ecology and Management 207: 189-199.

INE (2005) Chile: ciudades, pueblos, aldeas y caseríos. Instituto Nacional de Estadísticas. Available at: http://www.ine.cl/canales/chile_estadistico/demografia_y_vitales/demografia/ demografia.php. Accesed October 2005.

Instituto Interamericano de Cooperación para la Agricultura - IICA (1999) El pago por 
servicios ambientales y el desarrollo sostenible en el medio rural. San José, Costa Rica (Publicaciones Ruta $\mathrm{N}^{\circ}$ 2).

IUCN 2011. IUCN Red List of Threatened Species. Version 2011.1. http://www.iucnredlist.org. Accesed 01 August 2011

Lehtonen E, Kuuluvainen J, Pouta E, Rekola M, Li CZ (2003) Non-market benefits of forest conservation in Southern Finland. Environmental Science \& Policy 6: 195-204.

Luce D (1959) Individual Choice Behaviour. John Wiley, New York, NY.

McFadden D (1974) Conditional Logit Analysis of Qualitative Choice Behavior, in: P. Zarembka, (ed.), Frontiers in Econometrics, Academic Press, New York.

Minagri (2008) Ley sobre recuperación del bosque nativo y fomento forestal. Ministerio de Agricultura, Chile. http://www.leychile.cl/Navegar?idNorma=274894\&tipoVersion=0. Accessed 10 may 2011

Mogas J, Riera P, Bennett J (2006) A comparison of contingent valuation and choice modelling with order interactions. Journal of Forest Economics 12: 5-30.

Moreno G (2004) Present Status of Species of the genus Nothofagus in Chile, in: FAO Forest Genetic Resources 25.

Neira E, Verscheure H, Revenga C (2002) Chile's Frontier Forests: Conserving a Global Treasure, Global Forest Watch Report, Universidad Austral de Chile. www.pubs.wri.org/pubs_pdf.cfm?PubID=3151. Accessed 10 September 2006

Nielsen AB, Olsen SB, Lundhede T (2007) An economic valuation of the recreational benefits associated with nature-based forest management practices. Landscape and Urban Planning 80: 63-71.

Olivares P, San Martín J, Santelices R (2005) Ruil (Nothofagus alessandrii): Estado del conocimiento y desafíos para su conservación. Departamento de Protección de Recursos Naturales, Comisión Nacional del Medio Ambiente, Región del Maule. Talca, Chile.

Pagiola S, Platais G (2001) Selling Biodiversity in Central America. Paper presented at the International Workshop on Market Creation for Biodiversity Products and Services, OECD, Paris, January 25-2, 2001.

Pearce D, Pearce C (2001) The Value of Forest Ecosystems. Report to the Secretariat of the United Nations Convention on Biological Diversity, Montreal, Canada, Londres: CSERGE.

Riera P, Mogas J (2006) Una aplicación de los experimentos de elección a la valoración de la multifuncionalidad de los bosques. Interciencia 31: 110-115. 
Rolfe J, Bennett J, Louviere J (2000) Choice modelling and its potential application to tropical rainforest preservation. Ecological Economics 35: 289-302.

Watson DO, McFarlane BL, Haener MK (2004) Human dimensions of biodiversity conservation in the Interior forests of British Columbia. Journal of Ecosystems and Management 4: 1-20. 
Chapter 2

\title{
Economic valuation of river-based ecosystem services subject to fairness considerations in Central Chile using a Choice Experiment
}

Carlos Huenchuleo Pedreros, Jan Barkmann, Rainer Marggraf

\begin{abstract}
Fairness and justice considerations have been suggested to influence the outcome of stated preferences studies. For example, one of the standard reasons for protesting a willingness-to-pay question is the perception that it would be unfair to pay for the environmental good at stake. In this regard, we present results of a Choice Experiment (CE) study designed to analyze the influence of fairness considerations on part of CE survey respondents on the valuation of river water quality attributes affected by pulp mill wastewater in Central Chile. The CE included attributes on river pollution risk and on river water quality effects that impact threatened species as well as on the yield of local fisheries. The payment vehicle was an additional annual charge to the utility bill. Respondents believed that it is unfair to ask them for paying for water quality improvements necessitated by industry. Instead, they stated that government should pay. Still, most respondents were willing to pay for river water quality improvements. All three environmental attributes and the payment attribute were highly significant predictors of choice $(\mathrm{P}<0.001)$. Calculated mean WTP values for a scenario of substantial improvements for all river water attributes was $\sim 13$ USD/household/yr. The introduction of fairness-related cognitions improved model performance substantially. Nevertheless, the direct influence of fairness considerations is low on WTP for improving river water quality. Partly, this conclusion rests on the presumption,
\end{abstract}


however, that the payment rejection to the valuation scenario represents a more general rejection with only little meaning from a fairness perspective.

Keywords: river water quality, choice experiment, willingness-to-pay, fairness

\section{$1 \quad$ Introduction}

Although significant improvements have been achieved in past years, river water quality in Chile is still poor in some places (OCDE-CEPAL 2005). Main sources of water pollution are untreated wastewater from households and industries. In particular, the negative effect of pulp mill wastewater on river water quality has received a significant attention in Chile (Vasconi 2006; Espinosa 2001). Despite significant efforts to reduce wastewater toxicity, wastewater quality is still believed to impact aquatic organisms negatively (Orrego et al. 2006). Consequently, the river environments downstream pulp mills are considered as severely compromised in Chile (Vasconi 2006).

Our study presents results from an environmental economics study conducted downstream the pulp mills of the Mataquito and Itata rivers in Central Chile. Pulp mill wastewater violating national standards have produced substantial damages to Mataquito river ecology in the recent past (SISS 2008, Vergara and Encina 2008). While recent reports indicate positive chemical water quality parameters at the Mataquito and Itata rivers (Cade-Idepe ab 2004), a major share of fish populations is regarded as threatened (Habit et al. 2006). In this regard, it appears questionable to which degree these indicators of water quality fully represent the ecological status of the two rivers. Local fishermen at the Itata estuary see the pulp mill upstream as a major threat to their business and livelihood (Araya et al. 2006:298). 
Our contribution analyses willingness-to-pay (WTP) of households downstream the paper mills for potential river water quality improvements with the Choice Experiment (CE) method. Additionally, we study the importance of fairness concerns on WTP for river water quality improvements. In order to analyze the impact of fairness concerns, we partly use established questionnaire items from studies that investigate the reasons for protest responses in stated preference surveys (Jorgensen et al. 2001; Jorgensen et al. 2006). A problematic impact of fairness concerns on the frequency of protest responses has been empirically documented (Jorgensen et al. 2001).

The issue of fairness considerations is of substantial importance for emerging economy countries such as Chile. The institutional framework of the Chilean economy as well as its environmental policy is - despite several middle-left governments up to 2009 - characterized by a very pronounced free-market stance (Bamrud 2011). Under these circumstances, it is unclear if citizens favor the Industry-pays principle or rather a Citizens-pay principle to environmental legislation. Additionally, the intermediate position of Chile from an environmental Kuznets curve perspective (s.g., see Stern, 2004) may argue for a restricted social willingness to burden industry with more stringent environmental regulation. In effect, it may be more likely that even the population affected by industrial pollution agrees more strongly to a Citizens-pay principle than the population of the European Union, for example.

The CE method is based on reconstructing economic preferences from respondent choices on alternative valuation scenarios made during a valuation interview. The scenarios offered to respondents differ by the 'levels' (characteristics) that a number of different attributes display (Bateman et al. 2002:278). The CEs were applied to the valuation of different attributes of river water quality improvements in previous studies. Attributes of the status of river ecology 
such as presence of certain water plants, fish, bird and other animal species were studied by Hanley et al. (2006ab), Álvarez-Farizo et al. (2007), Morrison and Bennett (2004), and Bateman et al. (2006). Recreation attributes (boating, fishing, and swimming) were analysed by Morrison and Bennett (2004) and Bateman et al. (2006). Moreover, the importance of river flow rate and local jobs (Hanley et al. 2006a), aesthetics (Hanley et al. 2006b), and of water supply (Álvarez-Farizo et al. 2007) have been analyzed. In all cases, attributes were found to be significant determinants of choice.

In spite of the relative abundance of stated preference studies on non-market aspects of water quality, none of the studies was conducted in Chile. Consequently, the acute lack of data on the non-use and indirect use value of water quality attributes is frequently mentioned as a restriction in applied cost-benefit analyses prepared for legislation purposes in Chile (CONAMA 2006; EULA 2006; Zenteno et al. 2009).

Against this background, the objective of the paper is twofold. First, we attempt to determine the WTP of Central Chilean citizens for improvements in several policy-relevant attributes of river water quality. Specifically, we included attributes on river pollution risk, and on water quality effects impacting river ecosystem services such as habitat for potentially threatened species or yields of local fisheries. The resulting valuation results close a gap in the valuation of the Chilean river water resources, and contribute to the international database on valuation studies from emerging economies. Second, our investigation of the influence of fairness concerns on protest responses as well as on WTP should allow for an assessment if ultramarket approaches to improve water quality in Chile (i.e. "citizens pay" or the "pollutee pays") are a potential policy option. The results contribute to the international debate in the 
influence of fairness concerns on the results and interpretations of stated preference studies (Jorgensen et al. 2001-2006, Meyerhoff and Liebe 2008, Soderqvist 1998).

The paper is organized as follows. In section 2 (methods), we describe study area, CE design, operationalisation of fairness considerations, and general survey design. Section 3 (results) presents the main findings from the CE application including detailed results on the effect of fairness considerations and protest responses. Finally, section 4 presents a discussion and conclusions derived from the study.

\section{$2 \quad$ Methodology}

\subsection{Study area}

The study area is located at downstream sections of the Mataquito and Itata river watersheds in the VII Maule region and the VIII Bío-Bío region of Central Chile (figure 1). The

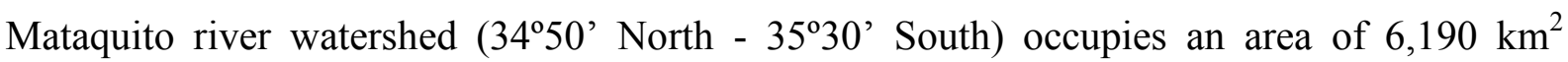
(Cade-Idepe 2004a); the Itata river watershed $\left(36^{\circ} 00^{\prime}\right.$ North $-37^{\circ} 20^{\prime}$ South) has an area of $11,294 \mathrm{~km}^{2}$ (Cade-Idepe 2004b). Both rivers receive wastewater from a pulp mill. The pulp mill on the Mataquito River is located in Licantén $30 \mathrm{~km}$ upstream the estuary. At the Itata River, the pulp mill is located $50 \mathrm{~km}$ upstream the estuary at Ranquil.

The study area includes four communities (Mataquito River: Licantén and Curepto; Itata River: Coelemu and Trehuaco). In these communities, we sampled respondents living downstream the pulp mills. The sampling frame included 2,141 inhabitants at the Mataquito river site and 13,521 inhabitants on the Itata river site (population data extracted from INE 
2005). In addition to the pulp mills, the main economical activities in the study area are agriculture, local fisheries at the estuary, and forestry with plantations of exotic Pinus radiata (Monterrey Pine) that provide wood to the pulp mills (INE 2009).

Cade-Idepe Consultores en Ingeniería (2004ab), a Chilean consultancy and environmental engineering company, indicated that chemical water quality of the Mataquito and Itata rivers is "good" on average, i.e. suitable for conservation and protection of aquatic flora and fauna, unrestrictived irrigation, aquaculture, and fit for sport fishing. In contrast, ecological studies indicate that the biological status at these rivers is severely compromised (Habit et al. 2006; Bioma 2008). From 15 species of native fish present in the study area, all are affected by conservation problems (Habit et al. 2006). In addition, almost half of 50 species of waterfowl are considered as threatened (Bioma 2008). This suggests that the chemical water quality measures employed by Cade-Idepe (2004ab) do not completely represent the ecological status of the river ecosystems in the study area.

\subsection{Choice Experiment design}

In the introductory framing section of the CE interview, respondents were asked to contribute to the identification of better water quality policy options for the two rivers. To this effect, policy option outcomes ('scenarios') were described through selected attributes of river water quality and a payment to be made. 


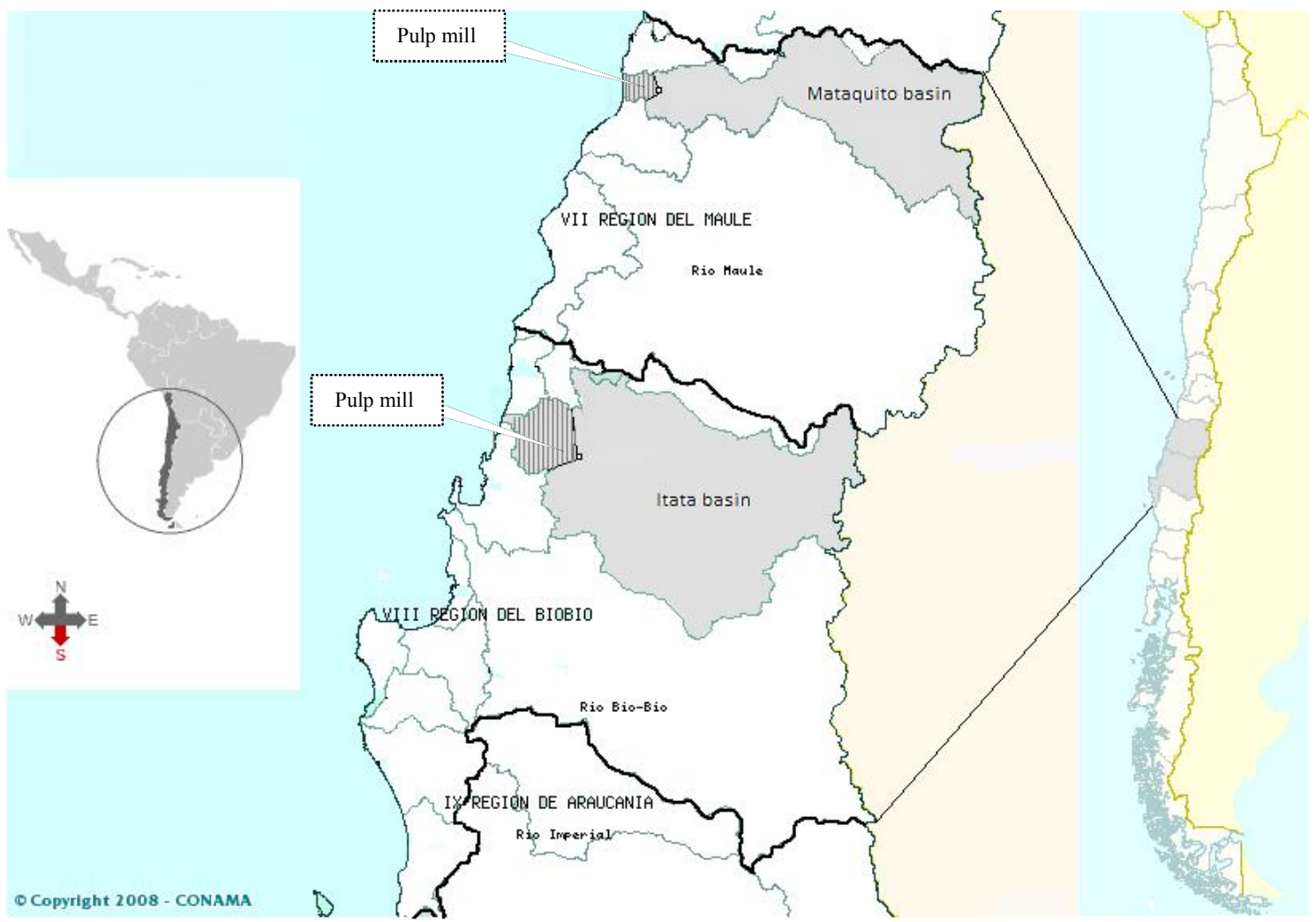

Figure 1. Location of the study area (adapted from CONAMA-SINIA 2008); actual study area hatched

For selecting river water quality attributes, ten qualitative interviews with local inhabitants were conducted at the Mataquito river basin during a pre-study phase. In addition, national environmental data available were consulted (SISS 2008-2009; SERNAPESCA 2007ab; Bioma 2008; Araya et al. 2006; CONAF 1993). Based on the information collected, three attributes on river water quality improvements were constructed: river pollution risk, number of threatened species, and local fisheries yield (for a summary, see Table 1). Each attribute and its respective levels were explained to respondents using examples with visual aids. For each attribute, one level corresponds to the current situation (status quo). Details of attribute construction are given below. 
The pulp mills are the main industrial operations in the research area ${ }^{4}$. Pollution spills leading to violations of national water quality standards have been a recurrent feature of the operation of the pulp mills. For example, reports of the Superintendencia de Servicios Sanitarios (Superintendency of Sanitary Services; SISS) document that the Mataquito river pulp mill did not comply with the national emission standard "DS90-2000", on average, in one of four months (25\%) during a period from 2006-2008 (SISS 2009). Thus, we decided to construct an attribute on river pollution risk that directly addresses such violations. In our CE design, this value corresponds to the current situation or status quo. Additionally, we offered respondents reductions of river pollution risk to $20 \%, 15 \%$ or $10 \%$.

The threatened species attribute deals with the number of fish and waterfowl species living in the river ecosystem with a poor ("threatened") conservation status. Currently, there are 25 such threatened species in the Mataquito and Itata rivers on average (Status Quo; Bioma 2008). Respondents were confronted with a substantial improvement on this situation defined by a reduction on the number of threatened species, i.e., there are more species without conservation problems. Proposed attributes levels were a reduction to 20, 15, and 10 threatened species.

The yield of local fisheries attribute refers to the yield of small fisheries operating mainly in estuaries of the two rivers. To explain this attribute to respondents, we choose the estuarine species Robalo (Eleginops maclovinus), which is a well known species in the study area. The current total yield of local fisheries for Robalo is 1 ton/year (Mataquito) and 10 ton/year (Itata) on average (SERNAPESCA 2007ab; Araya et al. 2006). Given the high yield

\footnotetext{
$4 \quad$ At the Mataquito research site, the pulp mill is the only industrial installation while there are two industrial installations at the Itata study area of which the pulp mill is one.
} 
fluctuation during the last five years, we proposed a significant increase in fisheries yield of $10 \%, 25 \%$, and $50 \%$.

For the payment attribute, an additional mandatory annual payment per household to the electricity bill was utilized. We explained to respondents that the money raised would be used to enforce compliance of the pulp mills with potential more stringent legislation on improving river water quality. Based on pre-study results, we proposed four payment levels $(500,1,000$, 2,000 and 3,000 Chilean pesos/CLP/yr) in addition to a zero status quo payment.

Table 1. Attributes and levels in the CE

\begin{tabular}{lll}
\hline Attribute & Definition & Levels \\
\hline Pollution risk & River pollution risk (\% non & $25_{\mathrm{SQ}}, 20,15,10$ \\
& compliance with national standards) & \\
Threatened species & Number of threatened species & $25_{\mathrm{SQ}}, 20,15,10$ \\
Fisheries yield & Increase in fisheries yield (\%) & $0_{\mathrm{SQ}}, 10,25,50$ \\
Payment $^{\S}$ & Charge to the electricity bill (CLP) & $0_{\mathrm{SQ}}, 500,1000,2000$, \\
& & 3000
\end{tabular}

Note: Payment in Chilean pesos - CLP (1 USD $\approx 606$ CLP, February 2009) per household per year.

SQ: current situation (status quo), §: zero payment was included only in the status quo alternative. This means that the ' 0 ' values is perfectly compounded with the ASC.

From a full-factorial design of four attributes with four levels each, $256\left(4^{4}\right)$ possible attribute level combinations can be obtained ${ }^{5}$. With an orthogonal main effects design, we generated a reduced orthogonal experimental design with 16 different scenarios (=choice cards) (Hensher et al. 2005:115). The choice cards were organised into sixteen choice sets. Using the shifting 
procedure described by Chrzan and Orme (2000), permutations among the attribute levels of these sixteen choice cards generated sixteen additional scenarios. These 16 pairs of alternatives were randomly assigned to four blocks of four choice sets each. Each choice set consisted of two water quality improvement scenarios (A and B) and an 'opt-out' scenario that represents a status quo where no water quality improvements are achieved and the payment is zero (scenario C). Each respondent was asked to choose one scenario from each of the four choice sets. Table 2 shows an example of a choice set.

Table 2. Example of choice set

\begin{tabular}{|c|c|c|c|}
\hline Attribute & $\begin{array}{l}\text { Alternative } \\
\text { A }\end{array}$ & $\begin{array}{l}\text { Alternative } \\
\text { B }\end{array}$ & $\begin{array}{l}\text { Alternative C } \\
\text { No improvement }\end{array}$ \\
\hline Pollution risk & $15 \%$ & $20 \%$ & $25 \%$ \\
\hline Number of Threatened species & 15 & 15 & 25 \\
\hline Fisheries yield & $10 \%$ & $25 \%$ & $0 \%$ \\
\hline Annual Payment & CLP 1,000 & CLP 3,000 & CLP 0 \\
\hline
\end{tabular}

\subsection{Fairness of paying for river water quality improvements}

In two related papers, Jorgensen et al. (2001-2006) investigated attitudes and beliefs that underlie protest responses in stated preference surveys on public environmental goods. A number of respective constructs were found to influence the occurrence of protest responses including constructs related to perceived fairness or justice issues. For example, respondents who felt strongly that they should pay for improvements of the status of the environment that others are threatening, protested the valuation task more frequently than respondents that less strongly thought so. In particular, fairness or justice considerations led to protest responses in the cited studies if respondents felt uncertain about the valuation task (Jorgensen et al. 2006). 
Based on these results, we adopted the respective items by Jorgensen et al. (2001) and added four items informed by own pre-study results on regional environmental fairness issues (Table 3). Respondents were asked to rate their agreement to a list of eleven resulting statements using a five-point Likert scale (1: 'completely disagree'; 5: ‘completely agree').

Most directly, the item UNFAIR asks if the respondent regards a payment as "unfair". Respondents who believe that it is unfair that they have to pay may display a higher propensity to opt for the status quo choice card (scenario C), which does not require an additional payment. While the wording of the UNFAIR item does not include a justification why payments may be unfair, the MYRIGHT item does. MYRIGHT suggests that respondents may have a (moral, property or other legal) 'right' to water quality improvements. The extent of such a belief should reduce the WTP a respondent expresses via her/his choices. The opposite argumentation holds for INDRIGHT, an item that stipulates that industry has the 'right' to pollute the river. A very similar item is $N O P R O B L$ : If industry has pollution rights respondents should not 'have a problem' with paying industry for improved river water quality. The opposite stance is addressed with INDPAY, an item that suggests that industry should pay for such improvements. Alternatively, respondents may think that it is unfair that they pay because the government should do so (GOVPAY). In contrast, additional payments may be perceived as unfair as respondents feel that they pay already a lot of taxes (PAYENOU).

The final four items address additional reasons for refusing payment or for low value statements other than fairness/justice issues. Obviously, budget constraints may hinder a respondent to state a substantial WTP (item $C A N T P A Y$ ). It is also possible that respondents do not consider river water quality improvement as important enough an environmental good as 
to pay for it. Such attitude is captured by the WORTH item. Furthermore, low WTP may be associated with a low belief on the efficacy of the suggested policy responses (item $P O L I C Y)^{6}$. Finally, respondents who require more information than given during the valuation interview - for example because of unfamiliarity with the environmental subject matter at stake (cf. Barkmann et al. 2008) - are expected to show lower WTP (item MOREINF).

Table 3. Fairness-related items on paying for river water quality improvements (RWQI)

1. It is unfair that I have to pay for RWQI. ${ }^{(\mathrm{J})}$ UNFAIR

2. It is my right to have RWQI. ${ }^{(\mathrm{J})}$ MYRIGHT

3. Industry has the right to deliver wastewater into the river. INDRIGHT

4. I have no problems with using my money to pay industry for $N O P R O B L$ RWQI.

5. Industry should pay for RWQI.

INDPAY

6. The government should use existing revenues for RWQI. ${ }^{(\mathrm{J})}$ GOVPAY

7. I already pay enough taxes for the environment. ${ }^{(\mathrm{J})}$ PAYENOU

8. I cannot afford to pay for RWQI. ${ }^{(\mathrm{J})}$ CANTPAY

9. It is not worth paying for RWQI. ${ }^{(\mathrm{J})}$ WORTH

10. I think that policies for RWQI do not work. POLICY

11. I need more information before making a decision on paying for MOREINF RWQI. $^{(J)}$

RWQI: River Water Quality Improvements

(J): Items adopted from Jorgensen et al. (2001).

To test for influences of fairness considerations on preferences for water quality improvements, we first conducted an explorative factor analysis of the fairness items. In order

\footnotetext{
$6 \quad$ For brevity of exposition, we do not explain the choice and wording of these items and their relation to socio-psychological theory here at any detail. It may be sufficient to mention that value and efficacy beliefs are hypothesized to influence pro-environmental intentions to act by theories such as Protection Motivation Theory (Rogers and Prentice-Dunn 1997) or Value-Belief-Norm Theory (Stern et al 1999). Empirical results from CEs in Chile and other non-industrialized countries support these hypotheses (e.g., Barkmann et al. 2008, Huenchuleo et al. 2011).
} 
to represent fairness items in the same semantic direction (as 'protest answers'), INDRIGHT and $N O P R O B L$ were reverse coded. In particular, we performed a varimax rotated factor analysis with binary squared Euclidean distance and Ward-linkage (Krömker 2004). Factor analysis generated empirical 'fairness' dimensions, for which descriptive labels were chosen that reflect content and wording of the underlying items. To calculate the individual values of the dimensions, we employed only items with a factor loading $>0.4$. We calculated Cronbach's Alpha scores as a measure of reliability (internal consistency) for each dimension. As a rule of thumb, alpha values around and above 0.7 indicate a 'reliable scale' (Spector 1992: 32).

Interaction terms can improve the predictive capacity of CE models, and can be used to test hypotheses on socio-economic or 'attitudinal' influences on preferences (Barkmann et al. 2007). If a deterministic utility component $U_{i}$ is hypothesized to be a linear function of attribute $X_{i}$ itself plus an interaction term of the attribute $X_{i}$ with an individually varying variable $Y, U_{i}$ can be expressed as

$$
U_{i}\left(X_{i}, Y\right)=\beta_{Y X} * X_{i} * Y+\beta_{X} * X_{i}
$$

with

$\beta_{Y X}$ : utility coefficient of the interaction term.

Thus, interaction terms of the resulting fairness dimensions with the ASC and with the attribute values were generated and included in model estimation (see section 2.4). To reduce collinearity between interaction terms and the non-interacted attribute terms, the fairness aspects were 0,1 -standardized before multiplication with the attribute. 


\subsection{Influence of socio-economic variables}

We also analysed demographic characteristics of respondents and respondent relations to the two rivers (Table 4). A correlation analysis of these variables with the fairness items is given in Table 7. Moreover, the significance of mean differences (two-tailed $t$-Test) between payers and non-payers for each socio-economic variable was estimated.

Table 4. Socio-economic variables

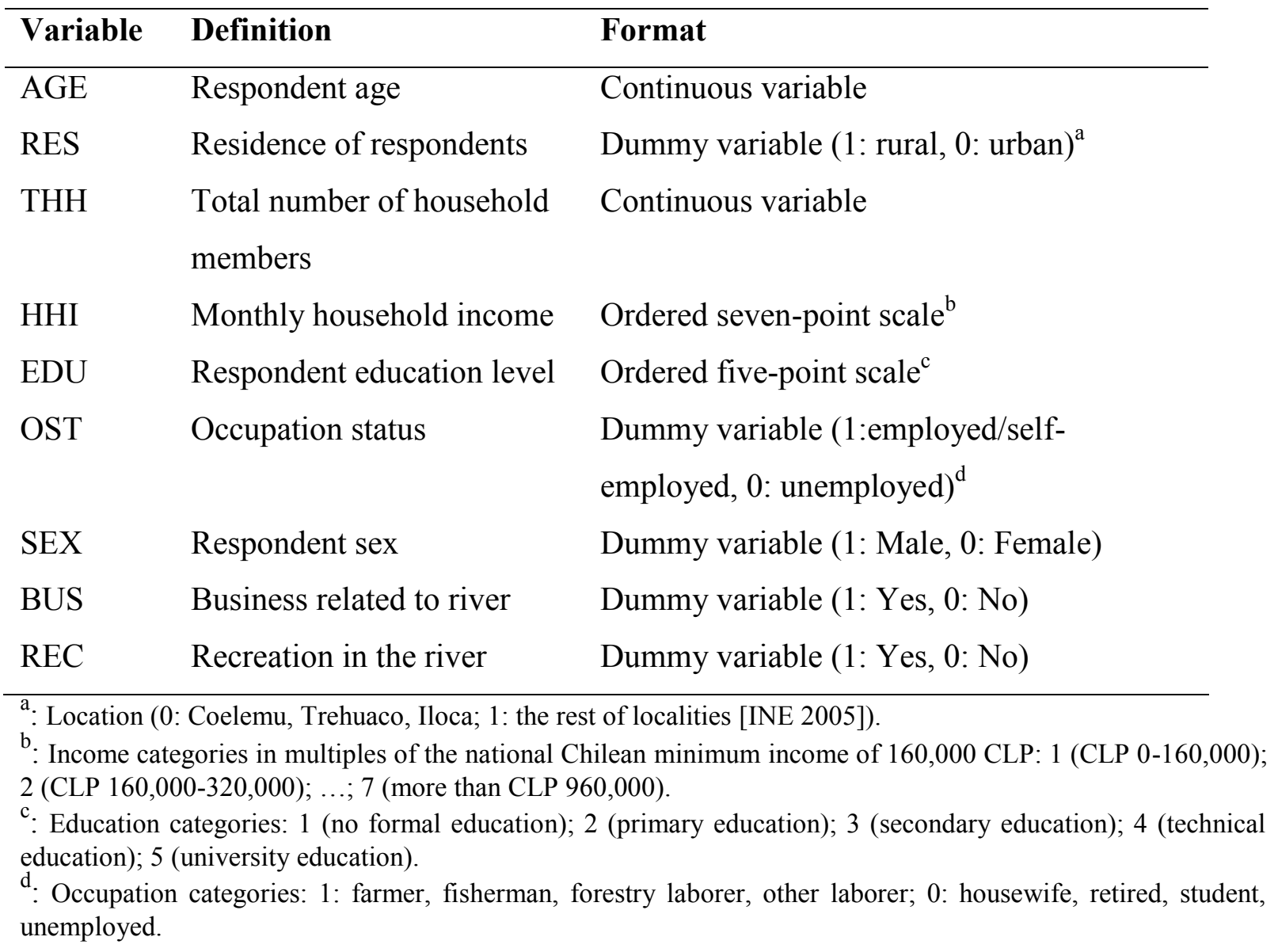

\subsection{Statistical analysis}

Factor analyses as well as parametric standard procedures (bivariate Pearson correlations of 
fairness items/dimensions with socio-economic variables) were conducted with SPSS 18.0.

From the CE data, we estimated two-level nested logit (NL) models (Hunt 2000). With three elemental alternatives, one branch with two alternatives and one branch with a single alternative (degenerated branch) were obtained (cf. Louviere et al. 2001:153). A suitable NL model tree structure was identified, and the corresponding models estimated with NLOGIT 4.0. The inclusive value was set to 1.0 for the degenerated branch (status quo), and the model initiated with starting values obtained from a non-nested NL model (Hensher et al. 2005:530). All scale parameters were normalized at the lowest level (RU1). The vector of utility coefficients was estimated with maximum likelihood estimation procedures. As model statistics, we report the conservative adjusted pseudo- $R^{2}$ values in relation to a 'constants only` model. Values between 0.1 and 0.3 correspond to $R^{2}$ values of 0.3 and 0.6 in their ordinary least squares equivalents (Hensher et al. 2005:338).

Two sets of NL models are presented. First, two basic NL models including only the main attributes of river water quality improvements, the payment attribute and the ASC were estimated. Model (a) includes all respondents, model (b) only those respondents 'payers' (see below; Table 8)). Second, a set of 'improved' NL models was generated utilising the interaction terms also differentiating between the full sample and 'payers' (Table 9, models (c) and (d)). For the generation of models (c) and (d), all interaction terms (see section 2.3) were introduced into the basic models one at a time. Then all statistically significant interactions terms $(\mathrm{P}>0.05)$ of these single interaction models were introduced into the model. The final 'improved' model was generated by the stepwise exclusion of non-significant interactions terms one-by-one. 
Both sets of NL models consist of a version that utilizes the choice data of the entire sample (models (a) and (c)), and one version that only includes respondents that chose at least once a scenario other than the zero payment status quo alternative (models (b) and (d), 'payers'). Necessitated by the choice of CE attribute levels in which the zero payment is exclusively assigned to the status quo scenario, this differentiation enables an assessment of the influence that a relatively small but with about $16 \%$ not negligible group of 'protesters' has on the quantification of preferences for the river water quality improvements at stake.

The estimated models include an alternative specific constant (ASC). The ASC picks up systematic choice variation between the status quo alternative and the alternatives A and B that cannot be explained by the attributes. The ASC was coded as a dummy variable with value 1 for the generic alternatives $\mathrm{A}$ and $\mathrm{B}$ and 0 for the status quo alternative $\mathrm{C}$.

The ASC may indicate a status quo bias (Meyerhoff and Liebe 2009). In our NL models, a status quo bias would be indicated by a significant ASC coefficient with a negative sign. This would indicate that positive respondent preferences for improvements of the offered river water quality attributes may be severely counterbalanced by a general refusal of the improvement scenarios as such. In some preliminary analyses, this situation showed up with a significant ASC and a high respective disutility value. In the 'payers' model (d) with justiceinteraction terms, the numerical value of the ASC coefficient was minute and the coefficient clearly insignificant. In this situation, we opted for presenting identical scenario analyses based on both models ('full sample' and 'payers'). 


\subsection{WTP estimation}

CE results can be used to calculate welfare measures if a status quo scenario is included in the choice set (Bateman et al. 2002). Hence, CEs allow for an estimation of respondent WTP. Based on the quantification of the utility coefficients of the NL model, a maximum marginal WTP (mWTP) for a marginal (1 unit) attribute level changes can be estimated as

$$
m W T P=-\frac{\beta_{X}}{\beta_{c}}
$$

where

$\beta_{x}$ : utility coefficient of any of the environmental attributes and,

$\beta_{c}$ : marginal utility of income given by the coefficient of the payment attribute.

mWTP is known as the implicit price. Furthermore, the welfare change generated by an improvement of river water quality was calculated. The change from river water quality level $Q^{0}$ (status quo) to an improved level $Q^{1}$ is calculated as a compensating variation $C V$ (Louviere et al. 2000:340). $C V$ is the amount of money that equates the status quo utility level

$\left(U^{0}\right)$ of respondents with the utility level of the improved river water quality level $\left(U^{l}\right)$. In other words, $C V$ can be expressed as the maximum willingness to pay of a respondent to achieve a higher river water quality level:

$$
C V\left(Q^{0} \rightarrow Q^{1}\right)=-\frac{1}{\beta_{C}} *\left[U^{1}-U^{0}\right]
$$


The estimated total aggregated WTP for the scenario change considers all households in the study area that expressed a willingness to pay. They corresponded to 4,104 households that represent $84 \%$ of total number of households ( $16 \%$ 'protesters').

\subsection{Administration of the survey}

The face-to-face interview survey was conducted by four trained university students and the first author from February to April 2009. For the survey, we considered households located (1) in 8 and 13 localities, respectively, downstream the pulp mills at the Mataquito and Itata rivers, and (2) adjacent to the river along the main roads. According to the National Census of 2002 (INE 2005), total household number at the Mataquito river site is 883 and 4,001 at the Itata site.

We sampled at least 150 households from each site by a systematic sampling procedure (Babbie 2008:224). First, the sampling ratio was calculated (Mataquito: 0.17; Itata: 0.04). Based in the inverse of the sampling ratio, every sixth household at the Mataquito site and every $25^{\text {th }}$ household at the Itata site were chosen for an interview. When we reached a locality, interviewers were given random points of departure. Then, fixed rules on the direction to walk, distance between households (depending on locality size), and the number of interviews to conduct in each sector were given. When a selected house did not have apparent occupants, the next house was chosen for the interview. From all household members older than eighteen years by the day of the interview, any member willing to answer the questionnaire was chosen. Accounting for the sampling bias, we re-weighted the CE data using exogenous weights based on the inverse of the sampling ratio divided by the number of respondents who completed the choice task for each river site (Hensher et al. 2005: 226). 
We administered 53 interviews during the pilot study (Mataquito: 21, Itata: 32), and finally 318 interviews during the main study (Mataquito: 160, Itata: 158). During the main study, 142 contacted households were found to be without occupants, 70 contacted respondents denied giving an interview, and 2 respondents were younger than 18. Of all successfully contacted 318 households, 313 respondents completed the choice task (98\%), and 292 provided all socio-demographic data (92\%). On average, an interview took about 45 minutes.

\section{$3 \quad$ Results}

\subsection{Descriptive Results}

Respondents were 51 years old on average (Table 5). 60\% of respondents were women. Households had roughly four members. $62 \%$ of respondents were rural residents, many of whom (35\%) did not have any formal education. A high share of all respondents were housewives (42\%). $62 \%$ of respondents received less than the national minimum income ( USD 264). $40 \%$ of respondents indicated that their occupation is related to the river. Only $25 \%$ of respondents had conducted recreational activities in the river in the last two years.

$84 \%$ of respondents choose alternatives other than the status quo scenario at least once during the CE interview ('payers'). $16 \%$ of respondents always choose the status quo scenario ('nonpayers'). Respondents agreeing to pay were younger $(\mathrm{P}<0.001)$, of larger households $(\mathrm{P}<0.01)$, of higher household income $(\mathrm{P}<0.05)$ and education level $(\mathrm{P}<0.001)$ than nonpayers on average. 


\subsection{Fairness impacts on paying for river water quality improvements}

Figure 2 shows that the fairness-related items do not suffer from ceiling or floor effects (Goodwin 2009: 562). In detail, 69.6\% of the respondents agreed ('rather agree' or 'completely agree') that it was unfair having to pay for river water quality improvements. Instead, $97.5 \%$ feel they have a right to the improvement. Just $9.5 \%$ of respondents agreed that industry has the right to discharge wastewater into the river, and $9.8 \%$ agreed they have no problems with using their money to pay industry reducing industrial pollution. In contrast, respondents stated that industry $(93 \%)$ or government $(90.5 \%)$ should pay to improve river quality.

Table 5. Socio-economic characteristics of respondents

\begin{tabular}{|c|c|c|c|c|}
\hline Variable & $\begin{array}{c}\text { Full sample } \\
\text { (N: 313) }\end{array}$ & $\begin{array}{l}\text { Payers } \\
\text { (N: 263) }\end{array}$ & $\begin{array}{c}\text { Non-payers } \\
(\mathrm{N}: \mathbf{5 0})\end{array}$ & $\begin{array}{c}t \text {-Test } \\
\text { (p-value) }\end{array}$ \\
\hline Respondent age & 51 & 49 & 63 & 0.000 \\
\hline Rural residence (\%) & 62 & 62 & 62 & 0.958 \\
\hline $\begin{array}{l}\text { Number of household } \\
\text { members }\end{array}$ & 3.86 & 4.01 & 3.10 & 0.001 \\
\hline $\begin{array}{l}\text { Monthly household income } \\
\text { (CLP) }^{\mathrm{a}}\end{array}$ & 170,479 & 176,122 & 140,800 & 0.044 \\
\hline Respondent education level ${ }^{\mathrm{b}}$ & 2.13 & 2.22 & 1.68 & 0.000 \\
\hline $\begin{array}{l}\text { Occupation (employed or } \\
\text { self employed \%) }\end{array}$ & 37 & 38 & 34 & 0.624 \\
\hline Respondent sex (male \%) & 40 & 38 & 48 & 0.202 \\
\hline $\begin{array}{l}\text { Business related with river } \\
\text { ( } \% \text { of respondents) }\end{array}$ & 40 & 39 & 42 & 0.713 \\
\hline $\begin{array}{l}\text { Recreation at river }(\% \text { of } \\
\text { respondents })\end{array}$ & 25 & 27 & 16 & 0.076 \\
\hline
\end{tabular}


Payments were not necessarily perceived as unfair as just $24.1 \%$ agreed that they already pay enough taxes, with a high percentage ( $46 \%$ ) of uncertain ('neither/nor') responses. $49.5 \%$ of respondents agreed that they cannot afford to pay and $75.4 \%$ stated that they need more information before making a decision about paying for river water quality. Moreover, $49.2 \%$ stated to believe that the suggested water quality policy does not work. Only $22.1 \%$ agreed that river water quality is not worth paying for.

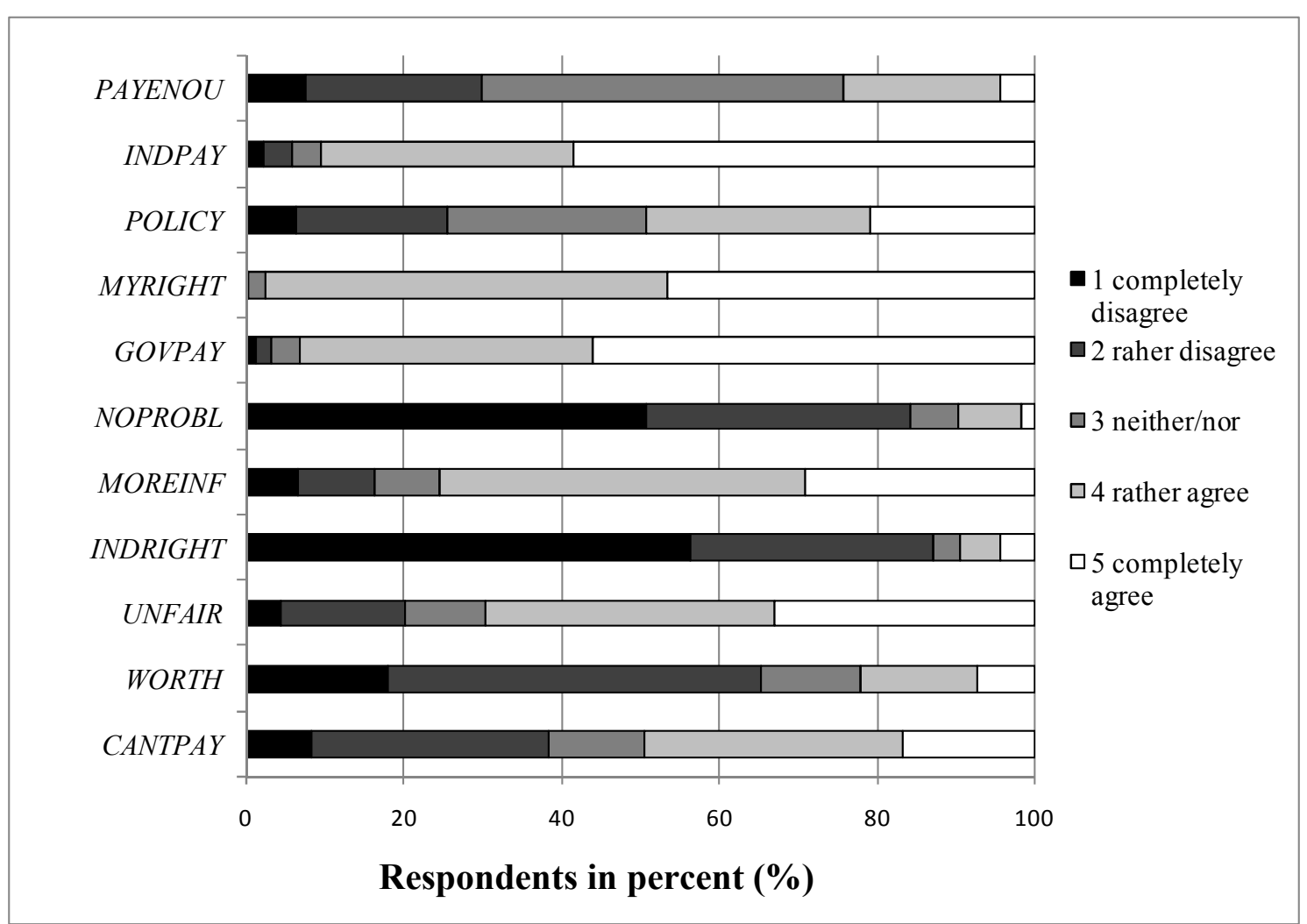

Figure 2. Beliefs on fairness of paying for river water quality improvements

From the 11 fairness-related items, factor analysis generated three dimensions (Table 6) explaining $19 \%, 15 \%$, and $14 \%$ of factor analysis variance. A total of $48 \%$ of variance is explained by the dimensions. The POLICY item was excluded as its factor loading was lower than 0.4 for any of the dimensions. Item loads, Cronbach's Alpha values, mean (raw score) and standard deviation (SD) of each dimension are presented in Table 6. 
The first dimension shows the highest Cronbach's Alpha score (0.662) and a mean raw score of 3.08 out of 5. The dimension consists of the items PAYENOU, CANTPAY, WORTH, and UNFAIR. Respondents with high scores in this dimension state that they pay already enough taxes for environmental protection, and that they also cannot pay for it. Furthermore, the proposed improvements are not considered worth paying for - and it was unfair that respondents should pay for the improvements anyway. Thus, the dimension consists mainly of items that express a rejection of individual payments by respondents for a mix of reasons. Consequently, we name the dimension personal payment rejection.

The second dimension has a Cronbach's Alpha score of 0.512 and a relative high mean raw score of 4.22. The dimension includes the GOVPAY, INDPAY, and MOREINF items. The items of this dimension focus on the suggestion that 'others' (government, industry) should pay. Such a belief is also correlated with the request for more information. The two first items constitute what is called external attribution of responsibility in social psychology terms (Forsterling 2001:23). Thus, we call the second dimension external attribution of responsibility.

The third dimension displays a (low) Cronbach's Alpha score of 0.421 . The overall mean raw score is the highest (4.32). The dimension comprises the MYRIGHT, INDRIGHT (coding reversed), and $N O P R O B L$ (coding reversed) items. Respondents with relatively high scores in this dimension tend to agree with the concept that good river quality is a citizen right, and likewise state that industry does not have the right to pollute river water. Consequently, such respondents tend to have a problem with paying industry for river water improvements. In short, this dimension is dubbed polluter pays dimension. 
Table 6: Fairness dimensions of paying for river water quality improvements.

\begin{tabular}{llccc}
\hline Fairness dimensions & Items & $\begin{array}{c}\text { Factor } \\
\text { loading }\end{array}$ & $\begin{array}{c}\text { Cronbach's } \\
\text { Alpha }\end{array}$ & $\begin{array}{c}\text { Mean (raw } \\
\text { score) } \pm \text { SD }\end{array}$ \\
\hline Personal Payment & CANTPAY & 0.720 & 0.662 & $3.08 \pm 0.81$ \\
Rejection & WORTH & 0.789 & & \\
& UNFAIR & 0.600 & & \\
& PAYENOU & 0.573 & & \\
\hline External attribution & MOREINF & 0.569 & 0.512 & $4.22 \pm 0.68$ \\
of responsibility & GOVPAY & 0.719 & & \\
& INDPAY & 0.794 & & \\
\hline Polluter Pays & INDRIGHT (reverse coded) & 0.654 & 0.421 & $4.32 \pm 0.61$ \\
& NOPROBL (reverse coded) & 0.632 & & \\
& MYRIGHT & 0.613 & & \\
\hline
\end{tabular}

Figure 3 shows differences on the fairness dimensions scores both to payers and non-payers. At the Personal Payment Rejection dimension, non-payers displayed a higher score than payers $(\mathrm{P} \leq 0.0001)$. In contrast, at the External Attribution of Responsability dimension, payers shown a higher score than non-payers $(\mathrm{P}=0.003)$. For the Polluter Pays dimension, no significant mean score differences between payers and non-payers were found. 


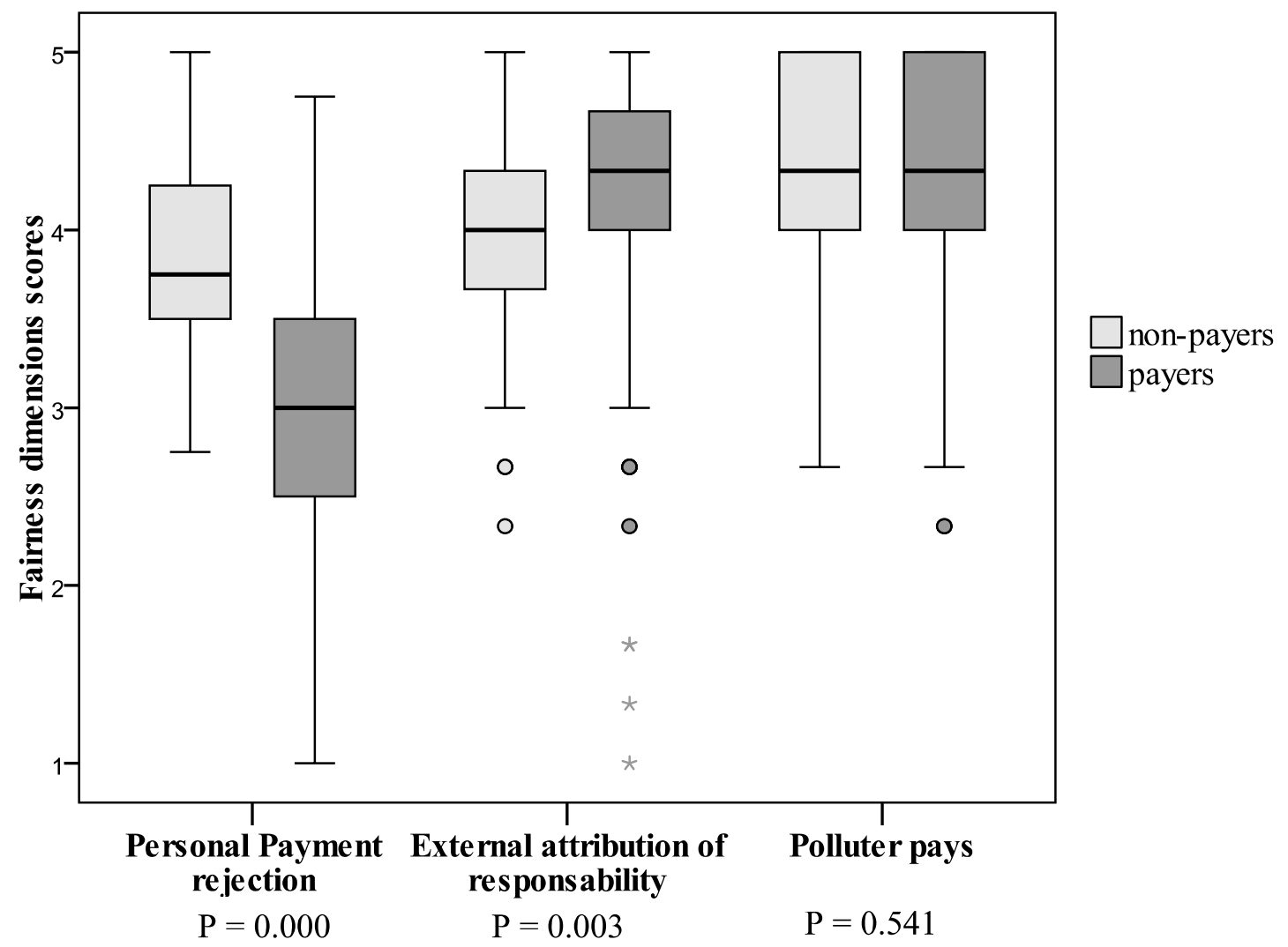

Figure 3. Box plot of fairness dimensions scores for payers and non-payers. The boxplots display: maximum, third quartile, median, first quartile, minimum; displayed minimum values are correted for outliers (circles) and extreme outliers (stars).

Table 7 displays statistically significant linear correlations between the fairness dimensions as well as their single items with the socio-economic variables. Older men of lower education and household income tend to agree with the items of the Personal Payment Rejection dimension. Respondents from urban areas more often display high scores in the External Attribution of Responsibility dimension. Polluter Pays attitudes and beliefs are relatively more common among younger respondents of higher education and from urban areas. 
Table 7. Pearson correlation analysis between fairness dimensions items and socio-economic variables $(\mathrm{n}=318)$

\begin{tabular}{|c|c|c|c|c|c|c|c|c|c|}
\hline & Age & Residence & $\begin{array}{l}\text { Total } \\
\text { household } \\
\text { members }\end{array}$ & $\begin{array}{l}\text { Household } \\
\text { income }\end{array}$ & Education & $\begin{array}{l}\text { Occupation } \\
\text { status }\end{array}$ & Sex & $\begin{array}{l}\text { Business } \\
\text { related } \\
\text { with river }\end{array}$ & $\begin{array}{l}\text { Recreation } \\
\text { in the river }\end{array}$ \\
\hline \multicolumn{10}{|c|}{ items of the first, Personal Payment Rejection dimension } \\
\hline CANTPAY & $0.291 * *$ & & & $-0.184 * *$ & $-0.346^{* *}$ & & & & $-0.154 * *$ \\
\hline WORTH & $0.246 * *$ & & & $-0.160 * *$ & $-0.259 * *$ & & $0.147 * *$ & & \\
\hline$U N F A I R$ & $0.204 * *$ & & & & $-0.232 * *$ & & $0.168 * *$ & & \\
\hline PAYENOU & $0.117^{*}$ & $-0.114^{*}$ & & & & & & & \\
\hline $\begin{array}{l}\text { Personal Payment } \\
\text { rejection }\end{array}$ & $0.311 * *$ & & & $-0.165 * *$ & $-0.341 * *$ & & $0.148 * *$ & & \\
\hline
\end{tabular}

items of the second, External Attribution of Responsibility dimension

MOREINF
GOVPAY
$-0.146 * *$
INDPAY
$-0.127 *$

External Attribution of Responsibility

items of the third, Polluter Pays dimension

\section{$N O P R O B L^{r}$}

$\begin{array}{llll}\text { INDRIGHT } & -0.122 * * & 0.129 * * & \\ \text { MYRIGHT } & -0.125 * & 0.178 * * & 0.184 * *\end{array}$

Polluter Pays

$-0.111 *$

**: significant at $\mathrm{p} \leq 0.01 ; *$ : significant at $\mathrm{p} \leq 0.05$

r: variables were reverse coded 


\subsection{Choice Experiment results}

The two basic models were highly significant overall (Table $8 ; P\left(\chi^{2}\right)<0.0001$ ). With the exception of the non-significant ASC (model a: $p$-value $=0.596$; model b: $p$-value $=0.698$ ), the numerical values of the utility coefficients of both models hardly differ. The pseudo- $\mathrm{R}^{2}$ value of the 'payers' model (b: 0.21 ) is substantially higher than the value for the all respondents model (0.14). All attribute coefficients show the expected signs: The signs indicate a disutility for higher river pollution risk, for higher numbers of species that are threatened, and for higher payments for water quality improvements. Positive utility is indicated for higher fisheries yields.

Table 8. Valuation of river water quality improvements in Central Chile (basic models)

\begin{tabular}{|c|c|c|c|c|}
\hline Variable & (a) Full sample & P-value & (b) Payers & P-value \\
\hline River pollution risk & $-0.150 * *$ & 0.003 & $-0.151 * *$ & 0.003 \\
\hline Threatened species & $-0.127 * *$ & 0.004 & $-0.131 * *$ & 0.004 \\
\hline Fisheries yield & $0.027 *$ & 0.029 & $0.028^{*}$ & 0.025 \\
\hline Payment $\%$ & $-0.065 * * *$ & 0.0001 & $-0.066^{* * *}$ & 0.0001 \\
\hline ASC (non Status Quo) & -29.328 n.s. & 0.596 & -7.081 n.s. & 0.698 \\
\hline Log-likelihood & -109.200 & & -71.816 & \\
\hline $\mathrm{P}\left(\mathrm{Chi}^{2}\right) ; \mathrm{DF}$ & $<0.0001 ; 6$ & & $<0.0001 ; 6$ & \\
\hline $\begin{array}{l}\text { IV of non degenerated branch } \\
\text { (nonSQ) }\end{array}$ & 0.15 & & 0.32 & \\
\hline Pseudo-R ${ }^{2}$ (constant only) ${ }^{\S}$ & 0.14 & & 0.21 & \\
\hline Number of respondents & 313 & & 263 & \\
\hline
\end{tabular}

Table 9 shows the influence of fairness considerations on respondent choice ('improved' models). The explanatory value of both models increased compared to models (a) and (b) to a pseudo- $\mathrm{R}^{2}$ value of 0.24 . Improved models (c) and (d) differ structurally from basic models 
(a) and (b) only by the inclusion of the interaction Threatened species * Personal Payment Rejection. The numerical values of the utility coefficients of the river water quality attributes remain roughly constant across all four models.

Table 9. Valuation of river water quality improvements subject to fairness considerations ('improved' models)

\begin{tabular}{|c|c|c|c|c|}
\hline Variable & (c) Full sample & P-value & (d) Payers & P-value \\
\hline River pollution risk & $-0.159 * * *$ & 0.003 & $-0.160 * * *$ & 0.001 \\
\hline Threatened species & $-0.132 * *$ & 0.003 & $-0.144 * *$ & 0.002 \\
\hline Fisheries yield & $0.028 *$ & 0.024 & $0.029 *$ & 0.022 \\
\hline Payment $^{\%}$ & $-0.068 * * *$ & 0.0001 & $-0.068 * * *$ & 0.0001 \\
\hline ASC (non Status Quo) & -21.571 n.s. & 0.540 & -6.315 n.s. & 0.663 \\
\hline $\begin{array}{l}\text { Threatened species*Personal } \\
\text { Payment Rejection }\end{array}$ & $0.062 * * *$ & 0.0001 & $0.057^{*}$ & 0.037 \\
\hline Log-likelihood & -96.655 & & -68.696 & \\
\hline $\mathrm{P}\left(\mathrm{Chi}^{2}\right) ; \mathrm{DF}$ & $<0.0001 ; 7$ & & $<0.0001 ; 7$ & \\
\hline $\begin{array}{l}\text { IV of non degenerated branch } \\
\text { (nonSQ) }\end{array}$ & 0.19 & & 0.33 & \\
\hline Pseudo-R ${ }^{2}$ (constant only) ${ }^{\S}$ & 0.24 & & 0.24 & \\
\hline Number of respondents & 313 & & 263 & \\
\hline
\end{tabular}

With regard to policy scenario analysis, we use the 'payers' model results (d) for a simple stated preference valuation of river water quality improvement (Table 10). The marginal mean WTP values per household corresponds to $235 \mathrm{CLP} / \mathrm{yr} / 1 \%$ reduction in River Pollution Risk, 212 CLP/yr/1 fewer Threatened Species, and 43 CLP/yr/1\% of increased Fisheries Yield. The scenario considers that River Pollution Risk is reduced 15\%, the number of Threatened Species decreases to 15, and Fisheries Yield increases to 50\%. Estimated total aggregated WTP (compensating surplus) for the scenario change is about 36 million CLP/yr ( USD 
60,000/yr). The non-status quo ASC has a nominally high value but is not significant $(\mathrm{p}=0.663)$, so its inclusion in policy scenario analysis cannot be justified.

Table 10. Marginal stated preference WTP and exemplary policy scenario calculations based on model (d) statistics ('payers')

\begin{tabular}{lccc}
\hline & $\begin{array}{c}\text { River pollution } \\
\text { risk }\end{array}$ & $\begin{array}{c}\text { Threatened } \\
\text { species }\end{array}$ & Fisheries yield \\
\hline Marginal Unit & $\begin{array}{c}\text { 1\% less pollution } \\
\text { risk }\end{array}$ & $\begin{array}{c}1 \text { threatened } \\
\text { species less }\end{array}$ & $1 \%$ yield increase \\
Marginal mean WTP/household/yr & 235 & 212 & 43 \\
Scenario change & $15 \%$ less & 15 less & $50 \%$ increase \\
Mean scenario WTP/household/yr & $3,529.41$ & $3,176.47$ & $2,132.35$ \\
Total scenario WTP/household/yr & & 8,838 & \\
\hline Aggregated scenario WTP (Mio & & & \\
CLP/yr) & 14.48 & 13.04 & \\
Total aggregated scenario WTP (Mio & & $36(\sim$ USD $60,000 / \mathrm{yr})$ & \\
CLP/yr) & & & \\
\hline
\end{tabular}

Aggregation based on $4,884 *(1-16 \%$ no payers $) / 292=4,148$ households in the study area that are willing to pay; 1 USD $\sim 606$ CLP (February 2009)

The monetary equivalent of the - clearly insignificant - ASC corresponds to -9,287 CLP/household/yr

Table 11. Marginal stated preference WTP and exemplary policy scenario calculations based on full sample model (c) statistics

\begin{tabular}{|c|c|c|c|}
\hline & $\begin{array}{c}\text { River pollution } \\
\text { risk }\end{array}$ & $\begin{array}{c}\text { Threatened } \\
\text { species }\end{array}$ & Fisheries yield \\
\hline Marginal Unit & $\begin{array}{l}1 \% \text { less pollution } \\
\text { risk }\end{array}$ & $\begin{array}{l}1 \text { threatened } \\
\text { species less }\end{array}$ & $\begin{array}{l}1 \% \text { yield } \\
\text { increase }\end{array}$ \\
\hline Marginal mean WTP/household/yr & 234 & 194 & 41 \\
\hline Scenario change & $15 \%$ less & 15 less & $50 \%$ increase \\
\hline Mean scenario WTP/household/yr & $3,507.35$ & $2,911.76$ & $2,058.82$ \\
\hline Total scenario WTP/household/yr & & $8,477.94$ & \\
\hline $\begin{array}{l}\text { Aggregated scenario WTP (Mio } \\
\text { CLP/yr) }\end{array}$ & 14.39 & 11.95 & 8.45 \\
\hline $\begin{array}{l}\text { Total aggregated scenario WTP (Mio } \\
\text { CLP/yr) including ASC }\end{array}$ & \multicolumn{3}{|c|}{34,79 ( USD 57,400/yr) } \\
\hline
\end{tabular}

Aggregation based on $4,884 *(1-16 \%$ no payers $) / 313=4,104$ households in the study area that are willing to pay; 1 USD $\sim 606$ CLP (February 2009)

The monetary equivalent of the non-significant ASC corresponds to $-31,722 \mathrm{CLP} /$ household/yr 
Figure 4 shows the cumulative distribution curve of valuation scenario WTP with respondents ordered along the Personal Payment Rejection dimension for an optimistic reduction in the number of Threatened species based on model (c).

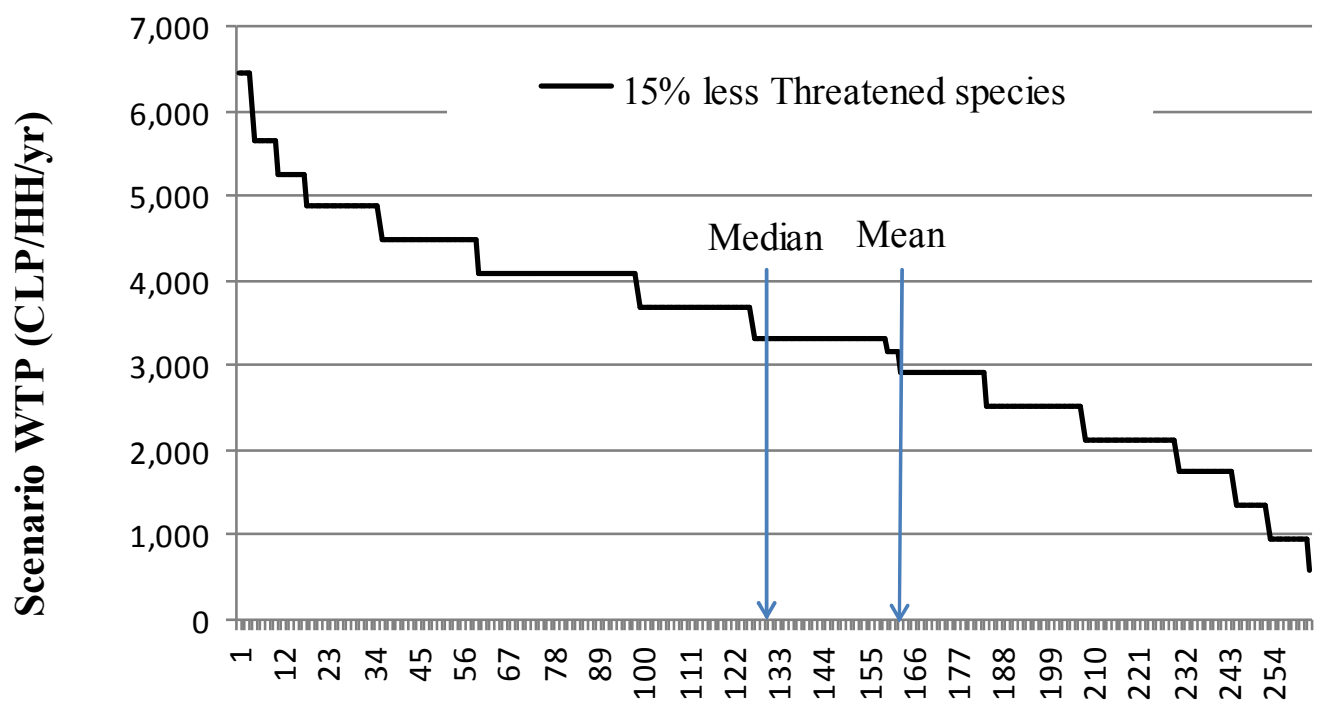

Respondents in order of Personal Payment Rejection dimension score

Figure 4. Scenario WTP for an optimistic reduction in the number of Threatened species (model c)

\section{$4 \quad$ Discussion and Conclusions}

We conducted a Choice Experiment (CE) to generate non-market valuation data useful for the discussion on the development of Chilean river water policies in the face of environmental threats from paper mills. Additionally, we investigated if and to which extent fairness-related cognitions impact respondent willingness-to-pay for ensuring the implementation of river water improvements mandated by the Chilean state. All water quality attributes as well as the payment attribute turned out to be highly significant predictors of choice. The introduction of 
fairness-related cognitions improved model performance substantially although only one significant influence was found.

First we discuss the fairness dimensions identified by exploratory factor analysis. Second, the impact of the dimensions on individual preferences will be discussed. Finally, we interpreted the result of the scenario analysis, and drew some overall conclusions.

\subsection{Interpretation of fairness dimensions}

At the single item level, more than two thirds of respondents stated that is was "unfair" that they may have to pay for cleaner river water. Even more agree that government and industry should pay for it. Just $22.1 \%$ of respondents agreed that it is not worth to pay for RWQI at all. The last result is consistent with results obtained by Lindsey (1994), Soderqvist (1998), and Jorgensen et al. (1999). They indicate that is usual that few respondents stated that an environmental improvement is not worth to pay for it.

The exploratory factor analysis yielded three dimensions:

- Personal Payment Rejection,

- External Attribution of Responsibility,

- Polluter Pays.

Using a majority of items from published studies (Jorgensen et al. 2001, 2006), the Cronbach's alpha values of the second and third dimension were still substantially lower than 0.7. Thus, we stress that the development of scales for the assessment of attitudes and beliefs for use in stated preference studies that fully satisfy psychometric requirements is in its 
infancy (cf. Huenchuleo et al. 2011). Still, the identified dimensions allowed for a first analysis of the potential impact of fairness considerations on respondent WTP.

The four items of the Personal Payment Rejection dimension formed the same dimension as in the study by Jorgensen et al. (2001), and this scale yielded the best reliability value. Regarding the Personal Payment Rejection dimension, it was at the first glance surprising to find the UNFAIR item here. The other three items directly rejected any potential request to pay as respondents feel that they do not have any money at all, pay already enough taxes for the environment and, anyway, do not think that river water quality is a worthwhile cause to spent money for. Jorgensen et al. (1999) drew the conclusion that such a dimension truly represents fairness considerations. However, the reasons for high agreement with the items of the dimension may in fact not be related to fairness-type attitudes but rather reflect a true inability to pay as indicated by the CANTPAY item (cf. Soderqvist 1998). In this regard it is important to note that agreement to the items of the dimension was most strongly found in older, low education and low income men. This entire setting suggests that UNFAIR may not only transport the intended meaning. Apparently, it also provided respondents who reject payments for a number of reasons only loosely related to fairness considerations with an additional opportunity to voice their rejection. In consequence, we regarded the dimension as our naming suggests - not as a strong variable to indicate true fairness considerations on part of the respondents. The dimension may still be able to explain individual differences in WTP (see next section).

The External Attribution of Responsibility dimension is thematically more compact. If industry and government are responsible to improve river water quality, respondents may regard it as unfair to request additional money from them. The additional inclusion of the 
uncertainty item MOREINF was in certain agreement with the results obtained by Jorgensen et al. (2006). They found that respondents who reported uncertainty on the information provided on the payment scenario relied more on fairness considerations when making a valuation statement.

The final Polluter Pays dimension covered a number of (psychometrically rather diverse) attitudes and beliefs that all indicated that respondents scoring high in this dimension do regard payments by them as unfair. The agreement with this dimension was markedly higher than the first dimension. With Cronbach's alpha values of 0.5 and below, the last two dimensions are clearly in need of further improvements.

Non-payers were more strongly rejecting a payment for river water quality improvements: they displayed higher scores at the Personal Payment Rejection dimension than payers $(\mathrm{P}=0.001)$. In contrast, non-payers less frequently stated that industry and government are responsible to improve river water quality (low External Attribution of Responsibility; $\mathrm{P}=0.003)$.

\subsection{Influence of fairness dimensions on respondents choice}

High values in the Personal Payment Rejection dimension represent those respondents who cannot afford to pay or believe that they already pay enough taxes. Who holds the respective attitudes and beliefs, displays lower preferences for reductions in the number of Threatened species number (also see Figure 4). A lack of the dimension to influence choice would had been highly surprising as several of the single items belong to socio-psychological constructs that have repeatedly been shown to influence intentions for environmental action, partly 
including CE studies (cf. the response efficacy item in Huenchuleo et al. 2011). Furthermore, the Personal Payment Rejection dimension is correlated with household income - for which fundamental economic theory suggests an influence on WTP.

The second ('External Attribution of Responsibility') and third ('Polluter Pays') fairness dimensions did not yield a significant predictor of choice in any model. These dimensions have the lowest standard deviation, so there is relatively little variance in the dimensions that could explain preference heterogeneity. Furthermore, the dimensions comprise heterogeneous items and have a low overall reliability. Additionally, there are strong topical reasons why no influence could be detected in the case of the Polluter Pays dimension. In the frame of the valuation exercise, we stipulate that the payments would be used to improve government oversight on industry responsibilities to conform to more stringent river water quality regulations. Thus, the suggested payments are less an issue from a polluter pays-perspective as compared to a situation in which respondents would directly be asked to pay industry to implement water quality improvements ${ }^{7}$.

In sum, we find that the direct influence of fairness or justice considerations is low on WTP for improving the regulative and monitoring capacity of government agencies with respect to future, more stringent water quality regulations and the resulting improvements of river water quality. Partly, this conclusion rests on the presumption, however, that the Personal Payment Rejection dimension does, in fact, represent a more general payment rejection with only little meaning from a fairness and/or justice perspective.

\footnotetext{
$7 \quad$ The questionnaire includes a brief contingent valuation question asking precisely for the maximum direct WTP for industry improvements. The respective results will be analyzed elsewhere (see Chapter 5).
} 


\subsection{Interpretation of welfare measures}

Based on an optimistic river water quality improvements scenario, we estimated a maximum willingness to pay (compensating variation) of USD 60,000/yr to achieve a higher level of river water quality. Most of this sum comes from reduction on River Pollution Risk and reduction on the number of Threatened Species. In cost-benefit analysis, the total WTP has to be contrasted with the cost of implementing management plans for improving current status. We are not in position to present costs of these plans because river water quality regulations are not implemented in the study area yet. However, main items on water quality regulation are associated with the monitoring and control of water quality parameters at the river level.

The estimated benefits from river water quality improvement give an idea on its importance in monetary terms. Considering that $62 \%$ of households get less than the national minimum

income ( USD 264/month), the valuation scenario captures a considerable share of total WTP for river water quality improvements. Moreover, WTP values are substantial if we consider that $40 \%$ of households relate their business with the river and just $25 \%$ of them conduct recreation activities in river surroundings. Because in some preliminary analysis we found a very high ASC (non-status quo), we have to have care with the interpretation of results (also because confoundation). We investigate a richer picture of heterogeneity of preferences one step further in Chapter 5.

\section{References}

Álvarez-Farizo B, Hanley N, Barberán R, Lázaro A (2007) Choice modelling at the "market stall": Individual versus collective interest in environmental valuation. Ecological Economics 60: 743-751. 
Araya I, Quiñones R, Dresdner J, Barriga O, Carrasco P, Campos N, Leiva M, Hernandez A, Ponce R, Rivas R (2006) Diagnóstico social, económico y productivo de las comunidades de pescadores artesanales de la desembocadura del Itata y zonas adyacentes, entre Cobquecura y Dichato. Programa de Estudios Económicos y Sociales del Sector Pesquero, Universidad de Concepción, Chile.

Babbie EA (2008) The basics of social research, Fourth Edition. Thomson Learning, Inc. USA.

Bamrud J (2011) The Chilean Model. Latin Trade 19: 6.

Barkmann J, Glenk K, Handi H, Sundawati L, Witte JP, Marggraf R (2007) Assessing economic preferences for biological diversity and ecosystem services at the Central Sulawesi rainforest margin - a choice experiment approach. In: Tscharntke T, Leuschner C, Zeller M, Guhardja E, Bidin A (eds), The stability of tropical rainforest margins, linking ecological, economic, and social constraints of land use and conservation, Springer Berlin 2007, pp 181-208.

Barkmann J, Glenk K, Keil A, Leemhuis C, Dietrich N, Gerold G, Marggraf R (2008) Confronting unfamiliarity with ecosystem functions: The case for an ecosystem service approach to environmental valuation with stated preference methods. Ecological Economics 5: 48-62.

Bateman I, Carson T, Day B, Hanemann M, Hanley N, Hett T, Jones-Lee M, Loomes G, Mourato S, Özdemiroglu E, Pearce D, Sugden R, Swanson J (2002) Economic valuation with stated preferences techniques: a manual, Edward Elgar, Cheltenham, UK and Northampton, MA, USA.

Bateman IJ, Cole MA, Georgiou S, Hadley DJ (2006) Comparing contingent valuation and contingent ranking: A case study considering the benefits of urban river water quality improvements. Journal of Environmental Management 79: 221-231.

Bioma (2008) Consultoría para la recopilación de información sobre la biodiversidad en apoyo a la elaboración del anteproyecto de norma secundaria de calidad ambiental para la protección de las aguas de la cuenca del Mataquito. Bioma BGA Consultores.

Cade-Idepe Consultores en Ingeniería (2004a) Diagnóstico y clasificación de los cursos y cuerpos de agua según objetivos de calidad - cuenca río Mataquito. Dirección General de Aguas, Ministerio de Obras Públicas, Chile. http://www.sinia.cl/1292/articles31018_Mataquito.pdf. Accessed 26 June 2008 
Cade-Idepe Consultores en Ingeniería (2004b) Diagnóstico y clasificación de los cursos y cuerpos de agua según objetivos de calidad - cuenca río Itata. Dirección General de Aguas, Ministerio de Obras Públicas, Chile. http://www.sinia.cl/1292/articles31018_Itata.pdf. Accessed 26 June 2008

Chrzan K, Orme B (2000) An overview and comparison of design strategies for choice-based conjoint analysis. Sawtooth Software 2000-2002, Research paper series.

CONAF (1993) Libro rojo de los vertebrados terrestres de Chile. Corporación Nacional Forestal - CONAF, Ministerio de Agricultura de Chile. Santiago, Segunda Edición. CONAMA-SINIA (2008) Información geográfica territorial regional. Sistema Nacional de Información Ambiental Territorial (SINIA), Ministerio del Medio Ambiente, Chile. http://territorial.sinia.cl/portal/descargas.php. Accessed 30 September 2010.

CONAMA (2006) Análisis económico y social de la norma de calidad secundaria para la protección de las aguas continentales superficiales en la cuenca del río Maipo. Región Metropolitana de Santiago.

Espinosa C (2001) Evaluación de los impactos de la producción de celulosa. Análisis de Políticas Públicas No 4, Publicaciones Terram.

EULA (2006) Análisis general del impacto económico de la norma secundaria de calidad de aguas en la cuenca del río Bio-Bio, en el sector silvoagropecuario. Universidad de Concepción.

Forsterling F (2001) Attribution: An introduction to theories, research and applications. Psychology Press Ltd, UK.

Goodwin CJ (2009) Research In Psychology: Methods and Design 6th Ed. John Wiley \& Sons, Inc. NJ.

Habit E, Dyer B, Vila I (2006) Estado de conocimiento de los peces dulceacuícolas de Chile. Gayana 70, 1: 100-113.

Hanley N, Colombo S, Tinch D, Black A, Aftab A (2006a) Estimating the benefits of water quality improvements under the Water Framework Directive: are benefits transferable? European Review of Agricultural Economics 33, 3: 391-413.

Hanley N, Wright RE, Alvarez-Farizo B (2006b) Estimating the economic value of improvements in river ecology using choice experiments: an application to the water framework directive. Journal of Environmental Management 78: 183-193.

Hensher DA, Rose JM, Greene WH (2005) Applied choice analysis: a primer. Cambridge University Press, Cambridge (UK). 
Huenchuleo C, Barkmann J, Villalobos P (2011) Social psychology predictors for the adoption of soil conservation measures in Central Chile. Land Degradation and Development, accepted.

Hunt GL (2000) Alternative Nested Logit Model Structures and the Special Case of Partial Degeneracy. Journal of Regional Science 40, 1: 89-113.

INE (2005) Chile: Ciudades, Pueblos, Aldeas y Caseríos. Censo 2002, Instituto Nacional de Estadísticas - INE, Chile. http://www.ine.cl/canales/chile_estadistico/ demografia_y_vitales/demografia/demografia.php. Accessed 20 April 2008

INE (2009) Censo Agropecuario 2007. http://www.censoagropecuario.cl/. Accessed 5 May 2008

Jorgensen BS, Syme GJ, Bishop BJ, Nancarrow BE (1999) Protest Responses in Contingent Valuation. Environmental and Resource Economics 14: 131-150.

Jorgensen BS, Syme GJ, Nancarrow BE (2006) The role of uncertainty in the relationship between fairness evaluations and willingness to pay. Ecological Economics 56: 104- 124. Jorgensen BS, Wilson MA, Heberlein TA (2001) Fairness in the contingent valuation of environmental public goods: attitude toward paying for environmental improvements at two levels of scope. Ecological Economics 36: 133-148.

Krömker D (2004) Naturbilder, Klimaschutz und Kultur. In: Ernst A, Frey D, Lantermann ED, Linneweber V, Sontag K, Staudinger UM, Psychologie forschung aktuell, Beltz Verlag, Programm PVU Psychologie Verlags Union, Weinheim, Basel, Berlin.

Louviere J, Hensher D, Swait J (2000) Stated Choice Methods - Analysis and Application. Cambridge University Press, Cambridge (UK).

Meyerhoff J, Liebe U (2008) Do protest responses to a contingent valuation question and a choice experiment differ?. Environmental and Resource Economics 39: 433-446.

Meyerhoff J, Liebe U (2009) Status Quo Effect in Choice Experiments: Empirical Evidence on Attitudes and Choice Task Complexity. Land Economics 85, 3: 515-528.

Morrison M, Bennett J (2004) Valuing New South Wales rivers for use in benefit transfer.

The Australian Journal of Agricultural and Resource Economics 48, 4: 591-611.

OCDE-CEPAL (2005) Evaluaciones del desempeño ambiental - Chile. Organización de Cooperación y Desarrollo Económicos - Comisión Económica para América Latina y el Caribe. Ed. Naciones Unidas, CEPAL.

Orrego R, Burgos A, Moraga-Cid G, Inzunza B, Gonzalez M, Valenzuela A, Barra R, Gavilán J (2006) Effects of pulp and paper mill discharges on caged Rainbow Trout 
(Oncorhynchus mykiss): Biomarker responses along a pollution gradient in the Bio-Bio river, Chile. Environmental Toxicology and Chemistry 25, 9: 2280-2287.

Rogers RW, Prentice-Dunn S (1997) Protection Motivation Theory, in: Gochman, D.S.:

Handbook of Health Behavior Research I: Personal and Social Determinants, Plenum Press, New York: 113-132.

SERNAPESCA (2007a) Valorización Desembarque Regional Años 2005 - 2006, Región del

Maule. Servicio Nacional de Pesca, Chile. http://www.sernapesca.cl/

index.php?option $=$ com_remository\&Itemid $=246 \&$ func $=$ fileinfo\&id $=1957$. Accessed 1 May 2008

SERNAPESCA (2007b). Concesiones de Acuicultura. Estuarios propuestos como Areas Apropiadas en la Región del Maule. Servicio Nacional de Pesca, Chile.

http://www.sernapesca.cl/index.php?option=com_content\&task=view\&id=498\&Itemid= 686. Accessed 1 May 2008

SISS (2009) Cumplimiento de normas de descargas de Residuos Líquidos, DS 90/00

Descarga a cuerpos de agua superficiales, años 2006-2007-2008. Superintendencia de Servicios Sanitarios - SISS, Chile. http://www.siss.cl/propertyvalue-2309.html. Accessed 25 January 2009

SISS (2008) Informe de Gestión Sector Sanitario 2007. Superintendencia de Servicios

Sanitarios, Chile. http://www.siss.cl/articles-6245_informegestion.pdf. Accessed 30 March 2008

Söderqvist T (1998) Why Give up Money for the Baltic Sea? Motives for People's

Willingness (or Reluctance) to Pay. Environmental and Resource Economics 12: 249254.

Spector PE (1992) Summated Rating Scale Construction: An Introduction. Sage University

Papers Series. Quantitative Applications in the Social Sciences, No. 07-082, Sage

Publications, Inc. UK.

Stern DI (2004) The Rise and Fall of the Environmental Kuznets Curve. World Development 32, 8: 1419-1439.

Vasconi P (2006) CELCO el caso de la planta Valdivia. Análisis de Políticas Públicas 36, Publicaciones Fundación Terram, Chile.

Vergara A, Encina F et al (2008) Informe Final - Evaluación Ambiental en el río Mataquito.

Facultad de Ingeniería - Facultad de Recursos Naturales, Universidad Católica de 
Temuco. http://www.cutchile.cl/paloma/04\%20articles-

44336_InformeFinalRioMataquito.pdf. Accessed 15 January 2009

Zenteno P, López A, Mardones C, Montoya F (2009) Análisis de impacto económico y social de anteproyecto de normas secundarias de calidad - cuenca río Mataquito. DSS Ambiente. Ministerio de Obras Públicas, Chile.

http://www.dga.cl/otros/SAD/CQA5072.pdf. Accessed 01 June 2010 
Chapter 3

\title{
Attitudinal determinants of willingness-to-pay for river water quality improvements in Central Chile: A choice experiment approach
}

Carlos Huenchuleo Pedreros, Jan Barkmann, Rainer Marggraf

\begin{abstract}
Respondent preferences for non-market goods depend not only on the attributes of the good but also on respondent attitudes towards the good being valued. Accounting for these characteristics may substantially improve the ability of stated choice models to represent preference heterogeneity. In this regard, we present findings of a Choice Experiment (CE) designed to analyze the influence of attitudes of $\mathrm{CE}$ respondents on the valuation of river water quality attributes affected by pulp mill wastewater in Central Chile. The CE included attributes on river pollution risk, and water quality effects on threatened species as well as on the yield in local fisheries. The payment vehicle was an additional annual charge to the electricity bill. All three environmental attributes and the payment attribute were highly significant determinants of choice $(\mathrm{P}<0.001)$. Calculated mean WTP values for an optimistic scenario of attributes derived from water quality improvement was 13 USD/household/yr. Interaction terms of the attributes with respondent attitudes displayed significant predictors of choice. The influence of these terms differed between the two study area sites to some extent. Inter alia our findings suggest that attitudinal variables deserve more attention in the analysis of preferences for water resource improvements in emerging economies.
\end{abstract}

Keywords: river water quality, choice experiment, willingness-to-pay, attitudes 


\section{$1 \quad$ Introduction}

Our study presents the case of the Mataquito and Itata rivers of Central Chile affected by pulp mill wastewater. Pulp mill wastewater violating national standards has produced significant damage to the Mataquito River ecology (SISS 2008, Vergara and Encina 2008). Local fishermen at the Itata estuary see the pulp mill upstream as a major threat to their business and livelihood (Araya et al. 2006:298). While recent reports indicate positive chemical water quality parameters in the Mataquito and Itata rivers (Cade-Idepe ab 2004), a major portion of fish populations is regarded as threatened (Habit et al. 2006).

Using the choice experiment method, we analysed the willingness-to-pay for river water quality improvement on part of householders living downstream from the pulp mills. Additionally, we analyzed the influence of respondent attitudes on respondent preferences. The CE method is based on reconstructing economic preferences from respondent choices in alternative valuation scenarios made during a valuation interview. The scenarios offered to respondents differ by the 'levels' (characteristics) that a number of different attributes display (Bateman et al. 2002:278).

There is evidence from CE that attitudinal factors affect respondent WTP for river water quality improvements (Álvarez-Farizo et al 2007; Morrison and Bennett 2004). Respondents having a 'pro-environmental' orientation are more likely to pay for water quality while those who have a pro-development environmental orientation are less willing to choose options for river water quality improvements (Morrison and Bennett 2004). Respondents who have no particular interest in the river but perceive its poor ecological condition, may be more likely to pay (altruist behaviour) for water quality improvements (Álvarez-Farizo et al. 2007). Those 
with a particular interest in the river (business) and perceiving the current poor state of river quality as having a high impact on the local economy may be more likely to be willing to take action to improve river water quality (Álvarez-Farizo et al. 2007).

CEs were applied to the valuation of different attributes of river water quality improvements by previous studies. Attributes of the status of river ecology such as presence of certain water plants, fish, bird and other animal species were studied by Hanley et al. (2006ab), ÁlvarezFarizo et al. (2007), and Morrison and Bennett (2004). Recreation attributes (boating, fishing, and swimming) were analyzed by Morrison and Bennett (2004). Moreover, the importance of river flow rate and local jobs (Hanley et al. 2006a), aesthetics (Hanley et al. 2006b), and of water supply (Álvarez-Farizo et al. 2007) have been analyzed. In all cases, attributes were found to be significant determinants of choice.

In spite of the relative abundance of stated preference studies on non-market aspects of water quality, none of the studies was conducted in Chile. Consequently, the acute lack of data on the non-use and indirect use value of water quality attributes is frequently mentioned as a restriction in applied cost-benefit analyses prepared for legislative purposes in Chile (CONAMA 2006; EULA 2006; Zenteno et al. 2009).

Against this background, the objective of the paper is twofold. First, we attempt to determine the WTP of Central Chilean citizens for improvements in several policy-relevant attributes of river water quality at the Mataquito and Itata rivers. Specifically, we included attributes on river pollution risk, and on water quality effects impacting river ecosystem services such as the habitat for potentially threatened species or yields in local fisheries. While Huenchuleo et al. (this thesis, Chapter 2) analyze CE data from the full sample, we analize attitudinal factors 
influencing respondent preferences on each single river site in this contribution. Second, the analysis of the influence of attitudinal factors on WTP would allow for the identification of variables affecting respondent preferences under a scenario of water resources threatened by the pulp mill industry. The results contribute to knowing whether and to what extent attitudinal factors influence preferences for river water quality improvements in Chile.

The paper is organized as follows. In section 2, we present the methodology that describes study area, choice experiment design, socio-economic variables studied, statistical analysis, and survey design. Section 3 presents the results and discussion from the CE application. Finally, section 4 presents the main conclusions derived from the study.

\section{$2 \quad$ Methodology}

\subsection{Study area}

The study area is located at downstream sections of the Mataquito and Itata river watersheds in the VII Maule region and the VIII Bío-Bío region of Central Chile (Figure 1). The

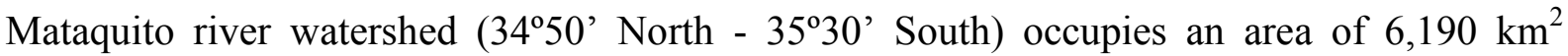

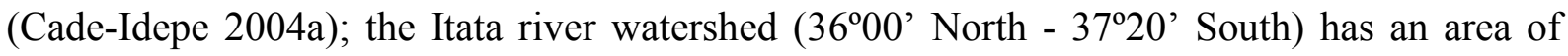
$11,294 \mathrm{~km}^{2}$ (Cade-Idepe 2004b). Both rivers receive wastewater from a pulp mill. The pulp mill on the Mataquito River is located in Licantén $30 \mathrm{~km}$ upstream from the estuary. On the Itata River, the pulp mill is located $50 \mathrm{~km}$ upstream from the estuary at Ranquil.

The study area includes four communities (Mataquito River: Licantén and Curepto; Itata River: Coelemu and Trehuaco). In these communities, we sampled respondents living 
downstream the pulp mills. The sampling frame included 2,141 inhabitants at the Mataquito River site and 13,521 inhabitants at the Itata River site (population data extracted from INE 2005). In addition to the pulp mills, the main economic activities in the study area are agriculture, local fisheries at the estuary, and forestry with plantations of exotic Pinus radiata (Monterrey Pine) that supply wood to the pulp mills (INE 2009).

Cade-Idepe Consultores en Ingeniería (2004ab), a Chilean consultancy and environmental engineering company, indicated that the chemical water quality of the Mataquito and Itata rivers is "good" on average, i.e. suitable for conservation and protection of aquatic flora and fauna, unrestricted irrigation, aquaculture, and able to support sport fishing. To the contrary, ecological studies indicate that the biological status of these rivers is severely compromised (Habit et al. 2006; Bioma 2008). All of the 15 species of native fish present in the study area are affected by conservation problems (Habit et al. 2006). In addition, almost half of the 50 waterfowl species are considered threatened (Bioma 2008). This suggests that the chemical water quality measures employed by Cade-Idepe (2004ab) do not realistically represent the ecological status of the river ecosystems in the study area.

\subsection{Choice Experiment design}

In the introductory framing section of CE interviews, respondents were asked to contribute to the identification of better water quality policy options for the two rivers. To this effect, policy option outcomes ('scenarios') were described through selected attributes of river water quality and a payment to be made. 


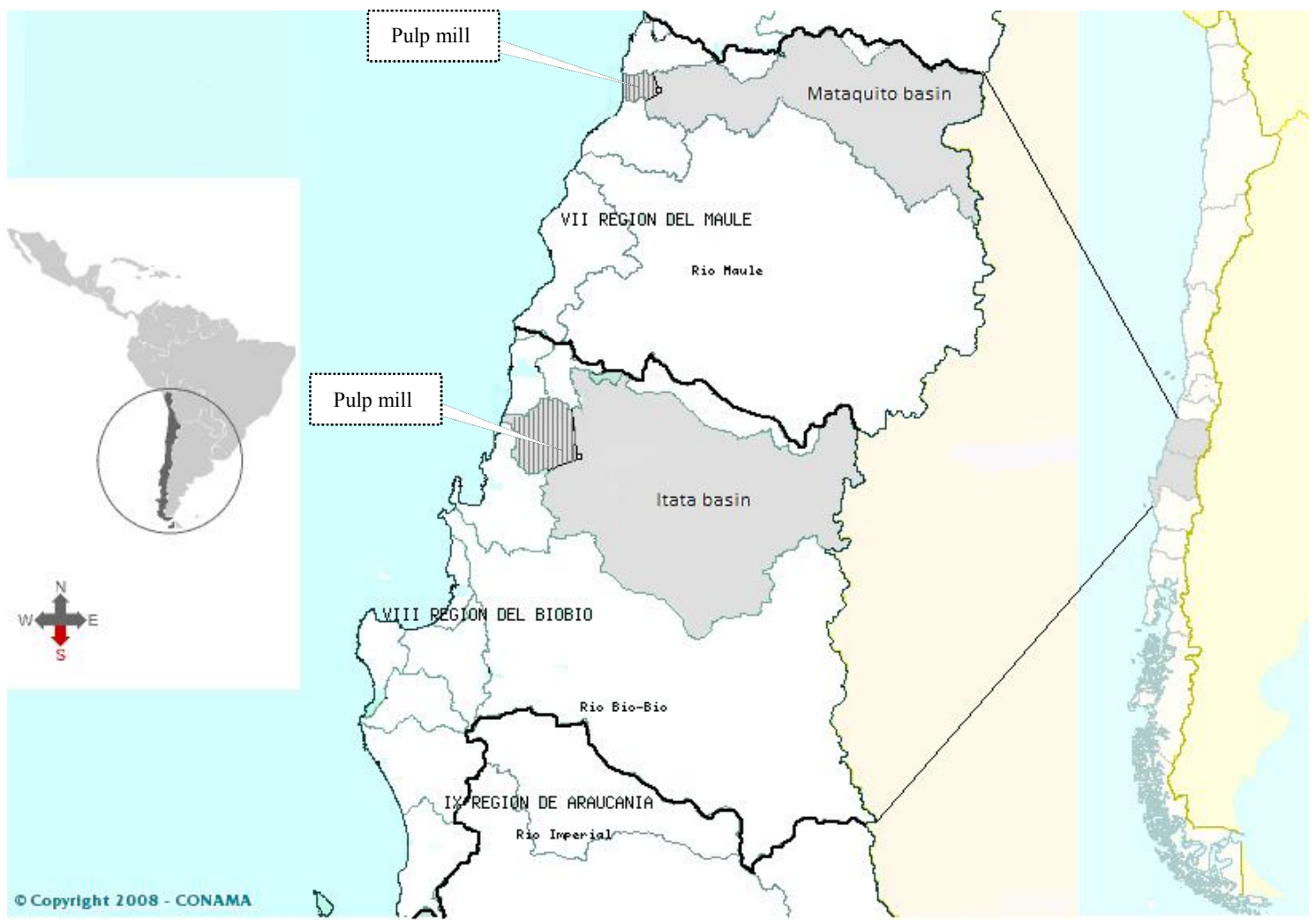

Figure 1. Location of the study area (adapted from CONAMA-SINIA 2008); actual study area hatched

For selecting river water quality attributes, available national environmental data were consulted (SISS 2008-2009; SERNAPESCA 2007ab; Bioma 2008; Araya et al. 2006; CONAF 1993). In addition, ten qualitative interviews with local inhabitants were conducted at the Mataquito River basin during a pre-study phase. Based on the information collected, three attributes on river water quality improvements were constructed: river pollution risk, number of threatened species, and local fishery yields (for a summary, see Table 1). Each attribute and its respective levels were explained to respondents using examples with visual aids. For each attribute, one level corresponds to the current situation (status quo). Details of attribute construction are given below. 
The pulp mills are the main industrial operations in the research $\operatorname{area}^{8}$. Pollution spills leading to violations of national water quality standards have been a recurrent feature of the operation of the pulp mills. For example, reports of the Superintendencia de Servicios Sanitarios (Superintendency of Sanitary Services; SISS) document that the Mataquito river pulp mill did not comply with the national emission standard "DS90-2000", on average, in one of four months (25\%) during the period from 2006-2008 (SISS 2009). Thus, we decided to construct an attribute on river pollution risk that directly addresses such violations. In our CE design, a violation in $25 \%$ of the time corresponds to the current situation or status quo. Additionally, we offered respondents reductions of river pollution risk to $20 \%, 15 \%$ or $10 \%$.

The threatened species attribute deals with the number of fish and waterfowl species living in the river ecosystem with a poor ("threatened") conservation status. Currently, there are 25 such threatened species in the Mataquito and Itata rivers, on average (Bioma 2008). Respondents were confronted with a substantial improvement on this situation defined by a reduction on the number of threatened species, i.e., there are more species without conservation problems. Proposed attributes levels were a reduction to 20, 15, and 10 threatened species.

The yield of local fisheries attribute refers to the yield of small fisheries operating mainly in the estuaries of the two rivers. To explain this attribute to respondents, we chose the estuarine species Robalo (Eleginops maclovinus), which is a well-known species in the study area. The current total yields in local fisheries for Robalo are 1 ton/year (Mataquito) and 10 tons/year (Itata) on average (SERNAPESCA 2007ab; Araya et al. 2006). Given the high yield industrial installations at the Itata study area of which the pulp mill is one. 
fluctuation during the last five years, we proposed to respondents an increase in fishery yields of $10 \%, 25 \%$, and $50 \%$.

For the payment attribute, an additional mandatory annual payment per household to the electricity bill was utilized. We explained to respondents that the money raised would be used to enforce pulp mill compliance with potentially more stringent legislation on improving river water quality. Based on pre-study results, we proposed four payment levels $(500,1,000,2,000$ and 3,000 Chilean pesos/CLP/yr) in addition to a zero status quo payment.

From a full-factorial design of four attributes with four levels each, $256\left(4^{4}\right)$ possible attribute level combinations can be obtained ${ }^{9}$. With an orthogonal main effects design, we generated a reduced orthogonal experimental design with 16 different scenarios (=choice cards) (Hensher et al. 2005:115). The choice cards were organised into sixteen choice sets. Using the shifting procedure described by Chrzan and Orme (2000), permutations among the attribute levels of these sixteen choice cards were performed to generate sixteen additional scenarios. These 16 pairs of alternatives were randomly assigned to four blocks of four choice sets each. Each choice set consisted of two water quality improvement scenarios (A and B) and an opt-out scenario that represents a status quo where no water quality improvement is achieved and the payment is zero (scenario C). Each respondent was asked to choose one scenario from each of the four choice sets. Table 2 shows an example of a choice set. 
Table 1. Attributes and levels in the CE

\begin{tabular}{|c|c|c|}
\hline Attribute & Definition & Levels \\
\hline Pollution risk & $\begin{array}{l}\text { River pollution risk (\% non } \\
\text { compliance with national standards) }\end{array}$ & $25_{\mathrm{SQ}}, 20,15,10$ \\
\hline Threatened species & Number of threatened species & $25_{\mathrm{SQ}}, 20,15,10$ \\
\hline Fisheries yield & Increase in fisheries yield (\%) & $0_{\mathrm{SQ}}, 10,25,50$ \\
\hline Payment $^{\S}$ & Charge to the electricity bill (CLP) & $\begin{array}{l}0_{\mathrm{SQ}}, 500,1000,2000, \\
3000\end{array}$ \\
\hline
\end{tabular}

Note: Payment in Chilean pesos - CLP (1 USD $\approx 606$ CLP, February 2009) per household per year. SQ: current situation (status quo), §: zero payment was included only in the status quo alternative. This means that the ' 0 ' values is perfectly compounded with the ASC.

Table 2. Example of choice set

\begin{tabular}{|c|c|c|c|}
\hline Attribute & $\begin{array}{c}\text { Alternative } \\
\text { A }\end{array}$ & $\begin{array}{c}\text { Alternative } \\
\text { B }\end{array}$ & $\begin{array}{c}\text { Alternative C } \\
\text { No improvement }\end{array}$ \\
\hline Pollution risk & $15 \%$ & $20 \%$ & $25 \%$ \\
\hline Number of Threatened species & 15 & 15 & 25 \\
\hline Fisheries yield & $10 \%$ & $25 \%$ & $0 \%$ \\
\hline Annual Payment & CLP 1,000 & CLP 3,000 & CLP 0 \\
\hline
\end{tabular}

\subsection{Potential influence of attitudinal and socio-demographic characteristics on respondent choice}

Based on previous studies (Álvarez-Farizo et al 2007; Morrison and Bennett 2004) and results from our pre-study, we analyzed the influence of two types of attitudinal items on respondent WTP (Table 3). They included items on respondent attitudes and beliefs about water resources and pollutant effects, and respondent attitudes towards hypothetical payment scenarios. Moreover, we incorporated items on respondent relations with the river, and demographic variables. 
Those respondents who perceive good conditions of river water quality ( $R W$ quality), of drinking water quality ( $R W$ drinking), and a good legal protection of rivers ( $R W$ protection) are expected to be less willing to pay for river water quality improvements. We hypothesized that those who perceive higher river pollution in the future are more likely to be willing to pay for improving river water quality ( $R W$ expectation). One would expect that those who believe that wastewater discharged into the river reduces fish quantity are more willing to pay for river water quality improvements ( $R W$ wastewater $)$. Respondents who believe that fertilizer pollution reduces river water quality ( $R W$ fertilizers) may display a lower willingness to pay as pulp mills may not be seen as responsible for river pollution in our valuation scenario. However, this attitude may also be an expression of a general environmental concern that affects the pulp mill problems as well. So, we have no previous expectation about the impact of $R W$ fertilizers on WTP for river water quality improvements.

Regarding our payment scenario, we included two additional potential determinants of WTP for river water quality improvements. Respondents who believe that our payment vehicle (electricity bill) is a suitable way to collect money are expected to be more willing to pay for river quality as this attitude may reduce the disutility of payments through this payment vehicle (Vehicle). Moreover, those who are more certain about their choices are hypothesized as more likely to be willing to pay for the implementation of more restrictive policies with the goal of improving river water quality (Certainty).

In addition, we analized the influence of socio-demographic variables on respondent WTP for river water quality improvements. Respondents whose business is related to the river are expected to be more likely to opt for an improved status of river water quality (River business). The same expectation applies to those who conduct recreational activities at the 
river (River recreation). We hypothesized that younger respondents of a higher income and educational level are more likely to pay for river water quality improvements (Age, Income, Education). Generally, women have more pro-environment attitudes (Birol et al. 2006) so we expect that females are more likely to be willing to pay for water quality improvements $(S e x)$. Rural residents may have more economic interest in river water quality while those in urban areas may have more interest in the recreational services of the river. So, the expected influence of Residence on respondent preferences is not defined at this point. Table 3 shows a definition of the attitudinal and demographic items analyzed and their expected influence on the WTP.

Interaction terms can improve the predictive capacity of CE models, and can be used to test hypotheses about socio-economic or 'attitudinal' influences on preferences (Barkmann et al. 2007). If a deterministic utility component $U_{i}$ is hypothesized to be a linear function of attribute $X_{i}$ itself plus an interaction term of the attribute $X_{i}$ with an individually varying variable $Y, U_{i}$ can be expressed as

$$
U_{i}\left(X_{i}, Y\right)=\beta_{Y X} * X_{i}^{*} Y+\beta_{X} * X_{i}
$$

with

$\beta_{Y X}:$ utility coefficient of the interaction term.

Thus, interaction terms of the attitudinal and demographic items with the alternative specific constant (ASC) and with the attribute values were generated and included in model estimation (see section 2.4). To reduce collinearity between interaction terms and the non-interacted attribute terms, the attitudinal and demographic variables were 0,1-standardized before multiplication with the attribute. Furthermore, the significance of mean differences between 


\subsection{Administration of the survey}

The face-to-face interview survey was conducted by four trained university students and the first author from February to April 2009. For the survey, we considered households fulfilling two conditions: (1) located in localities downstream from the pulp mills on the Mataquito and Itata rivers, and (2) adjacent to the river along the main roads. According to the National Census of 2002 (INE 2005), the total household number at the Mataquito river site is 883 and 4,001 at the Itata site.

We sampled a minimum of 150 households from each site by a systematic sampling procedure (Babbie 2008:224). First, the sampling ratio was calculated (Mataquito: 0.17; Itata: 0.04) to achieve a total of 300 observations. Based in the inverse of the sampling ratio, every sixth household at the Mataquito site and every $25^{\text {th }}$ household at the Itata site were chosen for an interview. When we reached a locality, interviewers were given random points of departure. Then, fixed rules on the direction to walk, distance between households (depending on locality size), and the number of interviews to conduct in each sector were given. When a selected house did not have an apparent occupant, the next house was chosen for the interview. From all household members older than eighteen prior to the day of the interview, any household member willing to answer the questionnaire was chosen.

We administered 53 interviews during the pilot study (Mataquito: 21, Itata: 32), and finally 318 interviews during the main study (Mataquito: 160, Itata: 158). During the main study, 142 contacted households were found to be without occupants, 70 contacted respondents refused to give an interview, and 2 available occupants were younger than 18. Of all successfully 
contacted 318 households, 313 respondents completed the choice task (98\%). On average, an interview took about 45 minutes.

\subsection{Statistical analysis}

From the CE data, we estimated two-level nested logit (NL) models (Hunt 2000) for the Mataquito and Itata samples separately. With three elemental alternatives, one branch with two alternatives and one branch with a single alternative (degenerated branch) can be obtained (cf. Louviere et al. 2001:153). A suitable NL model tree structure was identified, and the corresponding models estimated with NLOGIT 4.0. The inclusive value was set to 1.0 for the degenerated branch (status quo), and the model initiated with starting values obtained from a non-nested NL model (Hensher et al. 2005:530). All scale parameters were normalized at the lowest level (RU1). The vector of utility coefficients was estimated with maximum likelihood estimation procedures. As model statistics, we report the conservative pseudo- $R^{2}$ values in relation to a 'constants only' model. Values between 0.24 and 0.3 correspond to $R^{2}$ values of 0.5 and 0.6 in their ordinary least squares equivalents (Hensher et al. 2005:338).

The estimated models include an alternative specific constant (ASC). It picks up systematic choice variation between the status quo alternative and the alternatives A and B that cannot be explained by the attributes. The ASC was coded as a dummy variable with value 1 for the generic alternatives A and B and 0 for the status quo alternative C (non-Status Quo ASC).

All interaction terms were introduced into the initial model (only attributes) one at a time. Then all statistically significant interactions terms $(\mathrm{P}>0.05)$ of the single interaction models were introduced into the model at once. The final 'improved' model was generated by the 
stepwise exclusion of non-significant interaction terms one-by-one. This model building strategy was used by Barkmann et al. (2008, 2010), and Rajmis (2009), for example.

NL models utilize the choice data only from respondents who chose at least once a scenario other than the zero payment status quo alternative ('payers', Mataquito 79\%, N: 125; Itata 90\%, N: 138). 'Non-payer' respondents were excluded from analysis as they essentially did not respond to the choice task (see Chapter 2). Preliminary analyses had shown that selected modells may display a significant ASC coefficient with a negative sign if the full sample was used. It means that positive respondent preferences for improvements of the offered river water quality attributes were severely counterbalanced by a general refusal of the improvement scenarios as such ('status quo bias', Meyerhoff and Liebe 2009). In the 'payers' model, the numerical value of the ASC coefficient was reduced and the coefficient clearly insignificant. In this situation, we opt for a restriction of the analysis to the 'payers' sample. In calculating aggregated scenario WTP values, the non-payers are of course included and represented as stating zero WTP (see next section).

\subsection{WTP estimation}

$\mathrm{CE}$ results can be used to calculate welfare measures if a status quo scenario is included in the choice set (Bateman et al. 2002). Hence, CEs allow for an estimation of respondent WTP. Based on the quantification of the utility coefficients of the NL model, a maximum marginal WTP (mWTP) for a marginal (1 unit) attribute level change can be estimated as

$$
m W T P=-\frac{\beta_{X}}{\beta_{c}}
$$


where

$\beta_{x}$ : utility coefficient of any of the environmental attributes and,

$\beta_{c}$ : marginal utility of income given by the coefficient of the payment attribute.

mWTP is known as the implicit price. Furthermore, the welfare change generated by an improvement in river water quality was calculated. The change from river water quality level $Q^{0}$ (status quo) to an improved level $Q^{1}$ is calculated as a compensating variation $C V$ (Louviere et al. 2000:340). $C V$ is the amount of money that equates the status quo utility level $\left(U^{0}\right)$ of respondents with the utility level of the improved river water quality level $\left(U^{l}\right)$. In other words, $C V$ can be expressed as a respondent's maximum willingness to pay to achieve a higher river water quality level:

$$
C V\left(Q^{0} \rightarrow Q^{1}\right)=-\frac{1}{\beta_{C}} *\left[U^{1}-U^{0}\right]
$$

To calculate $C V$, we used an optimistic scenario which considered that River Pollution Risk is reduced to $15 \%$, the number of Threatened Species decreased to 15, and Fisheries Yield increased $50 \%$. The estimated total aggregated WTP for the scenario change considered all households in the study area sites that expressed willingness to pay ('payers') for river water quality improvements. They corresponded to 3,585 (90\%) and $694(79 \%)$ households at the Itata and Mataquito river sites respectively. 


\section{$3 \quad$ Results}

\subsection{Descriptive results}

Respondents were 52 years old on average at both river sites (Table 4). 69\% of Itata respondents were women compared with only $52 \%$ at the Mataquito river site $(\mathrm{p} \leq 0.01) .87 \%$ of the Mataquito respondents were rural, only $36 \%$ of Itata respondents were $(p \leq 0.001)$. An important percentage of respondents did not have any formal education (Mataquito: 38\%; Itata: $31 \%$ ). $62 \%$ of the respondent households received less than the monthly national minimum income at both river sites ( USD 264). While $60 \%$ of the Mataquito respondents indicated that their occupation (business) was related to the river, only $19 \%$ of the Itata respondents stated this business-river relationship $(\mathrm{p} \leq 0.001)$. A low percentage of respondents (Mataquito: 21\%; Itata: 29\%) had conducted recreational activities related to the river in the last two years.

Few respondents agreed that water quality in the river (Mataquito: 13\%; Itata: 12\%) and drinking water quality in the household (Mataquito: $26 \%$; Itata: $31 \%$ ) were very good. $87 \%$ of Itata respondents strongly agreed that pollution in the river would be worse in the next 10 years while a reduced $76 \%$ of Mataquito respondents showed a similar attitude $(p \leq 0.001)$. A low percentage of respondents (Mataquito: 13\%; Itata: 9\%) believed that river water quality was well protected by law. The majority (Mataquito: 94\%; Itata: 89\%) agreed that wastewater reduces fish quantity. The Itata river site showed a higher percentage of respondents $(73 \%)$ strongly agreeing that fertilizers spoil river water quality than the Mataquito river site $(69 \%$, p-value $\leq 0.01$ ). Around one half of respondents (Mataquito: 47\%; Itata: 55\%) believed that the electricity bill is a suitable payment vehicle for collecting money to implement more 
restrictive policies for enforcing river water quality improvements. Finally, most of the respondents (Mataquito: 84\%; Itata: 85\%) reported that they were certain about their choices in the CE exercise.

Table 4. Attitudes and socio-demographic characteristics of respondents

\begin{tabular}{|c|c|c|c|}
\hline \multirow[t]{2}{*}{ Variable } & \multicolumn{2}{|c|}{ Mean } & \multirow{2}{*}{$\begin{array}{c}\text { Means } \\
\text { difference } \\
\text { (P-value) }\end{array}$} \\
\hline & $\begin{array}{c}\text { Mataquito sample } \\
\text { (N: 159) }\end{array}$ & $\begin{array}{c}\text { Itata sample } \\
\text { (N: 154) }\end{array}$ & \\
\hline$R W$ quality & 2.08 & 1.94 & 0.209 \\
\hline$R W$ drinking & 2.4 & 2.57 & 0.203 \\
\hline$R W$ expectation & 3.94 & 4.32 & $0.000 * * *$ \\
\hline$R W$ protection & 2.13 & 1.99 & 0.201 \\
\hline$R W$ wastewater & 4.23 & 4.23 & 0.993 \\
\hline$R W$ fertilizers & 3.6 & 3.86 & $0.013^{*}$ \\
\hline Vehicle & 3.13 & 3.32 & 0.178 \\
\hline Certainty & 4.03 & 4.06 & 0.630 \\
\hline River business $($ yes $=1)$ & 0.60 & 0.19 & $0.000 * * *$ \\
\hline River recreation $(\mathrm{yes}=1)$ & 0.21 & 0.29 & 0.083 \\
\hline Age & 52 & 51 & 0.586 \\
\hline Education & 2.03 & 2.24 & 0.078 \\
\hline Income & 165,535 & 175,584 & 0.552 \\
\hline $\operatorname{Sex}($ male $=1)$ & 0.48 & 0.31 & $0.003 * *$ \\
\hline Residence (rural=1) & 0.87 & 0.36 & $0.000 * * *$ \\
\hline
\end{tabular}

\subsection{Choice Experiment results}

Estimated models were highly significant overall (Table 5; $\left.P\left(\chi^{2}\right)<0.0001\right)$. All attributes were significant predictors of choice with very high pseudo- $\mathrm{R}^{2}$ values of $0.24-0.30$. Pseudo- 
$\mathrm{R}^{2}$ (constant only) values between 0.24 and 0.30 correspond to $\mathrm{R}^{2}$ values between 0.5 and 0.6 value in the OLS model equivalent, approximately (Hensher et al. 2005: 338-9). The attribute coefficients displayed the expected signs. The results indicate a disutility for higher river pollution risk, for higher numbers of species that are threatened, and for higher payments for water quality improvements. Positive utility was derived for higher fishery yields. The ASC was clearly not significant in the models. Attributes interacting with attitudinal and sociodemographic variables yielded several significant predictors of choice (see below).

In the Mataquito model (a), respondents who tended to agree that river is well protected by law showed lower preferences for improvements in the threatened species attribute (Threatened species $* R W$ protection). Rural respondents displayed higher preferences for reductions in the river pollution risk (River pollution risk*Residence). Moreover, those of higher education displayed a lower disutility of their payments for improving river water quality (Payment*Education).

In the Itata model (b), respondents who more strongly agreed that fertilizers have negative effects on river water quality displayed lower preferences for improvements in the fishery yields attribute (Fisheries yield* $R W$ fertilizers). Respondents who more strongly believed that the electricity bill is a suitable payment vehicle and were more certain about their choices derived higher preferences for reductions in the number of threatened species (Threatened species*Vehicle, Threatened species ${ }^{*}$ Certainty). Respondents of higher education displayed also higher preferences for reductions in the number of threatened species (Threatened species*Education). Those who related their business to the river showed lower preferences for improvements in the threatened species attribute (Threatened species*River business). 
Finally, respondents with higher income displayed a lower disutility of their payments for river water quality improvements (Payment*Income).

Table 5. Valuation of river water quality improvements in Central Chile

\begin{tabular}{|c|c|c|c|c|}
\hline Variable & (a) Mataquito & P-value & (b) Itata & P-value \\
\hline River pollution risk & $-0.094 * * *$ & 0.000 & $-0.184 * * *$ & 0.000 \\
\hline Threatened species & $-0.122 * * *$ & 0.000 & $-0.155 * * *$ & 0.000 \\
\hline Fisheries yield & $0.026 * * *$ & 0.000 & $0.032 * * *$ & 0.000 \\
\hline Payment ${ }^{\%}$ & $-0.058 * * *$ & 0.000 & $-0.078 * * *$ & 0.000 \\
\hline non Status QuoASC & 12.210 n.s. & 0.913 & -3.091 n.s. & 0.338 \\
\hline River pollution risk * Residence & $-0.041 * * *$ & 0.000 & & \\
\hline Threatened species * Education & & & $-0.061 * * *$ & 0.000 \\
\hline Threatened species $* R W$ protection & $0.031^{* *}$ & 0.007 & & \\
\hline Threatened species $*$ Business ${ }^{\&}$ & & & $0.023 *$ & 0.032 \\
\hline Threatened species * Vehicle & & & $-0.033 * *$ & 0.009 \\
\hline Threatened species $*$ Certainty & & & $-0.020 *$ & 0.047 \\
\hline Fisheries yield $* R W$ fertilizers & & & $-0.012 * *$ & 0.009 \\
\hline Payment $*$ Income & & & $0.025 * * *$ & 0.000 \\
\hline Payment $*$ Education & $0.040 * * *$ & 0.000 & & \\
\hline Log-likelihood & -288.27 & & -320.78 & \\
\hline $\mathrm{P}\left(\mathrm{Chi}^{2}\right) ; \mathrm{DF}$ & $<0.0001 ; 9$ & & $<0.0001 ; 12$ & \\
\hline IV of non degenerated branch (nonSQ) & 0.026 & & 0.516 & \\
\hline Pseudo-R ${ }^{2}$ (constants only) & 0.241 & & 0.297 & \\
\hline Number of respondents & 125 & & 138 & \\
\hline
\end{tabular}

***: significant at $\mathrm{p} \leq 0.001 ; * *$ : significant at $\mathrm{p} \leq 0.01 ; *$ : significant at $\mathrm{p} \leq 0.05$

$\%$ : Payment attribute in hundred Chilean pesos; n.s.: no significant coefficient.

\&: Null hypothesis on the positive effect of Business on WTP was rejected at $95 \%$ level of significance (twotailed t-test).

With regard to policy scenario analysis, we used model results for a simple stated preference valuation of river water quality improvement (Table 6). The marginal mean WTP values per household ranged between 162-236 CLP/yr/1\% reduction in River Pollution Risk, 199-210 CLP/yr/1 fewer Threatened Species, and 41-45 CLP/yr/1\% of increased Fisheries Yield. 
We obtained a total mean WTP per household of 7,828 CLP/yr and 8,571 CLP/yr for river water quality improvements for the Mataquito and the Itata sites respectively. Given the diference in the number of residents in the two sites, estimated total aggregated WTP (compensating surplus) for the scenario change differ substantially (Mataquito: 5.43 million CLP/yr; Itata: 30.73 million CLP/yr).

Table 6. Marginal stated preferences WTP and exemplary policy scenario calculations

\begin{tabular}{lcc}
\hline & Mataquito & Itata \\
\hline Marginal WTP: & & \\
River pollution risk (1\% less) & 162 & 236 \\
Threatened species (1 fewer) & 210 & 199 \\
Fisheries yield (1\% increase) & 45 & 41 \\
\hline Policy escenario: & & \\
River pollution risk (15\% less) & 2,431 & 3,538 \\
Threatened species (15 fewer) & 3,155 & 2,981 \\
Fisheries yield (50\% increase) & 2,241 & 2,051 \\
\hline Total scenario WTP/household/yr & 7,828 & 8,571 \\
\hline Total aggregated scenario WTP (Mio CLP/yr) & $5.43(\mathrm{~N}: 694)$ & $30.73(\mathrm{~N}: 3,585)$ \\
\hline 1 USD $\sim 606$ CLP (February 2009) & &
\end{tabular}

\section{$4 \quad$ Discussion and Conclusions}

We conducted a Choice Experiment (CE) to generate non-market valuation data useful for the discussion of the development of Chilean river water policies in the face of environmental threats from paper mills. Moreover, we analyzed the influence of attitudinal and demographic items on respondent preferences for ensuring the implementation of river water improvement mandated by the Chilean state. All river water quality attributes as well as the payment attribute turned out to be highly significant predictors of choice. The influence of these features differed per river site. 
The estimated benefits provided information on the importance of non-market river water quality attributes for people at the Mataquito and Itata rivers. Judged by the nested logit model results, the Threataned Species attribute had a significant relation with most of the attitudinal and socio-demogrpahic variables included in the final models. Although this attribute represents a non-use value of river water quality, respondents considered it important to improve the ecological status of the local rivers.

Respondents more strongly agreeing that the Mataquito river is well protected by law were likely to be willing to pay less for a reduction in the number of threatened species (Threatened species $* R W$ protection). Our payment scenario directly proposed a more restrictive regulation to increase supervision of pulp mills in the study area. So, respondents agreeing with current regulations had no motivation to pay for more restricive policies for river water quality improvements. However, this respondent attitude respresents just $13 \%$ of the sample.

Mataquito rural respondents on average, were willing to pay more for reductions in river pollution risk (River pollution risk*Residence). This means that those who rely on natural resources for their livelihood were more affected by the negative effects of wastewater and consequently willing to support action to enforce pulp mill wastewater reductions. The majority of Mataquito respondents live in rural areas (87\%) while, at Itata, the percentage of rural people is substantially lower (36\%). One may tend to think that this result contradicts findings by Alvarez-Farizo et al. (2007) who indicated that respondents working in the agricultural sector were less likely to take action to improve river water quality. However, most rural residents at the Mataquito study site were housewives (43\%) and just a relatively low percentage of them were farmers $(16 \%)$. Moreover, Mataquito respondents of higher 
educational level were more likely to choose the higher payments on the choice set scenarios (Payment*Education).

Itata respondents more strongly agreeing that fertilizers negatively affect river water quality were on average willing to pay less for higher fishery yields (Fisheries yield $* R W$ fertilizers). The majority of Itata respondents think that fertilizers negatively affect river water quality (88\%).This means that respondent awareness about negative effects of fertilizers on river quality does not represent an incentive to pay for improving fishery yields attribute. As a very low percentage of respondents are involved in local fishery business $(0.02 \%, n=3)$, they do not see any direct positive impact of improving fishery yield on their welfare. Figure 2 shows that higher scores at the $W Q$ fertilizer attitudinal variable generate lower WTP for an optimistic scenario for Fisheries yield increase. Nevertheless, the interquartile range (IQR) is very close to zero, so respondents did not show significant variability in their preferences in this range when a 5-point Likert scale is used for attitude statements $(\sim 2,000$ CLP/household/yr).

Itata respondents more strongly agreeing with the adequacy of our payment vehicle (electricity bill) tended to be willing to pay more for reductions in the number of threatened species, i.e., fewer species with conservation problems (Threatened species*Vehicle). 55\% of the respondents believed that the electricity bill was an adequate payment vehicle. This result highlighted the importance of a credible payment scenario that properly elicits respondent preferences. Moreover, Itata respondents more certain about their choices were likely to express a higher WTP for reductions in the number of threatened species (Threatened species * Certainty). $85 \%$ of respondents were certain about their choices. This result indicates that our choice experiment was substantially understood by respondents. It showed that 
scenario plausibility play a significant role in respondent preferences for river based ecosystem service attributes.

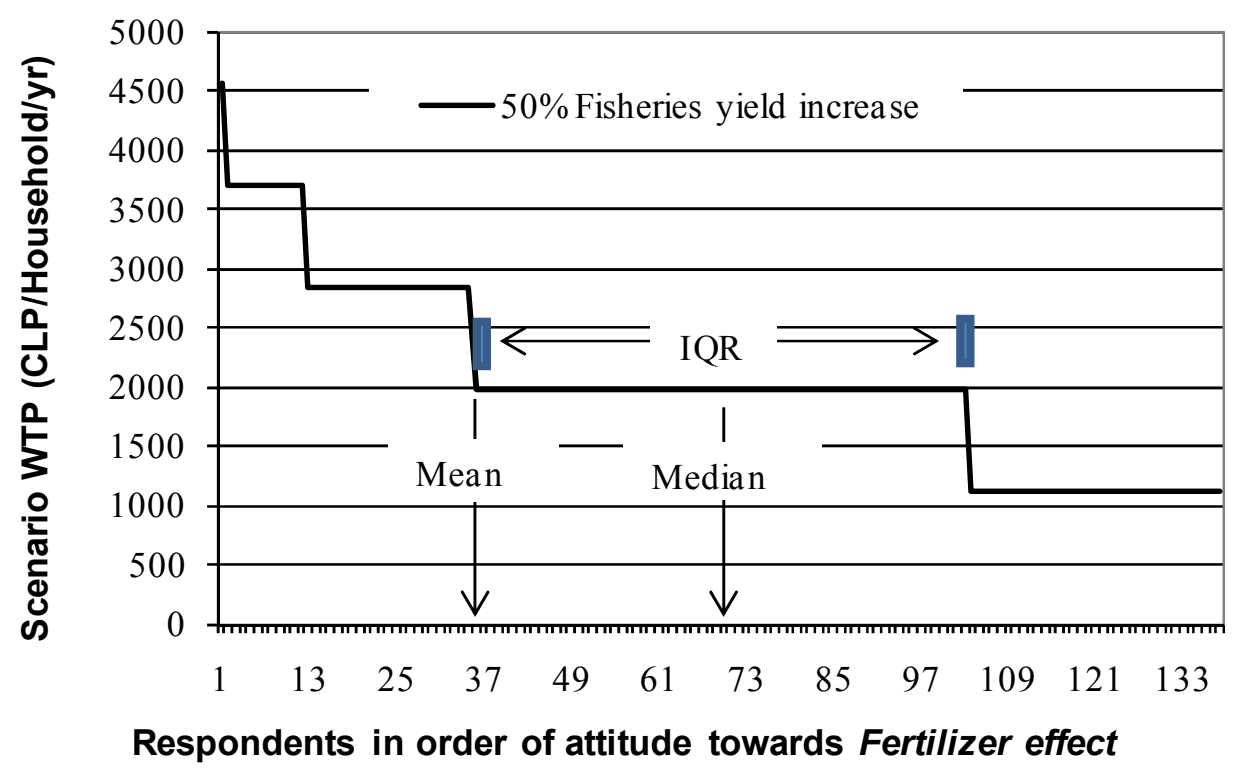

Figure 2. Scenario WTP for an optimistic 50\% increase in Fisheries yield for the Itata sample.

Itata respondents of higher Education were likely to be more willing to pay for reductions in the number of Threatened species. Similar results were shown by Álvarez-Farizo et al (2007) who indicated that respondents with a higher education were more likely to pay for an improvement in river water quality attributes in Navarra, Spain. In this regard, lack of access to formal education may represent a significant barrier to respondents taking action to improve river water quality in the study area. This issue is substantially important considering that $31 \%$ of the Itata respondents had no formal education at the study site.

Itata respondents who related their business (occupation) with the river were likely to be less willing to pay for reductions in the number of Threatened species (Threatened species*River 
business). This result was contrary to our expectation (see Table 3). Respondents may see more restrictive river water quality polices as a restriction to carried out their business. For example, local farmers may be forced to treat river water after using it. Nevertheless, just 19\% of Itata respondents actually related their business with the river. Finally, Itata respondents of higher income were more likely to choose the higher payments on the alternative choice set scenarios (Payment*Income). Similar influence of income interacting with the payment attribute on improved river health was found by Morrison and Bennett (2004) in New South Wales, Australia.

Considering that $62 \%$ of the households earn less than the national minimum income ( USD 264/month) the valuation scenario probably captures a considerable share of total WTP for river water quality improvement. It may represent a significant amount, at least, for improving government supervision downstream from the pulp mill. WTP values were also substantial if we consider that a relatively low percentage of respondents (Mataquito: 21\%; Itata: 29\%) carry out recreational activities in the river ecosystem and its surroundings. Moreover, only a $19 \%$ of Itata respondents related their business to the river.

The non-status quo ASC was clearly not significant. This result indicates that positive respondent preferences for improvements of river water quality attributes are not counterbalanced by a general refusal of the improvement scenarios as such. This result was achieved, however, by excluding $16 \%$ of respondents who never chose any of the scenarios other than the zero payment status quo.

We conclude that the influence of respondent attitudes and socio-demographic variables on WTP for river water quality improvements is river site specific even across relatively close 
sites. There were no interaction terms influencing WTP at both river sites simultaneously. This finding may have a justification on some differences in the socio-demograhic chacteristics of respondents between river sites. For example, a higher percentage of the Mataquito respondents had rural residence $(87 \%)$ and related their business with the river (60\%) compared with only $36 \%$ and $19 \%$ respectively at the Itata river. In fact, nested logit models displayed a significant influence of Residence (Mataquito) and Business (Itata) on respondents WTP for attributes of river water quality. Morrison and Bennett (2004) also found that respondent preferences for river water quality are river site specific. However, when populations resident outside river sites were sampled, value estimates were found to be statistically similar.

\section{References}

Álvarez-Farizo B, Hanley N, Barberán R, Lázaro A (2007) Choice modeling at the "market stall": Individual versus collective interest in environmental valuation. Ecological Economics 60: 743-751.

Araya I, Quiñones R, Dresdner J, Barriga O, Carrasco P, Campos N, Leiva M, Hernandez A, Ponce R, Rivas R (2006) Diagnóstico social, económico y productivo de las comunidades de pescadores artesanales de la desembocadura del Itata y zonas adyacentes, entre Cobquecura y Dichato. Programa de Estudios Económicos y Sociales del Sector Pesquero, Universidad de Concepción, Chile.

Babbie EA (2008) The basics of social research, Fourth Edition. Thomson Learning, Inc. USA.

Barkmann J, Glenk K, Handi H, Sundawati L, Witte JP, Marggraf R (2007) Assessing economic preferences for biological diversity and ecosystem services at the Central Sulawesi rainforest margin - a choice experiment approach. In: Tscharntke T., Leuschner C., Zeller M., Guhardja E., Bidin A. (eds), The stability of tropical rainforest margins, linking ecological, economic, and social constraints of land use and conservation, Springer Berlin 2007, pp 181-208. 
Barkmann J, Glenk K, Keil A, Leemhuis C, Dietrich N, Gerold G, Marggraf R (2008) Confronting unfamiliarity with ecosystem functions: The case for an ecosystem service approach to environmental valuation with stated preference methods. Ecological Economics 5: 48-62.

Barkmann J, Yan J, Zschiegner A-K, Marggraf R (2010) The Dao of the sceptic and the spiritual: attitudinal and cultural influences on preferences for sustainable tourism services in the domestic Chinese tourism market. International Journal of Services Technology and Management 13: 281-304.

Bateman I, Carson T, Day B, Hanemann M, Hanley N, Hett T, Jones-Lee M, Loomes G, Mourato S, Özdemiroglu E, Pearce D, Sugden R, Swanson J (2002) Economic valuation with stated preferences techniques: a manual, Edward Elgar, Cheltenham, UK and Northampton, MA, USA.

Bioma (2008) Consultoría para la recopilación de información sobre la biodiversidad en apoyo a la elaboración del anteproyecto de norma secundaria de calidad ambiental para la protección de las aguas de la cuenca del Mataquito. Bioma BGA Consultores.

Birol E, Karousakis K, Koundouri P (2006) Using economic valuation techniques to inform water resources management: A survey and critical appraisal of available techniques and an application. Science of the Total Environment 365: 105-122.

Cade-Idepe Consultores en Ingeniería (2004a) Diagnóstico y clasificación de los cursos y cuerpos de agua según objetivos de calidad - cuenca río Mataquito. Dirección General de Aguas, Ministerio de Obras Públicas, Chile. http://www.sinia.cl/1292/articles31018_Mataquito.pdf. Accessed 26 June 2008

Cade-Idepe Consultores en Ingeniería (2004b) Diagnóstico y clasificación de los cursos y cuerpos de agua según objetivos de calidad - cuenca río Itata. Dirección General de Aguas, Ministerio de Obras Públicas, Chile. http://www.sinia.cl/1292/articles31018_Itata.pdf. Accessed 26 June 2008

Chrzan K, Orme B (2000) An overview and comparison of design strategies for choice-based conjoint analysis. Sawtooth Software 2000-2002, Research paper series.

CONAF (1993) Libro rojo de los vertebrados terrestres de Chile. Corporación Nacional Forestal - CONAF, Ministerio de Agricultura de Chile. Santiago, Segunda Edición. CONAMA (2006) Análisis económico y social de la norma de calidad secundaria para la protección de las aguas continentales superficiales en la cuenca del río Maipo. Región Metropolitana de Santiago. 
CONAMA-SINIA (2008) Información geográfica territorial regional. Sistema Nacional de Información Ambiental Territorial (SINIA), Ministerio del Medio Ambiente, Chile. http://territorial.sinia.cl/portal/descargas.php. Accessed 30 September 2010

EULA (2006) Análisis general del impacto económico de la norma secundaria de calidad de aguas en la cuenca del río Bio-Bio, en el sector silvoagropecuario. Universidad de Concepción.

Habit E, Dyer B, Vila I (2006) Estado de conocimiento de los peces dulceacuícolas de Chile. Gayana 70, 1: 100-113.

Hanley N, Colombo S, Tinch D, Black A, Aftab A (2006a) Estimating the benefits of water quality improvements under the Water Framework Directive: are benefits transferable? European Review of Agricultural Economics 33, 3: 391-413.

Hanley N, Wright RE, Alvarez-Farizo B (2006b) Estimating the economic value of improvements in river ecology using choice experiments: an application to the water framework directive. Journal of Environmental Management 78: 183-193.

Hensher DA, Rose JM, Greene WH (2005) Applied choice analysis: a primer. Cambridge University Press, Cambridge (UK).

Huenchuleo C, Barkmann J, Marggraf R (2011) Economic valuation of river-based ecosystem services subject to fairness considerations in Central Chile using a Choice Experiment. Chapter 2 of this thesis, formatted for submission to Regional Environmental Change. Hunt GL (2000) Alternative Nested Logit Model Structures and the Special Case of Partial Degeneracy. Journal of Regional Science 40, 1: 89-113.

INE (2005) Chile: Ciudades, Pueblos, Aldeas y Caseríos. Censo 2002, Instituto Nacional de Estadísticas - INE, Chile. http://www.ine.cl/canales/chile_estadistico/ demografia_y_vitales/demografia/demografia.php. Accessed 20 April 2008

INE (2009) Censo Agropecuario 2007. http://www.censoagropecuario.cl/. Accessed 5 May 2010

Louviere J, Hensher D, Swait J (2000) Stated Choice Methods - Analysis and Application. Cambridge University Press, Cambridge (UK).

Meyerhoff J, Liebe U (2009) Status Quo Effect in Choice Experiments: Empirical Evidence on Attitudes and Choice Task Complexity. Land Economics 85, 3: 515-528.

Morrison M, Bennett J (2004) Valuing New South Wales rivers for use in benefit transfer. The Australian Journal of Agricultural and Resource Economics 48, 4: 591-611. 
Rajmis S, Barkmann J, Marggraf R (2009) Using community preferences for climate change mitigation and adaptation measures around Hainich National Park, Germany. Climate Research 40: 61-73.

SERNAPESCA (2007a) Valorización Desembarque Regional Años 2005 - 2006, Región del Maule. Servicio Nacional de Pesca, Chile. http://www.sernapesca.cl/ index.php?option $=$ com_remository\&Itemid $=246 \&$ func $=$ fileinfo\&id $=1957$. Accessed 1 May 2008

SERNAPESCA (2007b). Concesiones de Acuicultura. Estuarios propuestos como Areas Apropiadas en la Región del Maule. Servicio Nacional de Pesca, Chile. http://www.sernapesca.cl/index.php?option=com_content\&task=view\&id=498\&Itemid= 686. Accessed 1 May 2008

SISS (2009) Cumplimiento de normas de descargas de Residuos Líquidos, DS 90/00 Descarga a cuerpos de agua superficiales, años 2006-2007-2008. Superintendencia de Servicios Sanitarios - SISS, Chile. http://www.siss.cl/propertyvalue-2309.html. Accessed 25 January 2009

SISS (2008) Informe de Gestión Sector Sanitario 2007. Superintendencia de Servicios Sanitarios, Chile. http://www.siss.cl/articles-6245_informegestion.pdf. Accessed 30 March 2008

Vergara A, Encina F et al (2008) Informe Final - Evaluación Ambiental en el río Mataquito. Facultad de Ingeniería - Facultad de Recursos Naturales, Universidad Católica de Temuco. http://www.cutchile.cl/paloma/04\%20articles44336_InformeFinalRioMataquito.pdf. Accessed 15 January 2009

Zenteno P, López A, Mardones C, Montoya F (2009) Análisis de impacto económico y social de anteproyecto de normas secundarias de calidad - cuenca río Mataquito. DSS Ambiente. Ministerio de Obras Públicas, Chile. http://www.dga.cl/otros/SAD/CQA5072.pdf. Accessed 01 June 2010 
Chapter 4

\title{
Social-psychology determinants of river water quality improvements in Central Chile: a Choice Experiment application
}

\author{
Carlos Huenchuleo Pedreros, Jan Barkmann, Rainer Marggraf
}

\begin{abstract}
It has been suggested that social-psychology constructs influence behavioral intentions to cope with environmental risks. However, few applications have analyzed the impact of these variables on the outcome of stated preference studies. In this regard, we analyzed the influence of perceived severity of river pollution and response efficacy concerning water quality policies as part of a Choice Experiment (CE) survey for the valuation of river water quality attributes affected by pulp mill wastewater in Central Chile. The CE includes attributes on river pollution risk and on river water quality effects that impact threatened species as well as the yield of local fisheries. The payment vehicle was an additional annual charge to the electricity bill. All three environmental attributes and the payment attribute were highly significant determinants of choice $(\mathrm{P}<0.001)$. Severity and response efficacy constructs displayed a significant influence on preferences for reductions in river pollution risk and the number of threatened species. Moreover, most respondents showed 'problem focussed' behaviour in assessing river pollution risks. These results suggest that social-psychology constructs provide an attractive methodological tool for the assessment of preference heterogeneity regarding water quality improvements.
\end{abstract}

Keywords: social-psychology constructs, river water quality, choice experiment, willingnessto-pay 


\section{$1 \quad$ Introduction}

Although significant improvements have been achieved in past years, river water quality in Chile is still poor in some places (OCDE-CEPAL 2005). A main source of water pollution is untreated wastewater from households and industries. In particular, the negative effect of pulp mill wastewater on river water quality has received considerable attention in Chile (Vasconi 2006; Espinosa 2001). Despite significant efforts to reduce wastewater toxicity, it is still believed to negatively impact aquatic organisms (Orrego et al. 2006). Consequently, the river environment downstream from pulp mills is considered severely compromised in Chile (Vasconi 2006).

We estimate respondent willingness-to-pay (WTP) for different attributes of river water quality improvement with the Choice Experiment (CE) method. Moreover, we analyze the influence of perceived severity of river pollution and response efficacy of coping measures on the WTP for river water quality improvements by respondents living downstream from paper mills. Behavioral models assume that perceived severity and response efficacy are part of two cognitive processes regarding a threat: the threat-appraisal process and the coping-appraisal process (Rogers and Prentice-Dunn 1997). In our study case, river pollution by pulp mills may pose a severe threat to respondent livelihoods. The combination of these cognitive processes determines a behavioral intention to perform a specific action which is represented in this study by a WTP for implementing more restrictive water policies in order to improve river water quality. In the $\mathrm{CE}$, the behavioral intention is observed through respondent behavior (choice). 
Kantola et al. (1983) used severity and response efficacy constructs to analyze intentions to save water. More current studies have analyzed these constructs based on different socialpsychology frameworks, most of them applied to health issues. The frameworks include the health belief model (Janz and Becker 1984), the expanded health belief model (Burns 1992), protection motivation theory (Rogers and Prentice-Dunn 1997), the integrative theory of health appeals (Block and Keller 1998), and the model of preventive health care behavior (Jayanti and Burns 1998). Comparatively, few studies have been carried out to analyze the influence of these constructs regarding environmental threats (Mulilis and Lippa 1990, Vaughan 1993, Forsyth et al. 2004, Menzel and Scarpa 2005, Cerda et al. 2006, Lam 2006, Barkmann et al. 2008, Huenchuleo et al. 2011). Applied to water resources, Forsyth et al. (2004) analyzed the severity of watershed pollution by using the awareness-appraisal model of environmentally positive intentions and behaviors. Lam (2006) analyzed the influence of subjective effectiveness of alternative solutions as a predictor of intentions to save water. The influence of severity and response efficacy items on respondents WTP for hydrology attributes in Indonesia was analyzed by Barkmann et al. (2008). Moreover, only a few studies analyzed the influence of social-psychology items on preferences for protecting natural resources in a CE context (Menzel and Scarpa 2005, Barkmann et al. 2008; Cerda et al. 2006).

The CE method is based on reconstructing economic preferences from respondent choices on alternative scenarios made during a valuation interview. The scenarios offered to respondents differ by the 'levels' (characteristics) that a number of different attributes display (Bateman et al. 2002:278). The CEs were applied to the valuation of different attributes of river water quality improvement in previous studies. Attributes of the status of river ecology such as presence of certain water plants, fish, bird and other animal species were studied by Hanley et al. (2006ab), Álvarez-Farizo et al. (2007), Morrison and Bennett (2004), and Bateman et al. 
(2006). Recreation attributes (boating, fishing, and swimming) were analyzed by Morrison and Bennett (2004) and Bateman et al. (2006). None of the studies was conducted in Chile.

Considering this background, our paper has two objectives. First, we attempt to determine the WTP of Central Chilean citizens for improvements in several policy-relevant river water quality attributes. Specifically, we included attributes on river pollution risk, and on water quality effects impacting river ecosystem services such as habitat for potentially threatened species or yields in local fisheries. The resulting valuation findings close a gap in the valuation of the Chilean river water resources. Second, we analyze the influence of severity and response efficacy constructs on respondent WTP for river water quality improvement. The results contribute to the international debate on the influence of socio-psychology variables on the results and interpretation of stated preference studies.

The paper is organized as follows. In section 2 we present the methodology that includes a description of the study area, CE design, operationalization of socio-psychology constructs and general survey design. Section 3 presents the results from the CE application with emphasis on the effect of severity and response efficacy aspects. Then, section 4 interprets and discusses the main findings derived from the CE study.

\section{$2 \quad$ Methodology}

\subsection{Study area}

The study area is located at downstream sections of the Mataquito and Itata river watersheds in the VII Maule region and the VIII Bío-Bío region of Central Chile (Figure 1). The 


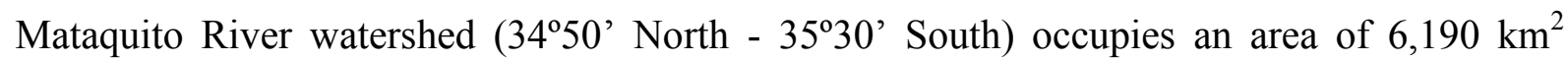
(Cade-Idepe 2004a); the Itata River watershed (36 $00^{\prime}$ 'North - $37^{\circ} 20^{\prime}$ South) has an area of $11,294 \mathrm{~km}^{2}$ (Cade-Idepe 2004b). Both rivers receive wastewater from the pulp mill industry. The pulp mill on the Mataquito River is located in Licantén $30 \mathrm{~km}$ upstream from the estuary. On the Itata River, the pulp mill is located $50 \mathrm{~km}$ upstream from the estuary in the Ranquil community.

The study area includes four communities (Mataquito River: Licantén and Curepto; Itata River: Coelemu and Trehuaco). In these communities, we sampled respondents living downstream the pulp mills. The sampling frame included 2,141 inhabitants at the Mataquito River site and 13,521 inhabitants at the Itata River site (population data extracted from INE 2005). In addition to the pulp mills, the main economic activities in the study area are agriculture, local fisheries at the estuary, and forestry with plantations of exotic Pinus radiata (Monterrey Pine) that supply wood to the pulp mills (INE 2009).

Pulp mill wastewater violating national standards has produced significant damage to the Mataquito River ecology in the recent past (SISS 2008, Vergara and Encina 2008). While recent reports indicate positive chemical water quality parameters in the Mataquito and Itata rivers (Cade-Idepe ab 2004), a major share of fish populations is regarded as threatened (Habit et al. 2006). Local fishermen at the Itata estuary see the pulp mill upstream as a major threat to their business and livelihood (Araya et al. 2006:298). In this regard, it appears questionable to what degree these indicators of water quality fully represent the ecological status of the two rivers. 


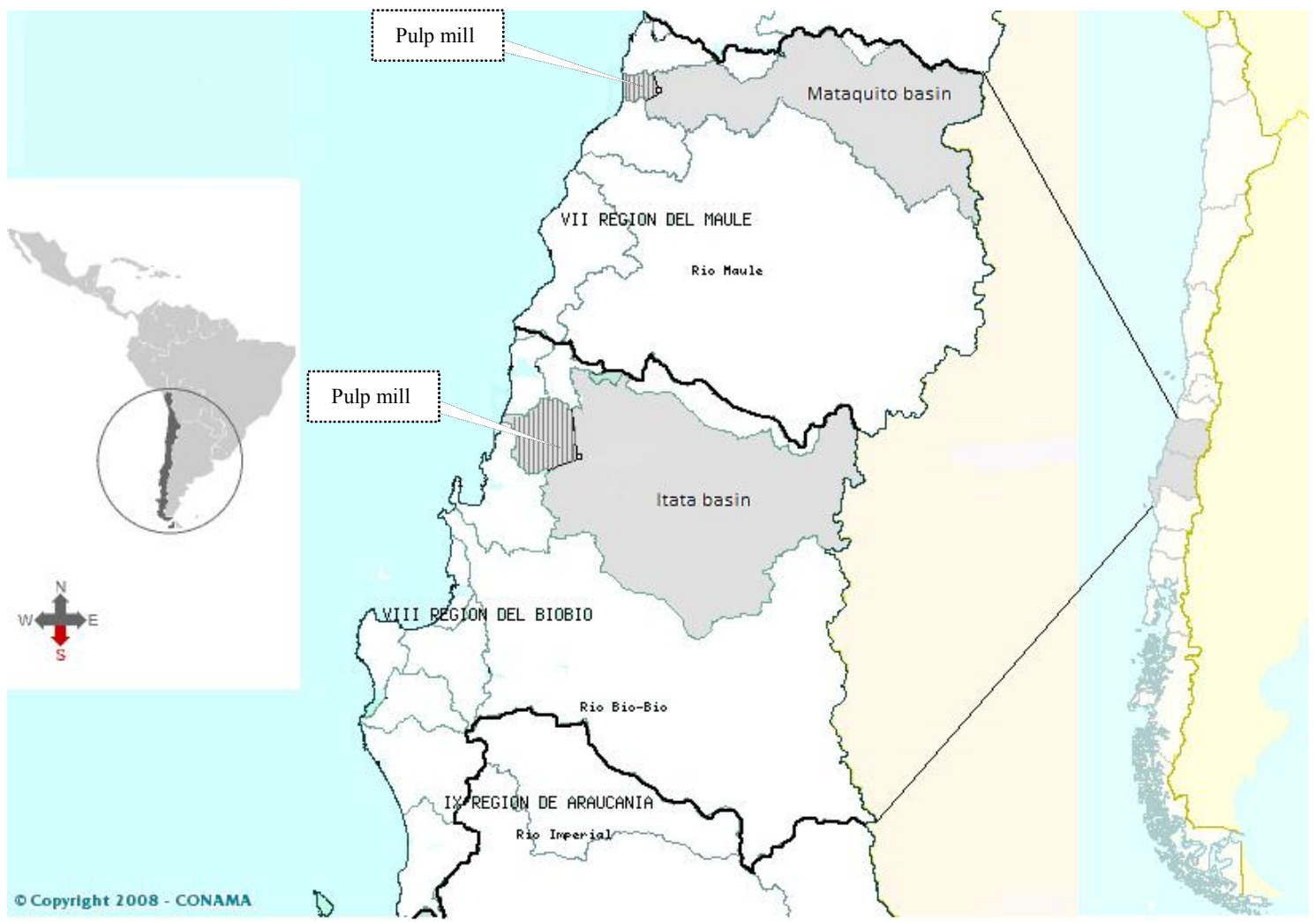

Figure 1. Location of the study area (adapted from CONAMA-SINIA 2008); actual study area hatched

\subsection{Choice Experiment design}

In the $\mathrm{CE}$ interviews, respondents were asked to contribute to the identification of better water quality policy options for the two rivers. To this effect, policy option outcomes ('scenarios') were described through selected attributes of river water quality and a payment to be made. Based on pre-study results and national environmental data (SISS 2008-2009; SERNAPESCA 2007ab; Bioma 2008; Araya et al. 2006; CONAF 1993), three attributes of river water quality improvement were constructed: river pollution risk, number of threatened species, and local fishery yields (Table 1). Each attribute and its respective levels were explained to respondents using examples with visual aids. For each attribute, one level corresponds to the current situation (status quo). 
The pulp mills are the main industrial operations in the research area ${ }^{10}$. Pollution spills leading to violations of national water quality standards have been a recurrent feature of the operation of the pulp mills. For example, reports of the Superintendencia de Servicios Sanitarios (Superintendency of Sanitary Services; SISS) document that the Mataquito river pulp mill did not comply with the national emission standard "DS90-2000", on average, in one of four months (25\%) during a period from 2006-2008 (SISS 2009). Thus, we decided to construct an attribute on river pollution risk that directly addresses such violations. In our CE design, a value of $25 \%$ violations corresponds to the current situation or status quo. Additionally, we offered respondents reductions of river pollution risk to $20 \%, 15 \%$ or $10 \%$.

The threatened species attribute deals with the number of fish and waterfowl species living in the river ecosystem with a poor ("threatened") conservation status. Currently, there are 25 such threatened species in the Mataquito and Itata rivers, on average (Bioma 2008). We proposed to respondents a substantial improvement of this situation defined by a reduction in the number of threatened species, i.e., there would be fewer species with conservation problems. Proposed attribute levels were a reduction to 20,15, and 10 threatened species.

The yield of local fisheries attribute refers to the yield of small fisheries operating mainly in the estuaries of the two rivers. To explain this attribute to respondents, we choose the estuarine species Robalo (Eleginops maclovinus), which is a well-known species in the study area. The current total yields in local fisheries for Robalo are 1 ton/year (Mataquito) and 10 tons/year (Itata) on average (SERNAPESCA 2007ab; Araya et al. 2006). Given the high yield fluctuation during the last five years, we proposed to respondents an increase in fishery yields 
of $10 \%, 25 \%$, and $50 \%$.

For the payment attribute, an additional mandatory annual payment per household to the electricity bill was utilized. We explained to respondents that the money raised would be used to enforce pulp mill compliance with potentially more stringent legislation on improving river water quality. Based on pre-study results, we proposed four payment levels $(500,1,000,2,000$ and 3,000 Chilean pesos/CLP/yr) in addition to a zero status quo payment.

Table 1. Attributes and levels in the CE

\begin{tabular}{lll}
\hline Attribute & Definition & Levels \\
\hline Pollution risk & River pollution risk (\% non & $25_{\mathrm{SQ}}, 20,15,10$ \\
& compliance with national standards) & \\
Threatened species & Number of threatened species (N $\left.{ }^{\circ}\right)$ & $25_{\mathrm{SQ}}, 20,15,10$ \\
Fisheries yield & Increase in fisheries yield (\%) & $0_{\mathrm{SQ}}, 10,25,50$ \\
Payment $^{\S}$ & Charge to the electricity bill (CLP) & $0_{\mathrm{SQ}}, 500,1000,2000$, \\
& & 3000
\end{tabular}

Note: Payment in Chilean pesos - CLP (1 USD $\approx 606$ CLP, February 2009) per household per year. SQ: current situation (status quo), §: zero payment was included only in the status quo alternative. This means that the ' 0 ' values is perfectly compounded with the ASC.

With an orthogonal main effects design, we generated a reduced orthogonal experimental design with 16 different scenarios (=choice cards) (Hensher et al. 2005:115). The choice cards were organised into sixteen choice sets. Using the shifting procedure described by Chrzan and Orme (2000), permutations among the attribute levels of these sixteen choice cards were carried out to generate sixteen additional scenarios. These 16 pairs of alternatives were randomly assigned to four blocks of four choice sets each. Each choice set consisted of two water quality improvement scenarios (A and B) and an opt-out scenario that represents a status quo where no water quality improvement is achieved and the payment is zero (scenario 
C). Each respondent was asked to choose one scenario from each of the four choice sets. Table 2 shows an example of a choice set.

Table 2. Example of choice set

\begin{tabular}{|c|c|c|c|}
\hline Attribute & $\begin{array}{c}\text { Alternative } \\
\text { A }\end{array}$ & $\begin{array}{c}\text { Alternative } \\
\text { B }\end{array}$ & $\begin{array}{c}\text { Alternative C } \\
\text { No improvement }\end{array}$ \\
\hline Pollution risk & $15 \%$ & $20 \%$ & $25 \%$ \\
\hline Threatened species & 15 & 15 & 25 \\
\hline Fisheries yield & $10 \%$ & $25 \%$ & $0 \%$ \\
\hline Payment & CLP 1,000 & CLP 3,000 & CLP 0 \\
\hline
\end{tabular}

\subsection{Influence of social-psychology constructs on respondents WTP}

We investigated social-psychology items on the perceived severity of river pollution for different uses (Severity) and perceived efficacy of water quality policy to improve the current status of river ecosystem services and other river-related services (Response Efficacy). Table 3 shows a description of items included in each social-psychology construct analyzed.

Severity covers the perception of how big or severe the outcome of a risky situation would be if a negative event (river pollution) actually occurs. The Severity construct was operationalized by using eight items that analyzed respondent perceived adequacy of river water quality for local businesses (4 items) and recreational activities (4 items). Thus, we regarded the perceived river water quality for different uses as an indicator of the perceived severity of river pollution. Respondents were asked to score river water quality for each activity by using a five-point Likert scale, from 1 'very bad' to 5 'very good'. Scores closer to one mean a 'very bad' quality of river water quality for a specific activity which is an 
indication of a higher Severity of river pollution. For data analysis, severity-related items were reverse coded to properly convey the Severity concept (5 'very high Severity' to 1 'very low Severity').

If an individual has high Response Efficacy with regard to water quality policies, this means that $\mathrm{s} /$ he is convinced that the measure - if implemented correctly—will actually reduce river pollution in the proposed way and amount. The Response Efficacy construct was operationalized by using nine items. They represented the perceived efficacy of future water quality policies for improving the current status of river ecosystem services (6 items) and other river-related services ( 3 items). Respondents were asked to rate the efficacy of water quality policies by using a closed ordered five-point scale, from 1 'no impact' to 5 'very high impact'. Scores closer to five indicate a higher Response Efficacy for water quality policies.

Table 3. Social-psychology constructs and their items

\begin{tabular}{ll}
\hline Components & Items \\
\hline $\begin{array}{l}\text { Severity of river water quality } \\
\text { for different purposes. }\end{array}$ & $\begin{array}{l}\text { 1: fishery, 2: farming, 3: tourism, 4: industry, 5: } \\
\text { camping, 6: sport fishing, 7: bathing, 8: boating }\end{array}$ \\
\hline $\begin{array}{l}\text { Response Efficacy of water } \\
\text { quality policies for improving }\end{array}$ & $\begin{array}{l}\text { 1: quantity of waterfowl, 2: irrigation water supply, } \\
\text { the current status of river-related } \\
\text { services. }\end{array}$ \\
& $\begin{array}{l}\text { riparian landscape, 6: pollutants reduction, 7: } \\
\text { riparian vegetation, 8: drinking water quality, 9: } \\
\text { local jobs supply }\end{array}$ \\
\hline
\end{tabular}

To test for influences of social-psychology constructs on preferences for water quality improvement attributes, we first conducted a confirmatory factor analysis of the socialpsychology-related items for each component (Gorsuch 1983). In particular, we performed a 
factor analysis with one factor extracted for each social-psychology component with SPSS 18. Factor analysis generated empirical social-psychology dimensions that represented the respective social-psychology construct. To calculate the individual values of the dimensions, we employed only items with a factor loading $>0.4$. We calculated Cronbach's Alpha scores as a measure of reliability (internal consistency) for each dimension. As a rule of thumb, alpha values around and above 0.7 indicate a 'reliable scale' (Spector 1992: 32). Factor analysis was conducted for the pooled sample, the Mataquito subsample and the Itata subsample.

Interaction terms can improve the predictive capacity of CE models, and can be used to test hypotheses about socio-demographic or 'social-psychology' influences on preferences (Barkmann et al. 2007). If a deterministic utility component $U_{i}$ is hypothesized to be a linear function of attribute $X_{i}$ itself plus an interaction term of the attribute $X_{i}$ with an individually varying variable $Y, U_{i}$ can be expressed as

$$
U_{i}\left(X_{i}, Y\right)=\beta_{Y X} * X_{i}^{*} Y+\beta_{X} * X_{i}
$$

with

$\beta_{Y X}:$ utility coefficient of the interaction term.

Thus, interaction terms of the resulting social-psychology and demographic variables with the alternative specific constant (ASC) and with the attribute values were generated and included in model estimation (see section 2.4). We included several socio-demographic variables such as sex, income, education, residence, and river use (Table 4). To reduce collinearity between interaction terms and the non-interacted attribute terms, the social-psychology and demogrpahic variables were 0,1-standardized before multiplication with the attribute. We 
tested the impact of social-psychology variables on respondent choice in two ways: (1) the main effect of each single social-psychology construct and (2) two-way interaction (multiplicative) effect of Severity and Response Efficacy. Moreover, the significance of mean differences between the Mataquito and Itata sites for the demographic variables was estimated (Pearson chi-square and $t$ tests). Missing values at the Income variable (Mataquito: 10 respondents; Itata: 6 respondents) were filled with corresponding averages.

Table 4. Socio-demographic variables studied

\begin{tabular}{ll}
\hline Variable & Definition \\
\hline Age & Respondent age \\
Education & ${\text { Respondent educational level. }{ }^{\mathrm{a}}}_{\text {Income }}$ \\
Mex & Responthly household income. ${ }^{\mathrm{b}}$ \\
Residence & Residence of respondents (1: rural, 0: urban) ${ }^{\mathrm{c}}$ \\
River business & Business related with river (1: Yes, 0: No) \\
River recreation & Recreation in the river (1: Yes, 0: No)
\end{tabular}

a: Education categories: 1 (no formal education); 2 (primary education); 3 (secondary education); 4 (technical education); 5 (university education).

${ }^{\mathrm{b}}$ : Income categories: 1 (CLP 0-160,000); 2 (CLP 160,000-320,000); 3 (CLP 320,000-480,000); 4 (CLP 480,000-640,000); 5 (CLP 640,000-800,000); 6 (CLP 800,000-960,000); 7 (more than CLP 960,000). National monthly minimum income is CLP 160,000 approximately (January, INE 2009).

${ }^{\mathrm{c}}$ : Urban locality: concentrated housing complex with more than 2,000 inhabitants, or between 1,001 and 2,000 inhabitants with more than $50 \%$ of economically active population (INE, 2005).

Based on the Protection Motivation Theory (PMT) framework (Gardner and Stern 1996), we display the respondent choice of strategies in coping with a threat by using a $2 \times 2$ table. Considering the simplified outcome indicators of the threat (Severity) and coping appraisal (Response Efficacy) processes, a respondent chooses the basic statregy s/he will use in coping with river pollution. If a person regards river pollution as minimal and believes that measures to cope with it are not effective, then no coping strategy is needed and the person will not take 
action (no WTP). If an individual appraises river pollution as minimal but perceives that measures to cope with it as effective, the person may be willing to pay for river quality improvements 'just to be sure'. If a person appraises river pollution as considerable and perceives that measures to cope with it as effective, the person will probably take an effective behavior (payment) called 'adaptive coping efforts' (problem focused) in the PMT frame. Finally, if an individual appraises river pollution as considerable and perceives that measures to cope with it as not effective, the person will probably engage in 'maladaptative coping efforts' (emotion focussed) in PMT terms.

\subsection{Administration of the survey}

The face-to-face interview survey was conducted by four trained university students and the first author from February to April 2009. For the survey, we considered households fulfilling two conditions: (1) located in localities downstream from the pulp mills on the Mataquito and Itata rivers, and (2) adjacent to the river along the main roads. According to the National Census of 2002 (INE 2005), the total household number at the Mataquito river site is 883 and 4,001 at the Itata site.

We sampled a minimum of 150 households from each site by a systematic sampling procedure (Babbie 2008:224). First, the sampling ratio was calculated (Mataquito: 0.17; Itata: 0.04) to achieve a total of about 300 observations. Based in the inverse of the sampling ratio, every sixth household at the Mataquito site and every $25^{\text {th }}$ household at the Itata site were chosen for an interview. When we reached a locality, interviewers were given random points of departure. Then, fixed rules on the direction to walk, distance between households (depending on locality size), and the number of interviews to conduct in each sector were 
given. When a selected house had no apparent occupants, the next house was chosen for the interview. From all household members older than eighteen prior to the day of the interview, any household member willing to answer the questionnaire was chosen.

We administered 53 interviews during the pilot study (Mataquito: 21, Itata: 32), and 318 interviews during the main study (Mataquito: 160, Itata: 158). During the main study, 142 contacted households were found to be without occupants, 70 contacted respondents refused to give an interview, and 2 available occupants were younger than 18 . Of all successfully contacted 318 households, and 313 respondents completed the choice task (98\%). On average, an interview took about 45 minutes.

\subsection{Statistical analysis}

From the CE data, we estimated a two-level nested logit (NL) model (Hunt 2000) for each of the Mataquito and Itata samples. With three elemental alternatives, one branch with two alternatives and one branch with a single alternative (degenerated branch) were obtained (cf. Louviere et al. 2000:153). A suitable NL model tree structure was identified, and the corresponding models estimated with NLOGIT 4.0. The inclusive value was set to 1.0 for the degenerated branch (status quo), and the model initiated with starting values obtained from a non-nested NL model (Hensher et al. 2005:530). All scale parameters were normalized at the lowest level (RU1). The vector of utility coefficients was estimated with maximum likelihood estimation procedures. As model statistics, we report the conservative pseudo- $R^{2}$ values in relation to a 'constants only' model. Values between 0.25 and 0.3 correspond to $R^{2}$ values of 0.5 and 0.6 in their ordinary least squares equivalents (Hensher et al. 2005:338). 
The estimated models include an alternative specific constant (ASC). It picks up systematic choice variation between the status quo alternative and the alternatives A and B that cannot be explained by the attributes. The ASC was coded as a dummy variable with value 1 for the generic alternatives $\mathrm{A}$ and $\mathrm{B}$ and 0 for the status quo alternative $\mathrm{C}$.

A set of NL models was generated utilising interaction terms with the ASC and attributes with the social-psychology and socio-demograpahic variables. For this purpose, all interaction terms were introduced into the initial model one at a time. Then all statistically significant interaction terms $(\mathrm{P}>0.05)$ from the single interaction models were introduced into the model. The final 'improved' model was generated by the stepwise exclusion of non-significant interactions terms one-by-one.

NL models utilize the choice data only from respondents who chose at least once a scenario other than the zero payment status quo alternative ('payers', Mataquito 79\%, N: 125; Itata $90 \%, \mathrm{~N}: 138)$. 'Non-payers' respondents have been before excluded from analysis as they essentially did not respond to the choice task (see Chapter 2). Previous analyses had shown that a significant ASC coefficient with a negative sign at the full sample can ocurr in some models. In these cases, positive respondent preferences for improvements of the offered river water quality attributes were severely counterbalanced by a general refusal of the improvement scenarios as such ('status quo bias', Meyerhoff and Liebe 2009). In the 'payers' model, the numerical value of the ASC coefficient was reduced and the coefficient clearly insignificant. In this situation, we opted for presenting scenario analyses based on the subset of 'payers' only. In calculating aggregated scenario WTP values, the non-payers (16\%) are represented as stating zero WTP (see next section). 


\subsection{WTP estimation}

CE results can be used to calculate welfare measures if a status quo scenario is included in the choice set (Bateman et al. 2002). Hence, CEs allow for estimating respondent WTP. Based on the quantification of the utility coefficients in the NL model, a maximum marginal WTP (mWTP) for a marginal (1 unit) attribute level change can be estimated as

$$
m W T P=-\frac{\beta_{X}}{\beta_{c}}
$$

with

$\beta_{x}:$ utility coefficient of any of the environmental attributes and

$\beta_{c}$ : marginal utility of income given by the coefficient of the payment attribute.

mWTP is known as the implicit price. Furthermore, the welfare change generated by an improvement in river water quality was calculated. The change from river water quality level $Q^{0}$ (status quo) to an improved level $Q^{1}$ is calculated as a compensating variation $C V$ (Louviere et al. 2000:340). $C V$ is the amount of money that equates the status quo utility level $\left(U^{0}\right)$ of respondents to the utility level of the improved river water quality level $\left(U^{l}\right)$. In other words, $C V$ can be expressed as a respondent's maximum willingness to pay to achieve a higher river water quality level:

$$
C V\left(Q^{0} \rightarrow Q^{1}\right)=-\frac{1}{\beta_{C}} *\left[U^{1}-U^{0}\right]
$$


To calculate $C V$, we used an optimistic scenario which considered that River pollution risk is reduced to $15 \%$, the number of Threatened species decreases to 15, and Fisheries yield increases $50 \%$. The estimated total aggregated WTP for the scenario change consideres all households in the study area sites that expressed willingness to pay ('payers') for river water quality improvements. They corresponded to 3,585 (90\%) and 694 (79\%) households at the Itata and Mataquito river sites respectively.

\section{$3 \quad$ Results}

\subsection{Descriptive Results}

Respondents were 52 years old on average at both river sites (Table 5). 69\% of Itata respondents were women compared with only $52 \%$ at the Mataquito river site $(p \leq 0.01) .87 \%$ of Mataquito respondents were rural residents but only $36 \%$ of Itata respondents $(p \leq 0.001)$. An important percentage of respondents did not have any formal education (Mataquito: 38\%; Itata: $31 \%$ ). $62 \%$ of the respondent households received less than the monthly national minimum income at both river sites ( USD 264). While $60 \%$ of Mataquito respondents indicated that their occupation (business) was related to the river, only $19 \%$ of Itata respondents stated this business-river relationship $(\mathrm{p} \leq 0.001)$. A low percentage of respondents (Mataquito: 21\%; Itata: 29\%) had conducted recreational activities related to the river in the last two years. 
Table 5. Socio-economic characteristics of respondents

\begin{tabular}{lccc}
\hline Variable & \multicolumn{2}{c}{ Mean } & $\begin{array}{c}\text { Means } \\
\text { difference }\end{array}$ \\
\cline { 2 - 3 } & $\begin{array}{c}\text { Mataquito sample } \\
\text { (N: 159) }\end{array}$ & $\begin{array}{c}\text { Itata sample } \\
\text { (N: 154) }\end{array}$ & \begin{tabular}{c} 
(Palue) \\
\hline Age
\end{tabular} $5^{\text {Education }}$ \\
Income & 2.03 & 51 & 0.586 \\
Sex (male=1) & 165,535 & 2.24 & 0.078 \\
Residence (rural=1) & 0.48 & 175,584 & 0.552 \\
River business $(\mathrm{yes}=1)$ & 0.87 & 0.31 & $0.003^{* *}$ \\
River recreation $(\mathrm{yes}=1)$ & 0.60 & 0.36 & $0.000^{* * *}$ \\
\hline
\end{tabular}

***: significant at $\mathrm{p} \leq 0.001 ; * *$ : significant at $\mathrm{p} \leq 0.01 ; *$ : significant at $\mathrm{p} \leq 0.05$

\subsection{Respondents perceptions on Severity and Response Efficacy items}

In general, most respondents perceived a bad river water quality for conducting different river-related activities (Table 6). We found significant differences on the perceived river water quality for recreation-related activities at the Mataquito and Itata river sites. The Itata respondents perceived a higher severity of river quality for tourism activities than the Mataquito respondents ( $p$-value $\leq 0.001$ ). Specifically, the Itata respondents perceived a higher severity of river quality for sport fishing ( $p$-value $\leq 0.01$ ), bathing ( $p$-value $\leq 0.01$ ), and boating ( $p$-value $\leq 0.001$ ) than the Mataquito respondents. Perceptions on the severity of river quality for fishery and camping showed no differences between river sites. Moreover, a lower percentage of respondents believed that the water quality is bad for farming (Mataquito: 39\%; Itata: 47\%) and industry (Mataquito: 26\%; Itata: 30\%). 
Table 6. Perceived river water quality for different pursposes (= indicator for Severity)

\begin{tabular}{lccc}
\hline Water use & \multicolumn{2}{c}{ Mean } & $\begin{array}{c}\text { Means } \\
\text { difference } \\
\text { (P-value) }\end{array}$ \\
\hline Fisheries & $\begin{array}{c}\text { Mataquito sample } \\
\text { (N: 159) }\end{array}$ & $\begin{array}{c}\text { Itata sample } \\
\text { (N: 154) }\end{array}$ & 0.195 \\
Farming & 3.57 & 3.70 & 0.333 \\
Tourism & 3.12 & 3.23 & $0.001^{* * *}$ \\
Industry & 3.63 & 3.97 & 0.554 \\
Camping & 2.88 & 2.94 & 0.474 \\
Sport fishing & 3.46 & 3.55 & $0.011^{* *}$ \\
Bathing & 3.39 & 3.65 & $0.009^{* *}$ \\
Boating & 3.68 & 3.97 & $0.000^{* * *}$ \\
\hline
\end{tabular}

Most of the respondents perceived that the Response Efficacy for future river water quality policy is high (Table 7). Findings indicated significant differences on the perceived Response Efficacy of river water policy at the Mataquito and Itata river sites. The Itata respondents perceived a higher Response Efficacy of water quality policy for improvements on irrigation water supply ( $p$-value $\leq 0.05$ ), camping sites number ( $p$-value $\leq 0.001)$, riparian landscape ( $p$ value $\leq 0.001$ ), river pollutants reduction ( $p$-value $\leq 0.05$ ), riparian vegetation ( $p$-value $\leq 0.05$ ), and drinking water quality ( $\mathrm{p}$-value $\leq 0.05$ ) than the Mataquito respondents. For the other riverrelated improvements such as waterfowl number, fish quantity, and local job supply statistical diffrerences between the Mataquito and Itata river sites were not found. 
Table 7. Perceived Response Efficacy of river water policies

\begin{tabular}{lccc}
\hline $\begin{array}{l}\text { Improvements on } \\
\text { river quality }\end{array}$ & \multicolumn{2}{c}{ Mean } & $\begin{array}{c}\text { Means } \\
\text { difference } \\
\text { (P-value) }\end{array}$ \\
\cline { 2 - 3 } wataquito sample & $\begin{array}{c}\text { Itata sample } \\
\text { (N: 159) }\end{array}$ & 3.63 & 0.885 \\
irrigation water supply & 3.65 & 3.84 & $0.047^{*}$ \\
fish quantity & 3.62 & 4.03 & 0.672 \\
camping sites number & 4.08 & 4 & $0.000^{* * *}$ \\
riparian landscape & 3.39 & 4.14 & $0.014^{* *}$ \\
pollutants reduction & 3.89 & 4.34 & $0.032^{* *}$ \\
riparian vegetation & 4.15 & 4.14 & $0.018^{*}$ \\
drinking water quality & 3.89 & 4.27 & $0.018^{*}$ \\
local job supply & 3.99 & 4.15 & 0.325 \\
\hline
\end{tabular}

The first factor analysis dimension explained $42 \%$ of factor analysis variance with regard to seven Severity-related items at the Mataquito river site (Table 8). The Severity construct showed at Cronbach's Alpha score of 0.760 and a mean raw score of 3.34 out of 5 . From 8 Response Efficacy-related items, the factor analysis dimension explained $46 \%$ of the factor analysis variance. The camping sites item was excluded from further inclusion in the analysis as its factor loading was lower than 0.4. The Response Efficacy construct showed a Cronbach's Alpha score of 0.812 and a mean raw score of 3.93 out of 5. Moreover, the interaction term Response Efficacy * Severity displayed a mean score of 13.25 (S.D.= 3.55). Loadings of social-psychology-related items are shown in Annex 1.

The factor analysis dimension explained $52 \%$ of the factor analysis variance, based on 7 Severity-related items at the Itata river site (Table 8). The Severity construct showed a Cronbach's Alpha score of 0.842 and a mean raw score of 3.63 out of 5. From 9 Response 
Efficacy-related items, the first factor analysis dimension explained $50 \%$ of the factor analysis variance. The Response Efficacy construct showed a Cronbach's Alpha score of 0.868 and a mean raw score of 4.07 out of 5. A construct with 8 Response Efficacy-related items showed similar results to the 9 Response Efficacy-related items version. Furthermore, the interaction term Response Efficacy * Severity displayed a mean score of 14.78 (S.D.=3.72). There exist a significant means difference ( $p$-value $\leq 0.001$ ) between Mataquito and Itata river sites for Severity and Response Efficacy * Severity constructs. So, Itata respondents perceived more strongly the Severity of river water quality for different purposes. The multiplicative effect of Response Efficacy * Severity on river pollution risk perception is higher at the Itata river site.

Table 8. Factor analysis results

\begin{tabular}{llccc}
\hline Population & Social-psychology construct & $\begin{array}{c}\text { Cronbach's } \\
\text { Alpha }\end{array}$ & $\begin{array}{c}\text { Mean (raw } \\
\text { score) } \pm \text { SD }\end{array}$ & $\begin{array}{c}\text { Means Difference } \\
\text { (P-value) }\end{array}$ \\
\hline Mataquito & $\begin{array}{l}\text { Response Efficacy }(8 \text { items) } \\
\text { Severity }(7 \text { items) }\end{array}$ & 0.812 & $3.93 \pm 0.71$ & 0.076 \\
& $\begin{array}{l}\text { Response Efficacy } \\
\text { (8x7 Severity }\end{array}$ & 0.760 & $3.34 \pm 0.61$ & $0.000 * * *$ \\
\hline Itata & Response Efficacy (9 items) & 0.868 & $4.07 \pm 0.65$ & \\
& $\begin{array}{l}\text { Response Efficacy (8 items) } \\
\text { Severity (7 items) }\end{array}$ & 0.863 & $4.07 \pm 0.67$ & $0.000 * * *$ \\
& $\begin{array}{l}\text { Response Efficacy } * \text { Severity } \\
\text { (8x7 items) }\end{array}$ & 0.842 & $3.63 \pm 0.65$ & $0.000 * * *$ \\
& & $14.78 \pm 3.72$ & $0.000 * * *$ \\
\hline
\end{tabular}

***: significant at $\mathrm{p} \leq 0.001 ; * *$ : significant at $\mathrm{p} \leq 0.01 ; *$ : significant at $\mathrm{p} \leq 0.05$

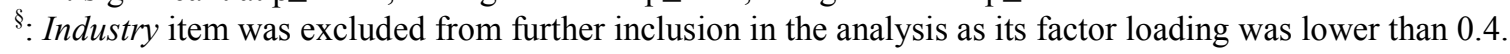

Coping strategies that respondents chose in coping with river pollution are shown in Figure 5. Gray points represent payers while black points represent non-payers. We note that most respondents who rated high scores for the Severity construct also rated high scores for the Response Efficacy construct. These effective behaviours correspond to the so called 'adaptive coping efforts' or 'problem-focused coping efforts' in the protection motivation theory 
framework (Gardener and Stern 1996). It means that the majority of respondents were focused on the reduction of river pollution risk. The second largest group of respondents appraised river pollution as minimal but perceived a high efficacy of water quality policy. So, respondents may likely support a water quality policy 'just to be sure'. In contrast, a few respondents perceived a high severity of river pollution but perceived a low efficacy of water quality policy to cope with river pollution. This behaviour is named 'maladaptive coping efforts' or 'emotion-focused coping efforts'. The lowest response efficacy scores for this group were displayed by non-payers. In addition, only a few respondents perceived a low severity of river pollution and low response efficacy of water quality policy. Consequently, no coping strategy was necessary and the respondent would probably take 'no action'. This group was represented mainly by non-payers.

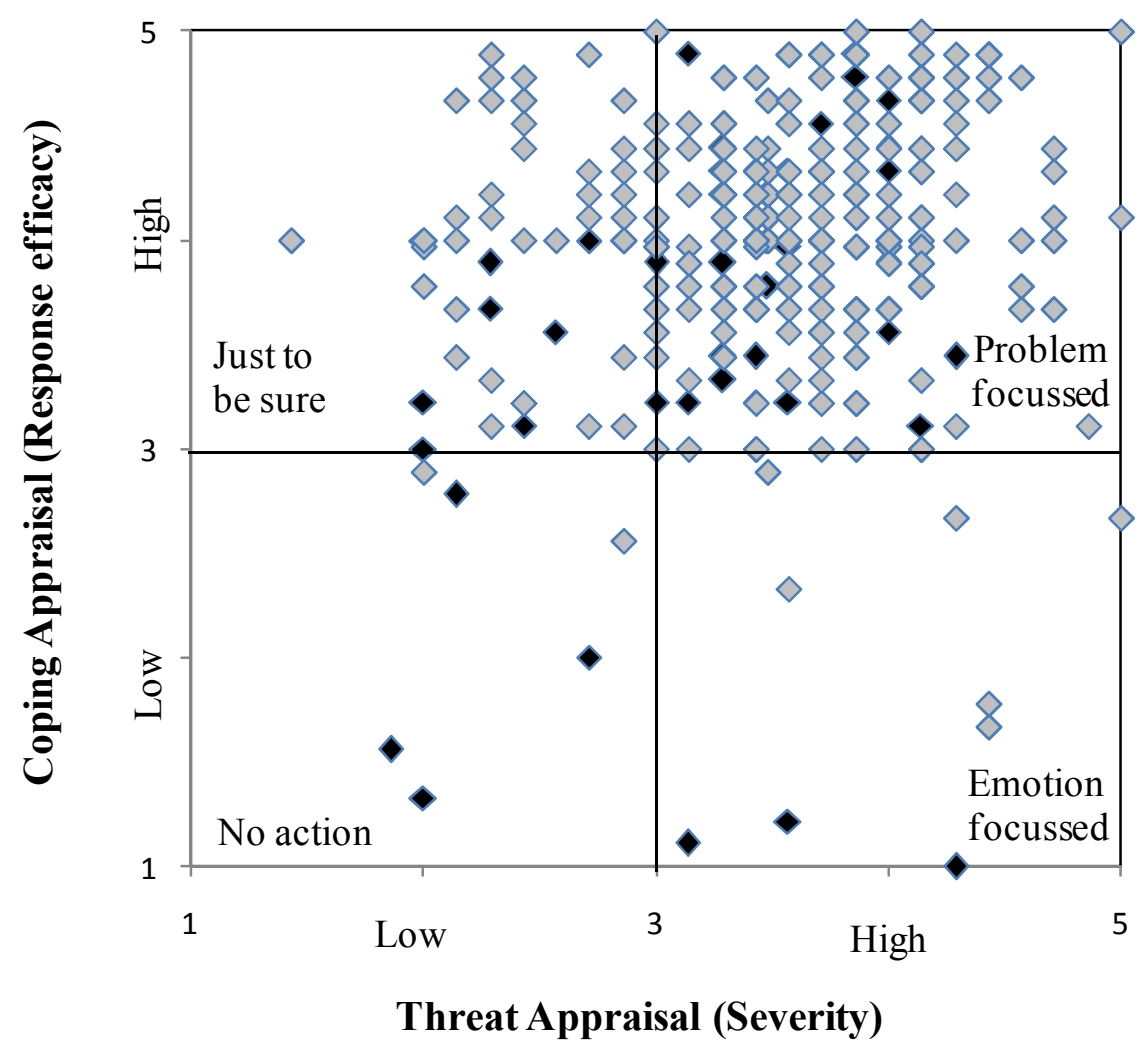

Figure 5. Coping strategies to cope with river pollution (adapted from Gardner and Stern 1996); gray points: payers, black points: non-payers 


\subsection{Choice Experiment results}

Estimated NL models were highly significant overall (Table 9; $\left.P\left(\chi^{2}\right)<0.0001\right)$. All attributes were significant predictors of choice (pseudo $\mathrm{R}^{2}: 0.29$ ) and their coefficients displayed the expected signs. They indicated a disutility for higher river pollution risk, for higher numbers of threatened species, and for higher payment for water quality improvement. Positive utility was derived for higher fishery yields. The non-status quo ASC was not significant in both models.

For the Mataquito model (a), respondents displaying higher scores at the Response Efficacy and Severity constructs had higher preferences for reductions in river pollution risk (River pollution risk * Severity * Response Efficacy). Respondents who displayed higher scores for the Response efficacy construct had higher preferences for reductions in the number of threatened species (Threatened species * Response Efficacy). Respondents who showed lower scores at the Response Efficacy construct displayed a higher disutility of their payments for river water quality improvement (Payment $*$ Response Efficacy). Rural respondents displayed higher preferences for reductions in threatened species number (Threatened species * Residence) and fishery yields increase (Fisheries yield * Residence). Respondents with lower income and education displayed a higher disutility of their payments for river water quality improvement (Payment $*$ Income, Payment $*$ Education $)$.

At the Itata model (b), respondents with above average scores in the Response Efficacy construct displayed higher preferences for reductions in the number of threatened species (Threatened species * Response Efficacy). Those with higher education showed higher preferences for reductions in the number of threatened species (Threatened species * 
Education). Those who related their business with the river showed lower preferences for reductions in the number of threatened species (Threatened species * River business). Respondents with lower income displayed a higher disutility of their payments for river water quality improvement (Payment * Income).

Table 9. Valuation of river water quality improvement in Central Chile

\begin{tabular}{|c|c|c|c|c|}
\hline Variable & (a) Mataquito & P-value & (b) Itata & P-value \\
\hline River pollution risk & $-0.104 * * *$ & 0.000 & $-0.183 * * *$ & 0.000 \\
\hline Threatened species & $-0.137 * * *$ & 0.000 & $-0.157 * * *$ & 0.000 \\
\hline Fisheries yield & $0.023 * * *$ & 0.000 & $0.033 * * *$ & 0.000 \\
\hline Payment ${ }^{\%}$ & $-0.061 * * *$ & 0.000 & $-0.077 * * *$ & 0.000 \\
\hline non Status Quo ASC & 2.994 n.s. & 0.197 & -4.103 n.s. & 0.268 \\
\hline $\begin{array}{l}\text { River pollution risk * (Severity * Response } \\
\text { Efficacy) }\end{array}$ & $-0.038 * *$ & 0.002 & & \\
\hline Threatened species * Response Efficacy & & & $-0.035 * *$ & 0.002 \\
\hline Payment $*$ Response Efficacy & $0.036^{* * *}$ & 0.000 & & \\
\hline Threatened species * Education & & & $-0.065 * * *$ & 0.000 \\
\hline Threatened species $*$ River business & & & $0.022 *$ & 0.028 \\
\hline Threatened species * Residence & $-0.036 * * *$ & 0.000 & & \\
\hline Fisheries yield $*$ Residence & $0.013^{*}$ & 0.034 & & \\
\hline Payment $*$ Income & $0.030 * *$ & 0.002 & $0.025 * * *$ & 0.000 \\
\hline Payment * Education & $0.022 *$ & 0.016 & & \\
\hline Log-likelihood & -270.59 & & -325.33 & \\
\hline $\mathrm{P}\left(\mathrm{Chi}^{2}\right) ; \mathrm{DF}$ & $<0.0001 ; 12$ & & $<0.0001 ; 10$ & \\
\hline IV of non degenerated branch (nonSQ) & -0.554 & & 0.471 & \\
\hline Pseudo-R ${ }^{2}$ (constant only) ${ }^{\S}$ & 0.288 & & 0.287 & \\
\hline Observations & 125 & & 138 & \\
\hline \multicolumn{5}{|c|}{$* * *$ : significant at $\mathrm{p} \leq 0.001 ; * *$ : significant at $\mathrm{p} \leq 0.01 ; *$ : significant at $\mathrm{p} \leq 0.05$} \\
\hline $\begin{array}{l}\text { \%: Payment attribute in hundred Chilean pesos } \\
\S: \text { Pseudo- } \mathrm{R}^{2} \text { (constant only) value of } 0.29 \text { corr }\end{array}$ & $\begin{array}{l}\text { ponds to } \mathrm{R}^{2} \text { value } \\
\text { po significant }\end{array}$ & f 0.6 in an & odel equival & \\
\hline
\end{tabular}

Regarding policy scenario analysis (Table 10), we used model results for a simple stated preference valuation of river water quality improvement at each river site. The marginal mean WTP per household ranged from about 170-238 CLP/yr/1\% reduction in River pollution risk, 
204-225 CLP/yr/1 fewer Threatened species, and 38-43 CLP/yr/1\% of increase in Fisheries yield.

We used an optimistic scenario which considered the reduction of the River pollution risk to 15\%, the number of Threatened species to 15 species, and an increase in Fisheries yield of $50 \%$. We obtained a total mean WTP per household that ranged between $7,811-8,766$ $\mathrm{CLP} / \mathrm{yr}$ for river water quality improvement. Given the diference in the number of residents in the two sites, estimated total aggregated WTP (compensating surplus) for the scenario change differ substantially (Mataquito: 5.42 million CLP/yr; Itata: 31.43 million CLP/yr).

Table 10. Marginal stated preferences (WTP) and exemplary policy scenario calculations

\begin{tabular}{lcc}
\hline & Mataquito & Itata \\
\hline Marginal WTP: & & \\
River pollution risk (1\% less) & 170 & 238 \\
Threatened species (1 fewer) & 225 & 204 \\
Fisheries yield (1\% increase) & 38 & 43 \\
\hline Policy escenario: & & \\
River pollution risk (15\% less) & 2,557 & 3,565 \\
Threatened species (15 fewer) & 3,369 & 3,058 \\
Fisheries yield (50\% increase) & 1,885 & 2,143 \\
\hline Total scenario WTP/household/yr & 7,811 & 8,766 \\
\hline Total aggregated scenario WTP (Mio CLP/yr) & $5.42(\mathrm{~N}: 694)$ & $31.43(\mathrm{~N}: 3,585)$ \\
\hline 1 USD $~ 606$ CLP (February 2009) & &
\end{tabular}

\section{$4 \quad$ Discussion and Conclusions}

We conducted a Choice Experiment (CE) to investigate whether and to what extent socialpsychology-related constructs influence respondent willingness-to-pay for ensuring the implementation of river water improvements potentially mandated by the Chilean state. Moreover, we generated non-market valuation data useful for the discussion on the 
development of Chilean river water policies in the face of environmental threats from paper mills. All water quality attributes as well as the payment attribute turned out to be highly significant predictors of choice. The social-psychology-related constructs displayed a significant impact on respondent preferences. First, we discuss the social-psychology constructs obtained by confirmatory factor analysis. Then, we discuss the main findings of the Choice Experiment application, and draw some overall conclusions.

\subsection{Interpretation of social-psychology constructs}

Cronbach's alpha value for the Severity construct was substantially higher than 0.7 at the Mataquito and Itata river sites. This means that this social-psychology construct represents a consistent latent dimension underlying the single Severity items with satisfactory reliability. Respondents with higher scores for the Severity construct perceived that river pollution is more severe for water uses related to business and recreation. The high mean score (3.34-3.63 out of 5) indicated that respondent perceived Severity of river pollution was substantial at both river sites.

The Response Efficacy construct displayed a Cronbach's alpha value higher than 0.7 at both river sites. Respondents displayed a high mean score (3.93-4.07 out of 5) for the Response Efficacy construct which means that respondents perceived a high efficacy of water quality policies to improve river water quality. Respondents displayed scores above the construct mean score for all Response Efficacy-related items. This indicated that respondents placed similar importance on single items even if they had no direct impact on respondent wellbeing (non-use value). Specifically, the camping sites item was excluded from the constructed factor (factor load < 0.4) at the Mataquito site. Given that only about a quarter of respondents 
(Mataquito: 21\%; Itata:29\%) use the river for recreation, the exclusion also appears justified form a material point of view. Usually, the differences of respondent perceptions across sampling sites were low. In all, we regarded the Response Efficacy construct as more reliable than the Severity construct.

\subsection{Interpretation of Choice Experiment results}

It is highly likely that 'problem focused' respondents display stronger preferences for reductions in river pollution risk (River pollution risk * [Severity * Response Efficacy]), specially at the Mataquito river site (see Table 9). As Figure 5 shows, these respondents simultaneously had the highest scores for the Severity and Response Efficacy constructs. This indicates that threat appraisal and coping appraisal processes were complementary in influencing respondent behavioral intention (WTP) and action (choice) for reducing river pollution risk.

Most of the surveyed German residents who perceived a high threat from the loss of biodiversity in developing countries also perceived a high efficacy of coping measures in a CE valuation (Menzel and Scarpa 2005). Those 'problem focused' respondents displayed a higher willingness to pay for biodiversity conservation. Nevertheless, Menzel and Scarpa did not analyze the influence of interaction effects between threat and coping appraisal on behavioral intentions. In line with our results, Mulilis and Lippa (1990) found significant influences of threat and coping appraisal items on the earthquake preparedness of respondents. Several studies demonstrated the influence of perceived severity of environmental risks on behavioral intentions to improve a problematic current situation (Forsyth et al. 2004, Barkmann et al. 2008, Cerda et al. 2006). More clearly that previously 
shown, our findings indicate that Severity had a significant influence on WTP only in interaction with Response Efficacy.

Respondents who perceive a lower efficacy of the current Chilean water quality policy showed a higher disutility of their payments for river water quality improvement (Payment * Response Efficacy) at the Matquito river site. It means that respondents who are uncertain or distrust the efficacy of measures to cope with river pollution were likely to be willing to pay less to improve conditions of river water quality through additional water quality regulations. Nevertheless, we stress that a low perceived efficacy of water policy represents just a small group of respondents (see Fig 5). Barkmann et al. (2008) found that respondents with higher perceived Response Efficacy of government showed a higher disutility of payments for the provision of functional ecosystem services in Central Sulawesi (Indonesia). This difference may rest in the way that Response Efficacy was operationalized. While Barkmann et al. (2008) asked about the efficacy of government in implementing a coping measure we asked directly about the efficacy of the measure without assessing the efficacy of the government in implementing such water quality policy. Nevertheless, we regarded the perceived efficacy of government as a crucial component for the successful implementation of a water quality policy.

Respondents who perceived a higher efficacy of water quality policy for coping with river pollution were more likely to be willing to pay for reductions in the number of threatened species at the Itata River site (Threatened species * Response Efficacy). The perceived efficacy of measures to improve river water quality persuaded people to protect endangered species even if the proposed measures were not applied by themselves. In this regard, we 
stress the importance of reliance on governmental institutions as, in the end, they will implement the water quality policies.

Previous studies found similar influences of Response Efficacy on behavioral intentions to cope with environmental threats. Lam (2006) found that respondents who perceived a high effectiveness of measures for saving water were more willing to take action for protecting water resources. Farm workers who judged safety precautions more effective were less likely to have frequent fear of exposure to environmental chemical agents (Vaughan 1993). Moreover, farmer perception of Response Efficacy of soil conservation measures influenced the WTP for the future adoption of such measures in Central Chile (Huenchuleo et al. 2011a).

In addition, we found a significant influence of socio-demographic variables on respondent willingness-to-pay for river water quality improvements at the Mataquito and Itata river sites. Respondents with higher education were more likely to be willing to pay more for reductions in the number of Threatened species at the Itata river site. Those of lower education displayed higher disutility of their Payments at the Mataquito river site. Respondents of lower income displayed higher disutility of their Payments at both river sites. Household income was the only predictor that had a significant influence on WTP at both river sites. Income and education variables are significant determinants of preferences for river water quality improvements also in other stated preferences studies (Álvarez-Farizo et al. 2007, Morrison and Bennett 2004).

In particular, rural Mataquito respondents were on averge willing to pay more for reductions in the number of Threatened species and increases in Fishery yields. Most of the respondents at the Mataquito river site were rural residents (87\%). As they rely substantially on natural 
resources for their livelihood, they are willing to pay more for protecting river water quality. At the Itata site, those whose businesses are related to the river were likely to be willing to pay less for reductions in the number of Threatened species. These respondents may see certain barriers to their business through implementing more restrictive water quality policies such as additional investment in water treatment.

In sum, we found that social-psychology-related items greatly influence WTP for reducing river pollution through improving the regulative and monitoring capacity of government agencies with respect to potential more stringent water quality regulations with the resulting improvement of river water quality. Compared to models on the influence of attitudinal variables on WTP (Chapter 3 of this thesis), the prediction capacity of the models improved slightly. Thus, our findings suggest that more studies in this direction should be carried out. Moreover, social-psychology theories offer a variety of other potential constructs that may be considered in the analyses of behavioral intention.

The last section of the study included a stated preference valuation of river water quality improvement. Considering that $62 \%$ of the households earned less than the national minimum income ( USD 264/month) valuation scenarios are likely to capture a considerable share of total WTP for river water quality improvement. Moreover, WTP values were also substantial if we consider that a relative low share of respondents (Mataquito: 21\%; Itata: 29\%) carries out recreational activities in the river environment. Moreover, only $19 \%$ of Itata respondents related their business to the river.

Our welfare measures estimation suggested that river water quality policy design processes in Chile should include information on the benefits of water quality protection derived from 
river-based ecosystem services. Some studies have already indicated the substantial lack of data on the non-use and indirect use value of water quality attributes as a restriction in applied cost-benefit analyses prepared for legislative purposes in Chile (CONAMA 2006; EULA 2006; Zenteno et al. 2009). Hence, the necessity of more studies that consistently include nonmarket valuation of river water quality improvement still remains.

\section{References}

Álvarez-Farizo B, Hanley N, Barberán R, Lázaro A (2007) Choice modeling at the "market stall": Individual versus collective interest in environmental valuation. Ecological Economics 60: 743-751.

Araya I, Quiñones R, Dresdner J, Barriga O, Carrasco P, Campos N, Leiva M, Hernandez A, Ponce R, Rivas R (2006) Diagnóstico social, económico y productivo de las comunidades de pescadores artesanales de la desembocadura del Itata y zonas adyacentes, entre Cobquecura y Dichato. Programa de Estudios Económicos y Sociales del Sector Pesquero, Universidad de Concepción, Chile.

Babbie EA (2008) The basics of social research, Fourth Edition. Thomson Learning, Inc. USA.

Barkmann J, Glenk K, Handi H, Sundawati L, Witte JP, Marggraf R (2007) Assessing economic preferences for biological diversity and ecosystem services at the Central Sulawesi rainforest margin - a choice experiment approach. In: Tscharntke T., Leuschner C., Zeller M., Guhardja E., Bidin A. (eds), The stability of tropical rainforest margins , linking ecological, economic, and social constraints of land use and conservation, Springer Berlin 2007, pp 181-208.

Barkmann J, Glenk K, Keil A, Leemhuis C, Dietrich N, Gerold G, Marggraf R (2008) Confronting unfamiliarity with ecosystem functions: The case for an ecosystem service approach to environmental valuation with stated preference methods. Ecological Economics 5: 48-62.

Bateman I, Carson T, Day B, Hanemann M, Hanley N, Hett T, Jones-Lee M, Loomes G, Mourato S, Özdemiroglu E, Pearce D, Sugden R, Swanson J (2002) Economic valuation 
with stated preferences techniques: a manual, Edward Elgar, Cheltenham, UK and Northampton, MA, USA.

Bateman IJ, Cole MA, Georgiou S, Hadley DJ (2006) Comparing contingent valuation and contingent ranking: A case study considering the benefits of urban river water quality improvements. Journal of Environmental Management 79: 221-231.

Bioma (2008) Consultoría para la recopilación de información sobre la biodiversidad en apoyo a la elaboración del anteproyecto de norma secundaria de calidad ambiental para la protección de las aguas de la cuenca del Mataquito. Bioma BGA Consultores.

Block LG and Keller PA (1998) Beyond Protection Motivation: An Integrative Theory of Health Appeals. Journal of Applied Social Psychology 28: 1584-1608.

Burns AC (1992) The Expanded Health Belief Model as a Basis for Enlightened Preventive Health Care Practice and Research. Journal of Health Care Marketing 12: 32-45.

Cade-Idepe Consultores en Ingeniería (2004a) Diagnóstico y clasificación de los cursos y cuerpos de agua según objetivos de calidad - cuenca río Mataquito. Dirección General de Aguas, Ministerio de Obras Públicas, Chile. http://www.sinia.cl/1292/articles31018_Mataquito.pdf. Accessed 26 June 2008

Cade-Idepe Consultores en Ingeniería (2004b) Diagnóstico y clasificación de los cursos y cuerpos de agua según objetivos de calidad - cuenca río Itata. Dirección General de Aguas, Ministerio de Obras Públicas, Chile. http://www.sinia.cl/1292/articles31018_Itata.pdf. Accessed 26 June 2008

Cerda C (2006) Valuing biological diversity in Navarino Island, Cape Horn Archipielago, Chile - a choice experiment approach. Doctoral dissertation, Institute of Agricultural Economics, Georg-August-Universität Göttingen.

Chrzan K, Orme B (2000) An overview and comparison of design strategies for choice-based conjoint analysis. Sawtooth Software 2000-2002, Research paper series.

CONAF (1993) Libro rojo de los vertebrados terrestres de Chile. Corporación Nacional Forestal - CONAF, Ministerio de Agricultura de Chile. Santiago, Segunda Edición. CONAMA (2006) Análisis económico y social de la norma de calidad secundaria para la protección de las aguas continentales superficiales en la cuenca del río Maipo. Región Metropolitana de Santiago.

CONAMA-SINIA (2008) Información geográfica territorial regional. Sistema Nacional de Información Ambiental Territorial (SINIA), Ministerio del Medio Ambiente, Chile. http://territorial.sinia.cl/portal/descargas.php. Accessed 30 September 2010 
Espinosa C (2001) Evaluación de los impactos de la producción de celulosa. Análisis de Políticas Públicas No 4, Publicaciones Terram.

EULA (2006) Análisis general del impacto económico de la norma secundaria de calidad de aguas en la cuenca del río Bio-Bio, en el sector silvoagropecuario. Universidad de Concepción.

Forsyth DR, Garcia M, Zyzniewski LE, Story PA, Kerr NA (2004) Watershed pollution and preservation: the awareness - appraisal model of environmentally positive intentions and behaviours. Analyses of Social Issues and Public Policy 4, 1, 115-128.

Gardner GT, Stern PC (1996) Environmental problems and human behaviour. Allyn and Bacon, Boston.

Gorsuch RL (1983) Factor Analysis, second edition. Lawrence Erlbaum Associates Inc. New Jersey, U.S.A.

Habit E, Dyer B, Vila I (2006) Estado de conocimiento de los peces dulceacuícolas de Chile. Gayana 70, 1: 100-113.

Hanley N, Colombo S, Tinch D, Black A, Aftab A (2006a) Estimating the benefits of water quality improvements under the Water Framework Directive: are benefits transferable?. European Review of Agricultural Economics 33, 3: 391-413.

Hanley N, Wright RE, Alvarez-Farizo B (2006b) Estimating the economic value of improvements in river ecology using choice experiments: an application to the water framework directive. Journal of Environmental Management 78: 183-193.

Hensher DA, Rose JM, Greene WH (2005) Applied choice analysis: a primer. Cambridge University Press, Cambridge (UK).

Huenchuleo C, Barkmann J, Villalobos P (2011a) Social psychology predictors for the adoption of soil conservation measures in Central Chile. Land Degradation and Development, accepted.

Huenchuleo C, Barkmann J, Marggraf R (2011b) Economic valuation of river-based ecosystem services subject to fairness considerations in Central Chile using a Choice Experiment. Chapter 2 of this thesis, formatted for submission to Regional Environmental Change.

Hunt GL (2000) Alternative Nested Logit Model Structures and the Special Case of Partial Degeneracy. Journal of Regional Science 40, 1: 89-113. 
INE (2005) Chile: Ciudades, Pueblos, Aldeas y Caseríos. Censo 2002, Instituto Nacional de Estadísticas - INE, Chile. http://www.ine.cl/canales/chile estadistico/ demografia_y_vitales/demografia/demografia.php. Accessed 20 April 2008

INE (2009) Censo Agropecuario 2007. http://www.censoagropecuario.cl/. Accessed 5 May 2008.

Janz NK and Becker MH (1984) The Health Belief Model: A Decade Later. Health Education and Behavior 11: 1-47.

Jayanti RK and Burns AC (1998) The Antecedents of Preventive Health Care Behavior: An Empirical Study. Journal of the Academy of Marketing Science 26: 6-15.

Kantola SJ, Syme GJ, Nesdale AR (1983) The effects of appraised severity and efficacy in promoting water conservation: an informational analysis. Journal of Applied Social Psychology 13, 2, 164-182.

Lam SP (2006) Predicting intention to save water: theory of planned behaviour, response efficacy, vulnerability, and perceived efficiency of alternative solutions. Journal of Applied Social Psychology 36, 11, 2803-2824.

Louviere J, Hensher D, Swait J (2000) Stated Choice Methods - Analysis and Application. Cambridge University Press, Cambridge (UK).

Menzel S, Scarpa R (2005) Protection Motivation theory and Contingent Valuation: perceived realism, threat and WTP estimates for biodiversity protection. Fondazione Eni Enrico Mattei, working paper 26. http://www.feem.it/userfiles/attach/Publication/NDL2005/ NDL2005-026.pdf. Accessed at 08.10.2007

Meyerhoff J, Liebe U (2009) Status Quo Effect in Choice Experiments: Empirical Evidence on Attitudes and Choice Task Complexity. Land Economics 85, 3: 515-528.

Morrison M, Bennett J (2004) Valuing New South Wales rivers for use in benefit transfer. The Australian Journal of Agricultural and Resource Economics 48, 4: 591-611.

Mulilis JP, Lippa R (1990) Behavior change in earthquake preparedness due to negative threat appeals: a test of Protection Motivation theory. Journal of Applied Social Psychology 20, $8,619-683$.

OCDE-CEPAL (2005) Evaluaciones del desempeño ambiental - Chile. Organización de Cooperación y Desarrollo Económicos - Comisión Económica para América Latina y el Caribe. Ed. Naciones Unidas, CEPAL.

Orrego R, Burgos A, Moraga-Cid G, Inzunza B, Gonzalez M, Valenzuela A, Barra R, Gavilán J (2006) Effects of pulp and paper mill discharges on caged Rainbow Trout 
(Oncorhynchus mykiss): Biomarker responses along a pollution gradient in the Bio-Bio river, Chile. Environmental Toxicology and Chemistry 25, 9: 2280-2287.

Rogers RW, Prentice-Dunn S (1997) Protection Motivation Theory, in: Gochman, D.S.:

Handbook of Health Behavior Research I: Personal and Social Determinants, Plenum Press, New York: 113-132.

SERNAPESCA (2007a) Valorización Desembarque Regional Años 2005 - 2006, Región del

Maule. Servicio Nacional de Pesca, Chile. http://www.sernapesca.cl/index.php?option= com_remository\&Itemid $=246 \&$ func $=$ fileinfo\&id=1957. Accessed 1 May 2008

SERNAPESCA (2007b) Concesiones de Acuicultura. Estuarios propuestos como Areas Apropiadas en la Región del Maule. Servicio Nacional de Pesca, Chile.

http://www.sernapesca.cl/index.php?option=com_content\&task=view\&id=498\&Itemid= 686. Accessed 1 May 2008

SISS (2009) Cumplimiento de normas de descargas de Residuos Líquidos, DS 90/00

Descarga a cuerpos de agua superficiales, años 2006-2007-2008. Superintendencia de Servicios Sanitarios - SISS, Chile. http://www.siss.cl/propertyvalue-2309.html. Accessed 25 January 2009

SISS (2008) Informe de Gestión Sector Sanitario 2007. Superintendencia de Servicios

Sanitarios, Chile. http://www.siss.cl/articles-6245_informegestion.pdf. Accessed 30 March 2008

Spector PE (1992) Summated Rating Scale Construction: An Introduction. Sage University

Papers Series. Quantitative Applications in the Social Sciences, No. 07-082, Sage Publications, Inc. UK.

Vasconi P (2006) CELCO el caso de la planta Valdivia. Análisis de Políticas Públicas 36, Publicaciones Fundación Terram, Chile.

Vaughan E (1993) Chronic exposure to an environmental hazard: risk perceptions and selfprotective behavior. Health Psychology 12, 1, 74-85.

Vergara A, Encina F et al (2008) Informe Final - Evaluación Ambiental en el río Mataquito.

Facultad de Ingeniería - Facultad de Recursos Naturales, Universidad Católica de

Temuco. http://www.cutchile.cl/paloma/04\%20articles-44336

InformeFinalRioMataquito.pdf. Accessed 15 January 2009

Zenteno P, López A, Mardones C, Montoya F (2009) Análisis de impacto económico y social de anteproyecto de normas secundarias de calidad - cuenca río Mataquito. DSS 
Ambiente. Ministerio de Obras Públicas, Chile.

http://www.dga.cl/otros/SAD/CQA5072.pdf. Accessed 01 June 2010 


\section{Annex}

Annex 1. Factor loadings of social-psychology-related items

\begin{tabular}{llcc}
\hline \multirow{2}{*}{$\begin{array}{l}\text { Social-psychology } \\
\text { constructs }\end{array}$} & Items & \multicolumn{2}{c}{ Factor loading } \\
\cline { 3 - 4 } & & Mataquito & Itata \\
\hline Response Efficacy & water birds & 0.461 & 0.548 \\
& irrigation water & 0.591 & 0.670 \\
& fish & 0.719 & 0.772 \\
& camping sites & 0.281 & 0.756 \\
& riparian landscape & 0.767 & 0.683 \\
& pollutants reduction & 0.758 & 0.785 \\
& riparian vegetation & 0.742 & 0.777 \\
& drinking water & 0.677 & 0.665 \\
& job supply & 0.653 & 0.661 \\
\hline Severity & fishery & 0.676 & 0.735 \\
& agriculture & 0.594 & 0.734 \\
& tourism & 0.653 & 0.817 \\
& industry & 0.375 & 0.269 \\
& camping & 0.566 & 0.716 \\
& sport fishing & 0.755 & 0.745 \\
& bathing & 0.799 & 0.773 \\
& boating & 0.407 & 0.505 \\
\hline
\end{tabular}




\title{
Chapter 5
}

\section{A matter of Coase: Influence of property right beliefs on Willingness-to-Pay for river water quality in absence of transaction costs}

\author{
Carlos Huenchuleo Pedreros, Jan Barkmann, Rainer Marggraf
}

\begin{abstract}
This study is designed to test if a different framing of a stated preference valuation exercise in terms of the environmental property rights distribution has an impact on stated demand for environmental quality improvements. Specifically, we use a contingent valuation question to investigate preferences for improvements of river water and ecosystem quality downstream the pulp mills of the Mataquito and Itata rivers in Cental Chile. For an effective zero-transaction cost setting such as provided by a stated preference study, we argue that the Coase Theorem would predict that the framing differences should not matter. We asked respondents for their maximum WTP for river quality improvements (i) via payments to the Chilean state to enforce the compliance of the pulp mill with more restrictive water quality policies ('Industry pays') or (ii) via direct payments to the pulp mills as a compensation to reduce their wastewater discharges into the river ('Citizens pay'). A much higher proportion of respondents were willing to pay under the 'Industry pays' frame (79\%) compared to the 'Citizens pay' frame (19\%). Mean maximum WTP under the 'Industry pays' frame was significantly higher than under the 'Citizens pay' frame. Respondents who felt more strongly that it was 'unfair' to pay industry directly were less likely to be willing to pay for river water quality improvements under both frames. Respondents who believed more strongly that a good river water quality is their personal right, had a higher WTP to bring about improvements under the 'Industry pays' frame. Respondents who tended not to 'have a
\end{abstract}


problem' with paying industry were more willing to pay under the 'Citizens pay' frame. In sum, respondents more strongly support the 'Industry pays' frame as the principle on which to base environmental legislation even though a free-market stance prevails in Chilean political discourse. The substantial difference in stated preferences depending on the selected property rights frame argue against the direct applicability of central implications of the Coase Theorem to applied environmental management.

Keywords: river water quality, contingent valuation, willingness-to-pay, Coase Theorem

\section{Introduction}

It is one of the central objectives of environmental economics to identify the social optimum level of environmental externalities (Grafton et al. 2004), and to devise mechanisms how such optimum levels can be attained (Perman et al. 1996). For example, government regulations on river water pollution should be informed by knowledge on the marginal costs of water quality improvements as well as on the marginal willingness-to-pay (WTP) for such improvements (O'Shea 2002). If the environmental externality at hand affects non-market ecosystem services, stated preference methods may have to be applied (Barkmann et al. 2008, O'Shea 2002). For textbook cases, the optimum level of river water pollution is defined where marginal WTP to avoid pollution damages equates marginal cost of the implementation of respectively improved or reduced production (cf. Perman et al. 1996: 218). Under certain idealised conditions, such an optimum level of an environmental externality can be achieved without government intervention. According to the work of Coase, private bargaining processes can identify and attain the optimum levels (Coase 1960). 
If state interventions are, nevertheless, deemed as useful in a specific case of environmental pollution, administrations may wish to quantify citizen demand for environmental improvements using state of the art methods of environmental valuation. Although there is continuing debate on the suitability of stated preference methods for the valuation of biological diversity and indirect use ecosystem services (e.g., Nunes and van der Bergh 2001), many stated preference academics and practitioners regard it as sufficiently reliable (Barkmann et al. 2008, Martín-López et al. 2008). Environmental valuation based on these methods should ideally identify the same optimum point as would be attained by a private bargaining process.

Consider a case in which a representative citizen survey is used to quantify the social demand curve for an environmental quality dimension, e.g. river water and river ecosystem quality (for short: river quality). Compared to an actual bargaining process, such a representative survey can substantially reduce the transaction cost on part of negatively affected citizens who wish to enter into a bargaining process with industry. In fact, stated preference studies present survey respondents with a "frame" of the valuation exercise that regularly mimics a central aspect of the situation in which citizens bargaining with industry find themselves: The citizens have to express their willingness-to-pay for an environmental improvement necessitated by someone else (Sivasakthi et al. 2010, Baskaran et al. 2009, Sangkapitux et al. 2009). It has been argued, however, that such a frame introduces a controversial normative element: The frame implicitly presupposes that industry has the right to pollute the river, and that citizens need to buy out industry pollution rights. It has been shown that disagreement on part of survey respondents with the property rights implications of a stated preference exercise can increase protest responses or may even lead to a refusal of respondents to finish the valuation interview (Jorgensen et al. 2001). 
According to the Coase Theorem, the initial distribution of property rights among the different groups of actors does not affect the optimal level of environmental quality. In the case of river water pollution brought about by a certain industry, the location of the optimum should consequently not depend on whether industry has a "right to pollute" or whether citizens have a right to an uncompromised level of environmental quality (cf. Perman et al. 1996). Studies investigating the empirical implications of the Coase Theorem are very scarce, however (e.g.: Hanley and Sumner 1995, Birner and Mappatoba 2002). Particularly, there is no direct evidence showing that the initial property rights distribution is irrelevant with respect to the 'identification' of the optimal level of environmental quality in cases of applied environmental policy. In fact, an accumulating body of evidence in the stated preference literature suggests that citizen stakeholders hold strong beliefs on the 'fairness' of the distribution of environmental property rights (Jorgensen et al. 2001, Jorgensen et al. 1999). As far as these fairness considerations impact citizen willingess-to-pay for an environmental improvement, these results cast doubt on the applicability of central implications of the Coase Theorem.

Against the background sketched above, this study is designed to test the extent to which a different framing of a stated preference valuation exercise in terms of the environmental property rights distribution impacts stated demand (i.e., willingness-to-pay: WTP) for environmental quality improvements. Specifically, we use a contingent valuation (CV) question to investigate preferences for improvements of river water quality downstream the pulp mills of the Mataquito and Itata rivers in Cental Chile. In doing so, we do not only contribute to the valuation of selected aspects of river water and river ecosystem quality and evaluate the impact of property rights beliefs on stated preferences, we also test central implications of the Coase Theorem with respect to applied environmental policy. 
In the following background section, we introduce the study area in Central Chile, and explain relevant aspects of Chilean environmental law (2.1). We also review empirical results on the economic valuation of water quality using contingent valuation surveys (2.2), and expand on the applicability of the Coase Theorem and on the impact of property rights related fairness beliefs on WTP (2.3). We do so by presenting a model of such impacts that formally relates the results of contingent valuation with the implications of the Coase Theorem. In the methods section, we present the general CV design (section 3.1) as well as the operationalisation of two alternative institutional frames with contrasting environmental property rights structures. Furthermore, we explain attitude and belief items used to investigate the main results in more detail (3.2). Statistical analysis details (3.3) and details of the survey administration are provided (3.4). Section 4 presents the results of the CV application including an explorative cluster analysis of different respondent groups based on the attitude and belief items. The final section 5 discusses our main findings, and presents some conclusions.

\section{Background}

\subsection{Chilean environmental law and study area}

In Chile, the institutional framework of environmental policy is - despite several middle-left governments up to 2009 - characterized by a pronounced free-market stance (Bamrud 2011). Under these circumstances, it is unclear if citizens favor industry contributions (Industry pays) or direct contributions by the affected population (Citizens pay) to improve environmental quality. Also the intermediate position of Chile from an environmental Kusnetz curve perspective (e.g., see Stern, 2004) may argue for a restricted social willingness 
to burden industry with more stringent environmental regulation. In effect, even the population affected by industrial pollution may agree to a Citizens pay principle to legislation on river water and ecosystem quality. If this is actually the case, is an empirically open issue, however.

To test the influence of beliefs on a 'just' assignment of environmental property rights, we use data from a CV study on river quality in Chile. Although significant improvements have been achieved in past years, river quality in Chile is still poor in several places (OCDE-CEPAL 2005). In particular, the negative effect of pulp mill wastewater has received substantial attention (Vasconi 2006; Espinosa 2001). Despite efforts to reduce wastewater toxicity, the river environments downstream pulp mills are considered as severely compromised (Vasconi 2006, Orrego et al. 2006).

One example is the water quality downstream the pulp mills of the Mataquito and Itata rivers in Central Chile. Apart from the pulp mills, the main economic activities in the area are agriculture, local fisheries at the estuary, and forestry with plantations of exotic Pinus radiata (Monterrey Pine) that supply wood to the pulp mills (INE 2009). Pulp mill waste water violating national environmental quality standards has damaged Mataquito river ecology in the recent past (SISS 2008, Vergara and Encina 2008). While reports indicate positive chemical water quality parameters (Cade-Idepe 2004a/b), a major share of fish populations is regarded as threatened (Habit et al. 2006). Likewise, local fishermen at the Itata estuary see the pulp mill upstream as a major threat to their business and livelihood (Araya et al. 2006:298). Also, ecological studies indicate that the biological status of the river ecosystems is severely compromised (Habit et al. 2006; Bioma 2008). 
The study area is located at downstream sections of the Mataquito and Itata river watersheds in the VII Maule region and the VIII Bío-Bío region of Central Chile (figure 1). The

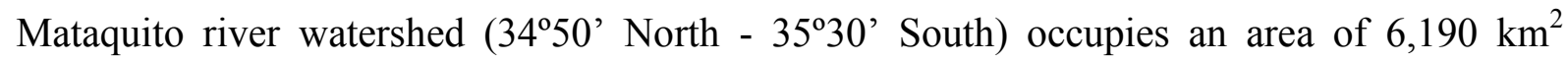

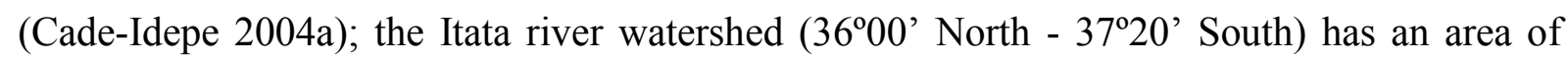
$11,294 \mathrm{~km}^{2}$ (Cade-Idepe 2004b). The pulp mill on the Mataquito river is located in Licantén $30 \mathrm{~km}$ upstream the estuary. At the Itata river, the pulp mill is located $50 \mathrm{~km}$ upstream the estuary at Ranquil.

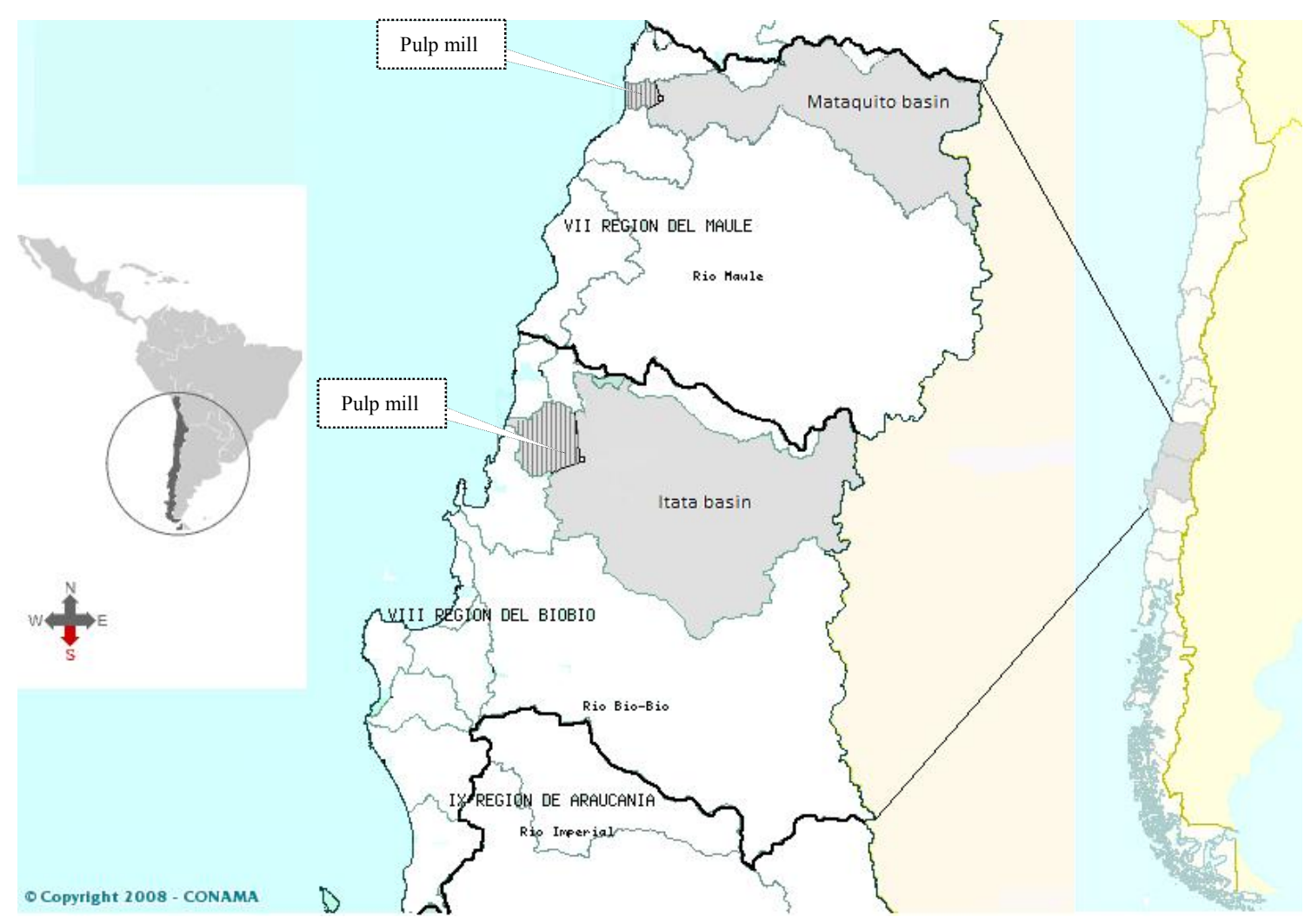

Figure 1. Location of the study area (adapted from CONAMA-SINIA 2008); actual study area hatched 


\subsection{Contingent Valuation of river water quality}

The CV method is based on quantifying individual preferences in monetary terms for changes in the quantity or quality of a non-market good or service (Bateman et al., 2002). The change is described in terms of the impact of a hypothetical policy or project. In micro-economic terms, CV measures the compensating variation for a change in the good or service in question. Compensating variation is defined as the amount that must be taken away from a person's income after an improvement in the environmental good or service has taken place in order to keep his/her total utility constant (Marggraf and Streeb, 1997).

The CV method has been applied to the valuation of river quality improvements for more than two decades (Desvousges et al. 1987; Carson and Mitchell 1993, Le Goffe 1995). Among others, health aspects (concentration of faecal coliform bacteria: Barton 2002) as well as ecological aspects (species diversity: Cooper et al. 2004; reductions of eutrophication: Atkins and Burdon 2006) have been addressed. In all reviewed studies, respondents stated substantial preferences for river quality improvements. As with other CV studies, the format of the valuation question can impact stated WTP (see e.g. Desvousges et al. 1987).

In spite of the relative abundance of stated preference studies on non-market aspects of water quality, none of the reviewed studies was conducted in Chile. Consequently, the acute lack of data on the non-use and indirect use value of river quality attributes is frequently mentioned as a restriction in applied cost-benefit analyses prepared for legislation purposes in Chile (CONAMA 2006; EULA 2006; Zenteno et al. 2009). 
We found few real applications of the Coase Theorem in the literature. Hanley and Sumner (1995) investigated the applicability of the Coase Theorem on external effects of red deer in the Scottish Highlands. Few private deals between sheep grazers and land owners were struck. Later on, the government intervention removed the bases for further bargaining solutions. The transaction costs of bargaining may have been substantial, even though few parties were involved. It was quite difficult, for example, to value deer damages to the forest accurately due to monitoring problems and due to uncertainty on the physical effects of damage on eventual tree growth. Finally, under zero liability rules, some sufferers of more deer (such as sheep grazers) may have not enough income to compensate land owners 'farming' free-ranging deer. Also, in this case, there is an incentive to free ride amongst the damaged people, since a reduction in deer grazing will be a non-excludable benefit to all sheep grazers. Hanley and Sumner (1995) concluded that the availability of government intervention and the possibly large transaction cost of bargaining may explain the apparent lack of bargaining.

Birner and Mappatoba (2002) suggested that the implementation of community conservation agreements (CCAs) at the Indonesian forest margin may be considered as a Coase solution to an externality problem. They investigated CCAs between local communities and state agencies concerned with the management of forest resources. They found that not all community agreements can be considered as the result of bargaining processes typical for Coase-type solutions. Specifically, NGOs played an essential mediating role that appeared to have a stronger effect on the content of the CCAs than strategic negotiation between the immediately affected parties. Birner and Mappatoba (2002) concluded that the Coase Theorem is not a sufficient analytical frame to capture all relevant aspects of the negotiation of CCAs. 
Relatively few studies highlight the importance of the influence of property rights related fairness beliefs on WTP. Respondents who believe that is 'unfair' that they have to pay for an environmental improvement tended to display a lower WTP for the respective improvements (Jorgensen et al., 1999-2001). Moreover, their findings suggest that respondents may believe that they have a (moral, property or other legal) 'right' to a good environmental quality. The extent of such a belief tends to reduce respondent WTP in stated preference studies.

\subsection{A formal hypothesis for testing the implications of the Coase Theorem}

In this subsection, we develop a formal model that allows for testing hypotheses on some implications of the Coase Theorem. The Coase Theorem claims that if trade in an externality is possible and if there are no transaction costs, bargaining between the affected parties will lead to an efficient outcome regardless of the initial allocation of property rights (Coase 1960). Specifically, we wish to test if it is realistic to suppose the existence of an efficient, unitary optimum point of environmental quality independently on the initial property rights distribution in environmental quality in absence of transaction costs.

In Figure 2(a), the curve MC represents the marginal costs to a pulp mill to prevent the pollution of river water and damanges to the river ecosystem. The horizontal axis is measured in units of an arbitrary index of river quality. If the pulp mill makes its production decisions without regard for its downstream neighbours (cf. definition of 'externality' in Mishan 1971) and in effective absence of government sanctions, it can maximise its profits by minimizing costs for pollution prevention. River quality would be at index value " 0 ". In contrast, MB represents the marginal benefits of river quality improvements to local citizens negatively 
affected by low river water quality, i.e. negatively affected by pulp mill effluents. Without any impact by the pulp mill, river quality would display the index value " 1 ".

According to the Coase Theorem, the optimum river quality level should be independent from the initial property rights distribution between any bargaining parties. In absence of transaction costs, an efficient, unitary optimum point should be reached by rationally bargaining agents. Given well behaved cost and demand curves, the optimum river quality level is found where $\mathrm{MB}=\mathrm{MC}$, i.e. at river quality $\mathrm{Q} 1$. Let us assume that industry has been granted legal river pollution rights that effecttively lead to SQ (status quo). Given some current river quality SQ, total citizen WTP for the implementation of Q1 equals area (1) plus area (2). The costs for the pulp mill to actually implement this level are only equal to area (2). Thus, a Pareto-improvement would be attained if citizens pay any amount between (2) and $(1)+(2)$ to the pulp mill and if the mill successfully implements Q1. This means that the unitary and efficient point Q1 will be attainable by bargaining parties.

In a CV survey administered by a research project, the typical coordination costs of collective bargaining situations are effectively reduced to zero. Thus, rationally acting respondents should state an identical WTP for a river quality improvement $d Q=S Q-Q 1$ no matter if respondents are presented with a frame in which the property rights in river quality are assigned to industry or to the community. We assume that the marginal costs curve MC of industry is known by the analyst. We hypothesize that an Industry pays frame leads to higher total WTP statements $(W T P-I P)$ than a Citizen pay frame (WTP-CP; see Figure $2 \mathrm{~b})$. Total benefits (TB) differ between the CP and IP frames. If WTP-IP actually differs from $W T P-C P$, can be tested empirically. 
What are the implications of empirically testing if $W T P-I P$ differs from $W T P-C P$ ? Assuming the correctness of empirically quantified mean preference statements for a the discrete river quality improvement $\mathrm{dQ}, W T P(I P)>W T P(C P)$ necessitates that the marginal benefits for river quality improvements display a corresponding relation $M B(I P)>M B(C P)$ across the interval dQ. This situation is depicted in Figure 2c. Consequently, the total benefit curves $T B(C P)$ and $T B(I P)$ differ (Figure $2 \mathrm{~b}$ ). That $W T P(I P)>W T P(C P)$ can easily be seen as $W T P(I P)$ consists of the areas $(1 \mathrm{a})+(1 \mathrm{~b})+(1 \mathrm{c})+(2 \mathrm{a})+(2 \mathrm{~b})+(2 \mathrm{c})$ while $W T P(C P)$ only consists of $(1 b)+(2 b)+(2 c)$.

Furthermore, if the existence of two differing marginal demand curves is corroborated empirically, one would have to conclude that two differing optimum points of river quality exist at $O p t Q-I P$ and $O p t Q-C P$. Thus, we regard a statistical rejection of the Null-hypothesis $W T P(I P)=W T P(C P)$ an indication for $W T P(I P)>W T P(C P)$, and hence OptQ-IP $\neq$ OptQ-IP. Such a result would argue against the applicability of a central implication of the Coase Theorem for cases of applied environmental policy as it rejects the neccesary conclusion that a unitary point exists. ${ }^{11}$

\section{$3 \quad$ Methodology}

\subsection{General valuation frame}

Respondents were asked to state their maximum WTP for a specific 'scenario' of river quality improvements. Based on pre-study results, three dimensions on river quality improvements

\footnotetext{
${ }^{11}$ We would like to stress that we do not pretend to test the Coase Theorem as such empirically. Instead, we explore its implications for applied environmental policy, and test if one central implication holds.
} 
were considered: river pollution risk, number of threatened species, and local fisheries yield. For each dimension, its respective current situation (status quo), and an improvement level were presented to survey respondents and explained using visual aids.
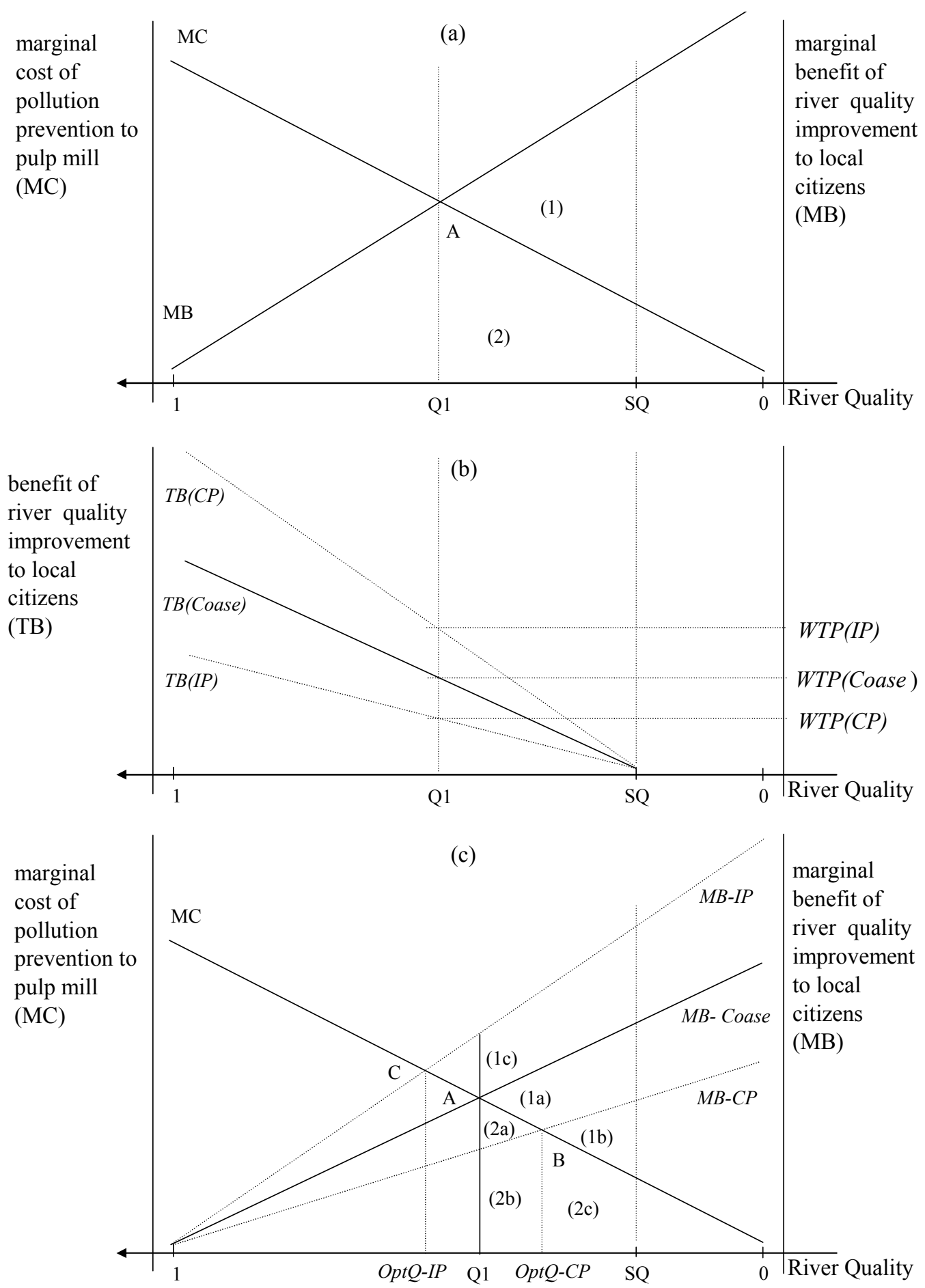

Figure 2. Coase-type hypothesis for solutions to externality problems 
Each respondent was consecutively asked to answer the CV question for different frames:

The first frame (Industry pays; IP) stated that any money paid conditional to the implementation of the presented river quality improvement scenario would be used to foster government capacity to force industry to bring about the improvement. I.e., the frame assigns the property right in river quality to the citizens. While citizens pay for monitoring and law enforcement, industry itself has to pay for the improvement, e.g. by upgrading its production and sewage technologies.

The second frame (Citizens pay; $C P$ ) stated that any money paid conditional to the implementation of the presented river quality improvement scenario would directly be given to industry to bring about the improvement, e.g., by upgrading its production and sewage technologies. With other words, the frame assigns the property right in river quality to the paper mills.

Respondents had experience with working with the above-mentioned scenarios as the $\mathrm{CV}$ question was asked directly after a choice experiment utilising the same attributes (for choice experiment methodology and results, see chapter 2). The choice experiment exclusively used an Industry pays frame asking respondents for contribution to better enforcement. $84 \%$ of respondents chose at least once a choice card that includes a payment.

The River pollution risk dimension represents the percentage of non-compliance of the pulp mill with the national water quality standard at a monthly basis. During 2006-2008, the Mataquito pulp mill was not complying with the standard $25 \%$ of the time (one month of noncompliance in four months; SISS 2009). Thus, this value was assigned to the status quo. The improvement scenario offered respondents a reduction of river pollution risk to $10 \%$. 
The Threatened species dimension deals with the number of fish and waterfowl species living in the river ecosystem that have a poor ("threatened") conservation status. Currently, there are about 25 such threatened species in the Mataquito and Itata rivers (status quo; Bioma 2008). Alternatively, respondents were asked to state their maximum WTP for a scenario that included an improvement to only 10 threatened species.

The Yield of local fisheries dimension refers to the yield of small fisheries operating mainly in the estuaries of the two rivers. All of the 15 species of native fish present in the study area have conservation problems (Habit et al. 2006). To illustrate this dimension to respondents, we choose the estuarine species Robalo (Eleginops maclovinus) which is a well known species in the study area. The status quo local yield of Robalo is about 1 ton/year (Mataquito) and 10 ton/year (Itata) on average (SERNAPESCA 2007ab; Araya et al. 2006). Given the high yield fluctuations during the last five years, the valuation scenario included a substantial improvement in yield by $50 \%$.

For eliciting respondent maximum WTP, we used an open-ended question format. Respondents had to indicate their maximum WTP for the suit of above-described scenario improvements. The scenario was displayed using a cardboard card that resembled the choice cards used just before during the choice experiment. The only difference was that the payment "attribute" did not have a preselected value. Instead respondents were asked to "fill in" their maximum WTP in terms of an additional mandatory annual payment per household via the electricity bill.

In the literature, potential biases using an open-ended format of the payment question have been described (Backhaus et al. 2005). Furthermore, the range of payment levels used in the 
preceding choice experiment may have furnished mental anchors with respect to the range of 'sensible' WTP statements ('anchor effect'; Aprahamian et al. 2007). Because we are mainly interested in systematic WTP differences between the two frames here, we accept the potential occurrence of these biases.

\subsection{Potential predictors of willingness to pay}

The reaction of respondents to differences in the property rights assignment may depend on the political stance of respondents with regard to economic and environmental policy. Respondents leaning towards the 'left' of the political spectrum are likely to espouse the idea of direct payments of citizens to industry in order to improve river quality, which they view as a public good. Likewise, respondents leaning towards the 'right' of the political spectrum are likely to espouse the idea of more government intervention in favour of the environment but burdening privately owned pulp mills. Consequently, different respondents are likely to judge any proposal to pay for improved river quality depending on the question of how fair they regard the payment under the respective property rights frames.

The influence of perceptions on the fairness of a suggested payment in stated preference studies was investigated by Jorgensen et al. (2001). They found that fairness considerations may have a substantial impact on the share of protest responses and on stated WTP. Thus, we adapted attitudinal items used by Jorgensen et al. (2001) to our case study, and designed a few additional items (see Table 1).

The item Unfair plainly asks if the respondent regards a payment for improved river quality as "unfair". Respondents who believe that is unfair that they have to pay may display a higher 
propensity to opt for zero payment under the Citizens pay frame. While the wording of the Unfair item does not include a justification why payments may be unfair, the Myright item does. Myright suggests that respondents may have a (moral, property or other legal) 'right' to water quality improvements. The extent of such a belief should reduce stated preferences under the Citizens pay frame. The opposite argumentation holds for Indright, an item that stipulates that industry has the 'right' to pollute the river. A very similar item is Noprobl: Here, respondents agree to a statement not to "have a problem" with paying industry for improved river quality. The opposite stance is addressed with Indpay. The item suggests that industry should pay for river quality improvements. Alternatively, respondents may think that it is unfair that they pay because the government should do so (Govpay).

To better differentiate 'true' protest responses or low bids in the Citizens pay frame from a response strategy that is fundamentally motivated by a genuine unwillingness to pay additional taxes, we added the Payenough item. This item suggests that respondents feel that they pay already a lot of taxes. Finally, Moreinfo requests a statement on the need for additional information.

Respondents were asked to rate their agreement or disagreement with the above statements using a five-point Likert scale (1: 'completely disagree'; 5: 'completely agree'). We include socio-demographic variables such as age, income, education, sex, residence, and river use as potential predictors of preferences. 
Table 1. Potential predictors of WTP for river water quality improvements

\begin{tabular}{|c|c|c|}
\hline Variable & Definition & Format \\
\hline \multicolumn{3}{|c|}{ Fairness-related items } \\
\hline Unfair & It is unfair that I have to pay for RQI. ${ }^{\mathrm{d}}$ & Five-point Likert scale \\
\hline Myright & It is my right to have RQI. & Five-point Likert scale \\
\hline Indright & $\begin{array}{l}\text { Industry has the right to deliver } \\
\text { wastewater into the river. }\end{array}$ & Five-point Likert scale \\
\hline Noproblem & $\begin{array}{l}\text { I have no problems with using my money } \\
\text { to pay industry for RQI. }\end{array}$ & Five-point Likert scale \\
\hline Indpay & Industry should pay for RQI. & Five-point Likert scale \\
\hline Govpay & $\begin{array}{l}\text { The government should use existing } \\
\text { revenues for RQI. }\end{array}$ & Five-point Likert scale \\
\hline Payenough & $\begin{array}{l}\text { I already pay enough taxes for the } \\
\text { environment. }{ }^{\mathrm{d}}\end{array}$ & Five-point Likert scale \\
\hline Moreinfo & $\begin{array}{l}\text { I need more information before making a } \\
\text { decision on paying for RQI. }^{\mathrm{d}}\end{array}$ & Five-point Likert scale \\
\hline \multicolumn{3}{|c|}{ Socio-demographic variables } \\
\hline Age & Respondent age & Integer variable \\
\hline Income & Monthly household income & Ordered seven-point scale ${ }^{a}$ \\
\hline Education & Respondent education level & Ordered five-point scale ${ }^{b}$ \\
\hline Sex & Respondent sex & Dummy (1: Male, 0: Female) \\
\hline Residence & Residence of respondent & Dummy (1: rural, 0 : urban $)^{c^{\prime}}$ \\
\hline Business & $\begin{array}{l}\text { Respondent relates her/his business/job } \\
\text { with the river }\end{array}$ & Dummy (1: Yes, 0: No) \\
\hline Recreation & $\begin{array}{l}\text { Respondent conducted recreational } \\
\text { activities at the river in the last two years }\end{array}$ & Dummy (1: Yes, 0: No) \\
\hline \multicolumn{3}{|c|}{$\begin{array}{l}\text { VI: Improvements to "river quality", i.e. to the quality of river water itself and to the river ecosystem. } \\
\text { bruary 2009): } 1 \text { (CLP 0-160,000); } 2 \text { (CLP 160,000-320,000); ...; } 7 \text { (more than CLP } 960,000 \text { ). Income is } \\
\text { esented as the average of original intervals } \\
\text { Education categories: } 1 \text { (no formal education); } 2 \text { (primary education); } 3 \text { (secondary education); } 4 \text { (technical } \\
\text { ucation); } 5 \text { (university education). Education is shown as equivalent years of education for each original } \\
\text { tegory. } \\
\text { Urban locality: concentrated housing complex with more than 2,000 inhabitants, or between } 1,001 \text { and 2,000 } \\
\text { labitants with more than } 50 \% \text { of economically active population (INE, 2005). }\end{array}$} \\
\hline
\end{tabular}

\subsection{Administration of the survey}

The study area includes four communities (Mataquito river: Licantén and Curepto; Itata river: Coelemu and Trehuaco). In these communities, we sampled respondents living downstream the pulp mills. The sampling frame included 2,141 inhabitants at the Mataquito river site and 
13,521 inhabitants on the Itata river site (population data extracted from National Census of 2002; INE 2005).

The face-to-face interview survey was conducted by four trained university students and the first author from February to April 2009. For the survey, we considered households located (1) in a total of 21 localities, and (2) adjacent to the river along the main roads. According to INE (2005), total household number at the Mataquito river localities was 883 and 4,001 at the Itata site. We sampled a minimum of 150 households from each site by a systematic sampling procedure (Babbie 2008:224). As the study focus is not in the quantification of aggregate WTP for the sampled population, no attempt was made to correct for the relative oversampling of Mataquito river households.

To determine the households to be sampled, first the sampling ratio was calculated (Mataquito: 0.17; Itata: 0.04). Based in the inverse of the sampling ratio, every sixth household at the Mataquito site and every $25^{\text {th }}$ household at the Itata site were chosen for an interview. When we reached a locality, interviewers were given random points of departure. Then, fixed rules on the direction to walk, distance between households (depending on locality size), and the number of interviews to conduct in each sector were given. When a selected house had not apparent occupants, the next house was chosen for the interview. From all household members older than eighteen years by the day of the interview, any member willing to answer the questionnaire was chosen.

Finally, we administered 53 interviews during a pilot study (Mataquito: 21, Itata: 32), and 318 interviews during the main study (Mataquito: 160, Itata: 158). During the main study, 142 contacted households were found to be without occupants, 70 contacted respondents denied 
giving an interview, and 2 respondents were younger than 18 . Of all successfully contacted 318 households, one respondent denied to complete the CV task $(0.3 \%)$. For Tobit model estimations, respondents with missing attitudinal or belief items answers were excluded resulting in $\mathrm{n}=285$ for the analysis.

\subsection{Statistical analysis}

Following Bateman et al. (2002), a CV survey presents respondents with the prospect of securing an improvement in river water quality from its present status quo level $\left(\mathrm{SQ}=\mathrm{Q}^{0}\right)$ to a better level $\left(\mathrm{Q}^{1}\right)$. The application of a $\mathrm{CV}$ assumes that the valuation survey is worded so as to elicit respondent maximum WTP for the improvement. Following standard economic theory, we define an indirect utility function, $\mathrm{V}($.$) :$

$V(Y, P, S, Q)$

in which $\mathrm{V}($.$) describes the maximum utility respondents derive from their income Y$ with given prices of market goods $P$, and given levels of provision of the non-market service $Q$. Under $S$, we include socio-economic and attitudinal variables. Increasing the provision of an environmental service from $Q^{0}$ to $Q^{1}$ represents an improvement for respondents:

$$
V\left(Y, P, S, Q^{0}\right)<V\left(Y, P, S, Q^{l}\right)
$$

The maximum WTP for $Q^{1}-Q^{0}$ equals the change in available income $Y^{0}-Y^{l}$ for

$$
V\left(Y^{0}, P, S, Q^{0}\right)=V\left(Y^{l}, P, S, Q^{l}\right)
$$


If WTP data generated by CV studies are used in welfare economic project appraisal, it is a methodological standard requirement to include 'attitudinal' variables (Arrow et al., 1992). This is done (i) to check whether the responses to hypothetical WTP questions conform to attitudes of the respondents, and (ii) to explain respondents WTP (cf. previous subsection).

We used a paired-samples $t$ test to compare the two WTP values of the alternative property rights frames stated by each individual. If a significant difference is found, we conclude that the $\mathrm{H}_{0}$ ('Coase-type hypothesis' on a unitary optimum point) is rejected and that the alternative hypothesis of a differing WTP - i.e. empirical non-existence a unitary optimum point - is accepted instead.

We used standard Tobit regressions censored at zero to quantify the impact of $S$ on maximum WTP (Green 2002:764). Tobit models are useful if the dependent variable is zero for a significant fraction of the observations. Conventional regression methods fail to account for the qualitative difference between limit (zero) observations and nonlimit (continuous) observations. For example, one may expect a high proportion of zero WTP values under Citizens pay frame with some respondents probably expecting even some compensation from the industry because of reduced water quality (Industry pays) $)^{12}$. The Tobit model assumes that there is an underlying response variable (i.e. the true WTP), defined by the regression relationship:

$$
y^{*}=X \beta+\varepsilon
$$

\footnotetext{
${ }^{12}$ Furthermore, because the Jarque-bera statistic indicated that residuals were not normally distributed if OLS regression models were applied (see Annex 1).
} 


$$
\begin{gathered}
y=y^{*} \text { if } y^{*}>0, \\
y=0 \text { if } y^{*} \leq 0
\end{gathered}
$$

where $X$ is a vector of respondent characteristics and $\varepsilon$ is a normally distributed error term. Estimations were carried out with Stata 10.1.

To provide more background for the interpretation of regression results, a series of post hoc analyses was carried out. We compared means (or distributions) between payers and nonpayers for both frames for each explanatory variable included in the study. In this regard, we used the Pearson $C h i^{2}$ test for dummy variables (Sex, Residence, Business, and Recreation), and independent samples $t$ test for near continuous variables (rest of variables).

Moreover, we inducted an exploratory cluster analysis based on the fairness-related attitude and belief items. We used K-means cluster analysis procedures that assign respondents to a pre-defined number of clusters whose characteristics were not yet known but which are based on the variables included. Visual inspection suggested that a four-cluster solution is reasonable. Each cluster was characterized based on mean values for fairness-related items and WTP.

\section{$4 \quad$ Results}

\subsection{Descriptive results}

Respondents were 51 years old on average (Table 2). $60 \%$ of respondents were women. $62 \%$ of respondents were rural residents. Respondents had 6.19 years of education on average. 
$35 \%$ did not have any formal education. Average household income was CLP 165,800/yr with $66 \%$ of respondents receiving less than the national annual minimum income (CLP 160,000/ $\approx$ USD 264). $40 \%$ of respondents indicated that their occupation was related to the river. Only $25 \%$ of respondents had conducted recreational activities in the river during the two years before the interview.

$70 \%$ of respondents agreed ('rather agree' or 'completely agree') that it was 'unfair' having to pay for river water quality improvements. In fact, $97.5 \%$ felt that they had a 'right' for to a good environmental river quality. In contrast, only $9.5 \%$ of respondents agreed that industry had the right to discharge wastewater into the river. Correspondingly, only $9.8 \%$ agreed that they had no problems with directly paying industry for river quality improvements. $93 \%$ of respondents thought it was the responsibility of industry, and $90.5 \%$ that it was the responsibility of government to pay for river quality improvements. $24.1 \%$ agreed that they already paid 'enough taxes' for the environment.

\subsection{Main results}

Figure 3 suggests that many respondents may have used the range of suggested payments in the choice experiment $(500-3,000 \mathrm{CLP} / \mathrm{yr})$ as a mental anchor for making their open question WTP bids. Overall, 75\% of respondents were willing to pay for river water quality improvements (15\% zero WTP bid) under the Industry pays frame. In contrast, just 19\% of respondents were willing to pay $(81 \%$ zero WTP bid) under the Citizens pay frame. Considering the full sample under the Industry pays frame, respondents were - on average willing to spend 3,342 CLP/HH/yr (SD: 5,615; Table 2). Under the alternative Citizens pay frame, the mean value was $731 \mathrm{CLP} / \mathrm{HH} / \mathrm{yr}$ (SD: 2,336). This difference was highly 
significant at $\mathrm{P}<0.0001$ at a paired $t$-test. Thus, we reject the $\mathrm{H}_{0}$ and accept the alternative hypothesis of differing WTP under the two frames. The existence of a unitary optimum river quality could not be ascertained empirically.

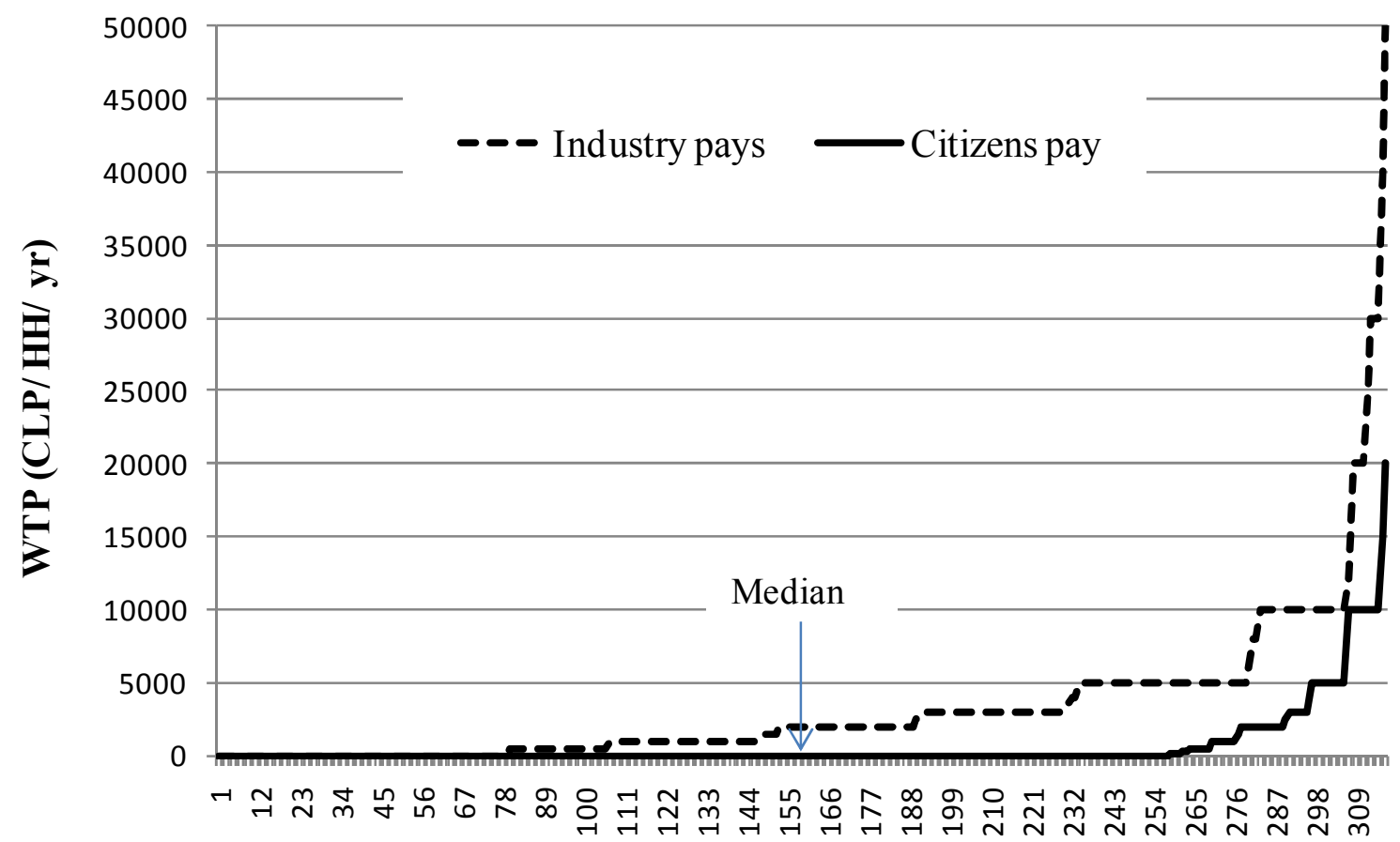

Respondents in order of WTP for river quality improvements $(n=317)$

Figure 3. WTP for river quality improvements under alternative institutional frames; respondent order for the two frames differ as, e.g. two different respondents may register the $287^{\text {th }}$ place for a WTP statement.

Table 2. Mean WTP comparison between alternative institutional frames.

\begin{tabular}{cccc}
\hline \multicolumn{2}{c}{ Industry pays } & Citizens pays \\
\hline Mean WTP & Standard deviation & Mean WTP & Standard deviation \\
3,342 & 5,615 & 731 & 2,336 \\
\hline \multicolumn{3}{c}{ Paired sample $\boldsymbol{t}$ test } \\
\hline \multicolumn{3}{c}{$28.94(\mathrm{p}$-value $<0.0001)$} \\
$\mathrm{N}=317$ & $\mathrm{~N}=317$ \\
\hline
\end{tabular}




\subsection{Comparison of payers and non payers}

Under both frames, respondents who agreed to pay (payers) thought to a lesser degree that it was "unfair" to do so (Table 3). Payers under the Industry pays frame thought to a higher degree that it was "their right" to have a high quality river ecosystem. Under the alternative Citizens pay frame, there is no difference. The opposite holds for the Noproblem item. Here, the payers under the Citizens pay frame had substantially less problems with paying the paper mills directly.

Under the Industry pays frame, payers agreed to a lower degree that they already paid enough taxes. Again, a difference could not be documented under the alternative frame. The payers under the Industry Pays frame felt more strongly that they needed more information than the non-payers. Finally, for the Indright, Indpay, and Govpay items, no differences were found.

Age, Income and Education of payers and non-payers differ under both frames. Payers were younger, better educated and had a higher income. Non-payers under the Citizens pay frame more frequently lived in rural areas. Payers under Industry pays used the river for recreational activities much more often. 
Table 3. Mean differences between payers and non-payers for each institutional frame ${ }^{\mathrm{a}}$

\begin{tabular}{|c|c|c|c|c|}
\hline \multirow[t]{2}{*}{ Variable } & \multicolumn{2}{|c|}{ Industry pays (means) } & \multicolumn{2}{|c|}{ Citizens Pay (means) } \\
\hline & $\begin{array}{l}\text { Payers } \\
(n=238)\end{array}$ & $\begin{array}{c}\text { Non-payers } \\
(n=79)\end{array}$ & $\begin{array}{l}\text { Payers } \\
(n=60)\end{array}$ & $\begin{array}{c}\text { Non-payers } \\
(\mathbf{n}=\mathbf{2 5 7})\end{array}$ \\
\hline Unfair & $3.65 * *$ & $4.18 * *$ & $3.19 * * *$ & $3.91 * * *$ \\
\hline Myright & $4.50 * *$ & $4.22 * *$ & 4.42 & 4.44 \\
\hline Indright & 1.68 & 1.77 & 1.88 & 1.66 \\
\hline Noproblem & 1.80 & 1.64 & $2.73 * * *$ & $1.54 * * *$ \\
\hline Indpay & 4.44 & 4.29 & 4.53 & 4.38 \\
\hline Govpay & 4.43 & 4.50 & 4.44 & 4.45 \\
\hline Payenough & $2.85 *$ & $3.11 *$ & 2.78 & 2.94 \\
\hline Moreinfo & $3.94 * * *$ & $3.44 * * *$ & 4.02 & 3.77 \\
\hline Age & $48 * * *$ & $62 * * *$ & $47 *$ & $52 *$ \\
\hline Income & $180,611 * * *$ & $120,000 * * *$ & $209,655 *$ & $155,720 *$ \\
\hline Education & $6.96 * * *$ & $3,64 * * *$ & $7.93 * *$ & $5.75 * *$ \\
\hline $\operatorname{Sex}(1=$ men $)$ & 0.38 & 0.47 & 0.42 & 0.40 \\
\hline Residence (1=rural) & 0.62 & 0.57 & $0.44 * *$ & $0.66 * *$ \\
\hline Business $(1=$ yes $)$ & 0.39 & 0.39 & 0.31 & 0.42 \\
\hline Recreation (1=yes) & $0.29 * *$ & $0.13 * *$ & 0.19 & 0.26 \\
\hline
\end{tabular}

\subsection{Influences on WTP of payers}

Tobit regression models displayed a significant linear relationship between variables (P-value $<0.0001$; Table 4). The Tobit model for the Industry pays frame includes Unfair, Noproblem, Age, and Business as significant predictors of WTP (pseudo- $\left.\mathrm{R}^{2}: 0.014\right)$. For the Citizens pay frame, the Tobit model includes Unfair, Noproblem, Moreinfo, Income, and Residence as significant predictors of WTP (pseudo-R $\left.{ }^{2}: 0.069\right)$. 
Table 4. WTP model (Tobit) of river water quality improvements under alternative frames

\begin{tabular}{|c|c|c|c|c|}
\hline \multirow[t]{2}{*}{ Variable } & \multicolumn{2}{|c|}{ Industry pays model } & \multicolumn{2}{|c|}{ Citizens Pay model } \\
\hline & Coefficient $(\beta)$ & p-value & Coefficient ( $\beta$ ) & p-value \\
\hline Unfair & $-993.30 * *$ & 0.009 & $-1,016 *$ & 0.038 \\
\hline Myright & 1,378 & 0.114 & $-1,620$ & 0.166 \\
\hline Indright & -498.53 & 0.218 & 503.36 & 0.308 \\
\hline Noproblem & $815.33 *$ & 0.047 & $3,109 * * *$ & 0.000 \\
\hline Indpay & -105.94 & 0.835 & -84.62 & 0.905 \\
\hline Govpay & 554.24 & 0.333 & 491.81 & 0.557 \\
\hline Payenough & -534.47 & 0.218 & -596.17 & 0.299 \\
\hline Moreinfo & 479.41 & 0.213 & $2,320 * * *$ & 0.000 \\
\hline Age & $-76.40 * *$ & 0.008 & $-97.68 *$ & 0.012 \\
\hline Income & 388.98 & 0.417 & $1,628 * *$ & 0.005 \\
\hline Education & 701 & 0.152 & -702.96 & 0.286 \\
\hline $\operatorname{Sex}($ men $)$ & 411 & 0.631 & 1,860 & 0.100 \\
\hline Residence (rural) & 271 & 0.782 & $-3,238 *$ & 0.015 \\
\hline Business (yes) & $1,980 *$ & 0.035 & 129 & 0.919 \\
\hline Recreation (yes) & 1,006 & 0.284 & -598 & 0.629 \\
\hline Constant & $-2,641$ & 0.615 & $-5,514$ & 0.439 \\
\hline $\mathrm{P}\left(\mathrm{Chi}^{2}\right) ; \mathrm{DF}$ & \multicolumn{2}{|c|}{$<0.0001 ; 15$} & \multicolumn{2}{|c|}{$<0.0001 ; 15$} \\
\hline Log likelihood & \multicolumn{2}{|c|}{$-2,252.7639$} & \multicolumn{2}{|c|}{-625.99} \\
\hline Pseudo- $\mathrm{R}^{2}$ & \multicolumn{2}{|c|}{0.014} & \multicolumn{2}{|c|}{0.069} \\
\hline $\mathrm{N}$ & \multicolumn{2}{|l|}{285} & \multicolumn{2}{|l|}{285} \\
\hline
\end{tabular}

\subsection{Explorative cluster analyses}

Cluster 1 ("Aware' respondents, $\mathrm{n}=69$ ) is characterized by the lowest scores at Unfair and Payenough items (Fig. 4). It means that respondents at this group did not consider it unfair to pay for river quality improvements supported by the fact that they tend to consider that not enough money is already spend on environmental matters by them. Moreover, they showed the second highest scores at Noproblem item which indicated that they tended to have no 
problem with paying industry for river water quality improvements. Respondents displayed the highest WTP values at both frames (Fig. 5).

Cluster 2 ('Industrialist' respondents, $n=32$ ) is the numerically smallest group which showed the highest scores at Indright and Noproblem items. Respondents tended to believe that industry has rights to deliver its wastewater into the river and not to have a problem with paying industry for river water quality improvements. Furthermore, they displayed the lowest scores at Myright item that indicates a willingness for 'sharing' rights on river water quality with industry. Respondents showed the second highest WTP values under both frames.

Cluster 3 ('Anti-industrialist' respondents, $n=170$ ) is the numerically biggest group. Its respondents displayed, on average, the highest scores at Unfair, Moreinfo, Myright, and Indpay items. In general, respondents considered it unfair to pay given that they believed it was their right to have an improvement on river water quality, and that industry should pay for it instead. They believed that more information should be displayed before taking a decision on paying. In addition, respondents showed the lowest scores at Indright item that indicated they strongly disagree that industry has rights to pollute the river. They displayed the second lowest WTP values under both frames, with also the second highest ratio of average payment under the Industry pays/Citizens pay frames.

Cluster 4 ('Rejecter' respondents, $\mathrm{n}=42$ ) represents respondents who showed the lowest scores at Moreinfo, Noproblem, and Indpay items. As they also were willing to pay only very little, they did not request more information to take decisions on paying. They expressed major concerns with paying industry directly for river quality improvements, and agreed that that industry should pay. They displayed the highest scores at the Payenough item which 
indicates that they more strongly believed that they already pay enough for environmental purposes. They showed the lowest WTP values at both frames with the average WTP under the Citizens pay frame close to zero.

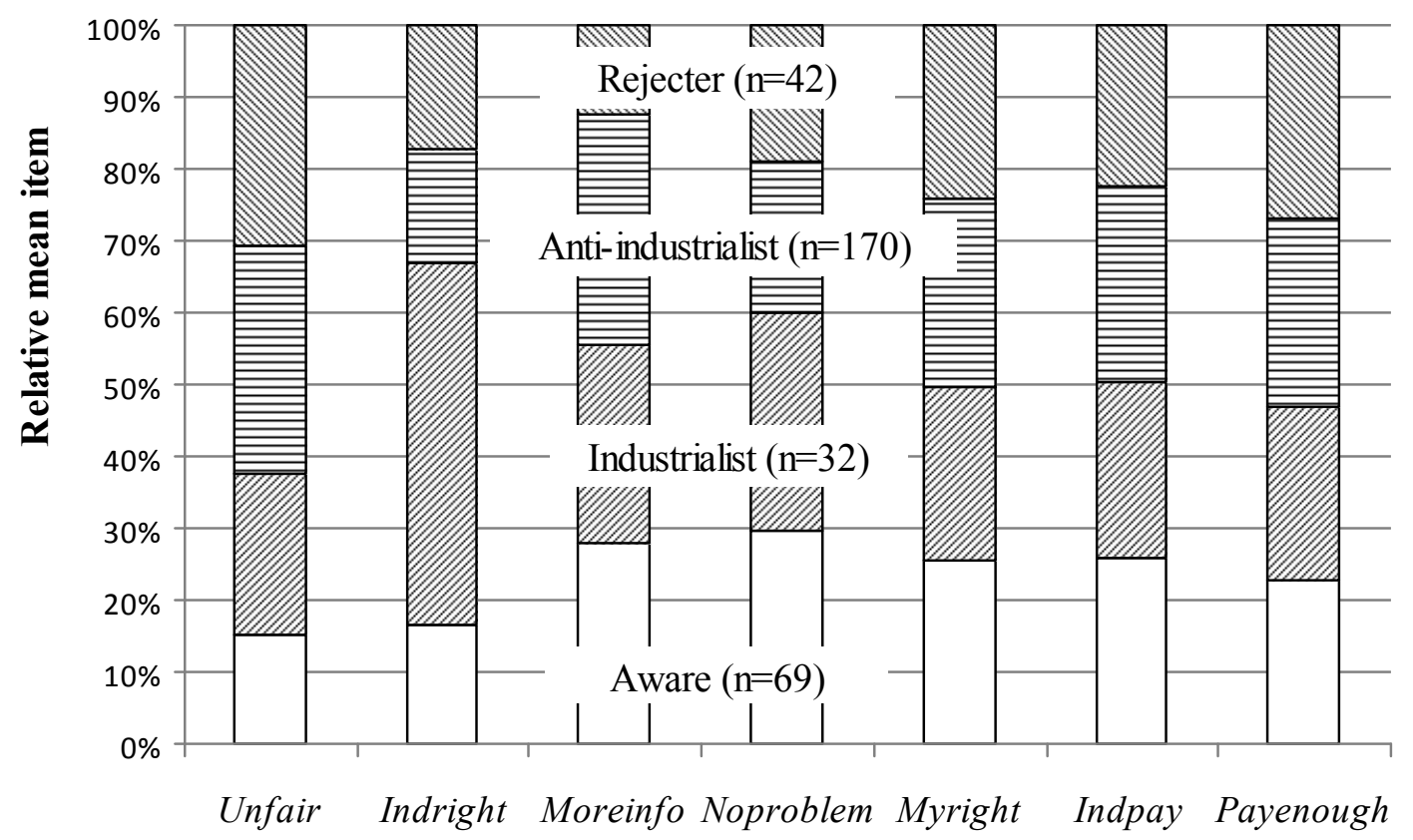

Figure 4. Relative mean item for six variables defining four respondents clusters $(n=313)$

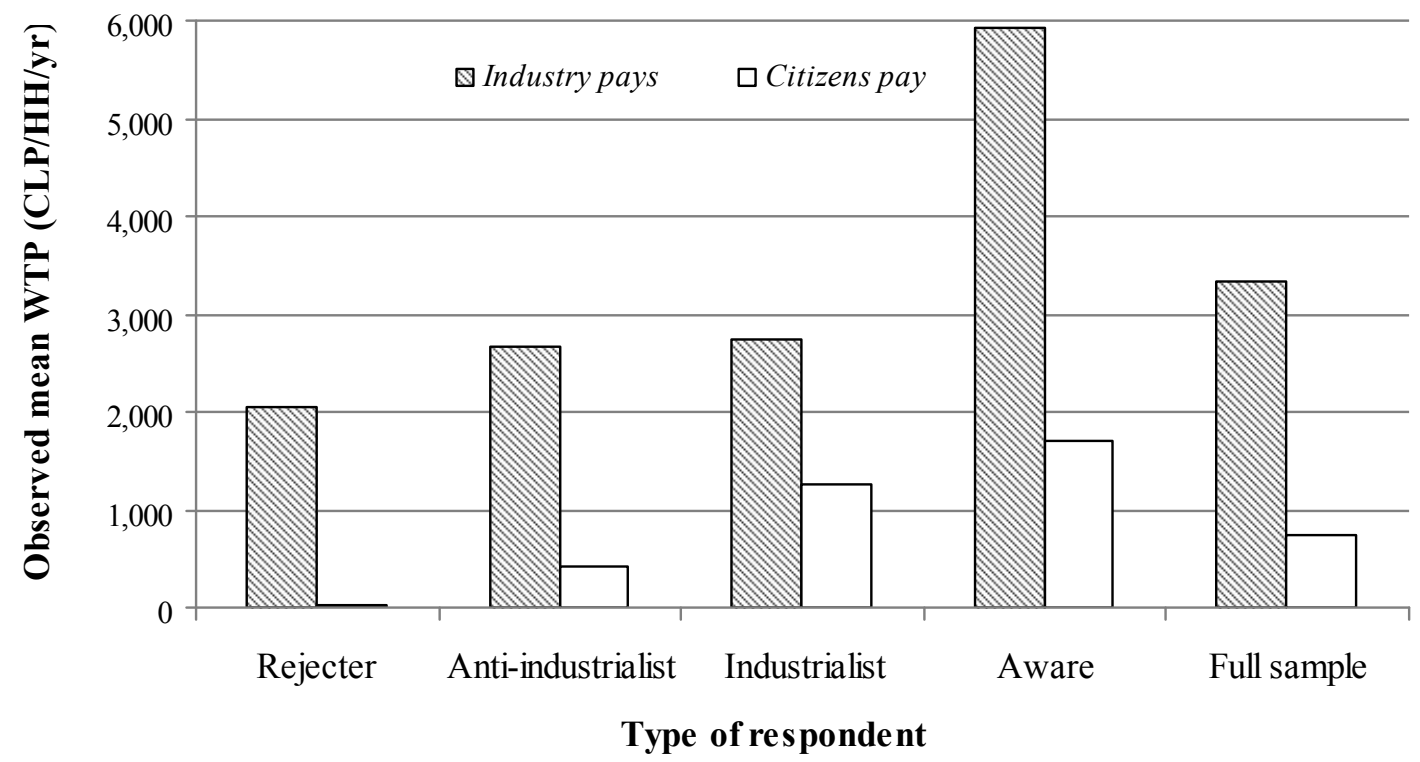

Figure 5. Extent of WTP for river water quality improvements to four clusters of respondents and the full sample; explorative K-means cluster analysis $(n=313)$ 


\section{$5 \quad$ Discussion}

\section{$5.1 \quad$ General}

In absence of transaction costs, the Coase Theorem predicts that rational bargaining between economic agents will be able to identify and implement an efficient and unitary optimum point of an externality, for example river water pollution. This optimum point is thought to be independent from the initial distribution of property rights, e.g. in river pollution or a good quality river ecosystem, respectively. We constructed a formal model to test by using stated preference data if this central implication of the Coase Theorem is empirically applicable to cases of applied environmental policy such as the determination of an efficient river water quality.

Using results from a contingent valuation survey, we found that the distribution of property rights implied in two alternative frames to a valuation question had a very strong impact on stated preferences. The share of respondents who stated zero WTP was much lower under a Citizens pay frame than under an Industry pays (i.e.: the polluter pays) frame. Likewise, the average WTP was much lower (731 vs 3,342 CLP/HH/yr). Even acknowledging a suit of potential biases that may principally distort the results of stated preference studies (e.g., anchoring bias, warm glow, mental budgeting; Bateman et al. 2002), the magnitude of the effect virtually excludes the possibility that other factors than the difference in the frame caused the differences. Consequently, the Coase-type hypothesis of equality of WTP under the two alternative frames had to be rejected. We conclude that the existence of a unitary optimum point independent from the initial property rights distribution could not be 
ascertained. This central implication of the Case Theorem does not seem to be directly applicable to the type of applied environmental externality problems investigated.

From this main result, a number of further conclusions can be drawn. Our results strengthen the results by Jorgensen et al. (2001) that fairness-considerations have an impact on stated WTP. Specifically, an environmental improvement brought about by regulation according to the "the polluter pays" principle is in higher economic demand than the same improvement brought about by direct payments to the party causing the externality, here to paper mills. Some economists may regard such a result as caused by "irrationally" behaving economic agents. Thus, we cannot claim that we have empirically tested the "truth" of the Coase Theorem which presupposes a certain rationality. But we can still claim that we tested the real world applicability of a central implication of the Coase Theorem to a quite common type of environmental policy issues. If our conclusion of low applicability is true, it provides an additional explanation for the low number of published case studies on implemented bargaining solutions to an externality problem in which ordinary citizen-consumers are involved: In addition to high transaction costs, the subjective utility derived from such a solution may be very low. Even moderate transaction costs may already be too high.

Methodologically, contingent valuation studies may have to take into account more acutely than commonly recognized that the property rights implications of their frame can impact valuation results substantially. This impact may be more pronounced in CV studies than in choice experiments because a direct "How much are you willing to pay for that improvement?" question appears more 'artificial' than the complex trade offs, on which choice experiments are based. In our study, the CV question was asked somewhat indirectly and using choice cards very similar to the ones used just before in a choice experiment. Thus, the 
impact of the alternative frames may even be larger if less contextualized CV-questions are used.

\subsection{Further observations on the WTP differences}

The Tobit models explain only a small share of the variance in stated WTP; nevertheless, both models are overall most highly significant $\left(\mathrm{p}\right.$-value $\left.\mathrm{Chi}^{2}<0.0001\right)$ and display a number of significant predictors of WTP.

The Unfair (-) and Noproblem (+) beliefs displayed a similar influence at both frames. If I think that it is fundamentally unfair that I pay for a river quality improvement, I am on average willing to pay less, no matter under which frame. A priori, we had expected this result only for the Citizens pay frame. The size of the effect is nearly identical. It turns out, however, that the "Aware" and "Industrialist" respondents have the highest average WTP also under the Industry pays frames. These are, at the same time, the respondents who generally think that it is less unfair to pay. The opposite holds true for the other two clusters of respondents. Under these circumstances, the item is less discriminatory than one may have expected. Likewise, we only had an explicit a priori expectation that agreement to the Noproblem item would be correlated with higher WTP under the Citizens pay frame. Both impacts are significant but the effect is clearly more pronounced here under the Citizens pay frame. Only in the direct comparison of means (Table 3) the expected result is visible.

For the two contrasting Myright and Indright items, the nominal mean values of the Tobit coefficients appear to indicate that these items display opposite correlations under both frames and compared to each other. Still, their impact is not significant in the Tobit models. For 
Indright this is astonishing since the "Industrialists" have, in fact, by far the highest Indright scores. However, the "Aware" cluster respondents have an even higher WTP but very low Indright scores.

One could conclude that in the above-mentioned respect, the "Aware" cluster respondents make more 'rational' statements on their economic preferences than could be deduced from their attitudes. In fact, their WTP under the 'Citizens pay' frame is not much lower than the average WTP of the "Rejecters" under the Industry pays frame. This argument is not completely convincing, though, as the WTP ratio under both frames is still about 1:3 in favor of the Industry pays frame. For the "Industrialists", this ratio is about 1:2, for the "Antiindustrialists" 1:6 and even more extreme for the "Rejecters". Thus, the very small group of the "Industrialist" respondents $(\mathrm{n}=32)$ actually made the preference statements most similar to the expectations based on the Coase Theorem.

Indpay and Govpay values are neither correlated with the respondent willingness to pay at all nor with the quantitative measure of WTP itself. The cluster analysis does not shed additional light on these items.

Finally, a higher demand for information (Moreinfo) is correlated with a higher WTP under the Citizens pay frame. This appears surprising as the item was thought to operationalize a factor that contributes to an uneasiness to state a positive willingness to pay. With more than $3 / 4$ of all respondents rejecting a payment under this frame, it appears that those rejecting any payment do in fact not need more information, as they do not pay anyway. Thus, those who do state a willingness-to-pay are the only respondents who actually feel that they need more information to safeguard their utility position. The differences between payers and non-payers 
are inconclusive. The cluster analysis shows, however, that the "Rejecters" with their low overall WTP do in fact report by far the smallest information needs.

Under both frames, a higher Age reduced WTP. Under the Citizens pay frame, a higher Income increased WTP. Ideally, one would wish to find an income effect under both frames also in the Tobit models. In fact however, the income of payers is significantly higher than the income of non-payers also under the Industry pays frame when analyzed independently from other variables. Furthermore, rural residents have a lower WTP under the Citizens pay frame and respondents with a business related to the river a higher WTP under the Industry pays frame.

In sum, our results (1) cast further doubt on the direct "real world" applicability of the Coase Theorem, (2) provide additional evidence for the importance of the property rights implications of the frame of stated preference studies, and (3) demonstrate that overall preferences as well as the impact of the property rights implications differ substantially among groups of respondents. In applied terms, we conclude that a substantial WTP for improvements of river water and river ecosystem quality is present in areas in Chile which are affected by pulp mill effluents. In spite of the clear "pro business" stance of all mainstream forces in the Chilean political system, Chilean citizens affected by environmental externalities strongly dislike an ultra-market approach to environmental policy as some may be tempted to propose based on the Coase Theorem. 


\section{References}

Aprahamian F, Chanel O, Luchini S (2007) Modeling starting point bias as unobserved heterogeneity in Contingent Valuation surveys: An application to air pollution. American Journal of Agricultural Economics 89: 533-547.

Araya I, Quiñones R, Dresdner J, Barriga O, Carrasco P, Campos N, Leiva M, Hernandez A, Ponce R, Rivas R (2006) Diagnóstico social, económico y productivo de las comunidades de pescadores artesanales de la desembocadura del Itata y zonas adyacentes, entre Cobquecura y Dichato. Programa de Estudios Económicos y Sociales del Sector Pesquero, Universidad de Concepción, Chile.

Arrow KJ (1992) Rationality of self and others in an economic system. In: M. Zey, Editor, Decision making: Alternatives to rational choice models, Sage, Newbury Park (1992), pp. 63-77.

Atkins JP, Burdon D (2006) An initial economic evaluation of water quality improvements in the Randers Fjord, Denmark. Marine Pollution Bulletin 53, 195-204.

Babbie EA (2008) The basics of social research, Fourth Edition. Thomson Learning, Inc. USA.

Backhaus K, Wilken B, Voeth M, Sichtmann C (2005) An empirical comparison of methods to measure willingness to pay by examining the hypothetical bias. International Journal of Market Research 47: 543-562.

Bamrud J (2011) The Chilean Model. Latin Trade 19: 6.

Barkmann J, Glenk K, Keil A, Leemhuis C, Dietrich N, Gerold G, Marggraf R (2008) Confronting unfamiliarity with ecosystem functions: The case for an ecosystem service approach to environmental valuation with stated preference methods. Ecological Economics 5: 48-62.

Barton D (2002) The transferability of benefit transfer: contingent valuation of water quality improvements in Costa Rica. Ecological Economics 42, 147-164.

Baskaran R, Cullen R, Colombo S (2009) Estimating values of environmental impacts of dairy farming in New Zealand. New Zealand Journal of Agricultural Research 52: 377389.

Bateman I, Carson T, Day B, Hanemann M, Hanley N, Hett T, Jones-Lee M, Loomes G, Mourato S, Özdemiroglu E, Pearce D, Sugden R, Swanson J (2002) Economic valuation 
with stated preferences techniques: a manual, Edward Elgar, Cheltenham, UK and Northampton, MA, USA.

Bioma (2008) Consultoría para la recopilación de información sobre la biodiversidad en apoyo a la elaboración del anteproyecto de norma secundaria de calidad ambiental para la protección de las aguas de la cuenca del Mataquito. Bioma BGA Consultores.

Birner R, Mappatoba M (2002) Community agreements on conservation in Central Sulawesi: A Coase solution to externalities or a case of empowered deliberative democracy? STORMA Discussion Paper Series, Subprogram A on Social and Economic Dynamic in Rain Forest Margins $N^{\circ} 3$, Research Project on Stability of Rain Forest Margins (STORMA), Georg-August-Universität Göttingen. http://ufgb989.uni-forst.gwdg.de/ DPS/index.htm. Accesed 10 June 2008

Cade-Idepe Consultores en Ingeniería (2004a) Diagnóstico y clasificación de los cursos y cuerpos de agua según objetivos de calidad - cuenca río Mataquito. Dirección General de Aguas, Ministerio de Obras Públicas, Chile. http://www.sinia.cl/1292/articles31018_Mataquito.pdf. Accessed 26 June 2008

Cade-Idepe Consultores en Ingeniería (2004b) Diagnóstico y clasificación de los cursos y cuerpos de agua según objetivos de calidad - cuenca río Itata. Dirección General de Aguas, Ministerio de Obras Públicas, Chile. http://www.sinia.cl/1292/articles31018_Itata.pdf. Accessed 26 June 2008

Carson R, Mitchell RC. 1993. The value of clean water: the public's willingness to pay for boatable, fishable, and swimmable quality water. Water Resources Research 9(7), 24452454.

Coase R (1960) The problem of social cost. Journal of Law and Economics 3, 1-44.

CONAMA (2006) Análisis económico y social de la norma de calidad secundaria para la protección de las aguas continentales superficiales en la cuenca del río Maipo. Región Metropolitana de Santiago.

CONAMA-SINIA (2008) Información geográfica territorial regional. Sistema Nacional de Información Ambiental Territorial (SINIA), Ministerio del Medio Ambiente, Chile. http://territorial.sinia.cl/portal/descargas.php. Accessed 30 September 2010

Desvousges WH, Smith VK, Fisher A (1987) Option price estimates for water quality improvements: a contingent valuation study for the Monogahela River. Journal of Environmental Economics and Management 14, 248-267. 
Espinosa C (2001) Evaluación de los impactos de la producción de celulosa. Análisis de Políticas Públicas No 4, Publicaciones Terram.

EULA (2006) Análisis general del impacto económico de la norma secundaria de calidad de aguas en la cuenca del río Bio-Bio, en el sector silvoagropecuario. Universidad de Concepción.

Grafton RQ, Adamowicz W, Dupont D, Nelson H, Hill RJ, Renzetti S. 2004. The economics of the environment and natural resources. Wiley-Blackwell Publishing Ltd.

Greene WH (2002) Econometric Analysis. Fifth edition, New York University.

Habit E, Dyer B, Vila I (2006) Estado de conocimiento de los peces dulceacuícolas de Chile. Gayana 70, 1: 100-113.

Hanley N, Sumner C (1995) Bargaining over common property resources: Applying the Coase Theorem to Red Deer in the Scottish Highlands. Journal of Environmental Management 43: 87-95.

INE (2005) Chile: Ciudades, Pueblos, Aldeas y Caseríos. Censo 2002, Instituto Nacional de Estadísticas - INE, Chile. http://www.ine.cl/canales/chile_estadistico/ demografia_y_vitales/demografia/demografia.php. Accessed 20 April 2008

INE (2009) Censo Agropecuario 2007. http://www.censoagropecuario.cl/. Accessed 5 May 2010.

Jorgensen BS, Wilson MA, Heberlein TA (2001) Fairness in the contingent valuation of environmental public goods: attitude toward paying for environmental improvements at two levels of scope. Ecological Economics 36: 133-148.

Jorgensen BS, Syme GJ, Bishop BJ, Nancarrow BE (1999) Protest Responses in Contingent Valuation. Environmental and Resource Economics 14: 131-150.

Le Goffe P (1995) The Benefits of Improvements in Coastal Water Quality: A Contingent Approach. Journal of Environmental Management, 45, 305-317.

Marggraf R, Streb S (1997) Ökonomische Bewertung der natürlichen Umwelt: Theorie, politische Bedeutung, etnische Diskussion. Berlin: Spektrum Akademischer Verlag.

Martín-López B, Montes C, Benayas J (2008) Economic Valuation of Biodiversity Conservation: the Meaning of Numbers. Conservation Biology 22: 624-635.

Nunes P, van der Bergh J (2001) Economic valuation of biodiversity: sense or nonsense? Ecological Economics 39: 203-222. 
OCDE-CEPAL (2005) Evaluaciones del desempeño ambiental - Chile. Organización de Cooperación y Desarrollo Económicos - Comisión Económica para América Latina y el Caribe. Ed. Naciones Unidas, CEPAL.

Orrego R, Burgos A, Moraga-Cid G, Inzunza B, Gonzalez M, Valenzuela A, Barra R, Gavilán J (2006) Effects of pulp and paper mill discharges on caged Rainbow Trout (Oncorhynchus mykiss): Biomarker responses along a pollution gradient in the Bio-Bio river, Chile. Environmental Toxicology and Chemistry 25, 9: 2280-2287.

O'Shea L (2002) An economic approach to reducing water pollution: point and diffuse sources. The Science of the Total Environment 282-283, 49-63.

Perman R, Ma Y, McGilvray J (1996) Natural resource and environmental economics. Addison Wesley Longman Limited. London and New York.

Sangkapitux C, Neef A, Polkongkaew W, Pramoon N, Nonkiti S, Nanthasen K (2009) Willingness of upstream and downstream resource managers to engage in compensation schemes for environmental services. International Journal of the Commons 3: 41-63.

SERNAPESCA (2007a) Valorización Desembarque Regional Años 2005 - 2006, Región del Maule. Servicio Nacional de Pesca, Chile. http://www.sernapesca.cl/ index.php?option $=$ com_remository\&Itemid $=246 \&$ func $=$ fileinfo $\& i d=1957$. Accessed 1 May 2008

SERNAPESCA (2007b) Concesiones de Acuicultura. Estuarios propuestos como Areas Apropiadas en la Región del Maule. Servicio Nacional de Pesca, Chile. http://www.sernapesca.cl/index.php?option=com_content\&task=view\&id=498\&Itemid= 686. Accessed 1 May 2008

SISS (2009) Cumplimiento de normas de descargas de Residuos Líquidos, DS 90/00

Descarga a cuerpos de agua superficiales, años 2006-2007-2008. Superintendencia de Servicios Sanitarios - SISS, Chile. http://www.siss.cl/propertyvalue-2309.html. Accessed 25 January 2009

SISS (2008) Informe de Gestión Sector Sanitario 2007. Superintendencia de Servicios Sanitarios, Chile. http://www.siss.cl/articles-6245_informegestion.pdf. Accessed 30 March 2008

Sivasakthi Devi T, Ramasamy C, Gurunathan S (2010) Farmers' Willingness to Pay to Avert the Negative Externalities of Pollution of Dyeing Industry in Tamil Nadu. Agricultural Economics Research Review 23: 245-252. 
Stern DI (2004) The Rise and Fall of the Environmental Kuznets Curve. World Development 32, 8: 1419-1439.

Vasconi P (2006) CELCO el caso de la planta Valdivia. Análisis de Políticas Públicas 36, Publicaciones Fundación Terram, Chile.

Vergara A, Encina F et al (2008) Informe Final - Evaluación Ambiental en el río Mataquito. Facultad de Ingeniería - Facultad de Recursos Naturales, Universidad Católica de Temuco. http://www.cutchile.cl/paloma/04\%20articles-

44336_InformeFinalRioMataquito.pdf. Accessed 15 January 2009

Zenteno P, López A, Mardones C, Montoya F (2009) Análisis de impacto económico y social de anteproyecto de normas secundarias de calidad - cuenca río Mataquito. DSS Ambiente. Ministerio de Obras Públicas, Chile.

http://www.dga.cl/otros/SAD/CQA5072.pdf. Accessed 01 June 2010 


\section{Annex}

Annex 1. OLS valuation of river water quality improvements under alternative frames

\begin{tabular}{|c|c|c|}
\hline Variable & (a) Industry pays ${ }^{\text {a }}$ & (b) Citizens pay ${ }^{\mathrm{a}}$ \\
\hline Unfair & $-0.208 * * *$ & $-0.135 *$ \\
\hline Myright & $0.124 *$ & \\
\hline Noproblem & & $0.416 * * *$ \\
\hline Age & $-0.225 * * *$ & \\
\hline Education & $0.188 * *$ & \\
\hline Business & $0.126 *$ & \\
\hline Residence & & $-0.117 *$ \\
\hline Income & & $0.113 *$ \\
\hline Constant $^{b}$ & $40.922 *$ & 2.116 n.s. \\
\hline $\mathrm{R}^{2}$ & 0.229 & 0.259 \\
\hline Adjusted $\mathrm{R}^{2}$ & 0.215 & 0.248 \\
\hline Sign. F statistic & 0.000 & 0.000 \\
\hline Paired samples $t$ test & \multicolumn{2}{|c|}{0.000} \\
\hline Jarque-bera statistic ${ }^{c}$ & 542.87 & 917.23 \\
\hline Observations & 317 & 317 \\
\hline
\end{tabular}

${ }^{\mathrm{a}}$ : standardized coefficients; ${ }^{\mathrm{b}}$ : unstandardized coefficient

$* * *$ : significant at $\mathrm{p} \leq 0.001 ; * *$ : significant at $\mathrm{p} \leq 0.01 ; *$ : significant at $\mathrm{p} \leq 0.05$

n.s.: no significant coefficient

c: J-b statistic has a $\mathrm{Chi}^{2}$ distribution with $2 \mathrm{df}$. So, if $\mathrm{J}-\mathrm{b}>\mathrm{chi}^{2}$ critical value $(5.99,5 \%$ sig.) reject null hypothesis that residuals are normally distributed. 


\section{Appendix 1: Questionarie (Spanish version)}

\section{Opinión pública acerca de la calidad del agua en el río Mataquito}

Introducción: Buenas días/tardes, mi nombre es XY. Soy asistente de investigación para un estudio que está realizando la Universidad de Goettingen de Alemania, relacionado con la calidad del agua en el río Mataquito. Estamos visitando varias comunas cercanas al río para conocer la opinión de la población acerca de la situación actual del río. ¿Sería Ud. tan amable de darme un poco de su tiempo para conversar con usted y conocer su opinión?.

(Si la respuesta es $\mathrm{NO}$, registrar motivo en hoja anexa)

\section{Introducción al cuestionario}

Este cuestionario es parte de un estudio acerca de la calidad de agua del río Mataquito. La calidad del agua puede ser protegida de diferentes maneras a través de Leyes ambientales. Las Leyes tienen diferentes efectos sobre la calidad del agua para beber, para el riego, para uso industrial y para usos recreacionales. Adicionalmente, estas Leyes podrían tener diferentes efectos sobre los animales y plantas que viven en el río.

Nosotros estamos interesados en conocer su opinión acerca de las condiciones, actual y futura, en la calidad del agua del río Mataquito. Por lo tanto, en este cuestionario no hay respuestas buenas o malas. Además, esta investigación no está relacionada con el gobierno ni con ninguna empresa. Lo único que le pedimos es que trate de expresar libremente sus propios intereses y opiniones. Para esta entrevista, su hogar ha sido seleccionado al azar desde la población local. De antemano, le agradecemos mucho su cooperación. La entrevista completa tendrá una duración de 20 a 30 min.

Hora de Inicio / Término: 


\section{Parte 1: Actitudes hacia el recurso agua}

1.1 Lo siguiente es un grupo de afirmaciones acerca del recurso agua en la cuenca del río Mataquito. En una escala de 1 a 5, por favor, indíquenos qué tan de acuerdo o en desacuerdo está usted con las siguientes afirmaciones; donde el número 5 significa que usted está "completamente de acuerdo" y el número 1 significa que usted está "completamente en desacuerdo" con la afirmación dada (formato respuesta 1).

\begin{tabular}{|c|c|c|c|c|c|}
\hline & $\begin{array}{l}\text { Compl } \\
\text { desacl }\end{array}$ & te en & $\begin{array}{l}\text { Ni uno ni lo } \\
\text { otro }\end{array}$ & Con & $\begin{array}{l}\text { iente de } \\
\text { acuerdo }\end{array}$ \\
\hline La calidad del agua en el río & & & & & \\
\hline Mataquito es muy buena................... & 1 & 2 & 3 & 4 & 5 \\
\hline $\begin{array}{l}\text { El río Mataquito está bien protegido } \\
\text { por nuestras Leyes.......................................... }\end{array}$ & 1 & 2 & 3 & 4 & 5 \\
\hline $\begin{array}{l}\text { Botar residuos líquidos en el río } \\
\text { reduce la cantidad de peces....... }\end{array}$ & 1 & 2 & 3 & 4 & 5 \\
\hline 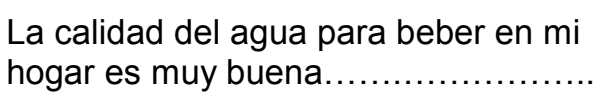 & 1 & 2 & 3 & 4 & 5 \\
\hline $\begin{array}{l}\text { La contaminación en el río Mataquito } \\
\text { será peor en los próximos } 10 \text { años..... }\end{array}$ & 1 & 2 & 3 & 4 & 5 \\
\hline $\begin{array}{l}\text { Los fertilizantes agrícola afectan } \\
\text { negativamente la calidad del agua...... }\end{array}$ & 1 & 2 & 3 & 4 & 5 \\
\hline
\end{tabular}

\section{Parte 2: Uso y consumo de agua}

En esta sección nos gustaría conocer la relación que usted tiene con el río Mataquito en función de sus diferentes usos.

2.1. ¿Está su actividad económica o trabajo relacionado con el río Mataquito?

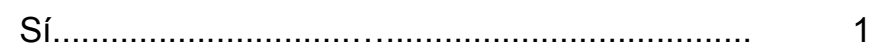

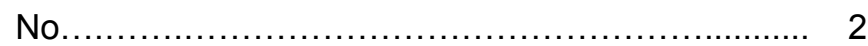


2.1.1. En una escala de 1 a 5, en su opinión, ¿Qué tal es la calidad del agua en el río Mataquito para las siguientes actividades económicas?, donde 1 significa "muy mala" y 5 significa "muy buena" (formato de respuesta 2 ).

\begin{tabular}{|c|c|c|c|c|c|c|c|}
\hline & Muy mala & & $\begin{array}{l}\text { Ni uno ni lo } \\
\text { otro }\end{array}$ & & Muy buena & $\begin{array}{l}\text { No } \\
\text { sabe }\end{array}$ & \\
\hline Pesca artesanal. & 1 & 2 & 3 & 4 & 5 & 0 & $(8-9)$ \\
\hline Agricultura & 1 & 2 & 3 & 4 & 5 & 0 & $(10-11)$ \\
\hline 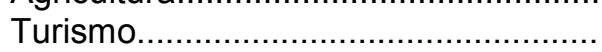 & 1 & 2 & 3 & 4 & 5 & 0 & $(12-13)$ \\
\hline 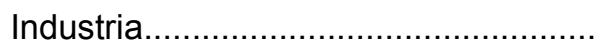 & 1 & 2 & 3 & 4 & 5 & 0 & $(14-15)$ \\
\hline Otra (especificar): & 1 & 2 & 3 & 4 & 5 & & (16) \\
\hline
\end{tabular}

2.2. Ha llevado a cabo usted actividades recreacionales en el río Mataquito durante los últimos dos años?

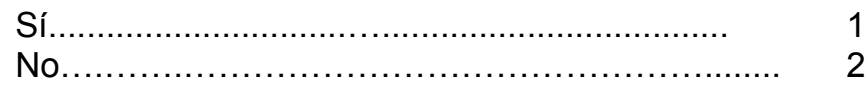

2.2.1. En una escala de 1 a 5, en su opinión, ¿Qué tal son las condiciones en el río Mataquito para permitir las siguientes actividades recreacionales?, donde 1 significa "muy mala" y 5 significa "muy buena” (formato de respuesta 2 ).

\begin{tabular}{|c|c|c|c|c|c|c|c|}
\hline & Muy mala & & $\begin{array}{l}\text { Ni uno ni lo } \\
\text { otro }\end{array}$ & & Muy buena & $\begin{array}{l}\text { No } \\
\text { sabe }\end{array}$ & \\
\hline Camping... & 1 & 2 & 3 & 4 & 5 & 0 & $(18-19)$ \\
\hline Pesca deportiva & 1 & 2 & 3 & 4 & 5 & 0 & $(20-21)$ \\
\hline 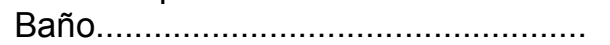 & 1 & 2 & 3 & 4 & 5 & 0 & $(22-23)$ \\
\hline Paseos en bote & 1 & 2 & 3 & 4 & 5 & 0 & $(24-25)$ \\
\hline Otra (especificar): & 1 & 2 & 3 & 4 & 5 & 0 & (26) \\
\hline
\end{tabular}

2.3. En relación al agua para beber en su hogar, ¿ha tenido usted problemas con la calidad de esta recientemente (últimos dos años)?.

Sí......... Ir a P. 2.3.1....... 1 No. Ir a P. 2.3.2........ 2

2.3.1. A continuación le presentaré varios tipos de problemas. En una escala de 1 a 5 , ¿Cuán severos o grandes han sido estos problemas recientemente?, donde 1 significa "sin problemas" y 5 significa "problema muy grande" (formato de respuesta 3). 
Mal olor

Sin

problemas

Demasiado Cloro.

Sucia (color café).

Cantidad insuficiente.

Otro:
Moderada\% problemático
Problema muy grande

2.3.2. ¿Cuál es su principal fuente de agua para beber?

Compañía de agua potable

Sistema propio de captación de agua subterránea (noria o pozo)

\section{3}

3

4

5

5

5

3

\section{4}

3

Sistema comunitario local (Cooperativa de agua $u$ otro)

Sistema propio de captación desde vertiente.

Otro:

\section{Parte 3: Opinión acerca de las Leyes para proteger de calidad del agua}

3.1. En esta sección, queremos conocer su opinión acerca de los posibles resultados que podrían tener nuevas Leyes para proteger el río Mataquito, incluyendo una adecuada supervisión para su implementación. A continuación, le presentaré posibles resultados que podrían tener estas Leyes. En una escala de 1 a 5, en su opinión ¿Cuán efectivas (o exitosas) serían estas Leyes para lograr cada uno de estos resultados?, donde 1 significa "sin efecto o éxito" y 5 significa "efecto o éxito muy alto" (formato de respuesta 4).

$\begin{array}{lccccccc} & \begin{array}{l}\text { Sin efecto } \\ \text { o éxito }\end{array} & & \begin{array}{c}\text { Éxito } \\ \text { medio }\end{array} & \begin{array}{c}\text { Efecto o éxito } \\ \text { muy alto }\end{array} & \begin{array}{c}\text { No } \\ \text { sabe }\end{array} \\ \text { Mayor cantidad de aves en el río........ } & 1 & 2 & 3 & 4 & 5 & 0 & (34-35) \\ \text { Más agua para riego agrícola............ } & 1 & 2 & 3 & 4 & 5 & 0 & (36-37) \\ \text { Mayor cantidad de peces en el río....... } & 1 & 2 & 3 & 4 & 5 & 0 & (38-39) \\ \text { Más sitios para hacer camping........... } & 1 & 2 & 3 & 4 & 5 & 0 & (40-41) \\ \text { Mejoramiento del paisaje en el río....... } & 1 & 2 & 3 & 4 & 5 & 0 & (42-43) \\ \text { Menos contaminantes en el río.......... } & 1 & 2 & 3 & 4 & 5 & 0 & (44-45) \\ \text { Más vegetación en los bordes del río... } & 1 & 2 & 3 & 4 & 5 & 0 & (46-47) \\ \text { Mejor calidad del agua para beber...... } & 1 & 2 & 3 & 4 & 5 & 0 & (48-49) \\ \text { Más oferta de trabajo en la zona......... } & 1 & 2 & 3 & 4 & 5 & 0 & (50-51)\end{array}$




\section{Parte 4: Preferencias por políticas para la protección de la calidad de aguas}

En esta sección, me gustaría hacerle algunas consultas relacionadas con las Leyes que usted preferiría para proteger la calidad del agua del río Mataquito en el futuro. Las Leyes para proteger el río pueden tener impactos sociales, económicos y ambientales. A continuación, le presentaré varias Leyes posibles, las cuales se diferencias en cuatro aspectos. Estos son:

1. Riesgo de contaminación del río

2. Número de especies amenazadas o en peligro que viven en el río

3. Aumento de la pesca en el río

4. Pago para mejorar la calidad del agua

Actualmente, el riesgo de contaminación del río es considerable. En los últimos tres años, en uno de cada cuatro meses (25\%) la industria de celulosa no ha cumplido con la Ley que regula cantidad de líquidos residuales que se pueden descargar en el río. Una nueva Ley más estricta, podría permitir una reducción en el porcentaje de no cumplimiento a un 20\%, 15\% ó un $10 \%$ después de su implementación. De esta manera, el riesgo de contaminación disminuiría notablemente.

4.1. En una escala de 1 a 5, en su opinión, ¿cuán importante es para usted este aspecto?, donde 1 significa "no importante" y 5 significa "muy importante" (formato de respuesta 5).

\begin{tabular}{lllclr} 
& No importante & Ni uno ni lo & \multicolumn{2}{c}{ Muy importante } \\
otro & & 3 & 4 & 5
\end{tabular}

Actualmente, 25 tipos de animales, incluyendo peces y aves que viven en el río Mataquito, podrían desaparecer. Ellas son llamadas “especies amenazadas localmente”. Esta situación podría cambiar en el futuro si Leyes más estrictas fueran implementadas. Posibles resultados podrían ser una reducción en el número de especies amenazadas a 20, 15 ó 10. De esta forma, habría una mayor abundancia de especies fuera de peligro de extinción. Por otro lado, si estas especies llegaran a desaparecer completamente del río Mataquito, aún sería posible encontrarlas en otros ríos de la zona centro-sur de Chile. 
4.2. En una escala de 1 a 5, en su opinión, ¿cuán importante es para usted este aspecto?, donde 1 significa "no importante" y 5 significa "muy importante" (formato de respuesta 5).

No importante

Disminución del número de especies

amenazadas.

$$
\begin{aligned}
& \text { Ni uno ni lo } \\
& \text { otro }
\end{aligned}
$$

2
3
Muy importante

4

5

La cantidad de peces en el río es afectada por causas naturales y por las actividades del hombre. Actualmente, la pesca de algunos tipos de peces en el río Mataquito, como el Robalo, corresponde a 1 ton/año aproximadamente. Esta cantidad podría aumentar si algunas Leyes para proteger la calidad del agua del río son implementadas. Por ejemplo, se estima que la pesca de Robalo podría aumentar un $10 \%$ (a 11 ton/año), un $25 \%$ (a 12,5 ton /año) o un 50\% (a 15 ton/año).

4.3. En una escala de 1 a 5, en su opinión, ¿cuán importante es este aspecto para usted?, donde 1 significa "no importante" y 5 significa "muy importante" (formato de respuesta 5).

\begin{tabular}{cccccc} 
& No importante & Ni uno ni lo & \multicolumn{2}{c}{ Muy importante } \\
otro & & 2 & 3 & 4 & 5
\end{tabular}

La implementación de Leyes para la protección de la calidad del agua en el río Mataquito, requiere que las empresas ubicadas aguas arriba cambien sus procesos de producción. Si esto ocurre, el riesgo de contaminación disminuiría, menos especies estarían amenazadas y una mayor cantidad de peces estaría disponible. Si cualquiera de estos cambios llegara a ser una Ley, las empresas deberían gastar el dinero que fuera necesario para mejorar sus procesos de producción. Sin embargo, habría que estar seguro que las empresas realmente implementen estos cambios. De esta manera, las instituciones de gobierno, tales como la SISS, DGA y SAG, necesitarán más fondos (o dinero) para una mayor cantidad de inspectores, mejores equipos para controlar la calidad del agua, etc. Imagínese que una Ley que obligue a las empresas a implementar mejoras para reducir la contaminación, también incluyera un impuesto adicional. Este impuesto es una suma de dinero fija por hogar y debería ser pagada a través de la cuenta de electricidad una vez al año. 
4.4. ¿Cree usted que la cuenta de electricidad sería una forma efectiva de recolectar dinero?, donde 5 significa “muy buena” y 1 significa “muy mala” (formato de respuesta 2).

\begin{tabular}{lccccc} 
& Muy mala & Ni uno ni lo & \multicolumn{2}{c}{ Muy buena } \\
otro & & & \\
Cuenta de electricidad como forma de & 1 & 2 & 3 & 4 & 5 \\
pago.............................................
\end{tabular}

En la siguiente sección, le presentaré cuatro escenarios de selección en total. En cada escenario usted debe seleccionar una de las tres alternativas que le presentaré (A, B y C [mostrar tarjeta de selección]). Cada alternativa varía de acuerdo al nivel de riesgo de contaminación del río, número de especies amenazadas, cantidad de pescados y el monto del cargo adicional a la cuenta de electricidad.

Por favor, considere que las alternativas A y B representan los resultados de la implementación de nuevas Leyes para proteger la calidad del agua del río. Si usted selecciona una de ellas, usted debería pagar el monto indicado en la tarjeta. El monto que usted seleccione sería cargado a la cuenta de electricidad que usted paga actualmente. Por otro lado, la alternativa $\mathrm{C}$ representa la continuidad de la situación actual, donde no se requiere una contribución adicional.

Antes de realizar su selección, por favor, revise las tres alternativas presentadas cuidadosamente. Cuando usted decida su opción, usted debe estar completamente seguro de que está dispuesto y en condiciones de pagar el monto indicado en su alternativa preferida como si esta fuera una situación real. En particular, ponga atención cuando seleccione una alternativa que contenga un pago anual adicional. Si esta alternativa es implementada, usted no puede gastar este dinero en alimentos, ropa, educación u otras cosas para el hogar.

¿Tiene alguna consulta al respecto? (Si es necesario, explicar primera tarjeta). Comencemos el ejercicio.!!! 
Escenario 1

\begin{tabular}{lccc}
\hline Atributo & Alternativa A & Alternativa B & $\begin{array}{c}\text { Alternativa C } \\
\text { Sin política adicional }\end{array}$ \\
\hline Riesgo de contaminación del río...... & $20 \%$ & $20 \%$ & $25 \%$ \\
Número de especies amenazadas.... & $10 \mathrm{sp}$ & $10 \mathrm{sp}$ & $25 \mathrm{sp}$ \\
Aumento de la pesca................... & $20 \%$ & $50 \%$ & $0 \%$ \\
Pago al año.............................. & $\$ 500$ & $\$ 2.000$ & $\$ 0$ \\
& & & \\
\hline Yo prefiero & A & B & C \\
\hline
\end{tabular}

Escenario 2

\begin{tabular}{lccc}
\hline Atributo & Alternativa A & Alternativa B & $\begin{array}{c}\text { Alternativa C } \\
\text { Sin política adicional }\end{array}$ \\
\hline Riesgo de contaminación del río....... & $10 \%$ & $10 \%$ & $25 \%$ \\
Número de especies amenazadas.... & $15 \mathrm{sp}$ & $25 \mathrm{sp}$ & $25 \mathrm{sp}$ \\
Aumento de la pesca..................... & $10 \%$ & $25 \%$ & $0 \%$ \\
Pago al año........................... & $\$ 500$ & $\$ 2.000$ & $\$ 0$ \\
& & & \\
\hline Yo prefiero & A & B & C \\
\hline
\end{tabular}

Escenario 3

\begin{tabular}{lccc}
\hline Atributo & Alternativa A & Alternativa B & $\begin{array}{c}\text { Alternativa C } \\
\text { Sin política adicional }\end{array}$ \\
\hline Riesgo de contaminación del río....... & $15 \%$ & $10 \%$ & $25 \%$ \\
Número de especies amenazadas.... & $20 \mathrm{sp}$ & $15 \mathrm{sp}$ & $25 \mathrm{sp}$ \\
Aumento de la pesca..................... & $50 \%$ & $0 \%$ & $0 \%$ \\
Pago al año........................... & $\$ 500$ & $\$ 1.000$ & $\$ 0$ \\
\hline Yo prefiero & A & B & C \\
\hline
\end{tabular}

Escenario 4

\begin{tabular}{lccc}
\hline Atributo & Alternativa A & Alternativa B & $\begin{array}{c}\text { Alternativa C } \\
\text { Sin política adicional }\end{array}$ \\
\hline Riesgo de contaminación del río....... & $25 \%$ & $20 \%$ & $25 \%$ \\
Número de especies amenazadas.... & $10 \mathrm{sp}$ & $15 \mathrm{sp}$ & $25 \mathrm{sp}$ \\
Aumento de la pesca.................. & $50 \%$ & $25 \%$ & $0 \%$ \\
Pago al año.............................. & $\$ 2.000$ & $\$ 500$ & $\$ 0$ \\
& & & \\
\hline Yo prefiero & A & B & C \\
\hline
\end{tabular}

4.5. En una escala de 1 a 5, ¿cuán seguro o inseguro se sintió usted en el ejercicio de selección realizado anteriormente?, donde 1 significa "muy inseguro" y 5 significa "muy seguro" (formato de respuesta 6).

Muy inseguro

En sus respuestas se sintió
1
Ni uno ni otro

2
3
Muy seguro

4

5 


\section{Ejercicio de selección adicional}

Escenario A. En esta tarjeta (mostrar tarjeta $\boldsymbol{A}$ ) el mayor mejoramiento ambiental es presentado. Asuma las mismas condiciones que en el proceso de selección anterior. Es decir, los pagos son invertidos en mejorar la capacidad de supervisión del gobierno para forzar a la industria contaminadora a mejorar la situación actual.

¿Cuál sería el máximo monto que usted estaría dispuesto a pagar si esta situación fuera exitosamente implementada?. Por favor, nuevamente considere que el monto indicado no puede ser gastado en otras cosas que su familia pueda necesitar.

\begin{tabular}{|c|c|}
\hline Atributo & $\begin{array}{c}\text { Máximo mejoramiento } \\
\text { (mayor supervisión del gobierno) }\end{array}$ \\
\hline Riesgo de contaminación del río....... & $10 \%$ \\
\hline Número de especies amenazadas.... & $10 \mathrm{sp}$ \\
\hline Aumento de la pesca.................... & $50 \%$ \\
\hline 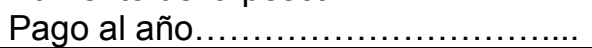 & $\$$ \\
\hline
\end{tabular}

Escenario B. Anteriormente, hemos asumido que sus pagos son usados por las instituciones de gobierno para forzar a las empresas contaminadoras a mejorar la situación ambiental actual. Sin embargo, el dinero recolectado desde usted y su comunidad, podría también ser usado para pagar directamente a la industria para que esta mejore la situación actual. Al igual que antes, las instituciones de gobierno supervisarían el éxito de estos cambios. Bajo estas condiciones (mostrar tarjeta B), ¿Cuál sería el máximo monto que usted estaría dispuesto a pagar si esta situación fuera exitosamente implementada?.

\begin{tabular}{|c|c|}
\hline Atributo & $\begin{array}{c}\text { Máximo mejoramiento } \\
\text { (pago a empresas con supervisión del gobierno) }\end{array}$ \\
\hline Riesgo de contaminación del río....... & $10 \%$ \\
\hline Número de especies amenazadas.... & $10 \mathrm{sp}$ \\
\hline Aumento de la pesca.................... & $50 \%$ \\
\hline Pago al año............................ & $\$$ \\
\hline
\end{tabular}

4.6. En una escala de 1 a 5, ¿cuán seguro o inseguro se sintió usted en el ejercicio de selección realizado anteriormente?, donde 1 significa "muy inseguro" y 5 significa "muy seguro" (formato de respuesta 6). 
Muy inseguro

En sus respuestas se sintió
Ni uno ni
otro

2
3
Muy seguro

4

\section{Parte 5: Aspectos de justicia, costos e implementación de Leyes}

5.1. En la siguiente sección, nos gustaría consultar su opinión acerca de aspectos relacionados a la implementación de nuevas Leyes para proteger la calidad del agua del río. En una escala de 1 a 5, ¿Cuán de acuerdo o en desacuerdo está usted con las siguientes afirmaciones?, donde el número 1 significa "completamente en desacuerdo" y el número 5 significa "completamente de acuerdo" (formato respuesta 1).

No estoy en condiciones de pagar para mejorar la calidad del agua.

\section{Completamente en desacuerdo}

$\begin{array}{lllll}1 & 2 & 3 & 4 & 5 \\ 1 & 2 & 3 & 4 & 5 \\ 1 & 2 & 3 & 4 & 5 \\ 1 & 2 & 3 & 4 & 5\end{array}$

para descargar sus residuos

Necesito más información antes de tomar una decisión acerca de pagar para mejorar la

calidad del agua del río

No tengo problemas en que se use mi dinero para ayudar a las empresas a reducir su contaminación.

El gobierno debería usar los recursos existentes (dinero) para mejorar la calidad del agua.

Es mi derecho tener un mejoramiento en la calidad del agua del río.

No creo que las Leyes para proteger la calidad del agua funcionen realmente.

Las industrias deberían pagar de acuerdo a la cantidad de residuos que descargan en el río.

Ya pago suficientes impuestos relacionados con el medio ambiente.

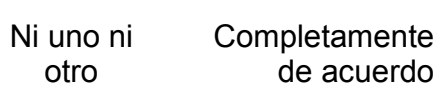




\title{
Parte 6: Preguntas Socio-demográficas
}

\author{
6.1. Edad
}

¿Cuál es su año de nacimiento?.

19

No se entrega respuesta.

\subsection{Ubicación}

Comuna:

Localidad:

Dirección:

\subsection{Tamaño del Hogar}

¿Cuántos adultos, mayores de 18 años, viven en su hogar?

¿Cuántos niños o jóvenes, menores de 18 años, viven en su hogar?

Total

No se entrega respuesta.

\subsection{Ingresos del Hogar}

Considerando todos los miembros del hogar que reciben algún ingreso monetario (incluyendo beneficios sociales tales como pensiones, subsidios familiares $\mathrm{u}$ otras fuentes de ingreso). Aproximadamente, ¿Cuánto es el ingreso mensual de su hogar? (mostrar los rangos de ingreso).

Menos de $\$ 160.000$ 1

Desde $\$ 160.000$ hasta $\$ 320.000$

Desde $\$ 320.000$ hasta $\$ 480.000$

Desde $\$ 480.000$ hasta $\$ 640.000$

Desde $\$ 640.000$ hasta $\$ 800.000$

Más de $\$ 960.000$

\subsection{Educación}

¿Cuál es el nivel de educación más alto alcanzado por usted?

Sin educación formal

Educación básica.

Educación media.

Eduación superior técnica 


\subsection{Ocupación}

¿A qué se dedica usted o cuál es su trabajo actual?.

Agricultor

Profesional dependiente.

7

Pescador.................................. 2

Pensionado............................. 8

Comerciante................................. 3

Trabajador dependiente..................... 4

Profesional independiente.................. 5

Dueña de casa....................... 9

Desempleado......................... 10

Estudiante.

Otro (indicar)

No se entrega respuesta............... 0

6.7. Sexo del entrevistado(a) (no preguntar, sólo anotar)

Masculino. 1

Femenino

2

Bueno, ya hemos terminado la encuesta. Le agradezco mucho su tiempo y colaboración.

¿Tiene usted algún comentario acerca de la entrevista realizada? (92)

Muchas gracias y que tenga un buen día!!! 
Appendix 2: Example a of choice set with visual aids (Spanish version)

\begin{tabular}{|c|c|c|c|}
\hline Atributo & $\begin{array}{c}\text { Alternativa } \\
\text { A }\end{array}$ & $\begin{array}{c}\text { Alternativa } \\
\text { B }\end{array}$ & $\begin{array}{l}\text { Alternativa C } \\
\text { Situación actual }\end{array}$ \\
\hline $\begin{array}{l}\text { Riesgo de } \\
\text { contaminación } \\
\text { (industria sin } \\
\text { cumplir la Ley) }\end{array}$ & $10 \%$ & $25 \%$ & $25 \%$ \\
\hline $\begin{array}{l}\text { Número de } \\
\text { especies } \\
\text { amenazadas (en } \\
\text { peligro) }\end{array}$ & 20 especies & 15 especies & 25 especies \\
\hline $\begin{array}{l}\text { Aumento en la } \\
\text { pesca de } \\
\text { Robalo }\end{array}$ & $\begin{array}{c}25 \% \\
(250 \mathrm{~kg} / \mathrm{año})\end{array}$ & $\begin{array}{c}50 \% \\
(500 \mathrm{~kg} / \mathrm{año})\end{array}$ & $\begin{array}{c}0 \% \\
(0 \mathrm{~kg} / \mathrm{año})\end{array}$ \\
\hline $\begin{array}{l}\text { Pago o aporte } \\
\text { (una sóla vez) }\end{array}$ & $\$ 2.000$ & $\$ 3.000$ & $\$ 0$ \\
\hline Yo preferiría & $\mathrm{A}$ & B & $\mathrm{C}$ \\
\hline
\end{tabular}




\section{Appendix 3: Curriculum Vitae}

\section{Personal Information}

Name: $\quad$ Carlos Alberto Huenchuleo Pedreros

Date/place of birth: January 07, 1975 in Cañete, Chile

\section{Education}

10/2007-07/2011 PhD student at the Department for Agricultural Economics and Rural Development, Georg-August-Universität Göttingen. Chair: Prof. Dr. Rainer Marggraf.

03/2003-04/2005 Master student at Georg-August-Universität Göttingen, Germany University of Talca, Chile. M. Sc. International Agribusiness, Tropical and International Agriculture.

03/1993-08/2000 Undergraduate student at University of Talca, Chile. Agronomist with specialization in Agribusiness, Licenciate in Agricultural Sciences.

\section{Work experience}

02/2007-09/2007 Coordinator for the Investment Development Program, Agricultural Development Institute INDAP, VII Maule region, Chile.

05/2005-01/2007 Research assistant and Lecturer at the Department of Agriculture Economics, University of Talca, Chile.

09/2000-12/2002 Agronomist for the Poor Communities Development Program PRODECOP - Secano Costero, Curepto community, VII Maule region. INDAP - University of Talca, Chile.

\section{$\underline{\text { Publications }}$}

$06 / 2010$

Villalobos P, Huenchuleo C. 2010. Ecosystem Service Valuation of Ruil (Nothofagus alessandrii) Forests in Central Chile: An application of the choice experiment method. In Bennett J. and Birol E. (eds) Choice Experiments in Developing Countries: Implementation, Challenges and Policy Implications, Edward Elgar Publishing Ltd., Cheltenham, UK.

12/2010 Huenchuleo C, Barkmann J, Villalobos P. 2011. Social psychology predictors for the adoption of soil conservation measures in Central Chile. Land degradation and Development. DOI: 10.1002/ldr.1093. 